Paula Rodrigues Almeida Polidoro

\author{
O impacto das Redes de Alianças e dos \\ recursos internos no desempenho de Inovação: \\ O caso da Embrapa
}

Dissertação de Mestrado

Dissertação apresentada como requisito parcial para obtenção do grau de Mestre pelo Programa de Pós-graduação em Administração de Empresas do Departamento de Administração da PUC-Rio.

Orientador: Fábio de Oliveira Paula

Rio de Janeiro

Abril de 2021 
Paula Rodrigues Almeida Polidoro

\section{O impacto das Redes de Alianças e dos recursos internos no desempenho de Inovação: 0 caso da Embrapa}

Dissertação apresentada como requisito parcial para obtenção do grau de Mestre pelo Programa de Pós-Graduação em Administração de Empresas da PUC-Rio. Aprovada pela Comissão Examinadora abaixo:

Prof. Fábio de Oliveira Paula

Orientador

Departamento de Administração - PUC-Rio

Prof. Marcos Cohen

Departamento de Administração - PUC-Rio

Prof. Roberto Carlos Bernardes

Faculdade de Economia, Administração, Contabilidade e Atuária - FEA-USP

Rio de Janeiro, 30 de abril de 2021 
Todos os direitos reservados. É proibida a reprodução total ou parcial do trabalho sem autorização da universidade, do autor e do orientador.

\section{Paula Rodrigues Almeida Polidoro}

Graduou-se em Secretariado Executivo Trilingue pela Universidade Federal de Viçosa - UFV. É Pós-graduada em Gerenciamento de Projetos pela Fundação Getúlio Vargas FGV. Analista da Empresa Brasileira de Pesquisa Agropecuária - Embrapa

Ficha Catalográfica

Polidoro, Paula Rodrigues Almeida

O impacto das redes de alianças e dos recursos internos no desempenho de inovação: o caso da Embrapa / Paula Rodrigues Almeida Polidoro ; orientador: Fábio de Oliveira Paula. - 2021.

251 f. : il. color. ; $30 \mathrm{~cm}$

Dissertação (mestrado)-Pontifícia Universidade Católica do Rio de Janeiro, Departamento de Administração, 2021.

Inclui bibliografia

1. Administração - Teses. 2. Inovação. 3. Inovação aberta. 4. Recursos e capacidades internas. 5. Portfólio de alianças. 6. Desempenho de inovação. I. Paula, Fábio de Oliveira. II. Pontifícia Universidade Católica do Rio de Janeiro. Departamento de Administração. III. Título. 
Aos meus pais Laércio e Olívia, ao meu filho, Guilherme e marido, Polidoro, por toda força, amor e incentivo 


\section{Agradecimentos}

Escrever uma dissertação, embora pareça um processo individual, é de longe uma experiência particular. Este trabalho é fruto da colaboração de várias pessoas que ao decorrer do processo foram contribuindo sobremaneira para a sua construção e resultado final. É por essa razão que, com certeza, os agradecimentos não serão completos, no entanto, feita esta ressalva, gostaria de agradecer algumas contribuições em especial.

Foram dois anos muito intensos e transformadores, que não teriam sido trilhados sem a presença diária do meu amor maior, meu filho Guilherme! Obrigada filho pela compreensão, por entender as minhas ausências e por ser meu combustível para enfrentar os desafios da vida! Agradeço ao meu marido, Polidoro, meu companheiro, pelo amor e apoio incondicional. Obrigada por me confortar nos momentos difíceis e por todo respaldo para que eu pudesse viver intensamente esse sonho. Aos meus pais, todo meu agradecimento por serem minha base, meu refúgio e por torcerem e vibrarem sempre por mim. Às minhas irmãs, Raquel e Bruna, pelas partilhas e pela nossa amizade e à minha sobrinha e afilhada Luísa, nosso mais novo amor! Ao Daniel, meu amigo e padrinho, por todo incentivo e por ser o grande responsável por me fazer trilhar esse mundo encantador da pesquisa! Aos meus grandes e queridos amigos de mestrado, em especial, Waleska, Michelle e Carol por dividirem as angústias e conquistas! Ao meu orientador, Prof. Fábio, obrigada por todos os direcionamentos, pela paciência, dedicação e sabedoria compartilhados. Em especial agradeço ao Ricardo Arcanjo, amigo e conselheiro deste trabalho. Obrigada pela paciência, sabedoria e inteligência que lhe são peculiares! Agradeço também a Petula, minha Chefe, pela presença e carinho constantes! Agradeço a Embrapa, instituição que me proporcionou obter este título. Aos demais amigos da Embrapa Solos, aos Chefes e profissionais da Agrobiologia e Agroindústria de Alimentos, os meus mais sinceros agradecimentos! Por fim, agradeço a Deus e Nossa Senhora por caminharem sempre comigo, renovando diariamente a minha força e fé! Obrigada por serem minha base e minha direção!

O presente trabalho foi realizado com apoio da Coordenação de Aperfeiçoamento de Pessoal de Nível Superior - Brasil (CAPES) - Código de Financiamento 001. 


\section{Resumo}

Polidoro, Paula Rodrigues Almeida; Paula, Fábio de Oliveira. O impacto das redes de alianças e dos recursos internos no desempenho de inovação: $O$ caso da Embrapa. Rio de Janeiro, 2021. 251p. Dissertação de Mestrado - Departamento de Administração, Pontifícia Universidade Católica do Rio de Janeiro.

Países do mundo todo têm envidado esforços para alcançar um crescimento econômico sustentável para enfrentar um ambiente de negócios cada vez mais globalizado, complexo e incerto. Nesse contexto a inovação é considerada como uma das principais soluções e caminhos. O Brasil, no que concerne à sua capacidade de inovação, está muito abaixo das grandes potências inovativas do mundo. Apesar dessa realidade, o setor de agricultura tem demonstrado crescimento considerável na sua capacidade de inovação e produção de conhecimento de fronteira. No entanto, mesmo dentro desse setor, a busca por resultados mais inovativos tem sido uma preocupação constante das empresas. Nesse sentido, a prática da inovação aberta como processo catalisador da inovação, tem se mostrado uma necessidade. Assim, o estudo de caso múltiplo, realizado em três unidades descentralizadas, da Empresa Brasileira de Pesquisa Agropecuária - Embrapa, empresa importante do setor agropecuário, permitiu analisar e avaliar como os recursos internos e as alianças estabelecidas por essas Unidades, interagem e afetam seus desempenhos de inovação, de modo que consigam aumentar suas contribuições para a capacidade de inovação do Brasil. O estudo constatou que, embora as Unidades pratiquem a inovação aberta, a interação entre suas fontes de conhecimento internas e externas propiciam um aumento de suas capacidades e desempenhos de inovação, ainda que tais interações propiciem apenas uma paridade competitiva às Unidades e desempenhos inovativos na média, os resultados confirmam a importância da interação entre os dois embientes internos e externos.

\section{Palavras-Chave}

Inovação; inovação aberta; recursos e capacidades internas; portfólio de alianças; desempenho de inovação. 


\section{Abstract}

Polidoro, Paula Rodrigues Almeida; Paula, Fábio de Oliveira. The impact of alliance networks and internal resources on innovation performance: The case of Embrapa. Rio de Janeiro, 2021. 251p. Dissertação de Mestrado - Departamento de Administração, Pontifícia Universidade Católica do Rio de Janeiro.

Countries around the world have made efforts to achieve sustainable economic growth in order to face an increasingly globalized, complex and uncertain business environment. In this context, innovation is considered as one of the main solutions and paths. Brazil, in terms of its capacity for innovation, is far below the great innovative powers in the world. Despite this reality, the agriculture sector has shown considerable growth in its capacity for innovation and the production of frontier knowledge. However, even within this sector, the search for more innovative results has been a constant concern of companies. In this sense, the practice of open innovation as a catalyst for innovation has been shown to be a necessity. Thus, the multiple case study, carried out in three decentralized units, of the Brazilian Agricultural Research Corporation - Embrapa, an important company in the agricultural sector, allowed to analyze and evaluate how the internal resources and the alliances established by these Units, interact and affect their performance innovation, so that they can increase their contributions to Brazil's innovation capacity. The study found that, although the Units practice open innovation, the interaction between their internal and external knowledge sources provides an increase in their innovation capacities and performances, even though such interactions provide only a competitive parity to the Units and innovative performances on average, the results confirm the importance of the interaction between the two internal and external environments.

\section{Keywords}

Innovation; open innovation; internal resources; dinamic capabilities; aliance portfolio; innovation performance. 


\section{Sumário}

1. Introdução 13

$1.1 \mathrm{O}$ problema 18

$\begin{array}{ll}1.2 \text { Objetivos Geral e específicos } & 19\end{array}$

1.3 Relevância do estudo 20

1.4 Delimitações do Estudo $\quad 21$

2 Referencial Teórico $\quad 23$

2.1 Inovação 23

2.1.1 Modelos de inovação e inovação aberta 27

$\begin{array}{ll}\text { 2.1.2 Desempenho de inovação } & 37\end{array}$

2.1.3 Sistema Nacional de Inovação 44

2.2 Teoria Baseada em Recursos - RBV 47

2.2.1 O papel dos recursos e capacidades internas no desempenho de inovação 49

2.3 Alianças Estratégicas $\quad 59$

2.3.1 Portfólio de Alianças

2.4 Agronegócio e Sistemas Nacionais de Agricultura 69

2.4.1 O Agronegócio Brasileiro e o SNPA $\quad 70$

2.4.2. A Embrapa

2.5. Posicionamento Teórico $\quad 84$

2.5.1. Recursos, capacidades e características internas $\quad 84$

2.5.2. Alianças Estratégicas/Portfólio de Alianças 86

2.5.3. Desempenho de Inovação $\quad 89$

3. Metodologia de Pesquisa 91

3.1. Caracterização do Estudo 91

3.2. Fase 2: Unidade de Análise e Definição dos Casos 94

3.2.1. Seleção dos sujeitos 95

$\begin{array}{ll}\text { 3.2.2. Coleta de Dados } & 96\end{array}$

3.2.2.1. Fontes de dados documentais 97

3.2.2.2. Levantamento de percepção tipo survey 98

3.2.2.3. Levantamento de percepções por meio de entrevistas 99

3.3. Fase 3: Análise individual dos Casos e tratamento dos Dados 100

3.4. Fase 4: Análise Comparativa dos Casos $\quad 100$

3.5 Avaliação do Rigor da Pesquisa 101

4 Resultados $\quad 102$

4.1 Estudos de Caso 102

$\begin{array}{ll}4.2 \text { Embrapa Solos - CNPS } & 102\end{array}$

4.2.1 Descrição dos dados da Embrapa Solos $\quad 104$

$\begin{array}{ll}\text { 4.2.1.1 Recursos, capacidades e características internas } & 104\end{array}$

4.2.1.2 Aliança/Portfólios de Alianças $\quad 119$

$\begin{array}{ll}\text { 4.2.1.3 Desempenho de Inovação } & 135\end{array}$

4.3 Embrapa Agroindústria de Alimentos - CTAA 138

4.3.1 Descrição dos dados da Embrapa Agroindústria de Alimentos 139

4.3.1.1 Recursos, capacidades e características internas 139

4.3.1.2 Alianças/Portfólios de Alianças 154

4.3.1.3 Desempenho de Inovação 169

$\begin{array}{ll}\text { 4.4 Embrapa Agrobiologia - CNPAB } & 173\end{array}$ 
$\begin{array}{ll}\text { 4.4.1 Descrição Embrapa Agrobiologia } & 174\end{array}$

$\begin{array}{ll}\text { 4.4.1.1 Recursos, capacidades e características internas } & 174\end{array}$

$\begin{array}{ll}\text { 4.4.1.2 Aliança/Portfólios de Alianças } & 185\end{array}$

$\begin{array}{ll}\text { 4.4.1.3 Desempenho de Inovação } & 199\end{array}$

5 Análise Cruzada dos Casos e Discussão dos Resultados 203

5.1 Identificação de Forças e Fraquezas internas semelhantes 203

5.2 Identificação de Forças e Fraquezas distintas 209

5.3 Contexto das Alianças e Portfólio de Alianças 212

$\begin{array}{ll}\text { 5.4 Desempenho de inovação das Unidades } & 217\end{array}$

$\begin{array}{ll}5.5 \text { Conclusão } & 221\end{array}$

5.6 Limitações do estudo $\quad 223$

$\begin{array}{ll}5.7 \text { Sugestões para futuras pesquisas } & 223\end{array}$

6 Referências Bibliográficas $\quad 224$

Anexos $\quad 235$

$\begin{array}{ll}\text { Anexo } 1 \text { - Questionário } & 235\end{array}$

Anexo 2 - Roteiro de Entrevista 248 


\section{Lista de Figuras}

Figura 1: Intensidade de P\&D $\quad 13$

Figura 2 Atores SNCTI $\quad 15$

Figura 3: Modelo de Inovação Linear. $\quad 27$

Figura 4: Modelo acoplado. 29

Figura 5: Modelo The Stage-Gate-Process. 30

Figura 6: Comparação entre os Modelos de Inovação Fechado e Aberto 31

Figura 7: Tipos de Relacionamentos Interfirmas. $\quad 60$

Figura 8: Crescimento e Comparação do Agronegócio com outros setores. 71

Figura 9: Série Histórica - Balança Comercial do Agronegócio Brasileiro. 72

Figura 10: Gastos em P\&D Agrícola na América Latina e Caribe 73

Figura 11: Lucro Social e Orçamento da Embrapa 78

Figura 12: Problemas Detectados e Soluções Implementadas Na Embrapa $\quad 80$

Figura 13: Escala de Maturidade Tecnológica TRL/MRL 81

Figura 14: Mapa Estratégico da Embrapa 2014-2034 83

Figura 15: Modelo Teórico 90

Figura 16: Quantidade de Recursos Humanos Envolvidos em P\&D no CNPS 105

Figura 17: Qualidade Técnica ee RH do CNPS 106

Figura 18: Cultura voltada para Inovação Aberta no CNPS 109

Figura 19: Gráfico de Concordância sobre Aspectos Culturais no CNPS 110

Figura 20: Sistemas de TI para Inovação Aberta no CNPS 112

Figura 21: Sistemas de TI no CNPS $\quad 112$

Figura 22: TIcomo repositório de Memória Organizacional no CNPS 112

Figura 23: Gerenciamento da Propriedade Intelectual no CNPS 114

Figura 24: Liderança Pessoal por Pares E Corretagem Social no CNPS 117

Figura 25: Mentalidade Tecnológica no CNPS 117

Figura 26: Capacidade de Alargamento de Fronteiras no CNPS 117

Figura 27: Alianças Estabelecidas pelo CNPS 119

Figura 28: Gráfico de Concordância do CNPS Participação em Alianças 121

Figura 29: Tipos de Parceiros do CNPS 122

Figura 30: Distância Geográfica dos Parceiros do CNPS 126

Figura 31: Principais Recursos-Chave dos Parceiros do CNPS 127

Figura 32: Quantidade de Ativos Pré-Tecnológicos produzidos pelo CNPS 135

Figura 33: Quantidade de Ativos Tecnológicos produzidos pelo CNPS 135

Figura 34: Quantidade de Apoio à Inovação produzidos pelo CNPS 135

Figura 35: Quantidade de RH em P\&D no CTAA 139

Figura 36: Qualidade Técnica de RH em P\&D no CTAA 140

Figura 37: Qualidade Inovativa de RH no CTAA 140

Figura 38: Infraestrutura Física , TI e Insumos para P\&D no CTAA 142

Figura 39: Suporte à Inovação no CTAA 142

Figura 40: Cultura como Suporte à Inovação Aberta no CTAA 143

Figura 41: Gráfico De Concordância sobre Aspectos Culturais do CTAA 144

Figura 42: TI como Suporte à Inovação Aberta no CTAA 146

Figura 43: Gráfico de Concordância sobre Aspectos de TI do CTAA 147

Figura 44: Mentalidade Tecnológica no CTAA 152 
Figura 45: Liderança Pessoal por Pares e Corretagem social- CTAA 152

Figura 46: Capacidade de Alargamento de Fronteiras no CTAA 152

Figura 47: Prática da Inovação Aberta no CTAA 154

Figura 48: Gráfico de Concordância Participação do CTAA em Alianças 155

Figura 49: Alianças Estabelecidas pelo CTAA 156

Figura 50: Tipos de Parceiros do CTAA 157

Figura 51: Força das Conexões das Alianças Estabelecidas pelo CTAA 159

Figura 52: Distância Geográfica dos Parceiros do CTAA 160

Figura 53: Recursos-Chave dos Parceiros do CTAA 162

Figura 54: Ativos Pré-Tecnológicos produzidos pelo CTAA 169

Figura 55: Ativos Tecnológicos produzidos pelo CTAA 169

Figura 56: Apoio à Inovação produzidos pelo CTAA 169

Figura 57: Quantidade De RH em P\&D no CNPAB 174

Figura 58: Qualidade Técnica de RH no CNPAB 175

Figura 59: Qualidade Inovativa de RH em P\&D do CNPAB 175

Figura 60: Infraestrutura Física, de TI E Insumos da P\&D do CNPAB 175

Figura 61: Suporte à Inovação (Adm, TT E Negócios) no CNPAB 175

Figura 62: Cultura como Suporte à Inovação Aberta no CNPAB 176

Figura 63: Gráfico de Concordância sobre Aspectos Culturais do CNPAB 177

Figura 64: TI Como Suporte à Inovação Aberta no CNPAB 178

Figura 65: Gráfico de Concordância sobre aspectos de TI do CNPAB 179

Figura 66: Tomada de Decisões no CNPAB 179

Figura 67: Definição de Responsabilidades $\quad 180$

Figura 68: Gerenciamento de PI no CNPAB 180

Figura 69: Processo de Seleção de Parceiros no CNPAB 180

Figura 70: Liderança por Pares e Corretagem Social 183

Figura 71: Mentalidade Tecnológica no CNPAB 183

Figura 72: Capacidade de Alargamento de Fronteiras no CNPAB 183

Figura 73: Alianças Estabelecidas pelo CNPAB 185

Figura 74: Gráfico de Concordância Alianças Estratégicas do CNPAB 186

Figura 75: Tipos de Parceiros do CNPAB 187

Figura 76: Força das Ligações Estabelecidas pelo CNPAB 189

Figura 77: Natureza das Ligações das Parcerias do CNPAB 190

Figura 78: Distância Geográfica dos Parceiros do CNPAB 191

Figura 79: Principais Recursos-Chave dos Parceiros do CNPAB 192

Figura 80: Ativos Tecnológicos do CNPAB 199

Figura 81: Ativos Pré-Tecnológicos do CNPAB 199

Figura 82: Apoio à Inovação do CNPAB 199

\section{Lista de Quadros}

Quadro 1: Principais proxies de Desempenho de Inovação 42

Quadro 2: Fatores e capacidades internas $\quad 51$

Quadro 3: Estrutura do modelo VRIO $\quad 85$

Quadro 4: Dimensões internas e Definições 85 
Quadro 5: Benefícios/Propósitos das Alianças $\quad 88$

Quadro 6: Categorias e Tipos de Resultados 89

Quadro 7: Análise VRIO dos Atributos de P\&D do CNPS 109

Quadro 8: Relação das Forças e Fraquezas Internas CNPS 118

Quadro 9: Resumo das Principais alianças do Cnps e suas Características 129

Quadro 10: Relação entre Fraquezas Internas e Forças Externas do CNPS 132

Quadro 11: Relação das Forças Internas e Externas do CNPS 134

Quadro 12: Resultado da análise Vrio dos Atributos de P\&D do CTAA 143

Quadro 13: Relação das Forças e Fraquezas no CTAA 153

Quadro 14: Resumo das principais alianças do CTAA e suas características 164

Quadro 15: Relação entre Fraquezas Internas e Forças Externas do CTAA 166

Quadro 16: Relação entre Forças Internas e Externas do CTAA 168

Quadro 17: Relação das Forças e Fraquezas Internas do CNPAB 184

Quadro 18: Resumo das principais Alianças Estratégicas do CNPAB 193

Quadro 19: Relação entre Fraquezas Internas e Forças Externas do CNPAB 195

Quadro 20: Relação das Forças Internas e Externas do CNPAB 196

Quadro 21: Forças e Fraquezas comuns às Unidades 204

Quadro 22: Exemplo dos principais Tipos de Parceiros por Unidade. 216

\section{Lista de Tabelas}

Tabela 1: Perfil Geral da Amostra. $\quad 95$

Tabela 2: Perfil da Amostra Embrapa Solos 95

Tabela 3: Perfil da Amostra Embrapa Agroindústria de Alimentos 96

Tabela 4: Perfil da Amostra da Embrapa Agrobiologia 96

Tabela 5: Resultado da Análise VRIO do Recurso TI do CNPS 112

Tabela 6: Resultado da Análise da Desorptive Capacity do CNPS. 116

Tabela 7: Tipos de Alianças por Tipos de Parceiros do CNPS 123

Tabela 8: Impactos dos Resultados Gerados pelo CNPS 136

Tabela 9: Tipos de Alianças de Inovação estabelecidas pelo CTAA 158

Tabela 10: Impactos dos Resultados Produzidos pelo CTAA 171

Tabela 11: Tipos de Alianças Estabelecidas pelo CNPAB 188

Tabela 12: Impactos dos Resultados Produzidos pelo CNPAB 200 


\section{Introdução}

Países do mundo todo têm envidado esforços para alcançar um crescimento econômico sustentável para enfrentar um ambiente de negócios cada vez mais globalizado, complexo e incerto. Nesse contexto a inovação é considerada como uma das principais soluções e caminhos (Paula, 2017; Kattel \& Mazzucato, 2018).

De acordo com o último Relatório de Indicadores Nacionais, o Brasil investiu 1,52\% de seu PIB em ciência, tecnologia e inovação em 2017 (MCTIC, 2019), o que the conferiu o $12^{\circ}$ lugar no ranking global de investimento em ciência e tecnologia (Figura 1). No entanto, no que concerne à sua capacidade de inovação, o Brasil ocupa o $66^{\circ}$ lugar no ranking global de inovação - ano 2019 (Global Innovation Index, 2019).

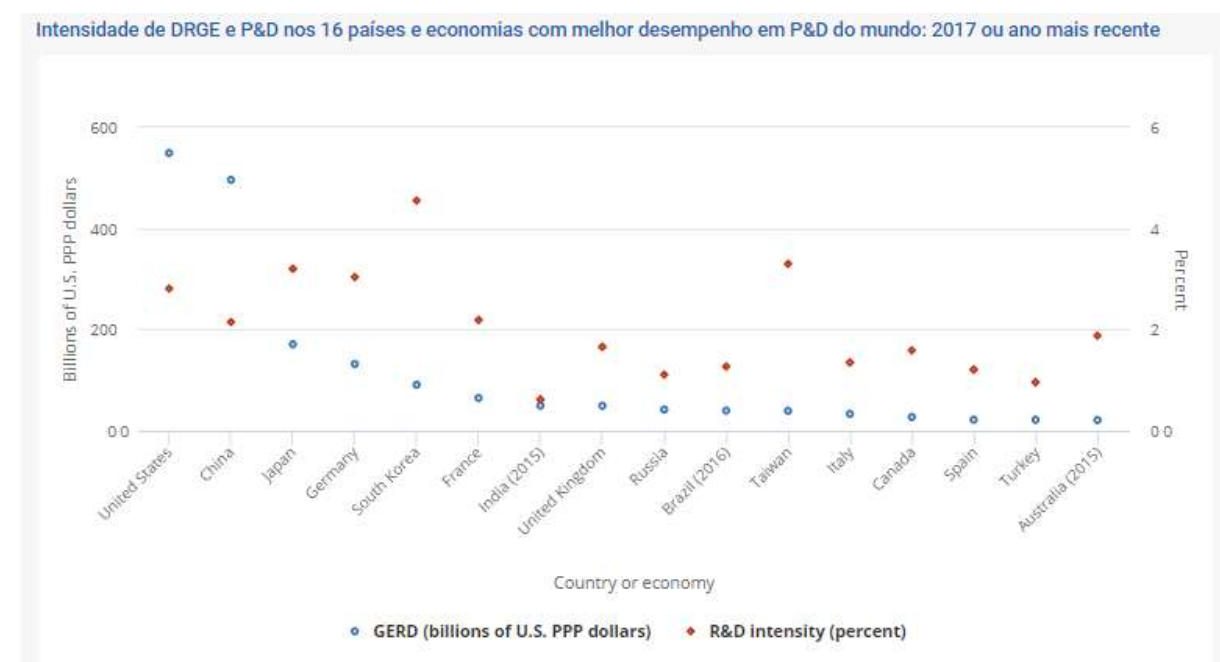

Figura 1: Intensidade de P\&D nos 16 países e economias com melhor desempenho em P\&D do mundo. Dados 2017.

Fonte: (National Science Board - Science and Engineering Indicators, 2018) 
Esses rankings mostram a existência de uma lacuna entre a capacidade de produção de $\mathrm{P} \& \mathrm{D}$ e a capacidade de inovação do Brasil. Apesar dessas evidências, o país, nas últimas décadas, apresentou crescimento considerável na sua capacidade de produção de conhecimento de fronteira, através de pesquisas científicas de qualidade, em setores como: petróleo e gás, aviação, saúde e agricultura. No entanto, embora os investimentos em $\mathrm{P} \& \mathrm{D}$ e a produção de conhecimento tenham sido consideráveis em algumas áreas, não foram suficientes para alavancar a capacidade de inovação do país. (Mazzucato; \& Penna, 2016).

$\mathrm{Na}$ verdade, segundo os mesmos autores, o sucesso no desenvolvimento tende a ser maior a medida em que evidencia a importância da integração contínua de políticas governamentais e estratégias empresariais, em uma sinergia de esforços e objetivos, alinhando a inovação às demandas empresariais e sociais. No entanto, a lógica brasileira é, na maioria das vezes, inversa, com vários sistemas operando de forma separada e desintegrada, dificultando o ciclo de Ciência, Tecnologia e inovação.

Nesse contexto de necessidade de alavancagem da capacidade de inovação para enfrentar ambientes cada vez mais complexos, o conceito de inovação aberta, como processo catalisador da inovação, tem se mostrado uma necessidade (Ades et al., 2013). A inovação aberta, é definida como conceito pelo qual as empresas fazem uso de conhecimento externo, alinhado aos seus recursos e conhecimentos internos (Chesbrough, 2003).

O desenvolvimento econômico de um país está, cada vez mais, pautado na inovação baseada no desenvolvimento científico e tecnológico e na necessidade do compartilhamento entre os principais atores de seus contextos nacionais de pesquisa, desenvolvimento e inovação. Nesse contexto, para que o Brasil preencha a lacuna existente entre sua produção de $P \& D$ e inovação em prol de seu crescimento sustentável, é imprescindível a existência de uma robusta estratégia e um robusto Sistema Nacional de Ciência e Tecnologia (Kattel \& Mazzucato, 2018).

Um sistema robusto de Ciência e Tecnologia é capaz de articular e mobilizar todos os principais atores e instrumentos constituintes do sistema, de maneira consistente, de forma a proporcionar a inovação, o aumento da produtividade, aumento dos benefícios econômicos e sociais para o país (MCTIC, 2016). 
No Brasil, o Sistema Nacional de Ciência, Tecnologia e Inovação - SNCTI, coordenado pelo Ministério de Ciência e Tecnologia e Inovações (MCTI) passou, nos últimos anos, por várias modificações para formar uma estrutura mais integrada, com vistas a alavancar a capacidade de inovação do país. As modificações foram implementadas pelo Novo Marco Legal que alterou nove leis no intuito de criar um ambiente mais favorável à pesquisa, desenvolvimento e inovação (Brasil, 2016). O SNCTI é composto por diversos atores conforme mostrado na Figura 2.
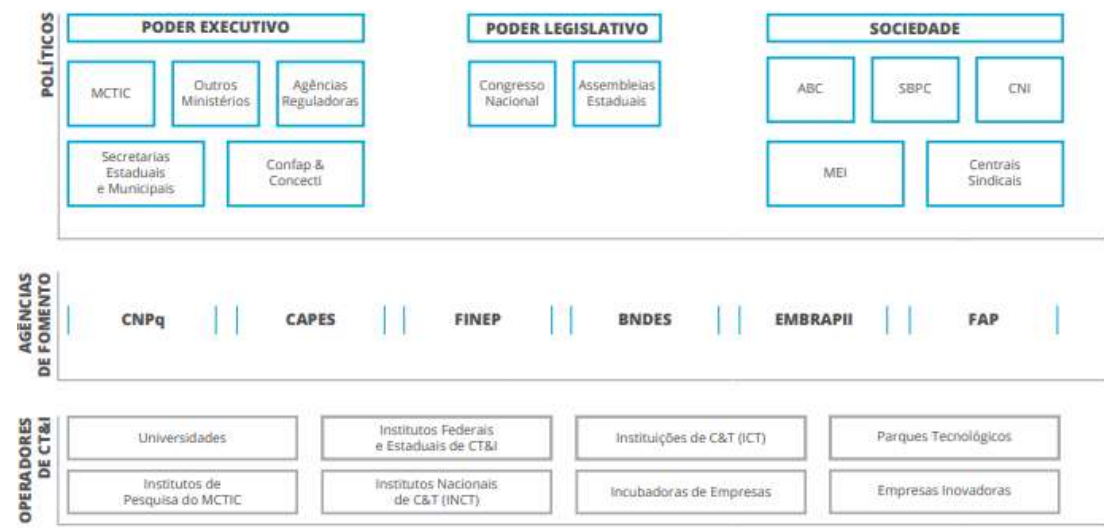

Figura 2 Principais atores do Sistema Nacional de Ciência, Tecnologia e Inovação (SNCTI). Fonte: MCTIC, 2016.

Dentre os principais atores, merece destaque as Instituições de Ciência e Tecnologia, como protagonistas e responsáveis, pelo nível tático e operacional do SNCTI, por meio da gestão e realização de programas e projetos de PD\&I (MCTIC, 2016).

De acordo com o Marco Legal de Ciência e Tecnologia - Lei № 13.243, de 11 de janeiro de 2016 (Brasil, 2016) - Instituição Científica, Tecnológica e de Inovação (ICT) é:

órgão ou entidade da administração pública direta ou indireta ou pessoa jurídica de direito privado sem fins lucrativos legalmente constituída sob as leis brasileiras, com sede e foro no País, que inclua em sua missão institucional ou em seu objetivo social ou estatutário a pesquisa básica ou aplicada de caráter científico ou tecnológico ou o desenvolvimento de novos produtos, serviços ou processos.

As Instituições de Ciência e Tecnologia - ICTs, protagonistas deste sistema, são assim consideradas, uma vez que funcionam como uma das operadoras deste sistema. No nível operacional é onde são de fato geradas as inovações, desenvolvidas as tecnologias e realizadas pesquisas relevantes para o país (MCTIC, 2016). 
Segundo a nova Lei 13.243/06 (Brasil, 2016), para a criação de um ambiente brasileiro mais inovativo, é necessário um estímulo à constituição de alianças estratégicas e o desenvolvimento de projetos de cooperação que envolvam vários agentes do Sistema Nacional de Inovação, como: empresas, ICT’s e entidades privadas sem fins lucrativos, para juntas, em uma conjunção de esforços, promover a melhoria da capacidade de inovação do país.

No Brasil, alguns setores, como petróleo e gás, aviação, saúde e agricultura, têm apresentado crescimento considerável na sua capacidade de produção de conhecimento de fronteira. O setor de agricultura, em especial, tem se mostrado estratégico para o país. Ele é um dos principais setores responsáveis por grande parte do PIB brasileiro. Em 2019, o PIB do agronegócio cresceu 3,81\%, correspondendo a aproximadamente $21,4 \%$ do PIB total da economia (CNA, 2019).

A participação do setor, portanto, é bastante expressiva, o que demonstra sua importância para o crescimento do país. Nas últimas décadas, a agricultura transformou o Brasil, tirando-o de uma condição de importador de alimentos básicos para a condição de um dos maiores produtores e exportadores do mundo (Embrapa, n.d.b). A agropecuária brasileira é hoje uma das mais eficientes e sustentáveis do mundo.

O trecho abaixo, retirado da reportagem do G1, de 05 de agosto de 2019 (G1, 2019), demonstra a importância desse setor não só em nível nacional quanto também mundial:

O impacto do agronegócio brasileiro não se restringe à economia doméstica. Hoje, o Brasil é o terceiro maior produtor de alimentos, atrás apenas dos Estados Unidos e da Europa, segundo a Organização das Nações Unidas para Alimentação e Agricultura. Isso significa que boa parte da segurança alimentar mundial - isto é, a garantia de que haverá fornecimento de alimentos de qualidade que podem ser consumidos sem fazer mal à saúde - está relacionada à capacidade brasileira de produzir grãos, oleaginosas e animais. (G1, 2019)

Muitos aspectos contribuíram para essas conquistas, como: o investimento público em pesquisa e ciência e a criação de um Sistema Nacional de Pesquisa Agropecuária - SNPA, formado pelas Organizações Estaduais de Pesquisa Agropecuária - Oepas, pela Embrapa - ICT, por universidades e institutos de pesquisa de âmbito federal e estadual, além de outras organizações públicas e privadas, direta ou indiretamente vinculadas à atividade de pesquisa agropecuária (Embrapa, n.d.b). 
Dentro desse contexto, a Embrapa - Empresa Brasileira de Pesquisa Agropecuária, tem papel fundamental para o crescimento e desenvolvimento da agricultura do país. A empresa, vinculada ao Ministério da Agricultura, Pecuária e Abastecimento, vem transformando a agricultura brasileira, desde sua criação na década de 70. Uma das grandes contribuições da empresa, em parceria com os outros membros do SNPA, foi tirar o Brasil de uma condição de importador de alimentos básicos para um dos maiores produtores e exportadores mundiais (Consepa, n.d.).

Como uma empresa de pesquisa, desenvolvimento e inovação, a Embrapa objetiva responder às demandas da agropecuária brasileira, bem como busca antecipar e enfrentar os desafios do futuro, por meio de suas pesquisas e conhecimentos traduzidos em produtos, processos, serviços, metodologias, sistemas e práticas agrícolas (Embrapa, n.d.b). Ciente desse papel importante para a agricultura do país, a empresa tem buscado promover ajustes e mudanças internas para permanecer como empresa de vanguarda e continuar entregando à população brasileira o valor que dela é esperado - viabilizar soluções de pesquisa, desenvolvimento e inovação para a sustentabilidade da agricultura em benefício da sociedade brasileira.(Stutz \& Pereira, 2019).

Assim, em 2018, a empresa adotou o macroprocesso de inovação como estratégia, com o objetivo de se reestruturar internamente e aumentar sua capacidade de produzir e de levar suas soluções tecnológicas para o ambiente produtivo e social, agregando o valor necessário à agricultura e gerando inovação. No entanto, como uma Instituição de Ciência e Tecnologia - ICT, a Embrapa não comercializa produtos e processos por si só, de forma isolada, ela precisa de um parceiro do setor produtivo para que as soluções tecnológicas geradas na Embrapa atinjam o ambiente produtivo e social. Deste modo, o processo de inovação da Embrapa se ancora necessariamente em um modelo de inovação aberta (Brasil, 2019).

Nesse contexto, a necessidade de estabelecimento de arranjos institucionais e de redes interorganizacionais surgem nesse novo cenário como forma organizacional mais propícia e adequada à geração de inovação. Por meio de redes de alianças, as empresas ampliam seus acessos a recursos heterogêneos que propiciam a criação de novos conhecimentos e melhoria nos seus desempenhos de inovação (Wang et al., 2018). 
No entanto, como grande parte das inovações ocorrem dentro das empresas, as decisões de como lidar internamente com o processo de inovação e como absorver esses conhecimentos externos são decisivos para melhorar as capacidades de inovação organizacionais (Paula \& Silva, 2017).

Assim as capacidades e competências organizacionais são consideradas críticas para adoção e implementação de práticas de inovação aberta. Elas são fundamentais como fontes para a construção da capacidade absortiva das empresas - "capacidade de assimilar e integrar o conhecimento externo e aplicá-lo para fins comerciais" (Cohen \& Levinthal, 1990). Dessa forma, investir nos recursos internos, de forma a torná-los fontes de vantagens competitivas (Barney \& Hesterly, 2015) e nas fontes de conhecimento externas com vistas a propriciar o acúmulo de conhecimento nas empresas, se mostra como sendo o caminho mais viável para ampliar a capacidade de inovação das empresas (Paula \& Silva, 2017).

Assim, apesar de todos as conquistas, há grandes desafios futuros que o setor agropecuário, e em especial a Embrapa, precisam enfrentar para melhorar suas capacidades de inovação, e consequentemente, suas capacidades de resposta às demandas atuais, para continuar mantendo sua vanguarda na agricultura tropical e mundial, que é baseada em Ciência e Tecnologia, fator principal de independência tecnológica do setor. Tal independência só será possível, a partir do desenvolvimento de pesquisa, desenvolvimento e inovação de ponta, de forma integrada por todos os atores que compõem o sistema nacional de ciência e tecnologia - SNCTI, com parceiros ligados direta ou indiretamente ao agronegócio e por meio do investimento nas fontes internas de conhecimento.

\section{1}

\section{O problema}

A Embrapa, faz parte do conjunto das operadoras do SNCTI. São essas instituições responsáveis pelas atividades de inovação do Brasil.

Diante do desafio de propor soluções de pesquisa cada vez mais inovadoras para a sustentabilidade da agricultura, a Embrapa, como corporação, adotou estrategicamente o macroprocesso de inovação, com foco na inovação aberta, para nortear suas atividades de pesquisa e desenvolvimento.

O ponto crítico dessa estratégia, no entanto, se esbarra no caráter descentralizado e amplo da empresa, que é constituída por 43 unidades 
descentralizadas, espalhadas por todo território nacional, inseridas em ecossistemas de inovação totalmente distintos e heterogêneos e onde ocorre, de fato, todo o processo de inovação da empresa.

Para o cumprimento da missão da Embrapa, cada unidade descentralizada possui um nível de autonomia, dentro do macroprocesso de inovação, para exercer seu processo de inovação, por meio de suas áreas distintas de atuação, levando em consideração seus recursos, capacidades internas e os estímulos externos correspondentes ao seu campo de atuação.

Nesse contexto, as unidades precisam estabelecer estratégias específicas e estruturas internas robustas que possibilitem suas atuações de forma integrada com os principais atores e parceiros, para que o ambiente externo e interno, interajam e impactem positivamente no desempenho de inovação.

Dentro desse contexto, portanto, esta pesquisa visa responder a seguinte questão de pesquisa: Como as redes de alianças e os recursos e capacidades internas afetam o desempenho de inovação de três unidades da Embrapa - Embrapa Agrobiologia, Agroindústria de Alimentos e Embrapa Solos?

\section{2 \\ Objetivos Geral e específicos}

Este trabalho tem como objetivo realizar um estudo de caso na Embrapa, Empresa Brasileira de Pesquisa Agropecuária - ICT, inserida no Sistema Nacional de Ciência, Tecnologia e Inovação do país - SNCTI e no Sistema Nacional de Pesquisa Agropecuária - SNPA.

Por meio deste estudo, pretende-se analisar como as redes de alianças e os recursos e capacidades internas se combinam e interferem no desempenho de inovação de três unidades da Embrapa.

A partir deste objetivo central, tem-se os seguintes objetivos específicos:

- Realizar uma revisão de literatura referente à inovação, com foco em inovação aberta, recursos, capacidades internas e alianças estratégicas; mapeando os principais recursos e capacidades, características e tipos de alianças que impactam no desempenho de inovação; 
- Propor um framework teórico que permita mapear os recursos e capacidades de uma empresa, seu portfólio de alianças e o desempenho de inovação por ela obtido e que possa ajudar a responder a pergunta de pesquisa;

- Aplicar o framework através de estudo de caso múltiplo em três unidades da Embrapa, a saber: Agrobiologia, Agroindústria de Alimentos e Solos;

- Fazer uma análise individual e conjunta dos casos, referentes à atuação dos recursos, capacidades e alianças para impulsionar o desempenho de inovação.

\section{3 \\ Relevância do estudo}

No que concerne à academia, este trabalho visa contribuir para os estudos na área de estratégia, com foco na inovação, mais especificamente na inovação aberta, evidenciando a importância da relação e complementariedade entre os recursos e competências internas e as redes de alianças, como fontes para alavancar o desempenho de inovação das empresas.

Dentro dessa perspectiva, é importante entender como uma empresa pública de pesquisa e desenvolvimento, considerada uma Instituição de Ciência e Tecnologia pode contribuir, por meio da prática da inovação aberta, para a formação de um robusto Sistema Nacional de Ciência e Tecnologia, orientado para a promoção da inovação, fornecendo suporte para o desenvolvimento e crescimento do país.

Uma das grandes lacunas que o Brasil pretende preencher, que faz parte do documento elaborado pelo Ministério da Ciência, Tecnologia e Inovações, denominado "Estratégia Nacional para o período de 2016-2022", diz respeito à melhoria da sua capacidade de inovação de modo a posicionar melhor o país quando comparado aos países considerados mais inovadores (MCTIC, 2016).

Nesse contexto, a melhoria da capacidade de inovação das empresas brasileiras, em especial as empresas públicas consideradas ICT, é fundamental para contribuir com o alcance desse objetivo. 
Em termos de aplicação prática pelos gestores, esta pesquisa poderá auxiliar à tomada de decisão com vistas a impulsionar as inovações por meio da melhoria de seus recursos e capacidades internas, considerados críticos em contextos de inovação, bem como por meio de alianças estratégicas, identificando assim as oportunidades a serem exploradas, com uma visão mais ampla de fatores e possibilidades de inovação não observadas pela análise tradicional (não relacional).

Ainda, poderá contribuir para a melhoria da capacidade de inovação das Instituições de Ciência e Tecnologia - ICT, atores essenciais no Sistema Nacional de Inovação. Para o agronegócio em especial, este trabalho poderá contribuir para a construção de um Sistema de Pesquisa Agropecuária mais integrado, que privilegie o trabalho em conjunto entre os diversos atores do sistema, aumentando a capacidade de geração de resultados e contribuindo para o fortalecimento da agropecuária nacional, setor imprescindível para o crescimento econômico do país.

\section{4}

\section{Delimitações do Estudo}

A primeira delimitação deste estudo se concentra na utilização de uma única empresa como unidade de análise, embora o estudo considere três unidades distintas. Como delimitação geográfica, a análise se dará em três unidades da Embrapa, sendo todas localizadas na cidade do Rio de Janeiro e região metropolitana, duas delas - Embrapa Agroindústria de Alimentos e Embrapa Solos, situadas na capital fluminense e a Unidade Agrobiologia, localizada na cidade de Seropédica.

Embora as três unidades, tenham esta delimitação espacial, todas possuem atuação em nível nacional, o que resulta em atividades e parcerias que envolvem essa dimensão ampla e diversificada. Sendo assim, as análises desse estudo compreendem todo este espectro nacional de atuação e de parcerias. Do ponto de vista temporal, as informações que compuseram a pesquisa, se referem aos últimos dois anos - período compreendido entre 2018 e 2020, por se referirem ao período de adoção do macroprocesso de inovação.

Quanto ao tema, a inovação aberta é uma área de estudo ampla e por este motivo é importante ter um recorte de como o tema será abordado, a fim de priorizar 
as áreas passíveis do estudo deste trabalho e que precisam ser aprofundadas, levando em consideração a população alvo da pesquisa e as limitações de tempo.

A proposta deste trabalho é avaliar, por meio de estudo de caso, como as redes de alianças e os recursos e capacidades internas se combinam e interferem no desempenho de inovação das três unidades da Embrapa descritas acima, de acordo com a visão de seus empregados.

Para a análise das redes de alianças, o estudo se concentrará no mapeamento dos parceiros diretos dessas Unidades, não considerando, portanto, os parceiros indiretos. Quanto aos recursos e capacidades internas serão considerados aqueles considerados críticos em contextos de inovação, de acordo com a Revisão de Literatura. 


\section{2 \\ Referencial Teórico}

\section{1}

\section{Inovação}

A teoria econômica da inovação foi introduzida na década de 1940, por Schumpeter, através do conceito de destruição criativa, pelo qual a criação de algo inédito destrói a dinâmica e as regras atuais de uma indústria e introduz novas dinâmicas e caminhos. Desde então, vários autores se debruçaram no estudo da inovação, de seus conceitos e definições (Paula \& Silva, 2017).

O conceito de inovação está intimamente associado ao desenvolvimento econômico (Reichert et al., 2015). Para o precursor do conceito de inovação, a teoria do equilíbrio neoclássico, era incompatível com o desenvolvimento econômico, sendo necessária a aplicação de uma abordagem mais dinâmica, na qual a inovação era a chave fundamental (Fritsch, 2017). A definição de inovação trazida por Schumpeter perpassa pela introdução da comercialização às ideias e invenções geradas e o consequente desenvolvimento econômico que essa comercialização proporciona (Fritsch, 2017; Reichert et al., 2015).

Nessa lógica, o impulso necessário para se obter desenvolvimento, parte do lançamento e introdução de novos produtos, novas formas de produção, novas formas de organização industrial, desenvolvimento de novas fontes de matériasprimas e outros insumos e de novos mercados (Schumpeter, 2003). Em outras palavras, o desenvolvimento de inovações está intimamente relacionado à geração de novas riquezas, rendas e negócios (B. dos S. A. F. Brasil, 2019).

Em consonância à essa definição, o Manual de Oslo (OECD, 2005), referência mundial para inovação, em sua $3^{\mathrm{a}}$ Edição, define inovação como a implementação de produtos novos ou significativamente melhorados, processos, 
métodos de marketing e métodos organizacionais. A $4^{\text {a }}$ Edição do Manual (OECD \& Eurostat, 2018) ainda acrescenta a inovação do tipo de modelo de negócios.

Este estudo focará nas definições de inovação, de acordo com a $3^{\mathrm{a}}$ e $4^{\mathrm{a}}$ Edição do Manual de Oslo cujas definições estão descritas e exemplificadas abaixo:

Uma inovação de produto é a introdução de um bem ou serviço novo ou significativamente melhorado no que concerne as suas características ou usos previstos. Incluem-se melhoramentos significativos em especificações técnicas, componentes e materiais, softwares incorporados, facilidade de uso ou outras características funcionais.

Um grande exemplo de inovação de produto, é o MP3, que revolucionou a indústria fonográfica através do consumo de música por meio de mídias digitais. A compressão MP3 dos dados permitiu a um leitor, como o Ipod, reproduzir milhares de músicas em contraponto a um CD áudio que dificilmente ultrapassava 80 minutos de reprodução de música (Gomes, 2014). A Royal Philips, marca mais valiosa da Holanda, é outro exemplo. A empresa é considerada líder em inovações de produto. Desde o início dos anos 2000, a empresa tem buscado expandir o seu portfólio de produtos, com a introdução de várias inovações dessa natureza: lâmpadas de energia eficiente, scanners médicos, câmeras com internet, chips para sistemas de entretenimento automotivo e diversos tipos de softwares (Mocker \& Ross, 2017).

Já uma inovação de processo, por sua vez, se refere:

... a implementação de um método de produção ou distribuição novo ou significativamente melhorado. Incluem-se mudanças significativas em técnicas, equipamentos elou softwares.

Um exemplo clássico de inovação de processo é o de Henry Ford com a introdução da linha de montagem para produção de automóvel. Essa inovação de processo proporcionou a diminuição dos preços na venda dos carros da Ford (Feldmann, 2015).

Uma inovação organizacional é a implementação de um novo método organizacional nas práticas de negócio da empresa, na organização do seu local de trabalho ou em suas relações externas.

As empresas, em geral, realizam inovações organizações com vistas a melhorarem suas produtividades. A empresa Google estabeleceu um moderno e inovador modelo de gestão organizacional, altamente flexível, com espaços físicos projetados para facilitar a livre circulação de idéias entre seus empregados. $\mathrm{O}$ foco 
da empresa é a satisfação e contribuição dos funcionários, não importando como e onde eles irão desenvolver essa contribuição (Feijó, 2015).

Uma inovação de marketing é a implementação de um novo método de marketing com mudanças significativas na concepção do produto ou em sua embalagem, no posicionamento do produto em sua promoção ou na fixação de preços.

As Havaianas, nos anos 90, por meio de uma nova proposta de valor e gestão de marca, reposicionou seus produtos para alcançar uma parcela maior de mercado e firmar sua posição no Brasil. A estratégia deu certo e a Havaianas foi considerada, em 2017, uma das marcas mais influentes do Brasil. Um dos motivos de seu sucesso, além da qualidade do seu produto são as ações de marketing e o cuidado com a marca. A empresa atribui seu sucesso à liderança e à inovação (Época, 2018).

Por fim, de acordo com a $5^{\text {a }}$ edição do Manual de Oslo (OECD \& Eurostat, 2018), uma inovação de negócios é definida como:

Uma inovação de negócios é um produto ou processo de negócios novo ou aprimorado (ou combinação de ambos) que diferem significativamente dos produtos ou processos de negócios anteriores da empresa e que foram introduzidos no mercado ou utilizados pela empresa.

Em outras palavras uma inovação no modelo de negócios de uma empresa deve proporcionar a ampliação de seu mercado e do setor econômico existente, por meio da atração de novos clientes para o mercado ou incentivando os clientes existentes a consumir mais. Corresponde ainda a descoberta de um modelo de negócios diferente dentro de um mercado já existente. A Amazon, por exemplo, redefiniu seu modelo de negócios através da venda online de livros. Naquele momento, a empresa apenas redefiniu a forma como seus produtos eram entregues aos clientes (Markides, 2006)

Outro exemplo sobre inovação de modelo de negócios é o da empresa Dell, a maior fabricante de computadores do mundo, que foi considerada a pioneira na venda de computadores via internet (Feldmann, 2015).

Além dos tipos de inovação, outra classificação importante proposta se refere ao grau de intensidade de mudança tecnológica da inovação, ou ainda, quanto sua capacidade de provocar mudanças no mercado.

Em relação ao grau de novidade, a inovação é classificada, de maneira geral, como incremental - quando é introduzida nos produtos e processos existentes, proporcionando melhorias e ajustes a eles; ou radical - que envolve mudanças 
revolucionárias as quais geram mudanças de paradigmas. A principal diferença entre elas, se refere ao grau de conhecimentos incorporados à inovação. Embora esse grau não seja fácil de ser medido, em geral, as classificações são atribuídas levando em consideração a percepção daqueles mais familiarizados com o grau de partida da inovação, ou seja, com o estado da arte do conhecimento antes da sua introdução (Dewar \& Dutton, 1986).

Outra diferença entre os dois tipos de inovação, destacada pelos mesmos autores, diz respeito ao risco e aos custos associados a cada uma delas, sendo tanto o risco quanto os custos maiores nas inovações radicais.

Essa conceituação também é compartilhada por Christensen (1999) que classifica a inovação como disruptiva e sustentada. Para este autor as inovações sustentadas, podem ser tanto de caráter incremental quanto radical, sendo ambas responsáveis por melhorias nos produtos e processos existentes. Já as inovações disruptivas promovem, a curto prazo, piora no desempenho dos produtos e processos existentes, uma vez que trazem propostas de valor novas e diferentes para novos clientes, indo além de suas necessidades e quebrando dinâmicas de mercado até então estabelecidas (Christensen, 1999).

Esses tipos de inovação, portanto, começam com desempenho inferior quando comparados aos líderes de mercado, no entanto, a longo prazo, o desempenho do líder se estabiliza enquanto o da inovação disruptiva o supera. As inovações disruptivas são consideradas também como radicais, no entanto, nem todas as inovações radicais são disruptivas, portanto, embora esses dois conceitos estejam interligados, não podem ser considerados como sinônimos (Paula, 2017).

Garcia \& Calantone (2002) propuseram uma classificação das inovações de produto quanto suas intensidades podendo ser categorizadas como novas para a empresa, novas para o mercado ou novas para o mundo.

Há, portanto, uma miríade de conceitos e definições de inovação que coexistem e compartilham elementos comuns que perpassam os mais diversos conceitos. O interesse pelos estudos em inovação tem sido demonstrado por diversos pesquisadores das áreas de economia e negócios em todo o mundo pelos impactos positivos que ela pode gerar para as empresas, para regiões e países. No âmbito das organizações, esse impacto é visto na melhora significativa de seus desempenhos, considerados como superiores quando comparados aos seus concorrentes (De Carvalho et al., 2017). 


\subsection{1}

\section{Modelos de inovação e inovação aberta}

As empresas utilizam a inovação estrategicamente como meio para alcançarem desempenhos superiores, como lucratividade, sobrevivência e competitividade. Com essa finalidade, a inovação tem sido definida como um processo dinâmico pelas organizações que adotam caminhos ou trajetórias de inovação diferentes, de acordo com suas realidades, o que resulta em desempenhos de inovação heterogêneos entre as empresas (Juliao-Rossi et al., 2020).

Para direcionar a inovação para geração de desempenhos superiores, as empresas adotam modelos de inovação (Taferner, 2017). A definição do modelo de negócios de uma empresa é importante, pois reflete suas escolhas estratégicas, as estruturas adotadas, os sistemas e as implicações operacionais que ajudam a testar, comunicar e validar as relações de causa e efeito das escolhas estratégicas adotadas (Carayannis et al., 2015). Em suma, para se obter boas inovações e inovações de sucesso, a implementação de processos de inovação dentro das empresas, é indicada como um bom caminho. A capacidade de inovar é considerada umas das competências essenciais para uma empresa competir em um ambiente cada vez mais dinâmico e desafiador (Taferner, 2017).

Dentro desse contexto e segundo o mesmo autor, a literatura traz diferentes modelos de inovação que foram elaborados à luz das realidades econômicas e necessidades das empresas. Uma geração desses modelos, foi baseada no modelo linear de Rothwell (1994) considerado o modelo mais antigo e de primeira geração (criado em meados da década de 60). A partir desse modelo outras derivações e gerações se estabeleceram, até o modelo considerado de quinta geração. Embora existam atualmente outros modelos, a grande maioria deles é uma extensão ou adaptação do modelo de primeira geração de Rothwell (1994).

O primeiro modelo de Rothwell, considerado linear, divide o processo de inovação em cinco etapas: pesquisa básica, pesquisa aplicada, desenvolvimento experimental, produção e comercialização, conforme exemplificado na Figura 3.

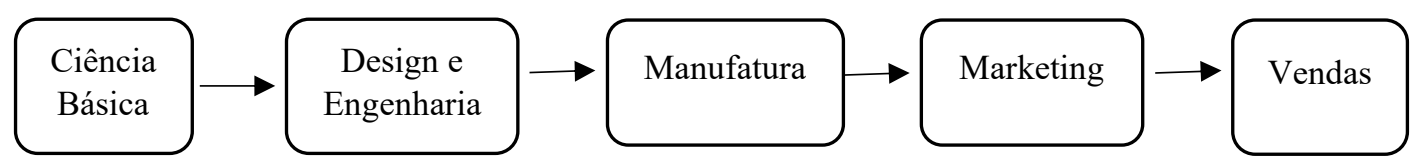

Figura 3: Modelo de inovação linear. Fonte: Baseada em Rothwell (1994) 
Por meio deste modelo, Rothwell (1994) enfatiza o papel da ciência básica como impulsionadora da inovação e a consequente importância do investimento em P\&D interno nas empresas para melhorar os resultados dos seus produtos e serviços produzidos.

A Empresa Brasileira de Aeronáutica - Embraer, criada em 1969, é um exemplo de empresa que nasceu dentro dessa lógica, uma vez que os elementos essenciais que impulsionaram sua criação foram pautados no investimento e na ênfase à pesquisa básica. O primeiro modelo - Bandeirantes, desenvolvido dentro do então Centro Técnico da Aeronáutica - CTA, não foi criado a partir de uma demanda de mercado, mas foi o resultado de parte do esforço de adequação tecnológica brasileiro (Silveira \& Cabral, 2007).

A segunda geração deste modelo, data da segunda metade da década de 60 e nasceu dentro de um contexto em que a produção industrial e a concorrência cresciam de forma substancial. $\mathrm{O}$ foco na demanda para subsidiar os processos de inovação se tornou mais expressivo, assim o mercado e suas demandas (market pull) passou a ser usado como uma fonte de ideias para conduzir as atividades de P\&D (Rothwell, 1994).

Já a terceira geração, promoveu a junção da influência e demandas do mercado - market pull e a inovação advinda da ciência básica - technology push, dando origem ao modelo denominado como acoplado, conforme ilustrado na Figura 4 (Rothwell, 1994). Esse modelo, embora ainda linear, acrescenta loopings de interação e feedback e foi adotado por muitas empresas no final da década de 70 e início da década de 80 , período marcado por crises econômicas intensas, que demandaram um foco das empresas na racionalização, na diminuição das incidências de falhas no processo de inovação e no conhecimento das demandas de mercado (Taferner, 2017).

Em outras palavras, o processo de inovação, de acordo com esse modelo, realça a importância da junção das capacidades tecnológicas, ciência básica com as necessidades de mercado, no âmbito de uma empresa considerada inovadora (Rothwell, 1994). 


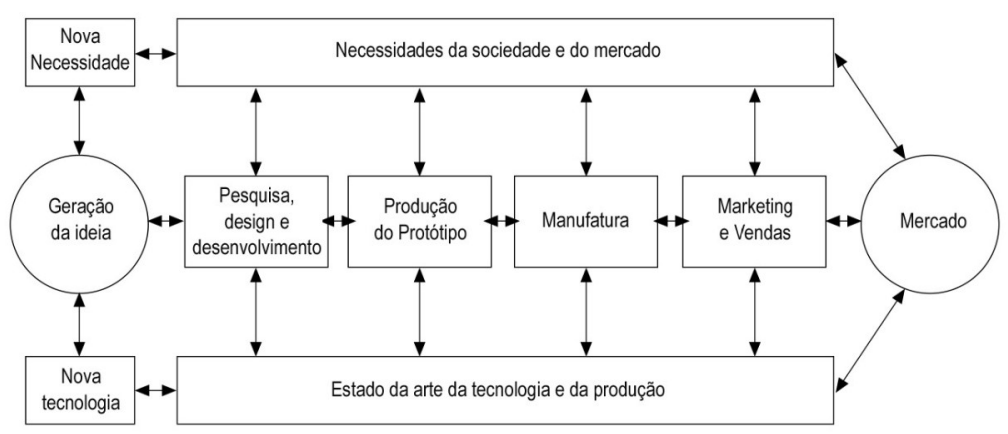

Figura 4: Modelo Acoplado. Fonte: (Rothwell, 1994)

A quarta geração do modelo já revela um contexto de recuperação econômica dos anos 80 , no qual os avanços tecnológicos levaram a ciclos menores de produção e exigiram um enfoque na velocidade de produção e a necessidade do estabelecimento de alianças estratégicas. Nesse período, chamou a atenção dos especialistas da época, o sucesso das empresas japonesas em relação às empresas ocidentais, que por meio da estratégia de integração de suas equipes com seus fornecedores, em um desenvolvimento em paralelo, contribuíram para a alta eficiência da produção (Silveira \& Cabral, 2007).

A quinta geração desses modelos de inovação, uniu as melhores práticas das gerações precedentes, cujos principais aspectos estavam na criação do conhecimento, no desenvolvimento de novos produtos, levando em consideração as influências internas e externas, as alianças com parceiros, especialmente fornecedores, embora a inovação fosse ainda um processo desenvolvido nos limites internos das empresas (Taferner, 2017).

O paradigma da inovação fechada, modelo pelo qual as atividades de P\&D relativas a produtos e processos são realizadas dentro dos "muros" das empresas, funcionou muito bem até os últimos anos do século XX (Davoudi et al., 2018). Sob esse paradigma, vários modelos de negócios foram construídos.

Outro modelo baseado no paradigma da inovação fechada, e muito comum na área de gestão da inovação, é o "The Stage-Gate-Process", desenvolvido por Cooper (2008). Embora esse modelo não faça parte das gerações de modelos de Rothwell é também um modelo linear e composto por estágios definidos por critérios, separados por portões por onde as ideias caminham, dependendo da complexidade, do atendimento aos critérios estabelecidos e dos riscos associados à ideia (Taferner, 2017). 
O modelo The Stage-Gates se refere a um mapa conceitual e operacional para gerir os projetos de novos produtos, desde a sua ideia até seu lançamento, com o intuito de melhorar a eficiência e eficácia desse processo. Por meio dos portões ou pontos de decisão, as atividades desenvolvidas até então, são analisadas para definição se o processo continua, se ele para, se retorna para ajustes das atividades, ou ainda, se aguarda para melhorias futuras (Cooper, 2008).

O autor enfatiza a flexibilidade e agilidade do modelo, que pode ser adaptado de acordo com as necessidades e realidades das empresas. Muitas empresas, tais como P\&G, Emerson Electric e 3M, o adotaram como base e prosperaram e lucraram com o seu uso. Devido à sua característica de adaptabilidade, o modelo é usado para atender variados objetivos e não só para projetos de novos produtos. Novas aplicabilidades podem ser: desenvolvimento de novos negócios, projetos de parcerias e alianças, projetos de pesquisa e desenvolvimento dentre outros.

A figura 5 mostra o modelo The Stage-Gate-Process, suas etapas e os três possíveis caminhos que a ideia pode percorrer, após passar pelo primeiro portão. Cada uma dessas etapas são realizadas por vários departamentos e equipes multifuncionais, lideradas por um único setor. As atividades são executadas de forma simultânea, em paralelo. Não há, portanto, uma etapa de marketing, P\&D e engenharia, todas as etapas compreendem atividades dessas naturezas, que são realizadas conjuntamente. O caminho que a ideia irá percorrer, dentro das três possibilidades apresentadas após a passagem pelo primeiro portão, depende da sua complexidade, o que necessitará de números maiores ou menores de estágios e pontos de decisão (Cooper, 2008).

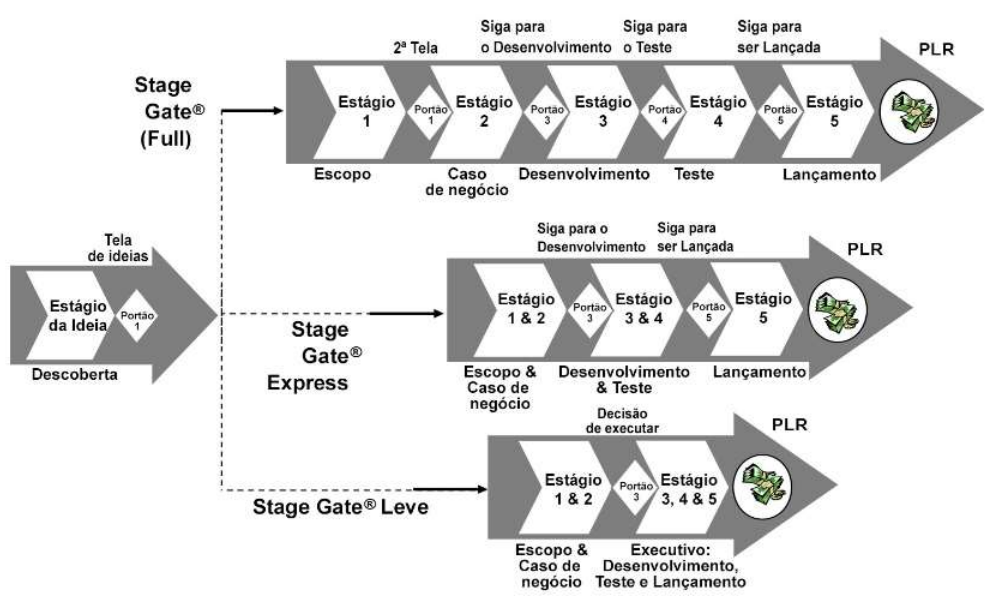

Figura 5: Modelo The Stage-Gate-Process. Fonte: Cooper (2008). 
No final do século XX, com o aumento da competitividade em nível global e os avanços tecnológicos, os modelos de inovação foram adaptados à lógica e paradigma da inovação aberta. Embora o conceito por trás da inovação aberta não seja novo, ou seja, as empresas historicamente já percebiam a importância de explorar novas oportunidades no meio externo, o conceito ganhou força (Lopes \& de Carvalho, 2018) quando Chesbrough (2003) cunhou o termo "inovação aberta", cuja definição considera os fluxos internos e externos de informações e conhecimentos no processo de inovação das empresas, de forma a acelerar suas capacidades de inovação. O modelo conceitual que traduz esse novo paradigma é apresentado na Figura 6.

O modelo exemplifica a permeabilidade do fluxo de conhecimento interno e externo, por meio das linhas pontilhadas do funil que dividem a empresa do seu ambiente externo (Lopes \& de Carvalho, 2018). O lado esquerdo da figura ilustra o modelo de inovação fechada enquanto o lado direito ilustra o modelo de inovação aberta.
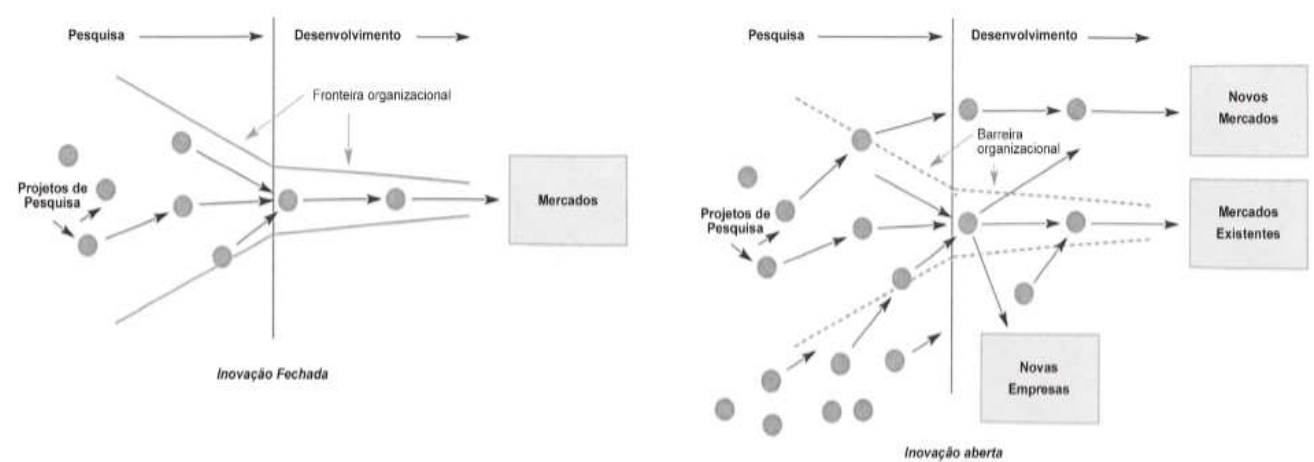

Figura 6: Comparação entre os Modelos de Inovação Fechado e Aberto Fonte: (Chesbrough, 2003)

Por meio do modelo de inovação aberta, é perceptível que os processos de pesquisa realizados no limite das empresas podem receber contribuições e ideias externas para auxiliar no avanço do desenvolvimento da inovação (Paula, 2017). Esse processo é definido como outside-in, no qual os conhecimentos externos são internalizados e incorporados aos recursos internos da empresa (Natalicchio et al., 2017), funcionando como catalisadores do processo de inovação (Macedo-Soares et al., 2017).

O processo inverso, denominado inside-out, é o processo pelo qual o conhecimento desenvolvido internamente é transferido para além dos limites da 
organização, seja para fins comerciais, ou ainda, para auxiliar nos processos de inovação de outras empresas (Natalicchio et al., 2017). A adoção de ambos processos pelas empresas, é denominado coupled process (Greco et al., 2016).

A abertura do modelo de negócios de inovação de uma empresa, parte do pressuposto que, dentro de um ambiente altamente competitivo e tecnológico, as empresas não conseguem mais inovar rapidamente sozinhas. Muitas empresas, por exemplo, encontraram as soluções para diversos de seus problemas no ambiente externo. A P\&G foi uma das empresas que percebeu essa possibilidade, e por isso, implantou o programa "Connect and Develop", o que resultou em mudanças também nas suas práticas organizacionais (Lopes \& de Carvalho, 2018).

De maneira semelhante, a Natura, após perceber grande oportunidade de ampliação da sua capacidade de inovação se abriu para o desenvolvimento junto com o seu meio externo, implantando o programa de inovação aberta, denominado "Natura Campus" (Ades et al., 2013).

De maneira a atender esse novo ambiente e essa nova lógica de inovação aberta, imposta pelas demandas do mercado, as empresas e seus modelos se adaptaram, como o caso do modelo The Stage Gate, que adicionou a todas as etapas, um processo iterativo com os clientes que possibilita ajustes e melhorias em todo o processo por meio da participação deles (Cooper, 2008).

No entanto, a definição de abertura das empresas foi passível de diferentes conceitos na literatura. Para Dahlander \& Gann (2010) a definição de abertura, se distancia da definição pura e simplista da inovação aberta como antagônica da inovação fechada. Pelo levantamento realizado por meio da revisão bibliográfica, os autores definiram que o conceito de inovação aberta se associa a diferentes graus de abertura das empresas. Eles identificaram quatro tipos diferentes de abertura, que apresentam vantagens e desvantagens e que estão divididos da seguinte forma: Dois tipos caracterizados como de entrada ou inbound e dois tipos denominados como processos de saída - outbound, cujas definições colocadas pelos autores, estão descritas abaixo:

Inbound - Aquisição de inovação realizada por outras empresas - Consiste na aquisição de insumos necessários para a inovação. As vantagens recaem nos benefícios de amplitude das capacidades de inovação por meio da aquisição de conhecimentos. No entanto, essa aquisição requer análises quanto à semelhança dos conhecimentos, uma vez que incorporar conhecimentos semelhantes não 
contribuirá para o aumento da base de conhecimento interna. O mesmo também é empregado no caso de conhecimentos muito discrepantes que exigem muito gerenciamento para adaptá-los e integrá-los ao corpo de conhecimento existente.

Outro tipo de abertura de entrada ou Inbound - Terceirizar inovação - As vantagens se pautam na quantidade de informações e conhecimentos externos aos quais as empresas podem ter acesso. Nessa lógica, quanto maior a quantidade de parcerias, mais informações a empresa terá. As desavantagens perpassam por questões de limitações cognitivas dos empregados de P\&D, por exemplo, cuja atenção deve estar focada na busca de um equilíbrio entre tarefas de pesquisa e exploração com o desenvolvimento interno. Um excesso de busca diminui o desenvolvimento interno sendo o inverso também prejudicial, uma vez que a empresa coloca todo seu foco internamente perdendo oportunidadades advindas do meio externo.

Já o primeiro tipo de abertura, denominada de saída ou Outbound - Consiste na revelação da inovação ao mercado, sem o envolvimento de interesses pecuniários. Nesse tipo de abertura, os objetivos são benefícios indiretos para a empresa. As vantagens consistem no recebimento de colaboração, com o uso de mecanismos formais e informais de proteção que protegem e auxiliam as empresas na apropriação das receitas advindas das soluções inovadoras resultantes das colaborações. A maior desvantagem consiste nos riscos da apropriação indevida das receitas por parceiros, ou ainda, pelo uso exagerado de mecanismos de apropriabilidade o que pode gerar miopia de proteção.

O segundo tipo de abertura de saída ou Outbound - Venda da inovação ao mercado - As vantagens advém da comercialização das tecnologias e das rendas consequentemente geradas. As desvantagens recaem sobre as possibilidades dos parceiros de se apropriarem das invenções indevidamente, por meio de um comportamento oportunista. Muitas vezes, as empresas evitam a venda de suas tecnologias com receio do roubo de ideias, o que gera falhas de mercado.

Quanto às definições de inovação aberta, as concepções originais focaram nas organizações como unidades de análise e no alinhamento dessa inovação ao modelo de negócios da empresa (West \& Bogers, 2017). Uma vez definida a adoção da inovação aberta como estratégia, as empresas precisam definir as práticas organizacionais e gerenciais necessárias para apoiar essa decisão, bem como definir como se dará o processo de implementação da inovação aberta (Ades et al., 2013). 
Na maioria das vezes, mudanças profundas nos modelos de negócios das empresas e reorganizações internas são necessárias; e embora as abordagens amplas de inovação aberta sejam compartilhadas entre as organizações, cada uma deve ajustar seu modelo às suas questões contextuais, mesmo que algum modelo genérico de inovação aberta seja adotado como referência (De Carvalho et al., 2017; Leon et al., 2020).

Tidd (2001) enfatiza a importância da identificação das contingências mais significativas em cada setor, a melhor configuração das estruturas organizacionais a serem adotadas e o gerenciamento que melhor se adeque neste cenário para o alcance de desempenho superior e vantagem competitiva.

Estudos mais recentes, afirmam que a implementação dos modelos de inovação deve ser gerenciada como um projeto, formado por um conjunto de subprocessos interligados e com realização de ciclos de feedbacks até que atinjam uma estabilidade. Os processos específicos a serem adotados, durante o processo de implementação dependerão das capacidades das empresas e de suas maturidades para incorporá-los nos demais procedimentos de gerenciamento, como no caso de empresas que realizam atividades de pesquisa e desenvolvimento (Leon et al., 2020).

Segundo os mesmos autores, nas organizações de $\mathrm{P} \& \mathrm{D}$, por exemplo, que atuam por projetos, as empresas podem adotar vários modelos simultâneos de inovação aberta com diferentes graus de abertura, uma vez que os projetos atuam de forma simultânea e requerem diferentes modelos que são, muitas das vezes, implementados em áreas específicas para apoiar as atividades de cada projeto (Leon et al., 2020). Ainda segundo esses autores, nessas empresas, o grande desafio é deixar a empresa mais flexível, tanto em termos de estrutura quanto de gerenciamento, mantendo a maior estabilidade possível.

$\mathrm{Na}$ prática, muitas empresas de diversos setores têm adotado modelos de inovação aberta, acoplados à escala de maturidade tecnológica (Escala TRL/MRL) (Leon et al., 2020). Essa escala foi desenvolvida pela Administração Nacional da Aeronáutica e Espaço Norte Americana - Nasa, na década de 70, e permite um mecanismo de acompanhamento da tecnologia em todo o seu processo de pesquisa e desenvolvimento, além de possibilitar a comparação direta com outras tecnologias (Mankins, 1995). Dentro do contexto da inovação aberta, o qual pode envolver parcerias para co-criação, co-desenvolvimento e colaboração entre diversas partes, 
a adoção desse sistema de medição se torna uma importante ferramenta para auxiliar na definição do nível de maturidade de uma determinada tecnologia (Capdeville et al., 2017) e na abordagem de inovação aberta a ser adotada pelas empresas (Leon et al., 2020) . As TRL's se referem à Technology Readiness Levels e são aplicadas para avaliar o grau de maturidade de um produto/tecnologia, já as MRL's Manufacturing Readiness Levels se referem à avaliação do grau de maturidade de processos (Mankins, 1995).

De todas as formas, a inovação aberta é adotada para oferecer possibilidades de compartilhamento dos riscos existentes, dos custos de desenvolvimento, para acesso a conhecimentos que a organização não possui, ou ainda, para melhorar o desenvolvimento de seus produtos e processos, a partir do alinhamento com os recursos e capacidades internas das organizações (Mortara \& Minshall, 2011).

De acordo com a OCDE (2008) as organizações podem executar a inovação aberta com sete diferentes tipos de parceiros: fornecedores, clientes, consultores, institutos privados de pesquisa e desenvolvimento, concorrentes, universidades, centros de pesquisas públicas e governamentais e outros centros de ensino superior.

A eficiência da adoção da inovação aberta será maior quanto maior for a capacidade das organizações em reconhecer as oportunidades e integrá-las às organizações (Lopes \& de Carvalho, 2018). Em outras palavras, quanto maior for a capacidade absortiva das empresas, "capacidade de uma firma de reconhecer o valor de novas informações externas, assimilá-las e aplicá-las a fins comerciais" (Cohen \& Levinthal, 1990 - pg. 128) maior será a influência do conhecimento externo na amplitude da base de conhecimento interno das empresas, e consequentemente, maiores serão suas capacidades de inovação. $\mathrm{O}$ resultado apresentado pelas organizações será fruto da conjunção do desenvolvimento interno e externo das empresas (Paula \& Silva, 2017)

A forma como as empresas geram inovação é parte importante de suas estratégias. De acordo com March (1991) a estratégia de exploração (exploration) de novas possibilidades, ocorre pela procura, flexibilidade, refinamento, experimentação e descoberta de novas tecnologias, por isso está diretamente associada à pesquisa básica. Já a estratégia de aproveitamento (exploitation) está ligada ao refinamento, à escolha, seleção, eficiência e implementação de tecnologias já conhecidas, portanto mais ligadas à pesquisa aplicada. 
As empresas que alcançam o equilíbrio entre essas duas estratégias são consideradas como ambidestras. Considerada como um antecedente da inovação, a ambidestria, consiste na capacidade das empresas em manter o foco tanto nas atividades de exploração (exploration) quanto nas atividades de aproveitamento (exploitation) o que amplia suas possibilidades de inovação (Vogel \& Güttel, 2013; Lopes \& de Carvalho, 2018; Zhao et al., 2016).

Dentro da concepção da abertura da inovação para adoção de conhecimentos externos, a P\&D interna passa a ter duas atividades principais: a do desenvolvimento e melhoria contínua da sua capacidade interna com a sua capacidade de rastrear e coletar informações fora dos limites organizacionais (Dahlander \& Gann, 2010).

Uma das formas de realizar a inovação aberta e explorar esse conhecimento externo é por meio do estabelecimento de alianças estratégicas, cujo tópico será detalhado na Seção 2.3. O foco nos recursos e capacidades internas, no entanto, é de igual importância, uma vez que o desenvolvimento das capacidades de aprendizagem e da capacidade absortiva das empresas impactam na capacidade de assimilação e integração dos conhecimentos externos. De forma semelhante, os investimentos e gastos em P\&D têm relação estreita com o desempenho de inovação das empresas (Lopes \& de Carvalho, 2018).

A literatura traz diversos estudos que enfatizam a importância de recursos, capacidades, competências (Vogel \& Güttel, 2013; Lichtenthaler \& Lichtenthaler, 2009 Podmetina et al., 2018) e atividades ligadas à P\&D (Castro, 2011) todas consideradas como críticas para a inovação aberta. Essas análises serão detalhadas na Seção 2.2.1.

Independente das abordagens utilizadas, a adoção da inovação aberta pode causar impacto nos resultados da empresa e em seus desempenhos de inovação, no entanto, medir essa inovação e definir os indicadores corretos, ainda é um desafio para as organizações e para os estudos sobre desempenho de inovação (De Carvalho et al., 2017).

A inovação não é um objetivo em si, mas um processo que auxilia as organizações a alcançarem melhores desempenhos quando comparadas a seus concorrentes, sendo fontes de desempenhos superiores (Ades et al., 2013). 


\subsection{2 \\ Desempenho de inovação}

O desempenho de inovação é difícil de ser medido. Uma grande dificuldade das empresas com relação à inovação, é definir métricas que sejam capazes de medir de forma mais precisa a inovação por elas praticadas. Em geral, as métricas são muito limitadas (Muller et al., 2005).

A eficiência da inovação aberta é considerada ainda como um campo fértil de pesquisa. Segundo Greco et al.(2017) uma empresa pode ser considerada mais eficiente que outra, em termos de adoção e implementação da inovação aberta, quando alcança resultados melhores diante do recebimento dos mesmos insumos.

Zhao et al. (2016) analisaram a eficiência da inovação aberta e verificaram a existência de elementos críticos, tais como a estratégia das empresas, suas capacidades tecnológicas, sua cultura e suas capacidades absortivas. Sendo a cultura e a estrutura organizacional os elementos mais relevantes nesse contexto, uma vez que refletem como as empresas se preparam internamente para criar um ambiente propício que ampare a inovação aberta.

$\mathrm{Na}$ literatura, vários autores abordaram esse tema observando diversos aspectos em vários momentos distintos. Alguns estudos focaram na definição de métricas e indicadores para avaliar a capacidade tecnológica das organizações para gerar inovações, e para isso, focaram em atividades de $\mathrm{P} \& \mathrm{D}$, melhoria de suas atividades de produção e processos de aprendizagem. Outros estudos focaram na avaliação dos resultados alcançados após finalizado o processo de inovação, ou seja, após o produto ou serviço ser colocado no mercado, ou ainda, após todo o processo ter gerado resultados, seja no aumento da qualidade ou na redução dos custos. Práticas de inovação aberta, como parcerias com empresas ou alianças também são usadas como fatores que influenciam o desempenho de inovação das empresas (Ades et al., 2013).

Alguns autores definem as medidas de inovação por meio de: "inputs", consideradas como entradas, que compreendem - investimentos em pesquisa, gastos e intensidade em pesquisa e desenvolvimento - P\&D (Lopes \& de Carvalho, 2018); qualificação da equipe de P\&D (De Carvalho et al., 2017), número de cientistas, engenheiros e outros técnicos contratados (Paula, 2017) dentre outros; e por meio de "outputs", considerados saídas, que se referem a: número de inovações, a porcentagem de receitas advindas da venda de novos produtos (De 
Carvalho et al., 2017) aspectos relacionados à melhoria da produtividade que resultam em diminuição do tempo de colocação de novos produtos no mercado, ou ainda, processos que propiciam a expansão do acesso a novos mercados dentre outros (Greco et al., 2016).

Em contextos de países emergentes, no entanto, os indicadores relacionados às inovações tecnológicas, por exemplo, como patentes e indicadores de $\mathrm{P} \& \mathrm{D}$, muitas vezes não refletem a realidade de todas as empresas, visto que a grande parte delas são empresas tradicionais com menor taxa de inovação. Nesses contextos, analisar outros aspectos como esforço de mudança, tais como: adaptações em produtos, novas formas operacionais, novas técnicas de marketing, ou mesmo, novas práticas de gestão, se torna importante e mais adequado. Assim, a eficiência operacional, a gestão da organização e as atividades comerciais também podem servir como fontes de inovação (Reichert et al., 2015).

Segundo Tidd et al.(2005) as atividades realizadas pelas empresas e consideradas inovativas, apresentam de maneira geral, um padrão de sequência, cuja divisão ocorre da seguinte forma: (i) produção do conhecimento tecnológico; (ii) transformação desse conhecimento em elementos de trabalho; (iii) resposta a uma demanda de marketing. Em cada uma dessas fases específicas, as atividades recebem entradas consideradas como: conhecimento científico advindos da base de conhecimento existente; estratégias da empresa, recursos humanos para o seu desenvolvimento, bem como recursos financeiros necessários para a execução de cada um desses subprocessos.

Figueiredo (2009), por outro lado, propôs uma classificação distinta dessas atividades consideradas inovativas, cuja classificação foi importante para facilitar a criação de proxies que representam os esforços de inovação das empresas. $\mathrm{O}$ autor considerou os processos de inovação por elas adotados e não os resultados de inovação em si.

Segundo Figueiredo (2009) a classificação proposta divide as atividades, denominadas como partes do processo de inovação das empresas, em um espectro contínuo, que acompanha o grau de novidade e complexidade da inovação, sendo a divisão realizada da seguinte forma: (i) imitação duplicada; (ii) imitação criativa; (iii) pequenas e médias adaptações e modificações realizadas; (iv) robustas adaptações e modificações por meio de engenharia; (v) design e desenvolvimento realizados por meio de engenharia e $\mathrm{P} \& \mathrm{D}$, cujos resultados não são considerados 
novos para o país; (vi) design e desenvolvimento por meio de engenharia e P\&D, cujos resultados não são considerados novos para o mundo: (vii) design original realizado por meio de engenharia aberta e P\&D; (viii) descoberta de conhecimento considerado radicalmente novo que suporta novas atividades de design e desenvolvimento, baseados em esforços sofisticados de P\&D.

A escolha do processo e estratégia de inovação das empresas é de extrema importância, uma vez que determinam a distribuição de recursos, o posicionamento estratégico, a estrutura e as práticas organizacionais que deverão ser adotadas para apoiar as atividades de inovação.

De forma geral, esses processos, atividades e métricas utilizadas, embora representem um esforço organizacional em prol da inovação, são considerados por outro lado, como limitados, uma vez que podem refletir resultados pontuais, frutos de situações específicas, não garantindo que a empresa seja inovadora e que manterá essa inovação de forma sustentável. Para que essa sustentabilidade seja alcançada, as organizações precisam adotar a inovação como um processo, de forma que auxilie as empresas a não só obterem desempenhos superiores, mas contribuam para suas sobrevivências a longo prazo, principalmente em ambientes de alta incerteza (Muller et al., 2005).

De acordo com o Manual de Oslo OECD \& Eurostat (2018), os impactos da inovação no desempenho das empresas variam de efeitos sobre as vendas, a partir da introdução de produtos novos ou melhorados e sobre a fatia de mercado detida por meio da melhoria da produtividade e da eficiência das empresas. Outros indicadores relevantes são os de Ciência e Tecnologia, como os recursos direcionados à $\mathrm{P} \& \mathrm{D}$ e as estatísticas de patentes. Além disso, há indicadores bibliométricos e outros indicadores construídos a partir de informações qualitativas sobre o efeito da inovação, que funcionam como complementares, uma vez que as patentes e os recursos de $\mathrm{P} \& \mathrm{D}$, também são limitados quanto suas capacidades de medição. Alguns desses indicadores complementares são: Estatísticas sobre publicações científicas (bibliométricas); publicações em jornais técnicos, inovações baseadas em publicações, recursos humanos capacitados e indicadores de atividades em setores de alta tecnologia.

Muitos autores questionaram o uso de patentes como medidas de inovação, uma vez que, muitas inovações não geram patentes, assim como muitas patentes 
não refletem inovações de sucesso amplamente adotadas na sociedade, sendo portanto, um indicador questionável (Altuzarra, 2017).

O Manual de Frascatti (OECD, 2002) afirma que as atividades de P\&D são apenas uma parte do processo de inovação, que envolve também atividades nas fases finais de desenvolvimento para pré-produção, atividades de produção e distribuição, atividades para novos métodos de marketing, novos métodos organizacionais, dentre outros. O manual também disponibiliza diretrizes para os países em desenvolvimento e afirma que medir os esforços e as capacidades de inovação das empresas é tão importante quanto medir seus resultados de inovação (Muller et al., 2005).

No Brasil, o Instituto Brasileiro de Pesquisa e Estatística - IBGE realiza a PINTEC - Pesquisa de Inovação, realizada a cada três anos, que tem como objetivo construir indicadores setoriais, regionais e nacionais a partir das atividades de inovação coletadas de uma amostra de empresas brasileiras. A pesquisa, que consiste em perguntas, propõe uma escala de impacto à inovação, baseada no Manual de Oslo, que indica o impacto da inovação de produtos ou processos de acordo com quatro dimensões: dimensão do Produto; dimensão de mercado; dimensão de processo e outros impactos (OECD \& Eurostat, 2018).

De forma geral, as métricas de inovação mudam de acordo com o tipo de indústria e tipo de empresa. Aspectos macroeconômicos e/ou relativos à cultura dos países onde as empresas estão inseridas, também influenciam no desempenho de inovação das empresas (Greco et al., 2016). Em outras palavras, o processo inovativo é dependente do setor econômico, das características intraorganizacionais e do campo de conhecimento, que podem ser considerados como aspectos contingenciais que impactam na definição do grau de investimento de uma empresa em inovação (Paula, 2017).

Ahuja et. al (2008) identificaram 4 dimensões que impactam nos resultados e nos esforços de inovação das empresas: a estrutura da indústria, as características da empresa, a influência institucional e os atributos intraorganizacionais, que definem quais as principais fontes de conhecimento a empresa irá usar para subsidiar sua inovação.

Estrutura da Indústria: (i) Estrutura de mercado, que fornece recursos e segurança para financiar atividades de inovação e os riscos naturalmente envolvidos; (ii) Redes de colaboração, que por meio do acesso a parceiros com 
conhecimentos heterogêneos e a divisão dos riscos das atividades de inovação, podem contribuir para o aumento do desempenho de inovação; (iii) comprador/usuário em potencial, influenciando as empresas a inovarem para satisfazerem suas necessidades; (iv) fornecedores e complementadores, este último definido como os atores que fornecem um produto ou serviço que constitui um complemento que quando associado ao seu produto, o torna mais valioso a seus clientes (Nalebuff \& Brandenburger, 1997) podem ser motivados a inovar, para melhorar suas capacidades de inovação, principalmente quando percebem que possuem ativos complementares que os beneficiarão.

Características das empresas: (i) tamanho das empresas: as empresas maiores têm maior propensão a inovar, uma vez que possuem mais recursos tanto financeiros, quanto humanos e maior infraestrutura quando comparadas a empresas menores, embora em alguns casos, o tamanho também possa ser prejudicial pelo excesso de burocratização que as empresas maiores são normalmente sujeitas; (ii) escopo da empresa: empresas mais diversificadas têm maiores incentivos para investir na ciência básica e se tornam mais propensas a inovar, por outro lado a diversificação exige mais investimento; (iii) alianças e redes: as alianças permitem mais acesso a recursos e maiores capacidades de inovação, no entanto, exigem mais investimentos para gerenciar as alianças, para que elas tenham sucesso e gerem desempenhos superiores às empresas; (iv) desempenho abaixo do esperado pelas empresas pode resultar em desistência das empresas em optarem pela inovação ou, por outro lado, pode fazer com que as empresas percebam a necessidade de investir mais em P\&D, o que pode acarretar em aumento da capacidade de inovação.

Atributos intraorganizacionais - os processos, fluxos de informações e equipes diversificadas são imprescindíveis para a inovação; (vi) estrutura de governança, remuneração e incentivo são essenciais para encorajar as equipes a inovarem; (vii) histórico do gerente: o apoio da alta gerência, bem como as características individuais dos gestores influenciam nas estratégias de inovação que a empresa irá tomar; (viii) Processos de pesquisa organizacional: a eficiência desse processo afeta a produtividade e inovação, sendo portanto, imprescindíveis.

Influência Institucional: (i) $\mathrm{O}$ investimento na ciência permite que as empresas acompanhem os avanços tecnológicos e estejam mais preparadas para acompanhar os progressos e inovarem; (ii) condições de apropriabilidade - esses mecanismos são essenciais para que as empresas possam capturar valor das 
inovações que elas geram, se posicionando de forma correta para obter os lucros dessas inovações, evitando apropriações indevidas por parceiros oportunistas.

Embora a literatura traga diversos aspectos e fatores que influenciam o desempenho de inovação, as principais proxies utilizadas para medir o desempenho de inovação das empresas, descritas na maioria dos artigos sobre o tema, estão descritas na Quadro 1.

Quadro 1: Principais proxies de desempenho de inovação

\begin{tabular}{|l|l|}
\hline \multicolumn{1}{|c|}{ Proxies } & \multicolumn{1}{c|}{ Autores } \\
\hline Número de Patentes & $\begin{array}{l}\text { (Ades et al., 2013 (Laursen \& Salter, 2006) } \\
\text { (Greco et al., 2016); (Bei et al., 2008); (Muller } \\
\text { et al., 2005) }\end{array}$ \\
\hline Número de citações de Patentes & $\begin{array}{l}\text { (Laursen \& Salter, 2006) (Greco et al., 2016) } \\
\text { (Bei et al., 2008) }\end{array}$ \\
\hline $\begin{array}{l}\text { Número de inovações lançadas (produtos e } \\
\text { processos) }\end{array}$ & $\begin{array}{l}\text { (Paula \& Silva, 2018); (Altuzarra, 2017); } \\
\text { (Lopes \& de Carvalho, 2018) }\end{array}$ \\
\hline $\begin{array}{l}\text { Receitas advindas de novos produtos ou } \\
\text { serviços lançados }\end{array}$ & $\begin{array}{l}\text { (Paula \& Silva, 2018); (Altuzarra, 2017); } \\
\text { (Lopes \& de Carvalho, 2018) }\end{array}$ \\
\hline Atividades de P\&D & (Ades et al., 2013); (Altuzarra, 2017) \\
\hline
\end{tabular}

No entanto, embora haja uma série de proxies objetivas para medir o desempenho de inovação das empresas, já é consenso na literatura a necessidade da utilização de dados de natureza subjetiva, adotando uma análise multidimensional do desempenho, cuja percepção dos gestores e empregados de uma determinada organização, por exemplo, podem ser utilizados. As medidas subjetivas de desempenho são correlacionadas às medidas objetivas e fornecem uma visão mais ampla sobre o desempenho, como por exemplo, a avaliação dos empregados de uma empresa sobre a extensão do impacto e extensão do desempenho de um produto dentro da organização e na comparação dela com seus principais concorrentes (Manthey et al., 2016).

Alegre et al., (2006) criaram uma escala para medir o desempenho de inovação de produto, com a utilização de medidas relacionadas à eficiência e eficácia do desempenho no contexto da competitividade empresarial. A pesquisa foi aplicada em empresas de biotecnologia na França. A eficácia foi medida por meio dos resultados econômicos advindos da inovação de produto ou por meio da importância econômica das saídas do processo de inovação. A eficiência foi medida por meio dos recursos consumidos para atingir os resultados de inovação, ou seja, o esforço empreendido para o alcance do desempenho. A escala likert de sete pontos solicitou que os respondentes avaliassem seus desempenhos, levando em consideração os resultados dos principais concorrentes. Na escala, o valor um 
correspondia a "muito pior que o dos concorrentes" e sete "muito melhor do que os concorrentes". Após análises estatísticas, os resultados do estudo mostraram que ambas dimensões: eficiência e eficácia eram significativas para o desempenho de inovação e por isso deveriam ser consideradas de forma simultânea. Focar em uma única dimensão em detrimento da outra não era uma estratégia viável para o alcance do sucesso de desempenho.

De maneira semelhante, Hannachi (2015) realizou uma pesquisa nas empresas francesas de biotecnologia e propôs uma escala de medição do desempenho de inovação de produto, através de cinco dimensões: desempenho financeiro, desempenho do mercado, desempenho do cliente, desempenho técnico e desempenho estratégico. As dimensões consideradas neste estudo foram mais abrangentes. No total, foram elencados 18 itens divididos nessas cinco dimensões, que foram avaliados por meio de uma escala likert de cinco pontos, onde um correspondia a "resultado não alcançado, enquanto cinco correspondia a "resultado perfeitamente alcançado". Os resultados mostraram que essas cinco dimensões podem ser consideradas, em conjunto, para medir o desempenho de inovação de produto de uma organização.

Abu Bakar \& Ahmad (2010) realizaram uma pesquisa, com pequenas e médias empresas de vários setores da Malásia, com o intuito de analisar, por meio da percepção de seus gestores, o impacto dos recursos internos, sob a perspectiva da Teoria Baseada em Recursos, no desempenho de inovação dessas empresas. Por meio da definição de seis dimensões, compostas por 22 variáveis, sendo as dimensões: física, financeira, intelectual, humana, organizacional, reputacional e tecnológica.

Os autores analisaram as variáveis por meio de escala likert de cinco pontos, sendo: um - impacto comparativamente muito baixo no desempenho de inovação de produto das empresas e cinco - impacto comparativamente muito alto no desempenho de inovação de produto. Os resultados mostraram que os recursos intangíveis são os que mais impactam no desempenho de inovação de produto. Algumas varáveis utilizadas para medir o construto de recursos internos são: Recursos tangíveis: Estrutura física e organizacional, máquinas, caixa da operação, capital financeiro. Recursos intangíveis: Reputação do atendimento ao cliente, reputação do produto, reputação da empresa, know-how de tecnologia exclusivo, 
design de produto novo ou aprimorado, inovatividade, proatividade, cultura organizacional, políticas organizacionais.

No entanto, embora a definição de proxies e medidas que possam avaliar o desempenho de inovação das empresas sejam relevantes, aspectos externos às organizações também impactam em seus desempenhos inovativos. Nessa perspectiva há que se considerar a infraestrutura institucional do país ( MacedoSoares et al., 2017) e a existência de um robusto Sistema Nacional de Inovação que seja capaz de criar um ambiente mais inovativo que contribua para a melhoria da capacidade de inovação do país e das empresas (Brasil, 2016).

\subsection{3}

\section{Sistema Nacional de Inovação}

A primeira tentativa de conceituar Sistema Nacional de Inovação remonta à década de 70 e a várias rodadas subsequentes de sua elaboração. Essa primeira tentativa é resultado do trabalho de um grupo de pesquisa da Universidade de Aalborg - Dinamarca, formado por economistas, que perceberam a diferença no desenvolvimento econômico e na competitividade internacional entre várias nações e as dificuldades que os formuladores de políticas tinham no entendimento, por meio das teorias e políticas macroeconômicas, dos fatores existentes por trás dessas diferenças entre as nações. Na realidade, a grande parte do conhecimento que antecedia as inovações, impulsionadoras do crescimento econômico, não vinha somente da pesquisa e desenvolvimento e de setores específicos, como universidades, por exemplo, mas de áreas como marketing, engenharia e dos próprios usuários, cujas características eram únicas de cada país (Lundvall et al., 2002; Lundvall, 2016).

Esses aspectos, segundo os mesmos autores, levaram à percepção do grupo de pesquisa, da necessidade da criação de um sistema que abarcasse e integrasse esses outros setores, elementos, e até mesmo relacionamentos e desenvolvimento de competências que antecediam a geração da inovação dentro dos países.

Nesse sentido, embora o conceito de Sistema Nacional de Inovação pareça controverso dentro de um contexto de globalização, em que a definição de nações pareça ser obsoleto pela internacionalização do comércio e da produção, sua importância está nos padrões únicos e específicos de produção, de comércio e inovação dos países. Um exemplo, é o fato da Noruega ter forte especialização em 
tecnologia de pesca, o que advém de fatores como a estreita interação entre os produtores das máquinas e usuários domésticos extremamente competentes, bem como de questões geográficas, que são aspectos específicos e únicos daquela nação (Lundvall, 2016).

O conceito, então, foi aos poucos se ampliando para uma visão mais sistêmica da inovação e de todos os aspectos que a influenciavam, passando a ser utilizado, principalmente, por instituições nacionais e internacionais, como a OCDE, como uma estrutura analítica para entendimento dos fatores que exemplificavam a eficiência dos sistemas nacionais, suas restrições, seus incentivos, e os consequentes desenvolvimentos econômicos heterogêneos que ele gera na comparação econômica entre os Estados (Lundvall et al., 2002).

De acordo com Patel \& Pavitt (1994) sistemas nacionais de inovação são “...instituições nacionais, suas estruturas de incentivo e suas competências, que determinam a taxa e a direção do aprendizado tecnológico (ou o volume e a composição das atividades geradoras de mudanças) em um país”. Em suma, os autores argumentam que os sistemas nacionais de inovação tratam de processos de aprendizagem, de elementos de incentivo e de organizações componentes tais como: empresas, governos, universidades, outras instituições de ensino e as relações entre elas, além de normas e regras institucionais que direcionam e dão respaldo às atividades dos agentes inovadores.

Dentro desse contexto, os Sistemas Nacionais de Inovação são considerados um dos fatores externos às organizações que influenciam e impactam em seus desempenhos de inovação (Paula, 2017). O resultado inovativo das empresas, nesse sentido, não depende somente de fatores endógenos, mas da forma como as empresas interagem, cooperam, e estabelecem, à longo prazo, uma relação de confiança, aprendizado e capacitação tecnológica que dificilmente seriam alcançadas de forma isolada e que favorecem a melhoria de seus desempenhos e o fortalecimento do sistema como um todo (Cunha et al., 2009).

Segundo os mesmos autores, em países em desenvolvimento, há pouca ou quase nenhuma interação entre os agentes inovativos, como as universidades, empresas e institutos de pesquisa, por exemplo, Além disso, os investimentos públicos e privados destinados ao desenvolvimento dos recursos humanos é incipiente e desigual, o que compromete a capacidade de aprendizagem e a 
capacidade tecnológica dos diversos atores que compõem o sistema, e consequentemente, a capacidade de inovação do país.

No caso específico do Brasil, em relação à sua capacidade inovadora, de acordo com o ranking global de inovação - ano 2019, construído com base em várias dimensões, desde a análise das instituições nacionais até o desenvolvimento de recursos humanos, o país ocupa o $66^{\circ}$ lugar (conforme mostrado na introdução deste trabalho). (Global Innovation Index, 2019). Esse ranking evidencia a dificuldade do Brasil, assim como outros países em desenvolvimento, de alcançarem a fronteira tecnológica e inovarem na mesma proporção que países desenvolvidos. Nesse contexto, o estudo do processo de catch-up das empresas localizadas nesses países emergentes se torna importante (Paula, 2017).

Nesse contexto, Kim (1997) criou um modelo de processo de inovação apropriado para a realidade dos países em desenvolvimento, onde não há recursos suficientes para o investimento em pesquisa e desenvolvimento e pouca capacidade de desenvolvimento de inovações radicais. Assim, o processo de desenvolvimento de tecnologias, ocorre por meio da aquisição de tecnologias maduras advindas de países desenvolvidos e no desenvolvimento de habilidades e aprendizados da forma de produção para desenvolvimento de tecnologias semelhantes. O foco, portanto, recai na realização de melhorias dos produtos adquiridos, por meio de inovações incrementais, até que um novo produto, adaptado à realidade do país emergente, seja produzido. Esse processo, possibilita o aumento na capacidade de inovação das empresas e a diminuição do hiato tecnológico existente entre os países desenvolvidos e em desenvolvimento.

Ainda, no caso do Brasil, país de industrialização tardia, o desafio crítico e que tem sido almejado, é promover o emparelhamento do país com os sistemas mais avançados do mundo. Para isso, é necessário um enfoque em estratégias de crescimento que têm como eixo central a inovação e que promovam a incorporação do conhecimento em todas as atividades econômicas, o que exige um robusto Sistema Nacional de Inovação. Assim, diversos investimentos têm sido realizados com o objetivo de promover e acelerar avanços científicos e tecnológicos que subsidiem os processos inovativos (MCTIC, 2016).

Ainda, segundo o MCTIC, (2016) uma das grandes fragilidades do Sistema Nacional Brasileiro é o aporte de recursos destinados à importação de tecnologias 
e de serviços especializados, com pouca ênfase na pesquisa e desenvolvimento para produção de tecnologias nacionais de alto valor agregado.

De acordo com Mazzucato \& Penna (2016) análises das políticas de inovação brasileiras revelam que as mesmas falharam na tentativa de melhorar o sistema de inovação nacional, uma vez que tais políticas públicas estavam mais voltadas para a correção de falhas de mercado em detrimento a políticas que primavam para a construção de novos mercados, em um conceito de estado empreendedor que assume riscos e cria uma infraestrutura adequada para as empresas inovarem.

Nessa perspectiva de sistemas, além da importância do Estado, as Instituições de Ciência e Tecnologia assumem um papel essencial, uma vez que atuam como operadoras desse sistema e são consideradas como fontes de inovação e realização de pesquisas relevantes para o país (MCTIC, 2016).

No entanto, embora tais atores, bem como suas interações dentro do sistema sejam importantes, há que se considerar o ambiente interno das organizações, uma vez que grande parte das inovações ocorrem dentro das empresas (Paula, 2017).

\section{2}

\section{Teoria Baseada em Recursos - RBV}

Os estudos estratégicos se desenvolveram na tentativa de explicar e conduzir as organizações a alcançarem vantagens competitivas. Várias teorias estratégicas foram utilizadas tendo esse objetivo (Serra et al., 2008).

A Teoria baseada em Recursos - RBV, uma das teorias estratégicas, surgiu na tentativa de entender as fontes que levam as empresas a alcançarem essas vantagens competitivas, baseada nas premissas de que os recursos estratégicos são distribuídos de forma heterogênea entre as firmas e que essas diferenças são estáveis ao longo do tempo (Barney, 1991).

O trabalho de Penrose (1959) é reconhecido como a base teórica da RBV. Por meio deste trabalho, a autora argumenta que as empresas alcançam sucesso e crescimento sustentável através da posse de recursos e capacidades únicas e heterogêneas.

Barney (1991) acrescenta que tais recursos e capacidades só levam a melhoria da competitividade, se forem considerados valiosos, raros, difíceis de 
imitar e organizacionais. Tais recursos, segundo o autor, se relacionam aos ativos tangíveis e intangíveis de uma organização.

As capacidades, por sua vez, são definidas como um subconjunto dos recursos, podendo ser também tangíveis e intangíveis e se referem às competências e habilidades das empresas de executarem tarefas para o alcance de resultados específicos (Barney \& Hesterly, 2015).

Ainda, segundo Barney (1991) os recursos e capacidades de uma empresa podem ser classificados em 4 categorias amplas: Recursos financeiros, recursos físicos, recursos individuais/humanos e recursos organizacionais. $\mathrm{O}$ autor fundamenta-se na RBV para a criação de um modelo de desempenho, denominado modelo VRIO, para avaliar se os recursos e capacidades podem ser considerados como fontes de vantagem competitiva. A análise é realizada por meio das quatro classificações: valor, raridade, imitabilidade e organizacional - VRIO.

Quanto aos seus valores, os recursos e capacidades são definidos pela força ou fraqueza que possuem frente a uma oportunidade ou ameça externa. Quanto à sua raridade, os recursos e capacidades só serão fontes de vantagem competitiva se não forem dominados pelos concorrentes. A imitabilidade pressupõe que as capacidades e recursos raros e valiosos, são difíceis de serem copiados pelos concorrentes, uma vez que tal imitabilidade é custosa para a empresa. Por fim, o potencial de uma empresa para alcançar melhores desempenhos, depende também da forma como a empresa se estrutura e se organiza internamente para explorar e aproveitar todo o potencial que os recursos e capacidades raras, valiosas e difíceis de imitar proporcionam, caso contrário, a simples posse deles não ensejará em vantagens competitivas sustentáveis para as empresas (Barney, 1991).

A Teoria Baseada em Recursos - RBV, postula que as organizações são coleções de recursos que permitem a obtenção de vantagem competitiva e desempenho superior a longo prazo, se as configurações desses recursos forem: valiosas, raras, difíceis de imitar e não substituíveis (Barney, 1991). No entanto, as empresas alcançam vantagens competitivas quando conseguem dinamizar esses recursos e capacidades organizacionais, em prol da obtenção de desempenhos superiores (Hosseini et al., 2017). A teoria das capacidades dinâmicas, introduzida por Teece et al. (1997) busca mostrar a relevância do aspecto dinâmico dos recursos e capacidades organizacionais, como subsídios para as empresas melhorarem seus desempenhos. 
O conceito de capacidades dinâmicas se fundamenta na capacidade da empresa de integrar, criar e reconfigurar competências e recursos internos e externos para lidar com ambientes de alta incerteza e rápidas mudanças (Teece, 2007). Essa abordagem surge dentro de um contexto globalizado e competitivo cujos pressupostos da Teoria Baseada em Recursos - RBV já não se encaixavam pela falta de características de dinamicidade dos recursos e capacidades que o contexto passou a requerer (Vogel \& Güttel, 2013). A abordagem das capacidades dinâmicas, portanto, amplia a RBV e dá ênfase à importância das capacidades de aprendizagem organizacional e de como elas dinamizam e alavancam os ativos de conhecimento, tanto por meio do capital humano quanto por meio das capacidades organizacionais em relação à melhoria do desempenho da empresa. Isso revela que o processo de criação, recombinação e integração do conhecimento, pressupostos das capacidades dinâmicas, são cruciais para a capacidade geral de inovação das empresas (Vogel \& Güttel, 2013).

\subsection{1 \\ O papel dos Recursos e capacidades internas no desempenho de inovação}

Em ambientes de incerteza e alta complexidade, a inovação se torna imprescindível para as empresas, no entanto, não é trivial inovar com sucesso. Para se obter capacidade de inovação, as empresas precisam acumular conhecimento, para então, alcançarem a fronteira tecnológica. Para que isso seja possível, as empresas podem se beneficiar de diferentes fontes, como fontes de conhecimento internas e fontes de conhecimento externas. Muitos estudos foram realizados mostrando a relação entre as duas fontes de conhecimento e o desempenho de inovação das empresas (Paula \& Silva, 2017; Lichtenthaler \& Lichtenthaler, 2009)

Com relação às fontes de conhecimento internas, a conciliação das Teorias - RBV e Capacidades Dinâmicas, vinculadas à gestão estratégica empresarial, mostram estreita relação com a eficiência e a capacidade de inovação das empresas. Pela visão schumpeteriana, as capacidades dinâmicas enfocam a capacidade de ambidestria das organizações, no sentido de conciliar a exploração por novos recursos e o aproveitamento dos recursos existentes, fornecendo às empresas capacidade de responder de forma tempestiva à dinamicidade e as incertezas do ambiente (Kattel \& Mazzucato, 2018). 
As capacidades e competências organizacionais são considerados recursos críticos para adoção e implementação de práticas de inovação aberta. Elas são fundamentais, por exemplo, como fontes para a construção da capacidade absortiva das empresas - capacidade dinâmica essencial na prática da inovação aberta (Petraite et al., 2020). Definida como a capacidade de uma firma de reconhecer o valor de novas informações externas, assimilá-las e aplicá-las a fins comerciais (Cohen \& Levinthal, 1990), a capacidade absortiva das empresas, envolve váriaveis importantes, como a base e o potencial de conhecimento já existente nas empresas, principalmente conhecimento tácito, que impacta os processos de aprendizagem, além da intensidade do esforço ou compromisso para integrar o conhecimento, sendo ambos imprescindíveis para a capacidade da empresa de integrar o conhecimento externo e ampliar sua base de conhecimento, suas competências e capacidades organizacionais existentes (Petraite et al., 2020).

As capacidades consideradas críticas que facilitam a implementação da inovação aberta, foram abordadas pela primeira vez, por Lichtenthaler \& Lichtenthaler (2009). Os autores, por meio da capacidade de gerenciamento do conhecimento, criaram uma estrutura abrangente baseada em processo que complementa o conceito de capacidade absortiva. Essa estrutura refere-se à capacidade de uma empresa de gerenciar com êxito sua base de conhecimento ao longo do tempo e é composta por 6 capacidades denominadas como: capacidade inventiva, absortiva, transformadora, conectiva, inovadora e a desorptive capacity ${ }^{1}$. Essa última capacidade se refere, segundo os autores, à identificação de oportunidades de aproveitamento no meio externo, do conhecimento gerado pela empresa e sua habilidade em transferir esse conhecimento para o uso fora da empresa, ampliando assim, suas possibilidades.

Por meio do enfoque na capacidade inventiva, por exemplo, empresas como a Lucent e Xerox desenvolveram várias tecnologias radicais ao longo de décadas, no entanto, o foco maior na capacidade inventiva, que se limita à capacidade de explorar o conhecimento interno, restringiu a capacidade inovadora da Lucent em ambientes mais turbulentos, o que levou à sua fusão com a empresa Alcatel, em 2006 (Lichtenthaler \& Lichtenthaler, 2009).

\footnotetext{
${ }^{1}$ Termo sem tradução literal para a Língua Portuguesa. Seu uso será mantido em inglês em todo este estudo.
} 
A Procter \& Gamble promoveu a interface de sua capacidade inventiva e absortiva, com a aquisição de $50 \%$ de inovações de fontes externas, ampliando sua capacidade interna de inovação (Dodgson et al., 2006; Puffal et al., 2019). Já a Texas Instruments promoveu a integração do licenciamento de tecnologia com a sua capacidade transformadora, ou seja, sua capacidade de transformar o conhecimento adquirido em inovação, melhorando sua capacidade inovativa e fortalecendo a integração entre essas capacidades. Tais exemplos evidenciam a importância das capacidades de conhecimento e do gerenciamento deste conhecimento dentro das organizações e a necessidade do alinhamento às estratégias das empresas, que por sua vez, devem estar alinhadas às mudanças constantes no ambiente. Assim, o gerenciamento do conhecimento deve ser dinâmico e evolutivo (Lichtenthaler \& Lichtenthaler, 2009).

Hosseini et al. (2017) propuseram uma estrutura holística, assim denominada por abranger capacidades levantadas por diversas correntes de pesquisas anteriores sobre implementação da inovação aberta, as quais focaram em aspectos pontuais referentes a esta implementação. A proposta dos autores, portanto, visa englobar em uma única estrutura, todos os fatores que influenciam na implementação e descrever as capacidades de forma holística. Assim, a estrutura é composta por 23 capacidades organizacionais para inovação aberta, divididas em 6 fatores importantes: Alinhamento estratégico, governança, métodos, tecnologia da informação, pessoas e cultura, conforme mostra o Quadro 2.

Quadro 2: Fatores e Capacidades internas

\begin{tabular}{|c|c|c|}
\hline \multicolumn{3}{|c|}{$\begin{array}{ll}\text { Estrutura Holística } \\
\end{array}$} \\
\hline \multirow{3}{*}{$\begin{array}{l}\text { Alinhamento } \\
\text { Estratégico. }\end{array}$} & $\begin{array}{l}\text { Alinhamento da } \\
\text { estratégia } \\
\text { de negócios } \\
\text { e inovação aberta }\end{array}$ & $\begin{array}{l}\text { Abertura em termos de amplitude de pesquisa }\left(\mathrm{n}^{\circ} \text { de }\right. \\
\text { fontes e canais externos envolvidos na inovação } \\
\text { aberta) e Profundidade da Pesquisa (intensidade de } \\
\text { colaborações individuais) é uma escolha estratégica. } \\
\text { O grau adequado de abertura junto com estruturas } \\
\text { internas que apoiem essa decisão contribui para } \\
\text { melhora no desempenho de inovação por meio da } \\
\text { inovação aberta (Cui et al., 2015). }\end{array}$ \\
\hline & $\begin{array}{l}\text { Alinhamento da } \\
\text { Estratégia de } \\
\text { Tecnologia da } \\
\text { Informação - TI } \\
\text { e estratégia de } \\
\text { inovação aberta. }\end{array}$ & $\begin{array}{l}\text { As estratégias de inovação aberta devem ser apoiadas } \\
\text { por TI apropriada e as empresas devem modelar seus } \\
\text { recursos de TI estrategicamente para apoiar a } \\
\text { inovação aberta. Um melhor desempenho de } \\
\text { inovação organizacional é alcançado quando a } \\
\text { estratégia de TI de uma empresa se alinha com sua } \\
\text { estratégia de inovação aberta. (Cui et al., 2015) }\end{array}$ \\
\hline & $\begin{array}{l}\text { Capacidade } \\
\text { resposta }\end{array}$ & $\begin{array}{l}\text { Capacidade de ajustar métodos de exploration, } \\
\text { exploitation e retenção de conhecimentos, à luz da }\end{array}$ \\
\hline
\end{tabular}




\begin{tabular}{|c|c|c|}
\hline & $\begin{array}{l}\text { às mudanças } \\
\text { ambientais. }\end{array}$ & $\begin{array}{l}\text { estratégia de inovação aberta adotada pela empresa, de } \\
\text { acordo com as exigências do ambiente externo para } \\
\text { gerar vantagem competitiva. Capacidade de } \\
\text { reconfigurar os recursos internos (Lichtenthaler \& } \\
\text { Lichtenthaler, 2009). }\end{array}$ \\
\hline \multirow{4}{*}{ Governança } & $\begin{array}{l}\text { Tomada de } \\
\text { Decisão de } \\
\text { inovação aberta }\end{array}$ & $\begin{array}{l}\text { Habilidade de decisão de um modelo de governança. } \\
\text { Definição de equipes envolvidas e de modelo de } \\
\text { inovação aberta apropriado. Ex; Parcerias; } \\
\text { participação em comunidades (Habicht et al., 2012) }\end{array}$ \\
\hline & $\begin{array}{l}\text { Funções } \\
\text { e } \\
\text { responsabilidades } \\
\text { de inovação } \\
\text { aberta }\end{array}$ & $\begin{array}{l}\text { Ajudam a garantir a adoção e execução bem sucedida } \\
\text { das atividades de inovação aberta. Ajudam a manter } \\
\text { os limites, a abrangência da inovaçãoaberta. Papéis } \\
\text { complementares de exploradores de novas ideias e } \\
\text { integradores dessas ideias são essenciais para o } \\
\text { sucesso, principalmente em ambientes com grande } \\
\text { volume de ideias externas para serem gerenciadas. } \\
\text { (Habicht et al., 2012) }\end{array}$ \\
\hline & $\begin{array}{l}\text { Gerenciamento } \\
\text { de } \\
\text { Relacionamento } \\
\text { com parceiros }\end{array}$ & $\begin{array}{l}\text { Capacidade de integrar o conhecimento externo, } \\
\text { selecionando parceiros que possuem conhecimentos } \\
\text { relevantes. Importância da governança da parceria e } \\
\text { do cuidado com os parceiros para manter o canal de } \\
\text { comunicação, confiança e de compartilhamento } \\
\text { abertos. (Habicht et al., 2012) }\end{array}$ \\
\hline & $\begin{array}{ll}\text { Gestão } & \text { da } \\
\text { Propriedade } & \\
\text { Intelectual. } & \end{array}$ & $\begin{array}{l}\text { Estrategicamente importante. Um maior grau de } \\
\text { abertura, aumenta o desafio de proteger a propriedade } \\
\text { intelectual. Necessidade de equilibrar e definir } \\
\text { seletivamente a quantidade ideal de informações a } \\
\text { serem divulgadas e compartilhadas. (Habicht et al., } \\
\text { 2012;Barchi \& Greco, 2018; Grimaldi et al., 2021) }\end{array}$ \\
\hline \multirow{3}{*}{ Métodos } & $\begin{array}{l}\text { Exploração do } \\
\text { conhecimento }\end{array}$ & $\begin{array}{l}\text { Dividido em interna e externa. Interna: Requer } \\
\text { métodos que ajudem a desenvolver a capacidade } \\
\text { inventiva ou capacidade de pesquisa básica. } \\
\text { Capacidade de criar e integrar conhecimento. Externo: } \\
\text { Requer métodos para desenvolver a capacidade } \\
\text { absortiva - adquirir e assimilar conhecimentos. A } \\
\text { junção das duas capacidades - capacidade integrativa } \\
\text { - é essencial para alavancar o desempenho de } \\
\text { inovação. (Lichtenthaler \& Lichtenthaler, 2009; } \\
\text { Podmetina et al., 2018) }\end{array}$ \\
\hline & $\begin{array}{l}\text { Retenção de } \\
\text { Conhecimento }\end{array}$ & $\begin{array}{l}\text { As organizações devem ter a capacidade de manter o } \\
\text { conhecimento dentro e fora de seus limites. Retenção } \\
\text { interna (capacidade transformativa) requer métodos } \\
\text { para incorporar o conhecimento, explorado na base de } \\
\text { conhecimento e manter esse conhecimento vivo. } \\
\text { Retenção externa (capacidade conectiva) requer } \\
\text { manutenção do conhecimento nas relações } \\
\text { interorganizacionais, o que auxilia na entrada das } \\
\text { organizações em relações de troca com parceiros, } \\
\text { ampliando seus conhecimentos e a capacidade de } \\
\text { inovação. (Lichtenthaler \& Lichtenthaler, 2009; } \\
\text { Podmetina et al., 2018; Huang \& Rice, 2009) }\end{array}$ \\
\hline & $\begin{array}{l}\text { Aproveitamento } \\
\text { do } \\
\text { conhecimento }\end{array}$ & $\begin{array}{l}\text { Aproveitamento interno (Capacidade inovadora): } \\
\text { Alavancagem do conhecimento retido. Capacidade de } \\
\text { transformar o conhecimento retido em novos produtos }\end{array}$ \\
\hline
\end{tabular}




\begin{tabular}{|c|c|c|}
\hline & & $\begin{array}{l}\text { e serviços. Aproveitamento Externo: Refere-se à } \\
\text { transferência externa de conhecimento (Desorptive } \\
\text { Capacity), como licenciamento externo. } \\
\text { (Lichtenthaler \& Lichtenthaler, 2009; Podmetina et } \\
\text { al., 2018). Huang \& Rice, 2009) }\end{array}$ \\
\hline & Integração Social & $\begin{array}{l}\text { Métodos que facilitem a interação, coordenação e } \\
\text { comunicação entre os parceiros. Métodos formais, por } \\
\text { meio de coordenadores e informais por meio de redes } \\
\text { sociais, por exemplo. Promovem a conexão entre os } \\
\text { parceiros, entendimento compartilhado e contribuem } \\
\text { para resultados melhores de inovação. (Huang \& Rice, } \\
2009 \text { ) }\end{array}$ \\
\hline \multirow{4}{*}{$\begin{array}{l}\text { Tecnologia } \\
\text { da } \\
\text { Informação } \\
\text { como } \\
\text { suporte à } \\
\text { inovação } \\
\text { aberta }\end{array}$} & $\begin{array}{l}\text { Exploração do } \\
\text { conhecimento }\end{array}$ & $\begin{array}{l}\text { Necessidade de TI para apoiar as atividades de } \\
\text { procura e exploração do conhecimento, p.ex. através } \\
\text { de palataformas de pesquisa, softwares de mineração } \\
\text { de dados (Cui et al., 2015) }\end{array}$ \\
\hline & $\begin{array}{l}\text { Retenção do } \\
\text { conhecimento }\end{array}$ & $\begin{array}{l}\text { Sistemas que funcionem como repositórios de } \\
\text { conhecimento. Memória de conhecimento, banco de } \\
\text { dados (Cui et al., 2015) }\end{array}$ \\
\hline & $\begin{array}{l}\text { Aproveitamento } \\
\text { do } \\
\text { Conhecimento }\end{array}$ & $\begin{array}{l}\text { Tecnologias que auxiliem no design diferente de } \\
\text { produtos, melhorando as características de produtos } \\
\text { existentes, como, p. ex. melhoria de produtos e } \\
\text { serviços captados/copiados do mercado (Cui et al., } \\
\text { 2015) }\end{array}$ \\
\hline & Integração Social & $\begin{array}{l}\text { TI facilitando a inovação aberta. Ferramentas de } \\
\text { conferência online, facilitam a integração com } \\
\text { parceiros, o compartilhamento de ideias, tanto de } \\
\text { forma externa quanto interna (Dodgson et al., 2006). }\end{array}$ \\
\hline \multirow{4}{*}{ Pessoas } & $\begin{array}{l}\text { Domínio da } \\
\text { Tecnologia }\end{array}$ & $\begin{array}{l}\text { Necessidade dos indivíduos dominarem as } \\
\text { ferramentas de tecnologias da informação, como } \\
\text { mecanismos de pesquisa, ferramentas de mineração } \\
\text { de dados, plataformas de colaboração, kits de } \\
\text { multimídia (Habicht et al., 2012). (Dodgson et al., } \\
\text { 2006) }\end{array}$ \\
\hline & $\begin{array}{l}\text { Liderança } \\
\text { Pessoal } \\
\text { por Pares }\end{array}$ & $\begin{array}{l}\text { A inovação aberta pode ocorrer sem uma estrutura } \\
\text { formal. Indivíduos com capacidades de liderança } \\
\text { pessoal podem motivar parceiros de inovação de uma } \\
\text { maneira coerente em direção à um objetivo comum e } \\
\text { garantir a consecução do objetivo, através de esforços } \\
\text { coordenados. A liderança entre pares ajuda a garantir } \\
\text { o progresso da inovação aberta, mesmo com a } \\
\text { ausência de hierarquias formais (Lifshitz-Assaf, 2018; } \\
\text { Habicht et al., (2012) }\end{array}$ \\
\hline & $\begin{array}{l}\text { Corretagem } \\
\text { Social }\end{array}$ & $\begin{array}{l}\text { Indivíduos com capacidade de corretagem social, são } \\
\text { capazes de conectar os atores certos que, em geral, não } \\
\text { estariam em contato, e assim, garantir que ideias e } \\
\text { conhecimentos externos sejam utilizados. Conectando } \\
\text { atores desconectados, ajudam a superar, muitas vezes, } \\
\text { as distâncias das redes com determinados parceiros } \\
\text { (Habicht et al., 2012) }\end{array}$ \\
\hline & $\begin{array}{l}\text { Alargamento } \\
\text { das } \\
\text { fronteiras/limites. }\end{array}$ & $\begin{array}{l}\text { Diversidade de parceiros são fontes de variedades de } \\
\text { informações, desde que a diversidade não resulte em } \\
\text { dilemas comunicativos que dificultem à inovação. } \\
\text { Indivíduos com capacidades de alargamento de }\end{array}$ \\
\hline
\end{tabular}




\begin{tabular}{|c|c|c|}
\hline & & $\begin{array}{l}\text { limites, são capazes de lidar com heterogeneidades de } \\
\text { conhecimento, traduzindo e retransmitindo } \\
\text { informações e facilitando o diálogo. Permite superar } \\
\text { as distâncias cognitivas (Lifshitz-Assaf, 2018; } \\
\text { Habicht et al., 2012) }\end{array}$ \\
\hline \multirow[t]{4}{*}{ Cultura } & $\begin{array}{l}\text { Comportamento } \\
\text { voltados para } \\
\text { inovação aberta }\end{array}$ & $\begin{array}{l}\text { Superação da crise "do não inventado aqui" - NIH, } \\
\text { caracterizada pela não aceitação da inovação aberta, } \\
\text { de tecnologias, conhecimentos e ideias externas } \\
\text { adquiridas, o que leva a negação à retenção dos } \\
\text { conhecimentos externos obtidos, impedindo ou } \\
\text { dificultando as relações de trocas com os parceiros. } \\
\text { (Mortara \& Minshall, 2011; Lifshitz-Assaf, 2018; Cui } \\
\text { et al., 2015; Nestle et al., 2019) }\end{array}$ \\
\hline & $\begin{array}{l}\text { Atitude aberta ao } \\
\text { risco } \\
\text { de inovação }\end{array}$ & $\begin{array}{l}\text { Toda inovação corre o risco de fracassar. Na inovação } \\
\text { aberta esse risco é ainda maior, devido ao maior grau } \\
\text { de incerteza. Esse tipo de inovação, exige uma cultura } \\
\text { de inovação de tolerância aos riscos (Wu et al., 2019). }\end{array}$ \\
\hline & $\begin{array}{l}\text { Atenção da } \\
\text { liderança }\end{array}$ & $\begin{array}{l}\text { O nível de atenção da liderança influencia a eficácia } \\
\text { da inovação aberta. A alta direção deve criar um } \\
\text { ambiente propício, com estabelecimento de metas e } \\
\text { incentivos às práticas de inovação aberta. Histórias de } \\
\text { sucesso podem ser usadas para incentivar os } \\
\text { empregados. (Mortara \& Minshall, 2011; Wu et al., } \\
\text { 2019; Ades et al., 2013) }\end{array}$ \\
\hline & $\begin{array}{l}\text { Gestão } \\
\text { Propriedade } \\
\text { Intelectual }\end{array}$ & $\begin{array}{l}\text { Os departamentos jurídicos devem adotar uma atitude } \\
\text { construtiva de apoio à inovação aberta, em detrimento } \\
\text { de posicionamentos excessivos de proteção. Decisões } \\
\text { em que todas as partes saem ganhando devem ser } \\
\text { alcançadas e adotadas, de modo a possibilitar a OI. } \\
\text { Uma atitude muito protetora inibe que os profissionais } \\
\text { se envolvam, dado a riscos pessoais e profissionais } \\
\text { (Barchi \& Greco, 2018). }\end{array}$ \\
\hline
\end{tabular}

Fonte: Baseada em (Hosseini et al., 2017)

As 23 variáveis descritas por Hosseini et al. (2017) conforme Quadro 2, foram corroboradas por vários autores, que se empenharam em estudar os recuros internos, as capacidades e competências necessárias às empresas para prática de sucesso da inovação aberta. As referências estão descritas também na tabela 2, na última coluna.

As dimensões descritas por Hosseini et al. (2017) mostram a complexidade da implementação da inovação aberta nas empresas, que envolve a necessidade de diversas capacidades e reforça a importância da criação de uma estrutura holística, que integre a organização como um todo, em todos os seus aspectos, para a obtenção de sucesso nas práticas de inovação aberta. 
Em referência à importância das competências de inovação aberta, Mortara \& Minshall (2011) propuseram quatro categorias de habilidades que são consideradas relevantes:

$1^{\mathrm{o}}$ - Habilidades introspectivas: Ligadas à capacidade interna da organização em avaliar oportunidades;

$2^{\text {o }}$ - Habilidades extrospectivas: Ligadas à avaliação de oportunidades externas à organização;

$3^{0}$ - Habilidades interativas: Habilidade da organização em transmitir o conhecimento, tanto interamente quanto externamente.

$4^{\circ}$ - Habilidades técnicas - Abrange todas as habilidades técnicas, de gerenciamento e de negócios importantes para apoiar as outras três habilidades.

Podmetina et al. (2018) analisaram por meio de estudo empírico com empresas de diversos setores de vários países da Europa, a interdependência entre as capacidades organizacionais, as atividades de inovação aberta e o desempenho das empresas e concluíram um efeito positivo dessas dimensões no desempenho de inovação das empresas. Análises das competências individuais necessárias para a inovação aberta também foram realizadas. Quanto às competências individuais para a inovação aberta, algumas das variáveis propostas para o estudo foram: habilidades de gerenciamento de Propriedade Intelectual, habilidades de negociação, habilidades de liderança, habilidades de rede, habilidades de colaboração externa, mentalidade tecnológica e comercial, gerenciamento de projetos, flexibilidade e adaptabilidade, capacidade de trabalhar em equipes multifuncionais, criatividade, alfabetização em novas mídias, pensamento inovador, capacidade de compartilhar conhecimentos. As escalas descritas são consideradas genéricas pelos autores, podendo ser aplicadas em diversas empresas de tamanhos e setores diferentes.

Alguns estudos evidenciaram a importância dos indivíduos para o desempenho inovador das empresas, principalmente em empresas de pequeno e médio porte, onde a escassez de recursos evidenciam a necessidade do gerenciamento adequado do conhecimento em nível individual (Petraite et al., 2020).

A adoção do modelo de inovação aberta e a preocupação pelo desenvolvimento de habilidades, competências e capacidades organizacionais que favorecem a sua implementação, não significa que as atividades internas, como aquelas ligadas à Pesquisa e Desenvolvimento, também essenciais para a melhoria 
da capacidade inovativa das empresas, irão cessar, mas elas assumirão novos papéis e exigirão novos recursos que além de permitir seu desenvolvimento, deverão adicionar atividades de integração entre o conhecimento interno e externo (Ades et al., 2013).

Assim, investir nos recursos internos ligados à Pesquisa e Desenvolvimento também é primordial. Quanto aos recursos tangíveis, que são aqueles considerados como recursos físicos e visíveis, tais como: máquinas, equipamentos, recursos humanos e matérias-primas de propriedade da empresa, esses representam o esforço que as empresas fazem para manterem vivas suas capacidades de Pesquisa e Desenvolvimento, por meio da construção de uma infraestrutura física que suporte essas atividades (Castro, 2011).

Já os recursos intangíveis, são aqueles que não possuem forma física, mas que fornecem direitos às empresas, como: direitos de patentes, direitos de marca, de propriedade intelectual, direitos autorais, comerciais, de reputação, (Li et al., 2020) e informações que são considerados vitais para a sobrevivência, crescimento e competitividade das empresas (Ying et al., 2019).

Quanto aos recursos tangíveis, merece destaque, o papel dos recursos humanos, principalmente aqueles relacionados à Pesquisa e Desenvolvimento P\&D. Análises quanto sua qualificação, motivação e comunicação são importantes para a inovação nas empresas e perpassam por questões relacionadas à remuneração e à flexibilidade fornecidas pelas empresas aos seus empregados. A Google e 3M são empresas que exemplificam bem o incentivo e a flexibilidade, por meio da prática discricionária de tempo, que permite que seus empregados dediquem uma parcela de seu tempo com projetos de sua escolha, mesmo que estes não façam parte das metas da empresa. Essas atitudes fomentam e criam um ambiente favorável à inovação. (Cui et al., 2019).

Quanto à remuneração os mesmos autores também chamam a atenção para a importância dessa prática como incentivo aos empregados para envolvimento em atividades inovativas, principalmente àquelas relacionadas a atividades de exploração que envolvem uma alta parcela de incerteza e risco. Esse tipo de recompensa é considerada a mais eficaz para incentivar o envolvimento dos empregados em atividades dessa natureza.

Sendo desenvolvida de forma interna ou externa a P\&D necessita de pessoal qualificado, tanto para serem interlocutores com o mundo científico quanto 
para darem viabilidade comercial a novos produtos, processos ou serviços (Castro, 2011). Corroborando com essa afirmação Shipton et al. (2006) argumentam que a prática do gerenciamento de recursos humanos tem o potencial de promover a inovação organizacional nas empresas.

Por meio de um estudo longitudinal, com empresas do Reino Unido, os autores examinaram a relação entre tal prática e a inovação tecnológica. Os resultados revelaram que o treinamento, a indução e o trabalho em equipe têm relação estreita com a capacidade de exploração e inovação das empresas e a gestão dos recursos humanos é fundamental nesse contexto, uma vez que nem sempre as inovações surgem da equipe envolvida diretamente em $\mathrm{P} \& \mathrm{D}$, mas recebe importantes insights e participação de outros empregados da empresa, evidenciando a necessidade do envolvimento de todos nesse processo inovativo.

No entanto, para Castro (2011) a alocação de recursos humanos em atividades de $\mathrm{P} \& \mathrm{D}$ é um importante impulsionador para a inovação e a criação de uma estrutura para P\&D é crucial e deve ser vista como um recurso específico que centraliza as capacidades da empresa em torno da Pesquisa e Desenvolvimento, além de disponibilizar, por meio desta estrutura, ativos físicos e recursos organizacionais voltados para esta atividade. Portanto, tendo como base a visão baseada em recursos - RBV, a criação e estruturação de um departamento de $\mathrm{P} \& \mathrm{D}$ é uma estratégia que possibilita a concentração de ativos tangíveis e intangíveis, considerados cruciais pela empresa e para a obtenção de vantagens competitivas, por meio da melhoria de sua capacidade de inovação. Nesse contexto, a criação de uma estrutura de $\mathrm{P} \& \mathrm{D}$ não só torna esse processo formal e estruturado, como amplia suas possibilidades de gerar ganhos competitivos para as empresas.

De forma geral, a implementação da inovação aberta pelas empresas envolve diversos desafios, não só relacionados à estrutura interna necessária para abarcar de fato essa inovação, mas também desafios em nível individual. Os profissionais de P\&D têm dificuldades de abrir seus limites e fronteiras do conhecimento para os conhecimentos externos, com receio de perderem suas legitimidades e seus prestígios. A inovação aberta desafia esses limites e exige uma reorientação de identidade desses profissionais, que os levem a desmantelar esses limites e adotar a combinação de conhecimentos e saberes com o meio externo (Lifshitz-Assaf, 2018). 
Por meio de um estudo longitudinal em profundidade realizado na Nasa, no período de 2009 a 2012, o autor analisou como a abertura da empresa afeta a identidade dos profissionais de $\mathrm{P} \& \mathrm{D}$ e identificou que somente os profissionais que reorientaram sua identidade é que conseguiram de fato abrir seu modo de trabalho para a inovação aberta. Os demais profissionais que não foram capazes de mudar e readequar suas identidades, fingiram adotar ou rejeitaram fortemente à abertura de seus trabalhos para a inovação fora dos limites da Nasa.

As empresas, portanto, buscam, em última instância, melhorar seus desempenhos por meio da obtenção de vantagens competitivas. Nesse contexto e pela ótica da Teoria Baseada em Recursos - RBV, a inovação organizacional - OI torna-se uma relevante fonte de vantagem competitiva, através do favorecimento do desenvolvimento das capacidades de inovação tecnológica (inovações de produto e processo) e no impacto de ambas - inovação organizacional e capacidade tecnológica, na melhoria do desempenho das empresas (Camisón \& Villar-López, 2014).

Segundo a OECD, (2005) as inovações organizacionais são consideradas como a introdução de novos métodos organizacionais, novas práticas de negócio, novos métodos na organização do local de trabalho e/ou na relação da empresa com os agentes externos. Essa inovação favorece um ambiente organizacional mais eficiente e propício para a utililização de processos mais inovadores. Em outras palavras é como se as inovações organizacionais dessem subsídio e criassem um ambiente favorável para o desenvolvimento de inovações de processo e inovações de produto. Há portanto, uma conexão direta entre a inovação organizacional e a capacidade de inovação de processo das empresas e uma conexão indireta com a capacidade de inovação de produto, intermediada pela inovação de processo.(Camisón \& Villar-López, 2014).

Outra capacidade que pode ser considerada uma capacidade dinâmica valiosa, rara e inimitável para as organizações, importantes em um contexto de inovação aberta, são as capacidades denominadas como capacidades de colaboração interfirmas. Isso porque muitos dos recursos considerados como importantes fontes de vantagem competitiva são incorporados em recursos e rotinas que advém dos relacionamentos interorganizacionais, no entanto, é difícil coordenar as atividades que ocorrem além das fronteiras organizacionais - questões como divergências de objetivos entre as empresas geram muitas vezes conflitos, 
dificultando as relações. Essa realidade sugere que a colaboração pode ser considerada como uma capacidade dinâmica mediadora na redução do conflito, promovendo o alinhamento de metas, compartilhamento mais aberto e transparente das informações, desenvolvendo assim uma vantagem relacional distinta por meio do favorecimento à obtenção de recursos vitais complementares que geram vantagens competitivas (Allred et al. 2011).

Nesse contexto, o gerenciamento precisa ser dinâmico para acompanhar as mudanças e demandas do ambiente e mudanças advindas dos relacionamentos externos estabelecidos, no intuito de manter os relacionamentos, estimular o engajamento entre os parceiros e favorecer a criação de valor. Em outras palavras, é imprescindível a criação de uma estrutura interna às organizações para gerenciamento de suas parcerias, denominada como função da aliança. (Y. Yamakawa et al 2011). Ainda, segundo os mesmos autores, é necessária a adequação dinâmica dos relacionamentos com os objetivos da empresa e seus recursos organizacionais. As implicações de desempenho das alianças e de seu portfólio precisam ser consideradas em termos de sua adequação aos fatores organizacionais, estratégicos e ambientais. As alianças estratégicas e o conjunto de relacionamentos interfirmas, denominados como portfólios de aliança, serão explicitados nas sessões seguintes.

\section{3 \\ Alianças Estratégicas}

As alianças estratégicas são definidas como: "acordos voluntários entre empresas que envolvem troca, compartilhamento ou co-desenvolvimento de produtos, tecnologias ou serviços. Elas podem ocorrer como o resultado de uma ampla gama de motivos e objetivos e uma variedade de formas ocorrem através de limites horizontais e verticais"(Gulati, 1998). Para Teece, (1998) alianças estratégicas são “constelações de acordos bilaterais, possivelmente contratos multilateriais entre empresas e entendimentos entre firmas, tipicamente para desenvolver e comercializar novas tecnologias”. Para Barney \& Hesterly (2015) "aliança estratégica existe sempre que duas ou mais organizações independentes cooperarem no desenvolvimento, fabricação ou venda de produtos ou serviços".

O tipo específico de aliança estratégica está condicionado à magnitude dos_controles hierárquicos e ao relacionamento estabelecido interfirmas (Gulati \& 
Singh, 1998). A Figura 7, traz uma visão geral das possibilidades de relacionamentos interfimas que podem ser categorizados como alianças estratégicas de acordo com Kale \& Singh, (2009).

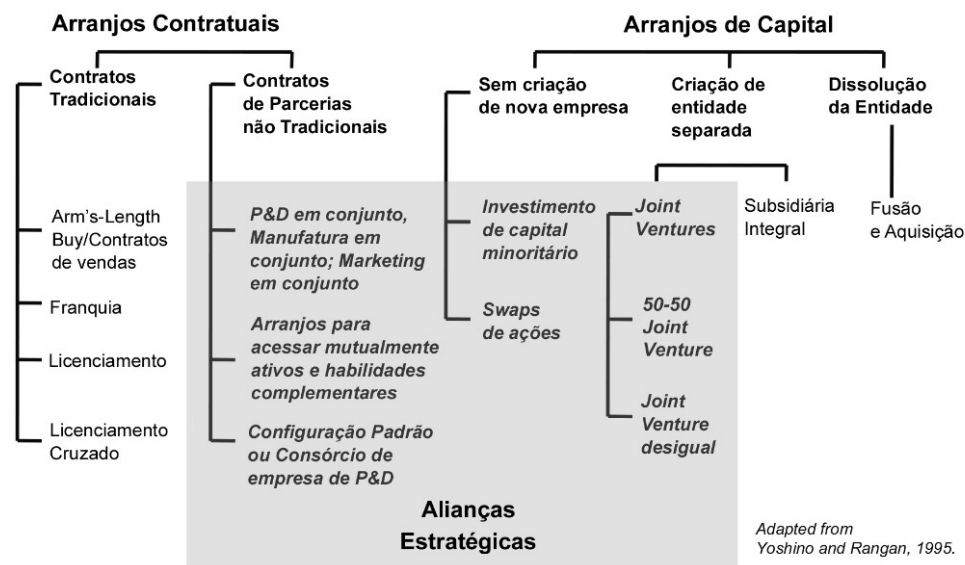

Figura 7: Tipos de relacionamentos interfirmas. Fonte: (Kale \& Singh, 2009)

As relações interfirmas descritas na Figura 7 mostram do lado esquerdo as relações sem a criação de novas entidades e sem o compartilhamento patrimonial, classificadas como arranjos contratuais, que podem se desdobrar nas seguintes estruturas: Acordos de P\&D; de fabricação; acordos de marketing, acordos para acesso a ativos e habilidades mutualmente complementares, além de consórcios de P\&D. Do lado direito, estão as relações baseadas em compartilhamento patrimonial, ora sem a criação de novas entidades, que podem se desdobrar nas estruturas: alianças por ações minoritárias e alianças por igualdade de ações; e ora com a formação de novas estruturas: joint ventures; $50-50$ joint venture, ou ainda, joint-ventures desiguais. Para os autores, apenas as relações descritas na parte azul da figura, se caracterizam como alianças estratégicas (Kale \& Singh, 2009).

Barney \& Hesterly (2015) sintetizam e agrupam as alianças estratégicas em três grandes categorias: (i) nonequity alliance - alianças sem o compartilhamento de ações; (ii)joint-ventures; e (iii) equity alliances - alianças com participação acionária. Na primeira categoria, a cooperação é gerenciada através de contratos. Incluem nessa categoria: os acordos de fornecimento; acordos de distribuição e, por fim os acordos de licenciamento que, diferentemente da classificação proposta por Kale \& Singh, (2009), os autores classificam como uma aliança estratégica. A segunda categoria é composta pelas joint-ventures, que representam uma nova entidade, criada como resultado da cooperação e na qual as 
empresas investem financeiramente. Nas joint ventures, os investimentos realizados são compensados pelos lucros obtidos. Na última categoria, além dos contratos de cooperação, um parceiro realiza investimentos acionáros no outro parceiro ou ambos realizam esses investimentos mutuamente.

Yu et al., (2019) definem as alianças estratégicas de acordo com duas dimensões. A primeira, classifica as alianças como simétricas e assimétricas, cujos presssupostos recaem sobre a diferença de tamanho das empresas envolvidas na aliança. A segunda dimensão desta classificação se refere a horizontalidade e verticalidade das alianças, cujos pressupostos da primeira, recaem sobre a inserção dos parceiros em um mesmo setor, já a verticalidade, pressupõe parceiros inseridos em setores distintos. As relações verticais, categorizadas pelas empresas e seus fornecedores - parceiros upstream - ou pelas empresas e seus distribuidores/clientes - parceiros downstream - objetivam a economia dos custos de transação (Gulati et al., 2005). Já as alianças horizontais, são formadas entre concorrentes e objetivam a conquista de benefícios mútuos advindos da resolução conjunta de problemas, aumento do poder de barganha das empresas e no oferecimento de produtos mais competitivos (Yu et al., 2019).

Contractor \& Lorange, (2002) classificam os tipos de alianças de acordo com o grau de intensidade ou interdependência das ligações, as quais abrangem desde ligações mais intensas a menos intensas, como fusões e aquisições; joint ventures; participação cruzada; investimento minoritário; pesquisa, produção, desenvolvimento ou marketing em conjunto; Franquias; licenciamento de knowhow ou patentes; até acordos para co-fornecimento ou co-fabricação.

Dentre tais ligações, com exceção de fusões e aquisições que se desdobram em uma nova empresa, todas são consideradas alianças, conforme definição de Gulati, (1998).

Para Gulati, (1998) o estudo das alianças está condicionado a cinco fatores chaves relevantes em cada fase do ciclo de vida das alianças: (i) a formação de alianças (ii) a escolha da estrutura de governança (iii) a evolução dinâmica das alianças (iv) o desempenho das alianças e (v) as consequências do desempenho para as empresas envolvidas.

A primeira fase do ciclo de vida, perpassa a escolha de parceiros, o que implica em habilidades para selecionar parceiros apropriados para o sucesso das alianças. A tarefa de seleção de parceiros, não é trivial e as empresas enfrentam 
dificuldades no processo de seleção. A incerteza de mercado a longo prazo, por exemplo, é um fator que impacta na seleção de novas alianças, o que leva as empresas a reforçar suas parcerias e redes existentes e não ampliar suas possibilidades por meio de novas parcerias. Em outros termos, as empresas enfrentam problemas de inércia na seleção de parceiros, causadas muitas vezes, por essas incertezas de mercado a longo prazo (Liang \& Mei, 2019).

Segundo o Manual de Oslo - 4a Edição OECD \& Eurostat (2018), existem sete tipos de parceiros diferentes com os quais as parcerias podem ocorrer: fornecedores; clientes; concorrentes, consultores, institutos privados de P\&D, universidades e outros institutos de Ensino Superior, Centros de Pesquisa Públicos e Governamentais.

A segunda e terceira fase de formação das alianças propostas por Gulati (1998) compreendem a formação propriamente dita das alianças e a escolha da sua estrutura, que perpassam pela escolha do design, criando uma estrutura de governança apropriada para o relacionamento estabelecido. A quarta fase, corresponde à evolução dinâmica das alianças, em que as empresas precisam combinar dinamicamente seus recursos e seus conhecimentos, o que demanda uma gerência complexa e ativa da parceria para que implique em consequências positivas para as empresas, materializadas em alcance de desempenhos superiores. (Kale \& Singh, 2009).

O desempenho das alianças, corresponde a última fase do seu ciclo de vida. Conforme proposto por Gulati, (1998) medir o desempenho das alianças não é tarefa fácil e usar como indicadores, a estrutura e a governança, pode ser um dos caminhos utilizados (Schreiner et al., 2009).

Todos esses fatores estão condicionados à capacidade de aliança das empresas, refletida nas habilidades de gerenciamento da aliança como um todo, notadamente por meio de três aspectos distintos: (i)coordenação (ii) comunicação e (iii) vínculo. Tais habilidades se desdobram na necessidade da existência de elementos críticos na aliança, como: (i)coordenação conjunta de interdependências estabelecidas com um parceiro; (ii) transmissão de informações relevantes ao parceiro e (iii) construção de laço social forte. Os impactos dessas habilidades são perceptíveis no sucesso das alianças, na conquista de metas e resultados planejados em conjunto pelas empresas (Schreiner et al., 2009) 
As empresas, em geral, são motivadas a formar alianças, uma vez que permitem o aumento da competitividade geral das empresas, seja por meio da formação de alianças diádicas, quando formadas entre duas empresas, ou ainda, alianças na forma de rede, compostas por vários atores. De acordo com Mowery et al. (1996) as empresas se envolvem em alianças estratégicas por vários motivos, tais como: (i)necessidade de compartilhar custos e riscos associados à inovação, possibilidade de rápida inserção em novos mercados, (ii) colaboração entre clientes e fornecedores para formular padrões técnicos (iii) coordenação entre rivais para obtenção de poder de barganha.

Para Liang \& Mei (2019) as empresas estabelecem parcerias para adquirir ou acessar recursos complementares e valiosos. Corroborando com essa visão, $\mathrm{Yu}$ et al., (2019) salientam que a interdependência existe quando um parceiro não detém todas as condições necessárias para a realização de uma atividade ou para atingir algum objetivo, sendo assim, as relações interorganizacionais funcionam como mecanismos que possibilitam o acesso aos recursos faltosos, possibilitando ao mesmo tempo, a manutenção do gerenciamento da dependência.

Wang et al. (2018) ainda descrevem que os relacionamentos interativos criam grande valor potencial e acúmulo de capital às empressas, ambos derivados do acesso a recursos heterogêneos que propiciam a criação de novos conhecimentos e melhora nos desempenhos. Tidd et al. (2005) analisam as desvantagens de se envolver em relações de colaboração, como riscos de oportunismo, roubo de knowhow ou de recursos por aliados não confiáveis, ou ainda, por meio da descoberta das fraquezas dos parceiros e do uso de informações para construção de uma estratégia competitiva que realce suas vulnerabilidades (Cook \& Mo, 2019).

Embora haja vários tipos de alianças estabelecidas por vários motivos distintos, esse estudo tem enfoque nos tipos de alianças propostas por Contractor e Lorange, descritas acima, que propiciam um aumento na capacidade de inovação das empresas (Martínez-noya \& Narula, 2018).

No caso específico das alianças de $\mathrm{P} \& \mathrm{D}$, elas se tornaram cruciais na estratégia de inovação das empresas, visto que a alta competitividade demanda que a pesquisa e desenvolvimento seja mais eficiente e englobe uma quantidade muito mais complexa de tecnologia. As alianças em P\&D são relacionamentos baseados em inovação, formadas por parceiros que coordenam suas atividades para alcançar um objetivo comum e na qual grande parte das atividades colaborativas são de 
pesquisa e desenvolvimento. As parcerias em P\&D podem levar as empresas a colocar produtos e serviços de forma mais rápida e complexa no mercado. No entanto, embora haja benefícios, as alianças de P\&D são arriscadas (Martínez-noya \& Narula, 2018).

As empresas enfrentam tensões entre o compartilhamento de conhecimento e a proteção do conhecimento, sendo, portanto, de extrema importância a estrutura das alianças e a sua governança (Monteiro et al., 2017).

A decisão de formar uma aliança estratégica perpassa pela busca da obtenção de melhores desempenhos. Nesse cenário, a Teoria Baseada em Recursos - RBV postula que os recursos e conhecimentos trazidos pelos parceiros para as alianças, promovem recursos idiossincráticos - definidos como aqueles exclusivos da aliança e desenvolvidos durante a parceria (Yu et al., 2019). Esses recursos são valiosos, raros, difíceis de imitar e organizacionais, e por isso ajudam as empresas a manterem vantagens de recursos perante suas concorrentes e a obterem posições privilegiadas no mercado competitivo (Barney \& Hesterly, 2015).

Essa busca por desempenho superior e a necessidade de obtenção de diferentes tipos de recursos levam as empresas a estabelecerem alianças com vários parceiros, levando-as a participar de uma rede ou portfólio de alianças. Portanto, entender a estrutura desses portfólios e o gerenciamento deles, torna-se cada vez mais necessário (Schreiner et al., 2009).

\subsection{1}

\section{Portfólio de Alianças}

Há uma série de definições conceituais quando se trata de portfólio de alianças, o que resulta em uma variação sobre o que exatamente constitui o portfólio de alianças. A falta de consenso na definição pode ter como base, a abordagem do tema por estudiosos de diversas áreas do conhecimento e a tentativa de definição à luz de teorias distintas. Sob a perspectiva da visão baseada em recursos - RBV, por exemplo, os portfólios são formados para estabilizar a troca de recursos entre as empresas e aumentar seus poderes de mercado (Xia et al., 2018).

De acordo com a Teoria de Aprendizagem Organizacional, as alianças são consideradas como fontes potenciais de aprendizado para as empresas, sendo fornecedoras de novos conhecimentos, recursos e capacidades. Em contrapartida, as empresas precisam equilibrar e gerenciar suas tentativas de aprendizado com sua 
capacidade de proteção, uma vez que podem se envolver em alianças com parceiros oportunistas e correrem riscos de perder suas principais habilidades e capacidades (Kale et al., 2000).

Wassmer, (2010) em sua revisão de literatura, identificou 14 lentes teóricas usadas para conceituar os portfólios de aliança. A abordagem mais comum, no entanto, perpassa pela adoção de uma perspectiva aditiva, que define o portfólio como uma agregação de alianças estratégicas de uma empresa denominada como empresa focal. Tendo como base a Teoria de redes, introduzida por Granovetter, (1973) este estudo adotará a seguinte definição de portfólio de alianças: Definido como uma ego rede (Knoke 2001), ou ainda, uma rede formada por uma empresa focal e suas ligações diretas (Ozcan \& Eisenhardt, 2009; Wassmer, 2010).

A análise dos portfólios de alianças por meio da Teoria de redes proporciona uma amplitude na análise e o envolvimento de um número maior de fenômenos a serem observados, abandonando a visão e análise puramente autônoma e autosuficiente do ponto de vista da empresa focal para a adoção de uma análise relacional e em nível estrutural (Zaheer et al., 2010).

O envolvimento das empresas em portfólios de aliança, se tornou uma realidade no cenário atual dos negócios, principalmente para as empresas que buscam alavancar seu desempenho de inovação, uma vez que a abertura das organizações ao conhecimento externo por meio de parcerias, aumenta sua base de conhecimento interna, e portanto, melhora a sua capacidade de inovar, e consequentemente, sua competitividade (Monteiro et al., 2017).

No entanto, o papel dos portfólios de alianças na melhoria dos desempenhos de inovação e melhoria da competitividade das empresas depende das características desses portfólios, como a estrutura da rede e o acesso aos recursos que ela disponibiliza (Macedo-Soares et al., 2017).

Hoffmann, (2007) chama a atenção para a importância da configuração do portfólio de alianças, que determina a qualidade, quantidade e diversidade de informações que a empresa tem acessso. A coletividade das alianças precisa contribuir para o alcance das necessidades estratégicas da empresa focal.

Outro atributo importante e crucial no portfólio é a confiança estabelecida entre os parceiros, o que propicia de fato as relações de colaboração, a fluidez das informações, a diminuição dos custos de transação, além de reduzir a probabilidade da ocorrência de oportunismo. Nesse sentido, embora haja mecanismos contratuais 
de proteção e estruturas hierarquizadas, a governança relacional, por exemplo, têm se mostrado bastante eficaz (Pellegrino, 2015). Ela é importante, uma vez que é possível a ocorrência de estruturas assimétricas, em termos de informação, de conhecimento e também de poder, ensejando muitas vezes os comportamentos oportunistas, cujos efeitos podem resultar em prejuízos para todo o portfólio. Nesses contextos, os interesses individuais se sobrepõem aos interesses coletivos, prevalecendo uma relação de competição em detrimento à colaboração. A confiança é nesse sentido, a variável chave para o sucesso de uma relação interorganizacional que se materializa na riqueza e na qualidade dos recursos e das informações que as empresas passam a ter acesso dentro do portfólio (Abbade, 2010).

Outra característica relevante com relação às parcerias estabelecidas nos portfólios, dizem respeito à natureza das ligações. De acordo com Macedo-Soares (2014) existem várias modalidades de ligações de alianças: (i) colaborativa versus competitiva; (ii) exploração (exploration) versus aproveitamento (exploitation); (iii) internacional versus local; (iv) fomal e informal; (v) profunda ou ampla; (vi) fortes ou fracas.

Laços considerados fortes estão relacionados à intensidade, frequência e interação entre os parceiros. Quanto maior a força da ligação, maior a probabilidade de sobreposição de informações. Se por um lado esse tipo de ligação beneficia a confiança e o fluxo de informações, por outro lado não favorece a busca por novas informações, importantes em contextos dinâmicos. Assim, laços dessa natureza, são favoráveis para empresas que adotam estratégias de aproveitamento (exploitation), que visam aumentar a qualidade dos recursos que possuem, favorecendo assim, inovações incrementais (Ozcan \& Eisenhardt, 2009).

Já os laços considerados fracos permitem maior flexibilidade, sendo mais adequados para estratégias de exploração (exploration) que visam novos parceiros, novas informações, novos conhecimentos e novas oportunidades por parte das empresas. Por permitirem acesso a uma quantidade maior de informações distintas, esses laços são considerados grandes potenciais para as empresas que visam lançar inovações consideradas radicais (Zaheer et al., 2010). Por outro lado, os laços fracos dificultam a circulação das informações e a transparência das relações, pela baixa confiança estabelecida entre as empresas (Ozcan \& Eisenhardt, 2009).

Para Macedo-Soares (2014) os laços fortes estão diretamente associados aos laços profundos, considerados como aqueles que envolvem muita confiança e 
parcerias duradouras. Já os laços fracos podem estar associados aos laços amplos, no sentido da ampla diversidade de informações. Já os laços considerados como formais são estabelecidos por meio de contratos e acordos bem estruturados que favorecem o fluxo de informações e a confiança, enquanto os laços informais enfrentam maiores desafios de gestão e são mais dependentes da confiança entre as partes envolvidas.

Por fim, os laços podem ser locais, o que significa abrangência nacional e podem ser realizados com parceiros internacionais.

No que tange à diversidade, esta pode estar relacionada aos parceiros e pode ser tanto funcional quanto geográfica. Tanto a diversidade funcional quanto geográfica constituem uma força para as empresas, já que envolve parcerias que vão desde organizações não governamentais até a sociedade e parcerias locais, regionais, nacionais e/ou globais. No entanto, há que se considerar um limite de diversidade para que esta seja benéfica, uma vez que uma diversidade demasiada gera altos custos de transação e a diminuição da capacidade absortiva, o que impacta negativamente no desempenho de inovação (Wassmer, 2010; Leeuw et al., 2014). No entanto, a diversidade também se refere à estrutura dos portfólios de alianças, no que diz respeito a formação de muitos ou poucos vínculos e da maneira como eles contribuem para o desempenho dos portfólios. Muitos vínculos podem afetar positivamente o desempenho de inovação da empresa, principalmente pela aliança com parceiros diferentes, enquanto poucos vínculos dão acesso à uma quantidade limitada de recursos distintos (Ajuha, 2000; Hoffmann, 2007).

Em outras palavras, os recursos aos quais a empresa tem acesso, por meio de suas relações interorganizacionais, devem ser complementados e/ou combinados com seus próprios recursos para que gerem vantagens competitivas à empresa focal. Assim, a diversidade das parcerias precisa resultar em sinergia, não redundância e amplitude dos recursos (Cobeña et al., 2017).

Outro aspecto crucial no estabelecimento de portfólio de alianças, é o seu gerenciamento (Schreiner et al. 2009). De acordo com esses mesmos autores, esse gerenciamento é definido pela capacidade de portfólio de aliança.

Haider \& Mariotti, (2016) definem essa capacidade como a capacidade de orquestração do portfólio, sendo a orquestração definida como ações intencionais tomadas pela empresa focal para criar e extrair valor de suas redes de relacionamentos. Por essa definição, os autores entendem que o portfólio é muito 
mais do que o somatório de alianças individuais formadas pela empresa focal e seus parceiros, e que por meio da sua coordenação é possível tirar maiores benefícios advindos das múltiplas alianças. Assim, leva-se em consideração a importância da gestão das alianças, dado o caráter dinâmico e não estático dos portfólios e de como o papel do tempo é importante nesse contexto, principalmente mediante a possíveis mudanças estratégicas dos parceiros à medida que os portfólios evoluem.

Os autores ainda enfatizam como as mudanças, muitas vezes, são depentes do caminho, levando por vezes, as organizações a reproduzirem e reforçarem as relações e as estruturas das alianças já existentes anteriormente. Isso mostra que mudar as conexões, discernir e priorizar recursos e conhecimentos não é algo trivial e a orquestração, gerenciamento e a forma de estruturação dos portfólios pode auxiliar nesse sentido.

Para Wassmer, (2010) os portfólios são resultados das escolhas estratégicas feitas pelas empresas, que levam em consideração, três áreas: (i) a abordagem de visualização dos portfólios no contexto de uma indústria; (ii) a decisão de envolver empresas desconectadas na exploração de oportunidades; (iii) e a capacidade de lidar com as incertezas do setor.

A teoria das alianças e redes estratégicas têm sobreposições significativas. Zaheer et al. (2010) na tentativa de organizarem a pesquisa sobre o tema, propuseram uma estrutura que relaciona os mecanismos teóricos/benefícios que podem ser provenientes das alianças ou da rede, com as características dos portfólios, considerando os três níveis de análise: (i) a díade - vínculo individual entre a empresa e um parceiro; (ii) o ego - o portfólio de alianças formado pela ligação entre a empresa focal e seus parceiros; (iii) e toda a rede - redes interorganizacionais. $\mathrm{O}$ foco da estrutura está em mecanismos teóricos/benefícios e suas relações com as características de cada nível de análise. Os mecanismos teóricos/benefícios são:

- Acesso a recursos: Recursos e capacidades fornecidas pela rede. No nível da díade, o acesso pode ser ampliado pela existência de laços fortes que favorecem o fluxo de recursos. No nível da ego rede, a posição/centralidade da firma focal e a existência de buracos estruturais favorecem o fluxo de recursos.

- Confiança: Essencial entre os parceiros do portfólio. A confiança facilita a troca de informações, diminui os riscos e os custos de transação, além de 
inibir o comportamento oportunista. No nível da ego rede, a centralidade da firma focal é importante e no nível de toda a rede, o fechamento é essencial.

- Poder/Controle: A desigualdade de poder no nível da díade, pode ser aprimorada pela dependência entre os parceiros. No nível da ego rede, os buracos estruturais podem servir como fontes de poder de barganha e no nível de toda a rede pode ajudar na formação de blocos estruturais.

- $\quad$ Sinalização: Esse benefício pode ser visto como fonte de status no nível da ego rede.

De forma geral, a principal contribuição desta estrutura é mostrar que algumas características contribuem para o aprimoramento de certos mecanismos teóricos/benefícios, enquanto reduzem as contribuições de outros (Zaheer et al., 2010).

\section{4 \\ Agronegócio e Sistemas Nacionais de Agricultura}

O conceito de agribusiness surgiu a partir da integração da agricultura aos setores industriais de fornecimento de insumos, de processamento e distribuição da produção até o consumidor final. A chamada industrialização da agricultura corresponde a um encadeamento de ações e processos interdependentes que traz consigo novas possibilidades e desafios importantes para o desenvolvimento econômico (Mendonça, 2013).

O conceito agribusiness, teve sua origem na Escola de Administração e Negócios da Universidade de Harvard, com a publicação do livro "A Concept of Agribusiness", na década de 50. A ideia central do livro recaiu sobre as intensas mudanças pelas quais o campo vinha passando, devido à revolução tecnológica e o progresso científico. Assim, as fazendas ditas como modernas, deixavam de ter uma função autossustentável para servirem a fins comerciais (Ramos, 2014).

No Brasil, o conceito foi amplamente usado em sua forma original até meados da década de 90, somente a partir da segunda metade desta década, o termo foi traduzido para o português e definido como agronegócio (Araújo, 2007). De forma semelhante, o conceito de agronegócio tem como base os sistemas integrados ligados às atividades agrícolas e pecuárias, envolvendo desde os insumos 
agropecuários, o processamento e distribuição até o consumidor final, apresentando assim, uma visão sistêmica (Ramos, 2014).

Essa visão sistêmica, resultado da interação agricultura-indústria, revela a importância da interação entre diversos agentes econômicos e não econômicos, e a maneira de como o conhecimento na agricultura é produzido e aplicado, enfatizando o papel da $\mathrm{P} \& \mathrm{D}$, como parte de um esforço inovativo maior e de melhor aproveitamento do aprendizado conjunto entre os agentes.

Assim, o conceito de sistemas de inovação na agricultura, tem sido empregado sob a perspectiva de que tal abordagem captura as relações necessárias dos diversos agentes, favorece os processos de aprendizagem e a interação da pesquisa com as atividades econômicas provenientes da agricultura (Beaulieu, 2013). Dessa forma, de maneira semelhante aos Sistemas Nacionais de Inovação, os Sistemas Nacionais de inovação na Agricultura focam nos atores importantes e necessários para estimular a inovação e o crescimento do setor, por meio da ênfase na geração de resultados e de conhecimentos para o crescimento econômico dos países (Anandajayasekeram \& Gebremedhin, 2009).

\subsection{1 \\ O Agronegócio Brasileiro e o Sistema Nacional de Pesquisa Agropecuária}

A Ciência e Tecnologia tiveram um papel importante para o desenvolvimento do agronegócio brasileiro nas últimas décadas, repercurtindo no crescimento da produção e na diversificação agrícola nacional. Há décadas, o governo brasileiro vem investindo em pesquisa agrícola, o que possibilitou avanços significativos, como o desenvolvimento de soluções adaptadas ao contexto agrícola nacional (Moreddu et al., 2017). Tais investimentos contribuíram para um expressivo crescimento econômico na agricultura. O setor é um dos principais responsáveis por grande parte do PIB brasileiro. Em 2019, o PIB do agronegócio cresceu 3,81\%, correspondendo a aproximadamente $21,4 \%$ do PIB total da economia (CNA, 2019). Esse é ainda o setor da economia com a maior capacidade de geração de empregos e o maior estimulador de outras atividades nacionais, movimentando recursos em torno de US\$ 200 bilhões por ano, com efeitos positivos na indústria e no comércio (cgee, 2016). A Figura 8 mostra o crescimento do 
agronegócio no Brasil no período de 2002 a 2018 e a comparação com outros setores da economia:

Agronegócio inova e puxa crescimento

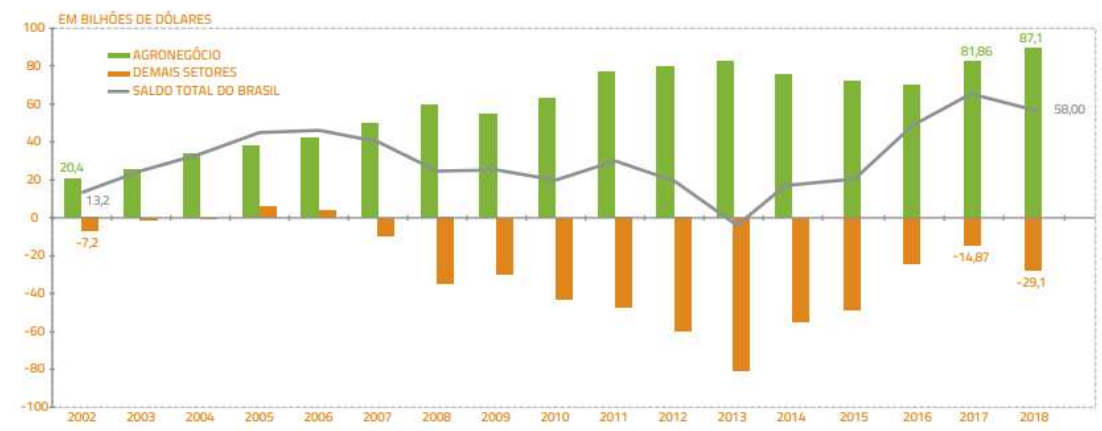

Figura 8: Crescimento e Comparação do Agronegócio com outros setores. Fonte: (Embrapa, 2019b).

A agricultura brasileira é baseada em mais de 300 espécies de cultivos. O país exporta 350 tipos de produtos para cerca de 200 mercados do planeta; é considerado o grande produtor de grãos, carnes e frutas; é o maior exportador de soja, café, açúcar, suco de laranja, etanol de cana-de-açúcar, carne bovina e de frango do mundo, além de ser destaque ainda na busca de fontes de energia renováveis (Embrapa, 2019; Cgee, 2016). Segundo dados do IBGE “entre 1975 e 2019 a produção de cana-de-açúcar, por exemplo, aumentou de 91,5 milhões de toneladas para 665 milhões de toneladas, ocupando pouco mais de 1\% do território nacional".

De acordo com a série histórica, período de 1989 a 2018, representada na Figura 9, é possível perceber que a balança comercial do agronegócio brasileiro apresenta saldos positivos, com expressivos crescimentos no período analisado (Embrapa, 2019b). 


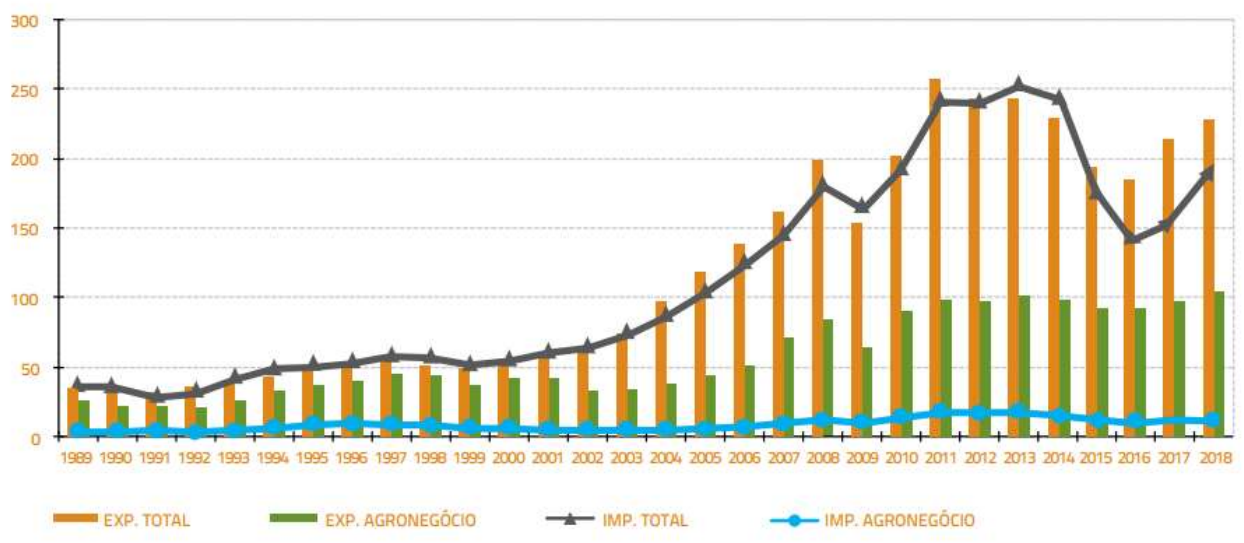

Figura 9: Série Histórica - Balança Comercial do Agronegócio Brasileiro. Fonte: (Embrapa, 2019b)

Além disso, em 2015, o Brasil foi considerado o segundo maior exportador agrícola do mundo e o maior exportador de produtos agroalimentares para a União Européia - EU, dominando uma parcela em torno de $12 \%$ das exportações mundiais para os países membros (Hubbard et al., 2017).

Outras grandes conquistas das últimas décadas dizem respeito ao abandono da insegurança alimentar, o crescimento da oferta de alimentos para o mercado interno superou a demanda existente, além do aumento em $400 \%$ da produção de grãos.

Todas essas conquistas na agricultura brasileira, realizadas nas últimas décadas, foram fruto de um esforço coletivo de diversos atores. Segundo reportagem do Estadão, de 05 de julho de 2016:

Não é demais louvar o desempenho da agricultura brasileira nas últimas décadas. A combinação de disponibilidade de terras, empreendedorismo e ousadia do produtor rural, investimento público e privado em pesquisa e desenvolvimento e políticas públicas, que, embora erráticas, tiveram papel relevante, permitiu que o País se transformasse na potência agrícola que, sem dúvida, hoje é. A inovação - base do crescimento da agricultura - resultou de parcerias formais e informais entre organizações públicas de pesquisa e grandes corporações do setor, que transferiram, adaptaram e até desenvolveram tecnologia para o clima tropical (Estadão, 2016).

Todo esse esforço coletivo no agronegócio brasileiro, foi portanto, materializado por meio da criação do Sistema Nacional de Pesquisa Agropecuária, na década de 90. O Sistema Nacional de Pesquisa Agropecuária Brasileiro - SNPA, foi criado em 1992, por meio da Portaria $n^{\circ}$ 193, de 07 de agosto, do Ministério da 
Agricultura, sob a coordenação da Embrapa e em convênio com os Estados, por meio das Entidades Estaduais de Pesquisa Agropecuária - OEPAS, além do Distrito Federal, dos municípios, das entidades públicas e privadas, universidades, sindicatos, fundações, cooperativas e associações, diretas ou indiretamente vinculadas às atividades de pesquisa agropecuária (Consepa, n.d.).

Na década de 70, a agricultura já representava muito para a economia do país, mas o investimento do governo para alavancá-la ainda mais, se limitava ao aumento da produtividade e a introdução de novos processos tecnológicos. A iniciativa da criação de um sistema de âmbito nacional, ressaltou a importância da união entre os níveis federal, estadual e municipal e a criação de um sistema integrado de pesquisa agropecuária (Canciani et al., 2016).

De acordo com os resultados da última pesquisa, período de 2007 a 2013, sobre investimentos, capacidades e desempenho em P\&D agrícola, realizado pelo Instituto Internacional de Pesquisa em Políticas Alimentares (IFPRI), vinculado ao Conselho de Pesquisa Agrícola Internacional (CGIAR), o sistema de inovação agrícola brasileiro foi considerado o maior da América Latina, com investimentos em pesquisa agrícola bastante superiores a de seus vizinhos, conforme mostra o gráfico (Figura 9). Ainda segundo a pesquisa, o país ficou atrás apenas da China e Índia, nos gastos públicos em P\&D agrícola (Penteado \& Fonseca, 2016).
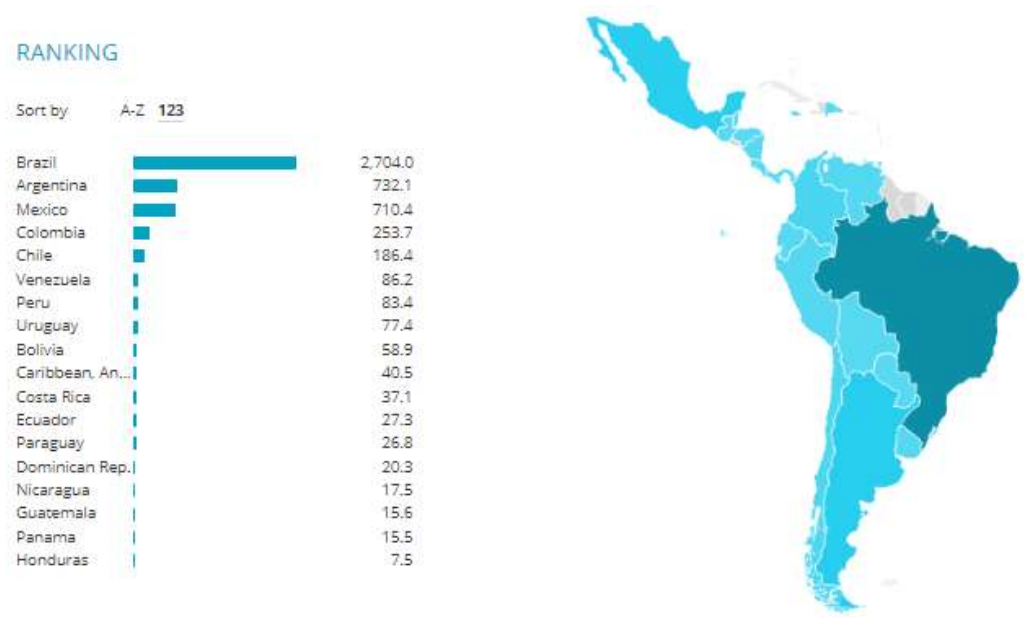

Figura 10: Gastos em P\&D agrícola na América Latina e Caribe Fonte: (ASTI, 2013).

A Figura 10 mostra os gastos em P\&D agrícola (ano 2011) pelos países da América Latina e Caribe, medidos por meio da conversão da Paridade do Poder 
de Compra individual dos países, em uma moeda comum. Para o cálculo dos gastos totais foram incluídos os indicadores de: salários, custos operacionais, programas e investimentos de capital para todas as agências governamentais sem fins lucrativos e de ensino superior que realizam pesquisas agrícolas nesses países. Pela nálise dos dados, é possível perceber que os gastos com P\&D agrícola variam muito de acordo com os países, sendo o Brasil, o país que lidera esses gastos - US $\$ 2,7$ bilhões em 2013 - representando mais da metade dos gastos totais dessa região (ASTI, 2013).

Desde a criação oficial do sistema, a Embrapa se tornou a empresa líder, e por meio de seu trabalho de excelência, em parceira com os outros membros, proporcionou diversos avanços sem precedentes, na agricultura brasileira (Embrapa, n.d.f).

De acordo com a Portaria 193 de 1992, o SNPA foi criado com os seguintes objetivos:

- Compatibilizar as estratégias de pesquisa agropecuária com as políticas de desenvolvimento do país, respeitando as particularidades das suas regiões;

- Garantir a organização e a coordenação de todos os agentes que compõem o sistema, em torno de uma uma agenda comum e sistematizada, evitando sobreposições de atividades e esforços;

- Favorecer o desenvolvimento de um sistema nacional de planejamento para pesquisa, acompanhamento e avaliação;

- Criar um sistema único de informação de dados que embase as atividades de pesquisa e desenvolvimento agrícola;

- Assegurar a informatização das instituições do sistema para a otimização de seus trabalhos;

- Fomentar as ações de parceria entre os membros, por meio da elaboração e execução conjunta de projetos;

- Coordenar as pesquisas em todos os níveis (federal, estadual e municipal) para que atendam de fato as demandas locais e favoreçam o desenvolvimento da agropecuária local;

- Promover o intercâmbio de informações e documentação técnicocientífica, nas áreas de interesse comum; 
- Favorecer o intercâmbio de recursos humanos qualificados entre os agentes;

- Fornecer apoio tanto na parte técnica, administrativa e financeira entre as instituições integrantes, de acordo com as necessidades e interesses da programação e missões que elas desempenham.

Embora o SNPA tenha contribuído para grandes conquistas na agricultura brasileira, o sistema tem recebido muitas críticas, que dentre outras, ressaltam a falta de sinergia e cooperação entre seus agentes. Na tentativa de melhorar o sistema, algumas reformulações foram propostas, construídas sob a afirmação de que o sistema foi se fragilizando ao longo dos anos, não ocorrendo sua implementação dentro da concepção e dos objetivos para os quais foi construído (Canciani et al., 2016).

Uma das reformulações propostas, culminou no estudo realizado pelo Grupo de Gestão de Estudos Estratégicos - CGEE do Ministério da Ciência e Tecnologia - MCTIC, cujo produto final seria: a proposta de um novo arranjo institucional entre instituições de CT\&I agropecuária e outras instituições públicas e privadas, com missões e programas semelhantes, com o objetivo de obter maior sinergia e cooperação para enfrentar os desafios para a produção da agropecuária brasileira. Algumas das fragilidades do sistema levantadas pelo estudo foram: falta de coordenação e cooperação (Cgee, 2016).

Essa visão da necessidade de reformulação do sistema foi proposta pelos próprios membros do SNPA, conforme trecho extraído do site do Conselho Nacional das Entidades Estaduais de Pesquisa Agropecuária - Consepa:

o Consepa está atento às variáveis globais que apresentam um quadro de necessidade de intensificação da pesquisa agropecuária. Este cenário demonstra claramente que o atual modelo de governança, do que se conhece como Sistema Nacional de Pesquisa Agropecuária, necessita ser repensado à luz dos atuais e futuros desafios e do ambiente de inovação nacional e internacional em Ciência Tecnologia e Inovação agropecuária (Consepa, n.d.).

Tais reformulações se fazem presentes, na tentativa de construção de um sistema mais robusto e integrado que promova interações entre os estados, os municípios e a federação e que dêem subsídios para a manutenção de uma agropecuária competitiva que consiga enfrentar os desafios futuros, tais como:

- Abastecimento do mercado interno a preços reais;

- Intensificação da produção de forma sustentável; 
- Inclusão produtiva e aumento do bem-estar das populações rural e urbana;

- Diversificação, especialização e agregação de valor para alcance de mercados mais dinâmicos, competitivos e rentáveis;

- Fortalecimento das exportações contribuindo para a geração de divisas que favoreçam as contas externas do país;

- Utilização eficiente dos recursos naturais dos biomas brasileiros (Cgee, 2016).

Somado a todos esses desafios, espera-se ainda, que a agricultura brasileira seja guardiã dos recursos naturais e do meio ambiente, o que demanda a construção de uma agricultura mais sustentável. É, neste ambiente de transformação, que se torna evidente a necessidade do avanço na geração e disseminação de tecnologias disruptivas e modernas, as quais sinalizam a premência de um sistema nacional de pesquisa agropecuária brasileiro fortalecido e integrado, que prime pela construção de uma agenda única de trabalho e de pesquisa orientadas para os mesmos desafios, além de aumentos significativos de investimentos em CT\&I (Cgee, 2016).

Assim, é primordial focar no fortalecimento da capacidade deste sistema, por meio da sinergia entre todos os atores para identificar novas necessidades e evitar esforços duplicados na busca de soluções inovativas (Moreddu et al., 2017).

No Brasil, embora o SNPA tenha sido oficialmente instituído em 1992, a ideia e intenção do governo federal na sua criação se remete ao ano de 1973, com a criação de uma empresa pública com capilaridade nacional, a Embrapa. Anos depois, com a criação oficial do sistema e com a integração de outros agentes, a Embrapa passou a ser a coordenadora do sistema, se tornando a empresa líder. De acordo com Canciani et al., (2016) "Em 1972 o SNPA era uma estratégia do Governo Federal. Depois, a Embrapa passou a ser estratégia do Sistema e, por fim, se tornou uma estratégia do Governo Federal”. Assim, o papel dessa empresa dentro do SNPA é de extrema relevância e é considerada como principal instrumento de reformulação da pesquisa agropecuária brasileira. 


\subsection{2}

\section{A Embrapa}

A Empresa Brasileira de Pesquisa Agropecuária - Embrapa, é uma empresa pública de Pesquisa, vinculada ao Ministério da Agricultura, Pecuária e Abastecimento - MAPA (Brasil, 2020).

A Embrapa foi criada na década de 70, período marcado pela abertura do comércio brasileiro para o mercado externo e de crescimento acelerado da população brasileira. Tal cenário mostrava que sem investimento em ciências agrárias, o país não conseguiria reduzir a diferença entre a demanda e a oferta de alimentos. Nesse contexto, dentro do Ministério da Agricultura, um grupo debatia a importância e a necessidade de investimento em conhecimento científico para apoiar o desenvolvimento agrícola, bem como a necessidade do investimento em conhecimento técnico direcionado aos agricultores nacionais (Embrapa, n.d.c).

Em 7 de dezembro de 1972, o então Presidente da República, Emílio Garrastazu Médici, sancionou a Lei $n^{\circ}$ 5.851, que autorizava o Poder Executivo a instituir empresa pública, sob a denominação de Empresa Brasileira de Pesquisa Agropecuária (Embrapa). O Decreto $n^{\circ}$ 72.020, de 28 de março de 1973, aprovou os estatutos da Empresa e determinou sua instalação em 20 dias (Mengel \& Aquino, 2015). Nascia, então a Embrapa com a seguinte missão: "Viabilizar soluções de pesquisa, desenvolvimento e inovação para a sustentabilidade da agricultura, em benefício da sociedade brasileira" (Embrapa, 2015).

Com sede em Brasília - DF, a empresa foi instalada e herdou uma ampla estrutura pertencente até então ao Departamento Nacional de Pesquisa e Experimentação (DNPEA), extinto após a instituição da Embrapa. Assim, a empresa já no seu início de atuação, contava com 92 bases físicas, divididas em institutos regionais, estações experimentais, imóveis e centros nacionais e com a responsabilidade de administrar a pesquisa agropecuária em todo território nacional (Embrapa, n.d.a).

Diante da criação de uma empresa voltada para a agricultura brasileira, a década de 70 foi marcada pelo investimento em ciência na agricultura, o que viabilizou o nascimento de uma agropecuária tropical, que se tornaria, anos adiante, a mais importante do mundo. Além disso, a Embrapa, já no início de sua atuação, investiu pesadamente em seus recursos humanos. Em 1974, um ano após sua criação, a empresa já tinha 317 pesquisadores, sendo que destes, 273 estavam em 
cursos de mestrado e doutorado, com alguns realizando cursos fora do país (Embrapa, n.d.a). Também no ano de 1974, foram criados os primeiros centros nacionais por produtos: Trigo (em Passo Fundo, RS), Arroz e Feijão (em Goiânia, GO), Gado de Corte (em Campo Grande, MS) e Seringueira (em Manaus, AM) (Embrapa, n.d.c).

Atualmente, a Embrapa é composta pela sua sede em Brasília - DF, denominada por unidade central e por 43 unidades descentralizadas, espalhadas por todo território nacional. As unidades são classificadas de três tipos distintos: Unidades Temáticas; Unidades de Produtos e Unidades Ecorregionais (Brasil, 2020).

Durante suas quatro décadas de existência, a Embrapa colecionou uma série de resultados que transformaram a agropecuária nacional. De acordo com o último Balanço Social da empresa, referente ao ano de 2019, em cada 1 real investido na empresa geraram $\mathrm{R} \$ 12,29$ reais de retorno para a sociedade. (Embrapa, 2019a). A figura 10 traz uma série histórica referente ao lucro social da Embrapa, no perído de 2001 a 2019, que representa a soma dos benefícios econômicos gerados anualmente por uma amostra de tecnologias, com uma comparação com o orçamento anual da empresa no mesmo período.

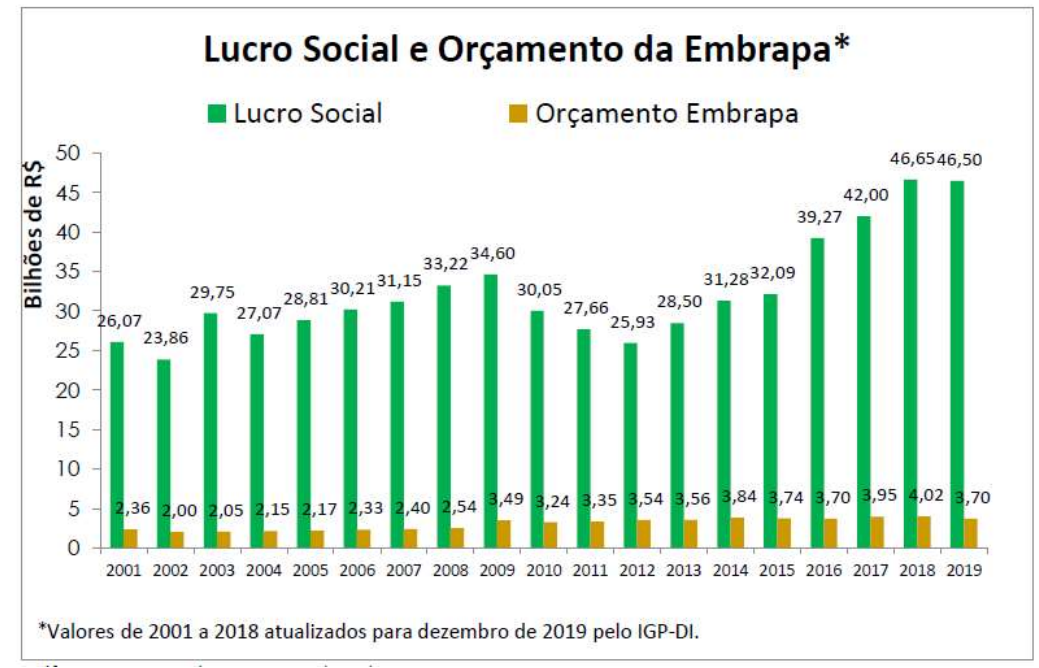

Figura 11: Lucro Social e Orçamento da Embrapa Fonte: (Embrapa, 2019a).

Pela análise do gráfico é possível dimensionar a importância da Embrapa para o setor agropecuário ao incorporar as soluções e tecnologias geradas pela empresa, o que demonstra que o investimento em pesquisa pública agropecuária é altamente rentável para a sociedade brasileira (Embrapa, 2019a). No entanto, 
conforme salientam os ex presidentes da Embrapa Silvio Crestana e Mauricio Lopes, em reportagem do Estadão, de 5 de julho de 2016:

...em um mundo movido por inovações cada vez mais rápidas e radicais, o sucesso no passado não é nenhuma garantia de sucesso no futuro. De fato, a agricultura está vivendo grandes transformações provocadas principalmente por desafios globais e mudanças institucionais relevantes que vêm sendo impulsionadas por pressões sociais relacionadas à qualidade (lato sensu) dos alimentos, às exigências ambientais, às relações de trabalho, à superação da pobreza rural e à inclusão social, assim como pelas próprias mudanças no meio rural, em particular as migrações e a maior interação campo-cidade. Mas é no âmbito da tecnologia e da inovação que as mudanças são mais radicais e ameaçadoras (Estadão, 2016).

Nesse contexto, o maior desafio enfrentado no processo de $\mathrm{P} \& \mathrm{D}$ da Embrapa é transformar conhecimentos e ativos em tecnologias e negócios que produzam benefícios para o público envolvido e se constituam em inovação para a sociedade. Assim no constante esforço para a melhoria da sua governança e no intuito de sanar esse gargalo, a Embrapa iniciou em 2018 um processo de remodelagem do seu modelo de gestão da programação, responsável pela execução da estratégia da empresa, com vistas a orientá-lo à geração de inovação, à melhoria da sua eficiência e eficácia frente às demandas presentes e futuras da sociedade. Essas mudanças consistiram em uma série de reestruturações internas e na reorientação dos seus projetos de pesquisa para um foco em resultados, por meio da adotação da escala de maturidade TRL/MRL (Embrapa, 2019c).

O ano de 2019 marcou a consolidação dessa mudança, através da remodelagem do Sistema Embrapa de Gestão (SEG), por meio do qual os compromissos assumidos pela empresa são executados e os resultados de suas pesquisas entregues à sociedade. Tal remodelagem foi guiada pela identificação de novos desafios de inovação, objetivos e diretrizes estratégicas da empresa, que orientaram a construção de portfólios, que mediante consulta ao setor produtivo e priorização com políticas públicas dentre outros critérios, induziram as chamadas para projetos do SEG, sendo as Unidades descentralizadas, por sua vez, responsáveis pela elaboração dos projetos que atendem as prioridades dos portfólios (Embrapa, 2019c).

Todos os desafios de inovação da Embrapa são correlacionados aos 17 Objetivos de Desenvolvimento Sustentável - ODS da Agenda 2030 das Nações Unidas e com as políticas públicas que norteiam toda a prática da Embrapa. Dessa forma, todos os elementos direcionadores do planejamento da empresa são 
trabalhados nas pesquisas realizadas (Embrapa, n.d.e). Essa mudança na gestão da programação teve como base, três problemas detectados internamente e que dificultavam uma maior aproximação da empresa com seus parceiros e o acesso a investimentos que não fossem somente de origem governamental (Embrapa, 2019c). A Figura 12 mostra os problemas e as soluções implementadas.

\begin{tabular}{|c|c|c|}
\hline Problemas Específicos & Metas & Soluções Implantadas \\
\hline Produção com viés acadêmico & $\begin{array}{l}\text { Produção focada em ativos, por } \\
\text { meio da implementação da } \\
\text { escala TRL }\end{array}$ & $\begin{array}{l}\text { Implantação da escala de níveis } \\
\text { de maturidade tecnológica. } \\
\text { (Escala TRL/MRL) }\end{array}$ \\
\hline Dispersão de foco de atuação & $\begin{array}{l}\text { Converter } 100 \% \quad \text { da } \\
\text { programação de pesquisa para } \\
\text { PD\&l orientada por missão }\end{array}$ & $\begin{array}{l}\text { Novos Portfólios com } \\
\text { Planejamento Orientado para } \\
\text { Desafios } \\
\text { (Problemas/Oportunidades) }\end{array}$ \\
\hline $\begin{array}{l}\text { Baixa colaboração com o Setor } \\
\text { Produtivo }\end{array}$ & $\begin{array}{l}\text { Alcançar até } 2022 \text { um } \\
\text { percentual de } 40 \% \text { de projetos } \\
\text { com o setor produtivo }\end{array}$ & $\begin{array}{l}\text { Criação e fomento a projetos de } \\
\text { Inovação Aberta em parceria } \\
\text { com o Setor Produtivo. }\end{array}$ \\
\hline
\end{tabular}

Figura 12: Problemas detectados e soluções implementadas na Embrapa Fonte (Embrapa, 2019c).

Com foco na produção de resultados e ativos, o novo modelo de gestão vincula a pesquisa e desenvolvimento $-\mathrm{P} \& \mathrm{D}$ à transferência de tecnologia $\mathrm{e}$ qualifica e avalia os ativos gerados para comporem uma vitrine tecnológica. Essa avaliação e qualificação ocorrem por meio da escala de maturidade de tecnologias (TRLs) desenvolvida pela NASA (Mankins, 1995). A empresa acredita que por meio de toda essa mudança poderá contribuir para o aumento da celeridade na transferência tecnológica em um contexto de inovação aberta (Capdeville et al., 2017).

A Figura 13, mostra o novo modelo adotado e exemplifica o caminho percorrido pelos ativos pré-tecnológicos até a adoção da inovação pela cadeia produtiva. A escala ainda embasa a categorização de tipos de projeto da Embrapa, que passaram a ser divididos em quatro tipos distintos que se reportam às etapas do desenvolvimento e grau de maturidade de inovação tecnológica à medida que as tecnologias avançam (Embrapa, 2019c). 


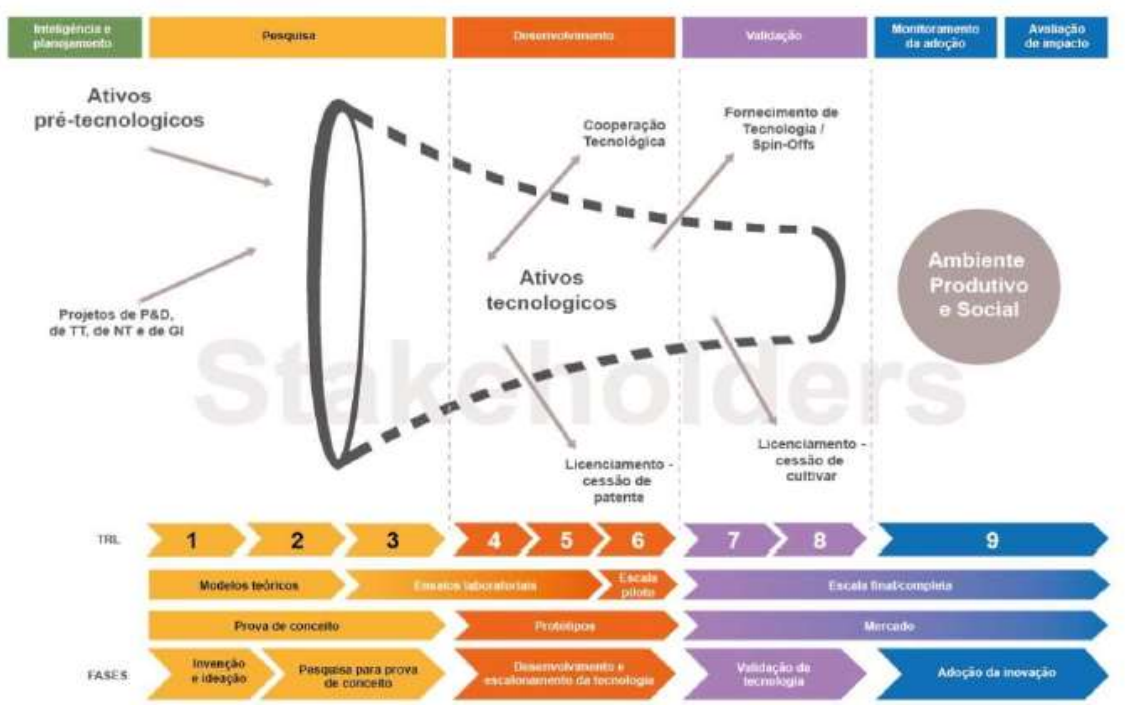

Figura 13: Escala de Maturidade Tecnológica TRL/MRL Fonte: (Embrapa, 2019c).

Os projetos foram assim categorizados (Embrapa, 2018):

- Projetos Tipo I - São projetos de P\&D cujos resultados são ativos pré-tecnológicos e/ou ativos tecnológicos que atinjam até, no máximo, o nível quatro da escala TRL/MRL;

- Projetos Tipo II - São projetos de pesquisa e validação, cujos resultados são ativos pré-tecnológicos e devem atingir, pelo menos, um resultado em nível de maturidade 5

- ou superior;

- Projetos Tipo III - São projetos que nascem a partir de demanda de mercado (market-pull) atuando em todo o funil de inovação, desde a concepção das ideias e dos ativos.

- Projetos Tipo V - São projetos que proporcionam apoio difuso ao modelo de inovação da Empresa e representam ações de de desenvolvimento organizacional, comunicação e/ou negócios.

Além das mudanças ocorridas no âmbito da gestão da programação, a Embrapa criou o Núcleo de Inovação Tecnológica - NIT, alocado à sua Secretaria de Inovação e Negócios - SIN, responsável pelos processos de gestão de ativos, gestão de inovação e negócios, gestão de marketing e gestão e exploração comercial de ativos. O modelo de negócios do NIT, ocorre em parceria com uma Fundação de Apoio e pressupõe uma flexibilidade de atuação; articulação com parceiros e parques tecnológicos; manutenção da gestão das principais ações estratégicas da 
empresa; corpo especializado nas áreas de gestão da propriedade intelectual e gestão de relacionamentos institucionais, com a coordenação da atuação em rede da Embrapa, bem como o domínio de temas sensíveis (Embrapa, 2019c).

O NIT é o responsável pela qualificação de ativos, por meio da escala TRL, com o intuito de gerar informações qualificadas para facilitar o processo de transferência das tecnologias para o mercado, consolidando o processo de inovação, por meio da adoção. Dentro do NIT também foi criada a figura dos "Gestores de Ativos", cuja função é dar suporte às unidades descentralizadas na qualificação dos ativos, no que tange à análise de mercado e na análise e qualificação também dos resultados dos projetos, exercendo o papel de acompanhar tais resultados que poderão ser passíveis de qualificação, facilitando a adoção pelo mercado em diversos estágios da escala (Embrapa, 2019c).

De maneira geral, todo esse arcabouço teve como intuito a melhoria da relação da Embrapa com uma rede de parceiros, desde instituições de venture capital, gestores de fundos de investimentos, aceleradoras, startups dentre outros. A melhoria dessas relações permitiu que a empresa passasse a ser vista como uma instituição que promove o elo entre o conhecimento científico e a inovação, ampliando as perspectivas de uso de seus ativos até mesmo por outros setores fora da agropecuária. As mudanças implementadas também permitiram a criação de uma estrutura que oferece mais segurança tanto jurídica quanto técnica à empresa para o desenvolvimento de modelos de negócios e parcerias com todo o mercado de inovação. Nesse cenário, a empresa busca uma estrutura que propicie ainda mais agilidade para prover soluções que atendam aos mais variados públicos e para melhorar ainda mais sua conectividade com os diversos setores com os quais mantém relacionamento e que possa entregar ainda mais resultados com menos burocracia.

No nível estratégico, a empresa possui seu documento orientador, seu Plano Diretor - PDE, já em sua sexta edição, que estabelece as prioridades da empresa, as grandes linhas e macrotemas que direcionam as atividades a serem desenvolvidas por suas Unidades descentralizadas. O VI PDE foi elaborado com base na análise do ambiente externo, no intuito de antecipar e identificar os principais desafios sustentáveis que serão impostos ao Brasil e sua agricultura nos próximos 20 anos (2014-2034), advindos das grandes transformações mundiais. Ele descreve, representa e integra, portanto, o processo de produção da empresa, sintetizando e 
facilitando suas ações, gestão institucional, gestão de PD\&I e desafios de PD\&I (Embrapa, 2015).

O mapa estratégico demonstrado na Figura 14, constante no VI PDE (Embrapa, 2015), ilustra e sintetiza o planejamento estratégico da empresa, os macrotemas, os desafios de inovação, os eixos de impacto e objetivos da empresa que devem ser observados na construção das agendas de prioridades das Unidades, as quais, de fato, são as responsáveis pela execução da pesquisa, desenvolvimento e inovação na empresa.

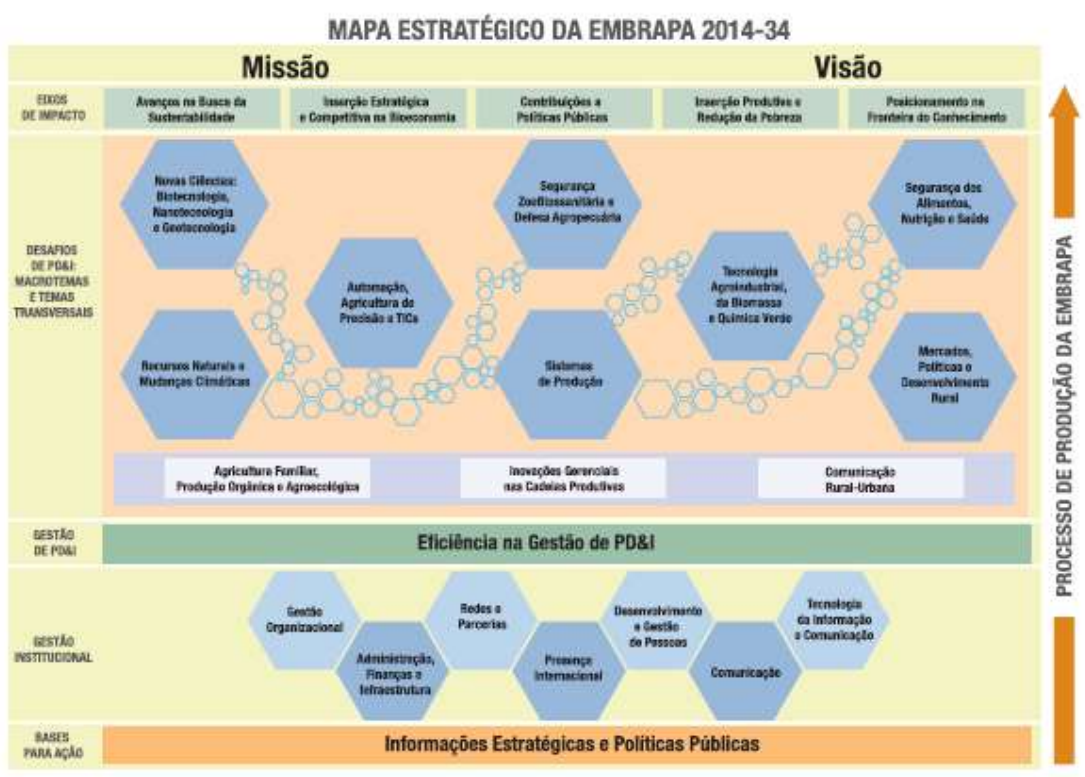

Figura 14: Mapa Estratégico da Embrapa 2014-2034

Fonte: (Embrapa, 2015).

O mapa, portanto, informa a definição e integração de esforços de inteligência, gestão e execução da empresa, com vistas a gerar as soluções frente aos principais desafios levantados. É a partir dessas diretrizes que as Unidades descentralizadas, elaboram anualmente suas agendas de prioridades e agendas institucionais, de forma a contribuir e alimentar o processo de planejamento global da empresa, de acordo com suas especificidades e suas áreas de atuação (Embrapa, 2020).

Assim, embora cada Unidade seja estruturada de forma semelhante, por meio de suas Chefias Geral, de Transferência de Tecnologia, de Administração e de Pesquisa e Desenvolvimento, cada Unidade, respeitando a vinculação necessária de suas ações com o VI PDE e demais documentos norteadores da empresa, têm autonomia para a construção de suas agendas e de definição de suas priorizações de pesquisa. 


\section{5}

\section{Posicionamento Teórico}

De acordo com a revisão de literatura realizada, foi elaborado/desenvolvido um modelo teórico de inovação aberta, o qual relaciona três diferentes construtos. Por meio da aplicação do modelo nas unidades de análise, foi possível mapear os construtos que ajudaram a responder a pergunta de pesquisa deste estudo. Para a construção destes construtos foram feitas escolhas de dimensões, fatores e conceitos, os quais serão também apresentados na próxima seção.

\subsection{1}

\section{Recursos e capacidades internas}

Este construto foi categorizado à luz da Teoria Baseada em Recursos RBV, de acordo com Barney (1991) que postula que as organizações são coleções de recursos que permitem a obtenção de vantagem competitiva e desempenho superior a longo prazo, se as configurações desses recursos forem: valiosas, raras, difíceis de imitar e organizacionais, verificadas por meio da aplicação do modelo VRIO.

Em contextos de inovação e de acordo com este modelo, os recursos são assim considerados (Barney \& Hesterly, 2015):

Valiosos: São aqueles que permitem que uma empresa melhore sua capacidade de inovação, e consequentemente, seu desempenho no que concerne à inovação.

Raros: São os recursos controlados por poucas empresas e que tendem a ser uma fonte de vantagem competitiva.

Imitáveis: Refere-se à facilidade que outras empresas têm para imitar/copiar o recurso raro e valioso da organização.

Organizacionais: Refere-se à estrutura organizacional - políticas e procedimentos - necessários para que a empresa explore e aproveite todo o potencial competitivo de seus recursos valiosos, raros e difíceis de imitar.

Assim, a categorização dos recursos e capacidades de acordo com as definições acima descritas, classificam os recursos e capacidades como forças ou fraquezas internas e fontes ou não de vantagem competitiva para as empresas. De 
acordo com a classificação proposta pelo modelo VRIO, há implicações estratégicas, as quais são descritas por Barney \& Hesterly (2015) conforme Quadro 3:

Quadro 3: Estrutura do Modelo VRIO

\begin{tabular}{|l|l|l|l|l|}
\hline Valioso & Raro & \multicolumn{1}{|c|}{$\begin{array}{c}\text { Difícil de } \\
\text { Imitar }\end{array}$} & $\begin{array}{c}\text { Aproveitado } \\
\text { pela Unidade }\end{array}$ & \multicolumn{1}{|c|}{ Implicância Competitiva } \\
\hline Não & Não & Não & Não & Desvantagem Competitiva \\
\hline Sim & Não & Não & Sim & Paridade Competitiva \\
\hline Sim & Sim & Não & Sim & Vantagem Temporária \\
\hline Sim & Sim & Sim & Sim & Vantagem Sustentável \\
\hline
\end{tabular}

Fonte: Barney \& Hesterly (2015)

Para a categorização e definição dos recursos e capacidades, contou-se também com a contribuição da Teoria das Capacidades Dinâmicas, introduzida por Teece et al.(1997), cujo aporte se dá, por meio da ênfase na dinamicidade dos recursos, necessária para que as empresas alcancem desempenhos superiores em contextos de inovação. Assim, a análise de como esses recursos e capacidades são organizados, combinados e recombinados remontam a definição de capacidades dinâmicas e são essenciais em ambientes de inovação.

Tendo o aporte de tais teorias e por meio da Revisão de Literatura, foram levantados os recursos e capacidades (definidas neste estudo como sinônimo de competências e habilidades, conforme Barney \& Hesterly, (2015)) cujas definições constam na Seção 2.2 deste trabalho, considerados como essenciais, que impactam na capacidade interna de inovação das empresas, e consequentemente, em seus desempenhos de inovação. Tais recursos e capacidades levantados, foram analisados sob à ótica do Modelo VRIO. Assim, este primeiro construto foi composto por seis dimensões, algumas destas compostas por capacidades específicas, conforme especificado no Quadro 4 e tiveram como base vários estudos pesquisados, dentre os quais, destacam-se os trabalhos de Hosseini et al. (2017); Lichtenthaler \& Lichtenthaler (2009); Podmetina et al. (2018); Mortara \& Minshall (2011), (Ades et al., 2013); Castro (2011) e (Cui et al., 2015).

Quadro 4: Recursos e Capacidades Internas e Definições

\begin{tabular}{|c|l|l|}
\hline Dimensão & \multicolumn{1}{|c|}{ Definição } & \multicolumn{1}{|c|}{ Base Teórica } \\
\hline & As empresas precisam manter vivas suas capacidades & (Ades et al., \\
de P\&D, por meio da construção e manutenção de & $2013)$; (Castro, \\
infraestruturas físicas, Recursos Humanos e insumos & 2011) \\
& $\begin{array}{l}\text { que dêem suporte à realização dessas atividades. } \\
\text { Essas atividades também precisam exercer novos } \\
\text { papéis na IO e exigirão novos recursos que devem } \\
\text { permitir o desenvolvimento da P\&D, tais como }\end{array}$ & \\
\hline
\end{tabular}




\begin{tabular}{|c|c|c|}
\hline & $\begin{array}{l}\text { atividades de integração entre o conhecimento interno } \\
\text { e externo. }\end{array}$ & \\
\hline Cultura & $\begin{array}{l}\text { Envolvem atitudes abertas ao risco e tolerância a eles. } \\
\text { Criação de um ambiente propício à inovação aberta } \\
\text { com integração de equipes, comunicação entre os } \\
\text { setores. Abandono de posicionamentos excessivos de } \\
\text { proteção para estimular a inovação aberta e superação } \\
\text { da crise do "Não inventado aqui", por meio da } \\
\text { valorização de conhecimentos externos. }\end{array}$ & $\begin{array}{l}\text { (Mortara \& } \\
\text { Minshall, 2011; } \\
\text { (Ades et al., } \\
2013 \text { ) }\end{array}$ \\
\hline $\begin{array}{l}\text { Tecnologia da } \\
\text { Informação } \\
\text { como suporte } \\
\text { à Inovação } \\
\text { Aberta }\end{array}$ & $\begin{array}{l}\text { TI para apoiar as atividades de procura e exploração } \\
\text { do conhecimento, armazenamento e repositório das } \\
\text { informações, além de apoio às atividades de } \\
\text { integração com parceiros. }\end{array}$ & $\begin{array}{l}\text { (Cui et al., } \\
\text { 2015; Hosseini } \\
\text { et al., 2017). }\end{array}$ \\
\hline $\begin{array}{l}\text { Alinhamento } \\
\text { Estratégico } \\
\text { e Governança }\end{array}$ & $\begin{array}{l}\text { Estratégia de Inovação aberta alinhada aos negócios } \\
\text { da empresa e à sua estrutura interna. Definição de um } \\
\text { modelo de governança para IO. Definição de } \\
\text { responsabilidades e funções que garantam a execução } \\
\text { bem sucedida das atividades de IO. Processo } \\
\text { estruturado de seleção de parceiros, que permita } \\
\text { selecionar os parceiros com conhecimentos } \\
\text { relevantes. }\end{array}$ & $\begin{array}{l}\text { (Hosseini et al., } \\
\text { 2017; Habicht } \\
\text { et al., 2012; } \\
\text { Cui et al., 2015) }\end{array}$ \\
\hline $\begin{array}{l}\text { Capacidade de } \\
\text { Gerenciamento } \\
\text { do } \\
\text { Conhecimento }\end{array}$ & $\begin{array}{l}\text { Capacidades: transformativa; inventiva; absortiva; } \\
\text { inovativa; desorptive capacity e capacidade } \\
\text { conectiva. Essas capacidades necessitam de métodos } \\
\text { para serem criadas e desenvolvidas. }\end{array}$ & $\begin{array}{l}\text { (Lichtenthaler } \\
\text { \&Lichtenthaler, } \\
\text { 2009; } \\
\text { Podmetina et } \\
\text { al., 2018) }\end{array}$ \\
\hline $\begin{array}{l}\text { Habilidades/ } \\
\text { Competências } \\
\text { Individuais }\end{array}$ & $\begin{array}{l}\text { Mentalidade tecnológica; Liderança pessoal por } \\
\text { pares; Capacidade de corretagem social; capacidade } \\
\text { de alargamento de fronteiras }\end{array}$ & $\begin{array}{l}\text { (Hosseini et al., } \\
\text { 2017; Habicht } \\
\text { et al., } \\
\text { 2012; Lifshitz- } \\
\text { Assaf, 2018) }\end{array}$ \\
\hline
\end{tabular}

\subsection{2}

\section{Alianças Estratégicas/Portfólio de Alianças}

Por meio deste construto e com o aporte da literatura, pretende-se demonstrar os principais tipos de parceiros, as principais alianças estabelecidas com cada tipo de parceiro, a modalidade e natureza das ligações realizadas pela empresa focal e seus parceiros diretos, bem como mapear os principais benefícios trazidos por estas alianças e que influenciam no desempenho de inovação das Unidades analisadas. Para análise das alianças e portfólio de alianças, foram utilizados estudos, os quais serão identificados nos passos descritos abaixo.

Além destes estudos, utilizou-se o conceito de Knoke (2001) para definição de portfólio de alianças. Segundo o autor, ego-rede é uma rede formada por uma empresa focal e suas ligações diretas com seus parceiros (Ozcan \& 
Eisenhardt, 2009; Wassmer, 2010). Os passos adotados para caracterização do portfólio de alianças, estão descritos abaixo:

$1^{\circ}$ - Classificação das alianças/ligações estratégicas estabelecidas entre a empresa focal e seus parceiros diretos, voltados para a melhoria da capacidade de inovação: Para caracterizar os tipos de alianças, foi considerada a classificação proposta por Contractor \& Lorange (2002) cuja classificação leva em consideração acordos cooperativos. Os acordos cooperativos, considerados com base na classificação dos autores acima, foram adaptados levando em consideração as unidades de análise escolhidas neste estudo e seu setor de atuação. Assim, para identificação das alianças/ligações estratégicas foram selecionados os seguintes acordos cooperativos: Pesquisa e Desenvolvimento em conjunto; Desenvolvimento/Co-Produção, Licenciamento de know-how ou patentes; Acordo/Contrato de fornecimento de outros insumos/materiais; Acordo/Contrato de Prestação de Serviço.

$2^{\circ}$ - Avaliação das implicações para a estratégia de inovação advindas das características das relações interorganizacionais estabelecidas pela empresa focal e seus parceiros diretos, utilizando-se, para tanto, as seguintes análises:

Modalidade das Ligações: Grau de interdependência - Forte e Profunda ou Fraca e Ampla (Macedo-Soares, 2014). As ligações consideradas fortes e profundas, favorecem o compartilhamento, a confiança e o fluxo das informações e criam relações positivas. A confiança e o comprometimento entre os parceiros acabam se tornando uma condição vital para o sucesso da relação formada. Essas ligações, em geral, são formadas por meio de contratos formais de parceria. Os laços fortes e a governança relacional favorecem a ação colaborativa que minimiza as possibilidades de comportamento oportunista (Pellegrino, 2015). No entanto, podem restringir a diversidade e gerar um ciclo vicioso, sendo favoráveis para inovações incrementais.

As ligações consideradas fracas, favorecem a diversidade por meio de maior flexibilidade e são propícias às inovações radicais. Por outro lado, possuem baixa confiança, o que dificulta o fluxo contínuo de informações. Idealmente deve haver um equilíbrio entre laços fracos e fortes (Ulrich Wassmer 2010; Zaheer, Gözu“büyu"k, and Milanov 2010); 
Natureza das ligações: Ligações de exploração (Exploration) e de aproveitamento (Exploitation). Esses conceitos de March (1991), conforme já explicados no Capítulo 2 - Referencial Teórico, são aplicados com vistas a análise das ligações que podem favorecer as inovações incrementais e/ou radicais. As alianças consideradas de exploração (exploration) favorecem as inovações radicais, por meio da busca por novos parceiros e exploração de novas informações e novos conhecimentos dos parceiros já existentes, e por isso, permitem acesso a uma quantidade maior de informações distintas.

As alianças denominadas de aproveitamento (exploitation) visam aproveitar os conhecimentos e recursos já existentes nos parceiros e favorecem as inovações incrementais. Para a inovação, o ideal é um equilíbrio entre esses dois tipos de alianças (Zaheer, Gözu“büyük, and Milanov 2010;Yamakawa et al 2011; Haider \& Mariotti, 2016).

Tipos de Parceiros: Considera-se nesta pesquisa, cinco tipos de parceiros para identificação de quais parcerias as Unidades estabelecem, com vistas a alavancar seus desempenhos de inovação. Os tipos de parceiros analisados são: Entidades Governamentais; Fomentadores/Financiadores; Clientes; Concorrentes; Complementadores (Definidos na seção 2.3) (OECD \& Eurostat, 2018; Moreira, 2016; Leeuw et al., 2014; Nalebuff \& Brandenburger, 1997). Além disso, considera-se a análise quanto à diversidade geográfica destes parceiros, desde parcerias locais a parcerias regionais, nacionais e globais ( Macedo-Soares, 2014).

\section{$3^{0}$ - Propósito das Alianças e Benefícios advindos das parcerias:}

As empresas se envolvem em alianças para atingir determinados propósitos e/ou adquirir benefícios. O Quadro 5 descreve uma série de motivos pelos quais as empresas se envolvem em alianças estratégicas.

Quadro 5: Benefícios/Propósitos das alianças

\begin{tabular}{|l|l|}
\hline \multicolumn{1}{|c|}{ Benefícios/Propósitos das alianças } & Base Teórica \\
\hline $\begin{array}{l}\text { Desenvolver, comercializar novas tecnologias e obter } \\
\text { vantagens competitivas, a partir do acesso a novos } \\
\text { conhecimentos e informações. }\end{array}$ & Teec, 1998 \\
\hline $\begin{array}{l}\text { Conquista de benefícios mútuos advindos da resolução } \\
\text { conjunta de problemas. }\end{array}$ & Teece, 1998 \\
\hline Aprendizagem com parceiros. & Teece, 1998 \\
\hline $\begin{array}{l}\text { Aquisição ou acesso a recursos complementares/heterogêneos, } \\
\text { valiosos e faltosos. }\end{array}$ & Teece, 1998 \\
\hline
\end{tabular}




\begin{tabular}{|l|l|}
\hline Compartilhar custos e riscos associados à inovação. & $\begin{array}{l}\text { Yu et al., 2019; Liang \& Mei } \\
\text { 2019; (Mortara \& Minshall, } \\
2011)\end{array}$ \\
\hline Pela possibilidade de rápida inserção em novos mercados. & $\begin{array}{l}\text { Yu et al., 2019; Liang \& Mei } \\
\text { 2019 }\end{array}$ \\
\hline $\begin{array}{l}\text { Redução do ciclo de vida do produto, reduzindo o tempo entre } \\
\text { a invenção e a introdução no mercado. }\end{array}$ & $\begin{array}{l}\text { Martínez-noya \& Narula, } \\
2018 ; \text { Mortara \& Minshall, }\end{array}$ \\
\hline Aumento da Eficiência. & 2011 \\
\hline Acesso ao conhecimento científico ou tácito. & Martínez-noya \& Narula, 2018 \\
\hline Transferência de Tecnologia. & Martínez-noya \& Narula, 2018 \\
\hline Monitoramento de mudanças ambientais e oportunidades. & Martínez-noya \& Narula, 2018 \\
\hline
\end{tabular}

\subsection{3}

\section{Desempenho de Inovação}

Para o construto "Desempenho de Inovação", a definição adotada foi a de que a inovação se refere à capacidade da empresa em lançar e introduzir novos produtos, novas formas de produção, novas formas de organização, de desenvolver novas fontes de matérias-primas, insumos e novos mercados, que gerem impactos significativos para a própria empresa e/ou para o setor em que está inserida, e/ou para o país e/ou para o mundo (OECD, 2005).

A caracterização do desempenho de inovação se deu por meio da análise dos resultados de acordo com a categorização trazida pelo novo Sistema Embrapa de Gestão -SEG, implementado na Embrapa, a partir da adoção do Macroprocesso de Inovação em 2018. As novas categorias de resultados compreendem: Ativos PréTecnológicos; Ativos Tecnológicos; Apoio à Inovação. Cada categoria é composta por tipos de resultados, os quais são descritos na Figura 15:

Quadro 6: Categorias e Tipos de Resultados

\begin{tabular}{|c|c|c|c|}
\hline $\begin{array}{c}\text { Categorla de } \\
\text { Resultado }\end{array}$ & Ativos pré-tecnológicos & Ativos tecnológicos & Apolo à Inovaçáo \\
\hline \multirow{8}{*}{$\begin{array}{c}\text { Tipo } \\
\text { de } \\
\text { Resultado }\end{array}$} & Coleçáo biológica & Cultivar & $\begin{array}{l}\text { Apolo à formulaçáo ou à } \\
\text { execuçáo de politicas públicas }\end{array}$ \\
\hline & $\begin{array}{c}\text { Metodologla } \\
\text { técnico-científica }\end{array}$ & Raça ou grupo genético & Arranjos institucionals \\
\hline & $\begin{array}{c}\text { Banco de dados, } \\
\text { Informaçóes e análises }\end{array}$ & $\begin{array}{l}\text { Produto/Insumo } \\
\text { Agropecuário/Industrial }\end{array}$ & $\begin{array}{c}\text { Capacitaçáo e atualizaçáo tecnológica } \\
\text { de agentes multiplicadores }\end{array}$ \\
\hline & & Processo Industrial & $\begin{array}{l}\text { Capacitaçáo Interna } \\
\text { em áreas estratégicas }\end{array}$ \\
\hline & & Processo Agropecuário & $\begin{array}{l}\text { Estudo de avaliaçáo de } \\
\text { Impactos ou socioeconômicos }\end{array}$ \\
\hline & & Máquinas e implementos & Estudo prospectivo \\
\hline & & \multirow{2}{*}{$\begin{array}{l}\text { Software para } \\
\text { Clientes Externos }\end{array}$} & $\begin{array}{c}\text { Processo, metodologia ou estudo técnico } \\
\text { com fins organizacionais e gerenciais }\end{array}$ \\
\hline & & & $\begin{array}{l}\text { Software corporativo } \\
\text { ou especifico }\end{array}$ \\
\hline
\end{tabular}

Fonte: (Embrapa, 2018). 
As análises se referiram à percepção dos participantes quanto à quantidade dos resultados produzidos, levando em consideração as três categorias, bem como a percepção quanto à efetividade das inovações geradas pelas Unidades em termos de seus impactos econômicos, socioambientais, impactos na cadeia produtiva e no desenvolvimento institucional. Além destas, foram realizadas análises quanto ao grau de novidade tecnológica produzida, em termos dos resultados serem considerados pelos participantes como inovações incrementais e/ou radicais.

Assim, o framework foi elaborado relacionando os três construtos descritos acima e é apresentado na Figura 16. Por meio deste modelo teórico foi possível mapear os recursos internos considerados cruciais em contextos de inovação, o portfólio de alianças e o desempenho de inovação das três Unidades de análise deste estudo.

\section{O modelo proposto:}

Recursos Internos para inovação

P\&D interno

- Cultura

- TI como suporte à IO

- Governança e Alinhamento Estratégico

- Gerenciamento do Conhecimento

- Habilidades e Competências Individuais

Figura 15: Modelo Teórico
Alianças/Portfólios

Desempenho de Inovação
- Tipos de Alianças

- Modalidade

Ligações

- Natureza

Ligações

- Tipos de Parceiros

- Benefícios proporcionados

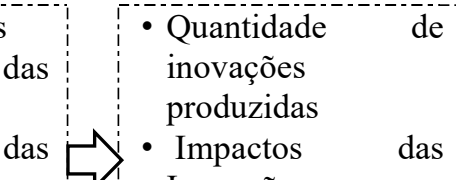

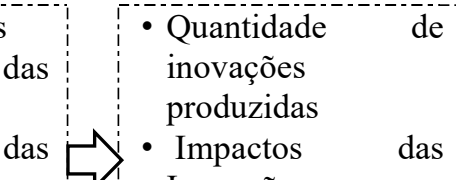

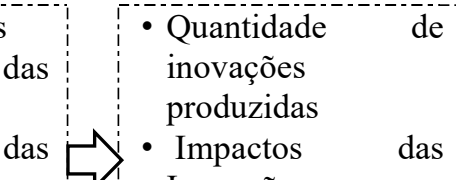

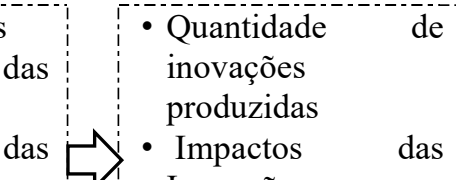

Inovações

i 


\section{3 \\ Metodologia de Pesquisa}

Este capítulo tem como objetivo apresentar os procedimentos metodológicos da pesquisa. Serão abordados a caracterização do estudo, incluindo o tipo de pesquisa e suas etapas, a escolha dos sujeitos, da Unidade de análise, as formas de coleta e tratamento de dados.

\section{1}

\section{Caracterização do Estudo}

O principal objetivo deste estudo, como explicado anteriormente, é compreender como as alianças/portfólios de alianças e os recursos, capacidades e características internas se combinam e interferem no desempenho de inovação de três Unidades descentralizadas da Embrapa - Empresa Brasileira de Pesquisa Agropecuária. Dentro desta finalidade, a abordagem qualitativa se apresenta como a mais apropriada, pois busca entender um fenômeno no seu contexto real e por meio da análise das experiências, percepções e outras contribuições de cunho qualitativo dos indivíduos inseridos nesse contexto (Remenyi et al., 2000).

A pesquisa qualitativa é adequada para situações em que o pesquisador não está interessado na quantificação dos dados, com sua representatividade puramente numérica, mas sua preocupação recai no aprofundamento dos conhecimentos sobre um determinado fenômeno, grupo social ou sobre uma organização e como se dão as complexas relações estabelecidas. A pesquisa qualitativa se vale de símbolos, crenças, aspirações, atitudes, em um universo amplo e profundo de análise dos fenômenos (Gerhardt \& Silveira, 2009).

A natureza exploratória do estudo possibilitou uma visão mais detalhada acerca dos principais recursos, capacidades, características e tipos de alianças consideradas críticas e que geram impacto no desempenho de inovação das 
Unidades. Além disso, a pesquisa de cunho exploratório permite obter uma maior familiaridade com o problema, possibilitando o esclarecimento e aprimoramento de idéias e conceitos relacionados ao fenômeno analisado (Gil, 2008 - pg. 46).

A estratégia de pesquisa adotada para responder a pergunta de pesquisa foi o estudo de caso, mais especificamente, estudos de casos múltiplos, já que as Unidades de análise escolhidas, são três das 43 Unidades descentralizadas da empresa, a saber: Embrapa Agrobiologia, Agroindústria de Alimentos e Solos.

Os estudos de casos são indicados para análises de fenômenos, cujas principais questões de pesquisa recaem sobre perguntas como "porquê"? ou “como?" (Yin, 2015 - pg. 31).

Segundo Remenyi et al. (2000 - pg.165),

...estudo de caso é definido como uma investigação empírica que analisa um fenômeno contemporâneo dentro do seu contexto real, quando as fronteiras entre o fenômeno e o contexto não são claramente evidentes e nas quais múltiplas fontes de evidências são usadas.

Para Yin (2015 - pg. 43) o estudo de múltiplos casos contribui também para um estudo mais convincente, pois este tipo de desenho permite contestar e contrastar as respostas obtidas de forma parcial com cada caso que se analisa. Deste modo, se as conclusões forem idênticas a partir de dois casos, elas incrementam a possibilidade de generalização analítica.

Embora as três Unidades escolhidas sejam pertencentes à mesma empresa, podem ser consideradas como casos únicos e distintos, uma vez que possuem temas e áreas de atuação bem distintas, estando sujeitas a estímulos externos diferentes, específicos dos seus campos de atuação. Nesse contexto, as Unidades precisam estabelecer estratégias específicas e estruturas internas robustas que possibilitem suas atuações de forma a responder de forma tempestiva às demandas de seus contextos de atuação.

Segundo os autores Yin (1994); Creswell (2010) no estudo de caso é importante o uso de múltiplas fontes de evidência. Assim, neste estudo, foram utilizadas múltiplas fontes de coleta de dados. Como fontes primárias foram utilizados: questionário, elaborado a partir da Revisão de Literatura e entrevistas com roteiro semi-estruturado, para o levantamento das percepções dos participantes da pesquisa, assim como Documentos Institucionais, tais como: Estatuto da Embrapa e Normas Institucionais. Como fontes secudárias foram utilizados: Relatórios de Gestão e Relatórios de Desempenho Institucional; Balanço Social e 
Plano Diretor da Embrapa. O uso de tais fontes propiciou uma triangulação que permitiu a convergência dos dados.

A temporalidade transversal adotada teve como objetivo fazer um recorte do objeto estudado, assim os dados foram coletados em um ponto específico no tempo (Creswell, 2010, p. 86) no período compreendido entre outubro de 2020 a janeiro de 2021 e corresponderam a análise da implementação formal pela Embrapa, do macroprocesso de inovação em 2018 e cuja adoção, ensejou a necessidade de análise dos recursos internos e tipos de alianças considerados críticos nesses contextos e que impactam no desempenho de inovação.

Nesse sentido, as Unidades fornecem dados ricos e profundos sobre a adoção deste novo macroprocesso e possibilitam estudos que possam contribuir para o refinamento e melhoria de sua implementação, execução e desenvolvimento, tendo em vista as áreas distintas de atuação e autonomia das Unidades.

Para a realização deste estudo de múltiplos casos, além do framework teórico construído, foi elaborado um Protocolo de Pesquisa, com a descrição das etapas seguidas em cada estudo único, com o intuito de uniformizar as fases e o registro das evidências, facilitando a comparação entre os três estudos realizados, bem como auxiliando na manutenção da confiabilidade e do máximo de imparcialidade durante todo o processo (Yin, 2015 - pg 73).

A construção do framework e do plano detalhado é importante também, pois permite a replicação por outros pesquisadores na realização de estudos de casos semelhantes, tendo em vista o design da pesquisa original (Remenyi et al., 2000).

Assim, tendo como referência o plano genérico de procedimentos utilizados em pesquisas qualitativas, descrito por Remenyi et al., (2000 - pg. 171) esta pesquisa segue a seguinte estrutura:

$1^{\text {a }}$ Fase: Definição do problema, a questão central do estudo. Delimitação da unidade de análise e dos casos do estudo, realização da revisão de literatura; proposição do framework teórico e pesquisa documental acerca da Embrapa e de suas três Unidades descentralizadas, selecionadas nesta pesquisa.

$2^{\mathrm{a}}$ Fase: Definição dos casos específicos escolhidos para este estudo, seleção e descrição dos sujeitos, Preparação e coleta de dados, descrição das principais fontes de dados documentais utilizadas, definição do roteiro de entrevistas, preparação do questionário e aplicação de ambos. 
$3^{\mathrm{a}}$ Fase: Análise inicial, tratamento e interpretação dos dados de cada Unidade de análise, com base nos aspectos identificados na literatura.

$4^{\text {a }}$ Etapa: Comparação dos dados analisados em cada Unidade, confrontação dos três estudos de caso e elaboração do relatório final da pesquisa, com as discussões, resultados alcançados e contribuições do estudo, considerando a limitação do método adotado.

Como a $1^{\text {a }}$ Etapa já foi discriminada nos capítulos anteriores, abaixo as fases 2, 3 e 4 serão melhor explicitadas.

\section{2}

\section{Fase 2: Unidade de Análise e Definição dos Casos}

Como já apresentado anteriormente, a pesquisa foi realizada na Empresa Brasileira de Pesquisa Agropecuária - Embrapa, empresa pública vinculada ao Ministério da Agricultura, Pecuária e Abastecimento - MAPA. A empresa foi escolhida, pois embora seja considerada a líder do setor agropecuário brasileiro, com fortes contribuições para o país, a empresa compreende a necessidade de melhorar sua capacidade de inovação, com o intuito de propor soluções de pesquisa cada vez mais inovadoras para a sustentabilidade da agricultura, frente aos desafios presentes e futuros, de modo a aumentar seus impactos e a geração de resultados que melhorem a vida da sociedade brasileira. A empresa é formada por sua sede, localizada em Brasília e por 43 Unidades descentralizadas, espalhadas por todo território nacional, onde ocorre, de fato, a pesquisa, desenvolvimento e inovação.

O ponto central desta pesquisa, portanto, é analisar como as redes de alianças e os recursos e capacidades internas afetam o desempenho de inovação de três, das 43 Unidades da Embrapa, a saber: Embrapa Agrobiologia, Embrapa Agroindústria de Alimentos e Embrapa Solos. As unidades foram selecionadas por conveniência, visto que todas estão localizadas no Estado do Rio de Janeiro - RJ, sendo uma delas, o local de trabalho da pesquisadora, além de representarem campo de estudo propício para investigação do problema de pesquisa proposto, visto que todas adotaram a inovação como estratégia, conforme preconizou a sede da empresa e com o intuito de aumentarem suas capacidades de inovação. 


\subsubsection{Seleção dos sujeitos}

A pesquisa qualitativa pressupõe a seleção intencional dos participantes, que dará ao pesquisador auxílio para compreender melhor o problema investigado (Creswell, 2010 -p. 212). Sendo assim, os sujeitos selecionados são Pesquisadores e Analistas, que participam de forma direta e indireta dos processos de tomada de decisão das Unidades e das atividades ligadas à inovação e inovação aberta.

Neste contexto e com a ajuda dos Chefes Gerais, foram selecionados previamente, um total de 55 profissionais, somando as indicações das três Unidades. Os profissionais escolhidos foram: Líderes de Projetos, Chefes das Unidades: Chefes Gerais, de Pesquisa e Desenvolvimento e de Transferência de Tecnologia; Membros dos setores de Transferência de Tecnologia, Comunicação e de Apoio à Pesquisa e Desenvolvimento, além de Pesquisadores envolvidos direta ou indiretamente com atividades de inovação aberta.

Dentre os 55 indicados, 39 aceitaram participar da pesquisa. Assim, a composição intencional da amostra, compreendeu 39 participantes, sendo divididos de acordo com a Tabela 1:

Tabela 1: Perfil Geral da amostra.

\begin{tabular}{l|l|l|l}
\multicolumn{2}{c|}{ Pesquisadores } & \multicolumn{2}{c}{ Analistas } \\
\hline Quantidade & $\begin{array}{l}\text { Tempo de } \\
\text { Empresa }\end{array}$ & Quantidade & $\begin{array}{l}\text { Tempo de } \\
\text { Empresa }\end{array}$ \\
\hline 9 & De 6 a 10 anos & 6 & De 6 a 10 anos \\
\hline 12 & De 11 a 20 anos & 1 & De 11 a 20 anos \\
\hline 10 & Mais de 20 anos & 1 & Mais de 20 anos \\
\hline Total & 31 pesquisadores & Total & 8 analistas
\end{tabular}

Nas tabelas 2, 3 e 4 constam os perfis dos respondentes divididos pelas Unidades.

Tabela 2: Perfil da amostra Embrapa Solos

\begin{tabular}{l|l|l|l}
\multicolumn{2}{c|}{ Pesquisadores } & \multicolumn{2}{c}{ Analistas } \\
\hline Quantidade & $\begin{array}{l}\text { Tempo de } \\
\text { Empresa }\end{array}$ & Quantidade & $\begin{array}{l}\text { Tempo de } \\
\text { Empresa }\end{array}$ \\
\hline 1 & De 6 a 10 anos & 5 & De 6 a 10 anos \\
\hline 6 & De 11 a 20 anos & 0 & De 11 a 20 anos \\
\hline 4 & Mais de 20 anos & 0 & Mais de 20 anos \\
\hline Total & $\mathbf{1 1}$ pesquisadores & Total & 5 analistas
\end{tabular}


Tabela 3: Perfil da amostra Embrapa Agroindústria de Alimentos

\begin{tabular}{l|l|l|l}
\multicolumn{2}{c|}{ Pesquisadores } & \multicolumn{2}{c}{ Analistas } \\
\hline Quantidade & $\begin{array}{l}\text { Tempo de } \\
\text { Empresa }\end{array}$ & $\begin{array}{l}\text { Qempo de } \\
\text { Empresa }\end{array}$ \\
\hline 4 & De 6 a 10 anos & 0 & De 6 a 10 anos \\
\hline 1 & De 11 a 20 anos & 1 & De 11 a 20 anos \\
\hline 4 & Mais de 20 anos & 1 & Mais de 20 anos \\
\hline Total & 9 pesquisadores & Total & 2 analistas
\end{tabular}

Tabela 4: Perfil da amostra da Embrapa Agrobiologia

\begin{tabular}{l|l|l|l}
\multicolumn{2}{c}{ Pesquisadores } & \multicolumn{2}{c}{ Analistas } \\
\hline Quantidade & $\begin{array}{l}\text { Tempo de } \\
\text { Empresa }\end{array}$ & Quantidade & $\begin{array}{l}\text { Tempo de } \\
\text { Empresa }\end{array}$ \\
\hline 4 & De 6 a 10 anos & 1 & De 6 a 10 anos \\
\hline 5 & De 11 a 20 anos & 0 & De 11 a 20 anos \\
\hline 2 & Mais de 20 anos & 0 & Mais de 20 anos \\
\hline Total & $\mathbf{1 1}$ pesquisadores & Total & $\mathbf{1}$ analista
\end{tabular}

De acordo com a Tabela 1, percebe-se que a amostra geral foi composta, de forma majoritária, por pesquisadores, o que correspondeu a 79\%, sendo a maioria destes com tempo de empresa compreendido entre 11 e 20 anos. Já a porcentagem de analistas, a maioria destes são da Embrapa Solos (conforme Tabela 2) e todos possuem tempo de empresa compreendido entre 6 e 10 anos. Conforme as Tabelas 2, 3 e 4, percebe-se que em nenhuma Unidade, o número de analistas foi maior que a de pesquisadores.

Os profissionais selecionados ocupam cargos em diferentes posições hierárquicas. A preocupação da seleção de cargos hierarquicamente distintos contribui para diminuição do viés da pesquisa (Yin, 2015).

Dentre os 39 participantes, todos responderam o questionário (Anexo 1), cujos quantitativos por Unidade, estão apresentados nas Tabelas 2, 3 e 4. Desses 39, um total de 20 foram também entrevistados, sendo 10 da Embrapa Solos; 6 da Embrapa Agroindústria de Alimentos e 4 da Embrapa Agrobiologia.

\section{2 .2}

\section{Coleta de Dados}

Os dados da pesquisa foram coletados em duas etapas: A primeira etapa correspondeu a uma survey, com a aplicação do questionário estruturado, elaborado de acordo com a Revisão de Literatura e com o framework, com o intuito de identificar a percepção dos participantes. 
A taxa de resposta obtida foi calculada a partir da fórmula para determinação do tamanho da amostra para variáveis de escala de intervalo em populações pequenas de Rea \& Parker, (2000).

$$
\text { Taxa de Respostas }=\frac{Z^{2}[p(1-p)] N}{Z^{2}[p(1-p)]+(N-1) C^{2}}
$$

Onde:

$\mathrm{C}=$ precisão ou erro máximo admissível em termos de proporções $=10 \%=0,1$

$Z_{-}=$transformada $Z$ para o nível de confiança desejado $=95 \%=1,96$;

$\mathrm{P}=$ proporção do universo $=50 \%=0,5$;

$\mathrm{N}=$ tamanho da população $=55$.

Aplicando-se a fórmula acima, com os parâmetros escolhidos, tem-se que o número mínimo de respostas ao questionário deveria ser de 35. Como foram obtidos um total de 39 questionários, o intervalo de confiança e o erro máximo desejados foram atingidos. As partes 1, 2 e 3 foram plenamente respondidas. Apenas três questionários, do total de 39, foram respondidos de forma parcial, no entanto, nenhum foi descartado. Em alguns itens, quando verificado erro na resposta, pela provável dificuldade de compreensão, estes foram confrontados com a resposta da entrevista para entender o real posicionamento do entrevistado. Nos casos em que tal confrontação não era possível, o item foi descartado.

Na segunda etapa, foi feito levantamento complementar com a realização de entrevistas individuais semi-estruturadas para aprofundar e validar as percepções apuradas nos questionários. Como os dados foram coletados por mais de uma fonte: por meio de questionários, entrevistas e documentos institucionais, a triangulação foi possível, visando a convergência dos dados e o reforço da validade do construto (Remenyi et al., 2000).

A seguir, os tipos de dados coletados: dados secundários, survey e as entrevistas em profundidade, são descritos com mais detalhes.

\subsubsection{1}

\section{Fontes de dados documentais}

Além da revisão de literatura para a obtenção dos fundamentos teóricos desta pesquisa, foi realizado em paralelo com as entrevistas e questionário, um 
levantamento de fontes de dados documentais para coleta de informações e dados referentes às Unidades analisadas, com o intuito de complementar as análises, bem como entender melhor as realidades das Unidades e suas áreas de atuação. Para tanto, dados de Relatórios Gerenciais da empresa, Relatórios do Governo, dados estatísticos sobre a empresa e do setor agropecuário no Brasil foram coletados.

As fontes documentais sobre a empresa e o setor agropecuário no Brasil, foram alcançadas essencialmente nos sites listados abaixo:

$\underline{\text { www.embrapa.br }}$ - Site oficial da Empresa Brasileira de Pesquisa Agropecuária

No site da Embrapa foi possível coletar algumas informações sobre sua história, missão, visão e seus valores, bem como alguns importantes resultados e contribuições da empresa para a agricultura brasileira. Sites das três Unidades descentralizadas da Embrapa, selecionadas como casos desta pesquisa. Nesses sites, foi possível obter informações quanto à área de atuação das Unidades, sua composição interna, bem como algumas notícias importantes referentes às suas atividades. Os endereços estão descritos abaixo:

https://www.embrapa.br/solos - Site oficial da Embrapa Solos;

https://www.embrapa.br/agrobiologia - Site oficial da Embrapa Agrobiologia;

https://www.embrapa.br/agroindustria-de-alimentos - Site oficial da Embrapa Agroindústria de Alimentos.

É importante ressaltar que algumas informações, foram obtidas também por meio da intranet da empresa, uma vez que o pesquisador, por ser empregado, tem acesso a essas informações.

\subsubsection{2}

\section{Levantamento de percepção tipo survey}

Um questionário predominantemente estruturado foi construído para captar as percepções dos profissionais da empresa. Uma parte das perguntas seguiu a Escala Likert, bem como escalas do Tipo Likert. Outras perguntas aplicaram o modelo VRIO, para coletar as informações de raridade, valor, de aproveitamento dos recursos pelas Unidades e de inimitabilidade, conforme detalhado no modelo teórico.

Os questionários foram divididos por blocos, conforme abaixo, os quais refletiram os construtos do framework: 
$1^{\text {a }}$ - Informações demográficas;

$2^{\mathrm{a}}$ - Recursos, capacidades e características internas críticas para alavancar o desempenho no que concerne à inovação;

$3^{\mathrm{a}}$ - Características e tipos de Alianças e portfólios de alianças para impulsionar o desempenho de inovação;

$4^{\mathrm{a}}$ - Desempenho de inovação das Unidades.

O questionário foi submetido primeiramente a um empregado da empresa, denominado como conselheiro deste estudo, para assegurar a coerência e pertinência do mesmo, levando em consideração o público. Após alguns ajustes, chegou-se à sua versão final. O mesmo foi elaborado no software Qualtrics, cujo link para acesso à pesquisa foi encaminhado via e-mail. O tempo médio de resposta, conforme o software, foi de 20 minutos. O questionário completo encontra-se no Anexo 1.

\subsubsection{3}

\section{Levantamento de percepções por meio de entrevistas}

Coerente com a metodologia de triangulação de dados, foi feito levantamento de percepções complementares, por meio de entrevistas individuais com alguns participantes. Um roteiro de entrevista foi elaborado e caracterizou-se como um direcionador para a coleta das informações necessárias, mantendo, no entanto, uma flexibilidade necessária para as pesquisas qualitativas.

Essa fase da pesquisa foi extremamente importante para verificar a consistência das respostas, validar informações coletadas no questionário, tirar dúvidas, aprofundar a compreensão acerca das percepções capturadas no primeiro levantamento, bem como detectar outros fatores que podem interferir na formação dos resultados.

As entrevistas foram realizadas por chamada de vídeo, tendo em vista a adoção, pela empresa, do regime de teletrabalho devido à pandemia da Covid $19 \mathrm{e}$ ocorreram entre os meses de outubro de 2020 a janeiro de 2021. Mediante autorização, as entrevistas foram gravadas e transcritas para facilitar as análises e tiveram, em média, a duração de 40 minutos. O roteiro encontra-se no Anexo 2. 


\section{3}

\section{Fase 3: Análise individual dos Casos e tratamento dos Dados}

Os dados coletados por meio dos questionários, foram tratados quantitativamente, por meio de análise dos percentuais das respostas, com o intuito de levantar a percepção dos participantes sobre os aspectos analisados, e em conformidade com a teoria, de modo a contribuir para a compreensão do problema. Quanto às entrevistas, essas foram transcritas e incluídas no software de análise qualitativa, MAXQDA.

A análise das entrevistas em profundidade foi realizada por meio da análise de conteúdo, técnica de análise de comunicações, que visa por meio de procedimentos sistemáticos, obter indicadores que permitam a inferência de conhecimentos (Gil, 2008 - pg. 152).

Primeiramente, criou-se uma tabela de categorias, definidas a priori, de acordo com a Revisão de Literatura (Elo \& Kyngäs, 2008). De posse das categorias, na segunda etapa, os dados foram codificados, por meio da identificação de trechos que se remetiam à uma mesma idéia (Gibbs, 2009 - pg. 60). Dessa forma, foi possível a análise dedutiva dos dados, uma vez que os trechos codificados foram ligados às categorias pré-estabelecidas, permitindo a análise empírica e aprofundada de tais categorias e seus contextos.

\section{4}

\section{Fase 4: Análise Comparativa dos Casos}

Quanto às análises dos estudos de casos múltiplos, em um primeiro momento, as análises foram feitas caso a caso, ou seja, de forma separada (withincase analysis), respeitando as particularidades de cada estudo de caso único . Em um segundo momento, os dados foram comparados (cross-case analysis), buscando diferenças e similaridades entre eles, com o intuito de aprofundar o entendimento e explicações para o fenômeno pesquisado. Em relação a este estudo, a análise conjunta dos casos teve como objetivo analisar a atuação dos recursos e alianças para impulsionar o desempenho de inovação das Unidades (Yin, 2015).

A partir da análise comparativa, foi realizada a confrontação dos resultados com a Teoria (pattern matching analysis) com o intuito de verificar se os casos 
analisados possuem os mesmos padrões daqueles encontrados na Teoria (Eisenhardt, 1989).

\section{5}

\section{Avaliação do Rigor da Pesquisa}

Assim como qualquer pesquisa social empírica, os estudos de caso precisam ter qualidade e rigor. Para tanto, são comumente utilizados critérios de avaliação da pesquisa qualitativa. De acordo com Yin, (2015 - pg. 46) os critérios são: validade do construto, validade externa e confiabilidade.

A validade do construto é alcançada por meio de uma extensão e robusta Revisão da Literatura para identificação de idéias e conceitos que serão estudados, bem como por meio do uso de múltiplas fontes de evidências (Remenyi et al., 2000, pg. 179; Yin, 2015, pg. 47). No caso deste estudo, a validade do construto foi atingida por meio da aplicação de questionários, entrevistas e pelo uso de fontes documentais.

A validade externa do estudo, trata das descobertas do estudo de caso e de sua generalização analítica, ou seja, até que ponto as lições descobertas e aprendidas podem ser replicadas para outros contextos (Yin, 2015 - pg. 51). Neste estudo, buscou-se, por meio dos questionários e das entrevistas obter o máximo de informações empíricas sobre como os fatores e os dados coletados na Revisão de Literatura ocorrem dentro dos casos analisados, ou seja, dentro de seus contextos, de modo a darem subsídios para suas aplicações em outros contextos ou para servirem de base para reinterpretações de casos já finalizados.

A confiabilidade, por sua vez, visa garantir que outros pesquisadores possam conduzir um mesmo estudo de caso, seguindo os procedimentos descritos nesta pesquisa (Yin, 2013). A confiabilidade deste estudo, portanto, foi atingida por meio da criação de um plano genérico de procedimentos que discriminou as fases desta pesquisa, bem como pelo modelo teórico construído a partir da Revisão de Literatura, que embasou a coleta dos dados. 


\section{Resultados}

\section{1 \\ Estudos de Caso}

Neste capítulo são apresentadas as análises fruto da aplicação, nas três Unidades, do framework criado, que se deu por meio da aplicação do questionário e da realização das entrevistas, que possibilitaram o mapeamento dos recursos e capacidades internas e dos tipos de alianças que impactam no desempenho de inovação destas Unidades.

Os resultados serão apresentados primeiramente de forma separada por Unidade: Embrapa Solos, em seguida os resultados da Embrapa Agroindústria de Alimentos, e por fim, os dados referentes à Embrapa Agrobiologia. Além da análise descritiva dos dados de forma separada, esse capítulo apresentará a análise conjunta dos casos e a discussão dos resultados.

\section{2 \\ Embrapa Solos - CNPS}

O Centro Nacional de Pesquisa de Solos - CNPS, é um centro temático da Embrapa e referência internacional em solos tropicais. A Unidade com atuação em todo território nacional, coordena e executa ações no sentido de prognosticar e promover medidas preventivas de riscos ambientais em decorrência do uso inadequado dos recursos solo e água.

Criado em 1975, o Centro recebeu inicialmente o nome de Serviço Nacional de levantamento e Conservação de Solos - SNLCS e deu continuidade ao trabalho de reconhecimento dos solos, executado desde 1947, pela Divisão de Pedologia e Fertilidade do Solo, vinculada ao então Departamento Nacional de Pesquisa Agropecuária (DNPEA), extinto com a criação da Embrapa (Embrapa, 2020). 
Em 1993, o SNLCS passa a ter a denominação atual de Centro Nacional de Pesquisa de Solos - CNPS, Embrapa Solos. A nova denominação deu um enfoque institucional ao Centro e ao objetivo da empresa de associar sua marca a diferentes temas, produtos, serviços e biomas.

A partir de então, a Unidade ampliou e diversificou suas linhas de pesquisa, englobando pesquisas em áreas como: recuperação de áreas degradadas, análise de água e plantas, matéria orgânica, sequestro de carborno, plantio direto, irrigação, agricultura de precisão, fertilizante e fertilidade do solo.

Hoje, além de todas essas linhas de pesquisa e atuação, as ações da Unidade estão concentradas também, e de forma central, na visão do solo como patrimônio para gerações futuras, assim seu foco está na priorização do planejamento do uso sustentável das terras, fornecendo subsídios para tomada de decisões e contribuindo para o avanço do conhecimento técnico-científico na área de Ciência do Solo como um todo. Por meio de suas ações de Pesquisa e Desenvolvimento, a Unidade busca encontrar soluções para grandes problemas nacionais, como: planejamento do uso da terra, recuperação de solos degradados/contaminados, zoneamentos agropedoclimáticos e tecnologias de uso sustentável dos recursos solo e água em sistemas produtivos. Além da responsabilidade de organização e disponibilização de dados e de conhecimentos sobre os solos tropicais.

A sede da Unidade está situada no Bairro Jardim Botânico, na cidade do Rio de Janeiro - RJ. Além dessa sede, a Unidade conta com uma Unidade de Execução de Pesquisa e Desenvolvimento - UEP, localizada na cidade de Recife/PE. A UEP atende, no contexto da região Nordeste, às demandas regionais de pesquisa, desenvolvimento, inovação e transferência de tecnologia que envolvem o tema solo e água, englobando levantamentos de solos e suas aplicações, zoneamentos e planejamento territorial, além de arranjos institucionais que promovam o uso e manejo apropriados do solo e a conservação da água e da biodiversidade.

A Unidade conta hoje com o quadro de 148 empregados, dos quais 63 são pesquisadores, 45 analistas, 17 assistentes e 21 técnicos.

Em 2019, devido à ocorrência do Plano de Desligamento Incentivado, 21 empregados desligaram-se da Embrapa Solos, ao mesmo tempo em que novas competências passaram a integrar o quadro de empregados da Unidade por meio de transferências e remoções de outras Unidades da Embrapa. 
Em seu quadro de empregados, a Unidade conta com especialistas nas áreas de agronomia, pedologia e zoneamentos agrícolas, fertilidade do solo e fertilizantes, planejamento do uso e ocupação das terras, hidrologia e recursos hídricos, uso, manejo e conservação do solo e da água, mudanças de clima, automação e agricultura de precisão, serviços ambientais e ecossistêmicos, políticas públicas e socioeconomia (Embrapa, 2020).

Para a realização e organização das suas atividades de pesquisa e inovação, cinco grandes núcleos, denominados Núcleos Temáticos foram estruturados na Unidade, os quais representam suas principais linhas de pesquisa, a saber: Pedologia e Zoneamento, Uso da Terra e Serviços Ambientais, Fertilizantes e Insumos para a Agricultura Tropical, Intensificação Sustentável na Agricultura e Convivência Produtiva com a Seca.

Com relação à infraestrutura, a Embrapa Solos conta hoje com 22 laboratórios nas áreas de geoprocessamento para a agricultura digital, tecnologias em fertilizantes e novos insumos para solos tropicais e pedologia aplicada. Além dos laboratórios, há uma infraestrutura tecnológica, com recursos de Tecnologia da Informação (TI) que também apoiam as atividades de pesquisa, desenvolvimento e inovação.

\subsection{1 \\ Descrição dos dados da Embrapa Solos de acordo com os construtos apresentados no modelo teórico.}

\subsubsection{1}

Recursos, capacidades e características internas.

O primeiro aspecto analisado, foi a Pesquisa e Desenvolvimento - P\&D. A análise desse fator, se deu pelo levantamento de cinco atributos relacionados à P\&D, considerados, pela literatura, essenciais para a melhoria da capacidade inovativa das empresas.

O $1^{\circ}$ atributo analisado foi: Quantidade de Recursos Humanos envolvidos em P\&D.

Com relação a este aspecto, conforme mostra a Figura 16, a grande maioria dos respondentes, correspondente a $87 \%$, considera o atributo uma força para a Embrapa Solos. No entanto, quanto à implicância estratégica, a visão dos participantes se mostrou bastante heterogênea. Destes $87 \%, 40 \%$ acreditam que o 
atributo permite a obtenção de uma paridade competitiva à Embrapa Solos em relação a seus pares. Isso porque, na visão dos entrevistados, embora o recurso gere valor, ou seja, possibilita que ela neutralize ameaças e aproveite as oportunidades advindas do ambiente externo, tal atributo não é considerado raro e difícil de imitar. Sendo assim, rapidamente outras empresas terão condições de copiá-lo e poderão obter a mesma vantagem. Para $27 \%$ da amostra, o atributo é considerado uma fonte de vantagem competitiva temporária, uma vez que além desta parcela considerar o atributo como valioso, também o considera como raro, embora de fácil imitação, o que lhe confere uma vantagem competitiva apenas por um determinado período. Já para $20 \%$ o atributo é visto como valioso, raro, difícil de imitar e organizacional, permitindo a obtenção de uma vantagem sustentável.

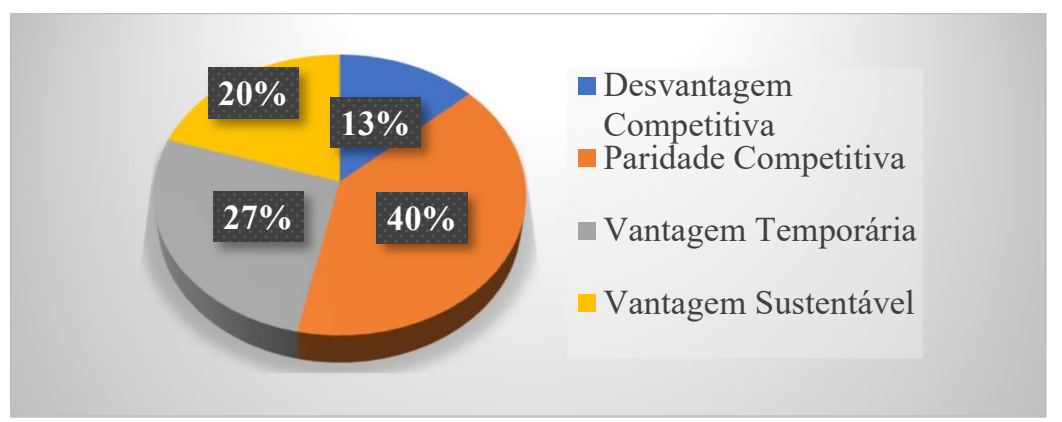

Figura 16: Quantidade de Recursos Humanos envolvidos em P\&D no CNPS

Segundo o Entrevistado (E4):

$E$, o ponto forte da P\&D na Embrapa Solos, em termos quantitativos e qualitativos também, é a equipe, porque nós temos um número de pesquisadores e pesquisadoras, e que são complementados agora com a carreira de analistas $A$, que eles têm mestrado e doutorado, um número assim bem elevado quando você compara com as outras unidades. Nós temos mais de 50 pesquisadores e pesquisadoras que atuam numa unidade temática.

Com relação ao $2^{\circ}$ atributo de P\&D: "Qualidade dos Recursos Humanos envolvidos em P\&D - Capacidade técnica em áreas estratégicas", a maioria dos respondentes acredita que o atributo representa uma força para a Embrapa Solos. 


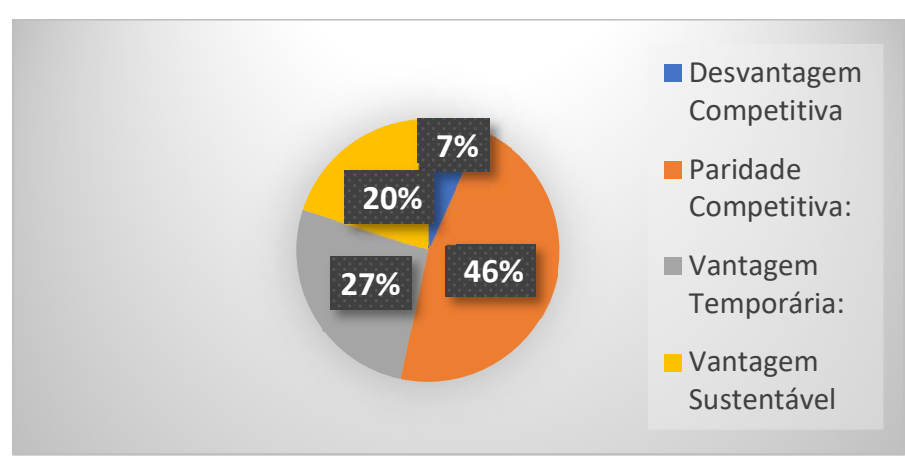

Figura 17: Qualidade Técnica de RH do CNPS

Conforme mostra a Figura 17, 93\% dos respondentes concordam que este atributo representa uma força, no entanto, também diferem no aspecto da implicância estratégica que tal atributo traz para a Unidade. Para $46 \%$ dos respondentes, o atributo é considerado como valioso e aproveitado pela Unidade, no entanto, esta parcela não acredita que tal atributo seja raro e nem tão pouco inimitável, o que confere à Embrapa Solos, uma paridade competitiva.

Alguns entrevistados deixam clara a força que a qualidade técnica dos Recursos Humanos tem para a Unidade.

Para o Entrevistado E (6) “... a equipe da Embrapa Solos é referência”. Para o Entrevistado E14 “...o grande diferencial da Embrapa Solos é a expertise da equipe técnica, nós temos uma equipe técnica extremamente qualificada, renomada nacional e internacionalmente...".

De fato, de acordo com o Relatório de Gestão da Unidade (Embrapa, 2020), a equipe técnica da Embrapa Solos é vista como extremamente qualificada, dos seus 148 empregados, 30 possuem mestrado e 45 possuem doutorado.

No que diz respeito ao $3^{\circ}$ atributo: "Qualidade dos Recursos Humanos envolvidos em $\mathrm{P} \& \mathrm{D}$, no que diz respeito à capacidade inovativa", 53\% dos participantes concordam que esta capacidade é insatisfatória, e portanto, pode ser considerada como uma fraqueza para a Unidade e uma desvantagem competitiva. Os participantes que defendem essa posição, acreditam que ainda há uma baixa produção de resultados produzidos pela Unidade que geram impactos na sociedade, e que dada a capacidade técnica dos recursos humanos, tais resultados poderiam ser mais expressivos. Dentre os argumentos constantes nas falas dos entrevistados para tal cenário, estão questões relacionadas à excesso de burocracia; mentalidade acadêmica dos pesquisadores; estabilidade, medo da inovação e falta de visão.

Algumas falas exemplificam esses posicionamentos. 
Então eu vejo que a gente tem muitos pesquisadores voltados ali pra uma ciência mais básica e muito pouco preocupados com a transformação desse conhecimento científico em um ativo tecnológico, em algo que possa ser adotado pela sociedade, pelo mercado e pelos produtores rurais. (Entrevistado E1).

$\mathrm{Na}$ visão de outros entrevistados, a maioria dos empregados envolvidos em P\&D não quer trabalhar com inovação ou não entende ainda os novos paradigmas da inovação, conforme pode ser observado pelos trechos a seguir:

“(...) não tem o menor interesse em trabalhar com inovação, porque quer continuar na estabilidade que está (...) porque a inovação, significa perigo (Entrevistado E9).

(...) Então, o modo de pensar a pesquisa e de pensar soluções de inovação, ele tem que ser muito mais ágil, no meu ponto de vista, e deixar aquela cultura, aquele modo de fazer pesquisa. (...) porque não é só fazer a pesquisa para publicar, não. Hoje você tem que atender as politicas públicas, você tem que atender o setor produtivo. Então essa agilidade e esse espirito colaborativo, é que eu acho que ele precisa ser melhorado dentro da empresa (Entrevistado E8).

Com relação ao atributo: "Infraestrutura física, de TI e insumos para realização especificamente da $\mathrm{P} \& \mathrm{D}$ ”, o resultado mostrou uma divisão entre as respostas. Metade dos entrevistados, ou seja, 50\% considera o atributo uma fraqueza e uma desvantagem competitiva para a Unidade e os outros 50\% consideram o atributo uma força e fonte de paridade competitiva. Com relação ao atributo "Suporte à inovação (ADM, TT e negócios), a maioria, correspondente a $56 \%$, consideram este atributo uma força e fonte de paridade competitiva.

Dentre os entrevistados que enxergam ambos os atributos como uma fraqueza, as queixas recaem sobre questões voltadas, por exemplo, sobre a falta de uma infraestrutura adequada que dê subsídios para a realização da pesquisa e da inovação, falta de TI apropriado que abarque as atividades de P\&D de forma mais eficiente, falta de apoio, no que tange aos Recursos Humanos que forneça suporte ao pesquisador em questões burocráticas.

\section{O Entrevistado (E3) afirma que}

(...) nosso grande gargalo é a falta de apoio administrativo. (...) Então, mas o que acontece é isso, não é só a minha opinião, mas assim, quase unânime dos pesquisadores, a gente acaba tendo que fazer tudo, desde tirar xerox até colocar a carteira de identidade do estagiário, do candidato à estagiário Pibic. Então assim, quando você abre uma vaga de Pibic, só um exemplo, você tem que gerar um projeto de pesquisa, você tem que entrevistar um bom aluno, você tem que ter contatos e etc., esse é o seu trabalho enquanto pesquisador. Agora não, nós, então, selecionamos dois a três candidatos, é uma quantidade enorme de documentos que é exigido pelo CNPq, isso não é nem nosso, mas isso, assim, pra mim, é um exemplo principal. 


\section{O Entrevistado (E8) afirma que}

Eu acho que, ao mesmo tempo que a gente tem esse potencial de captar parceiros ou de articular parceiros pelo nosso nome e pela nossa atuação, a gente tem entraves burocráticos. Eu acho assim, esse, hoje, é um dos entraves pra mim não só de inovação, mas pra realização de pesquisa no âmbito aí de um futuro de escassez de recursos, e de atuação colaborativa.

Ainda para o Entrevistado (E2):

Então, eu acho que tudo isso realmente tá faltando no ambiente interno. Outra coisa, eu percebo que muito da inovação, que a gente pode produzir ou uma finalização dos nossos processos, ela depende muito de um aporte de TI e a nossa TI tem muito pouca gente e por ter pouca gente não consegue se capacitar pra apoiar dentro daquilo que a gente precisaria, que tem muita coisa boa que acaba finalizando numa determinada etapa do processo de desenvolvimento ai da tecnologia, porque, na verdade, se tivesse um aporte de TI ia dar uma deslanchada.

No entanto, para aqueles que percebem tais atributos dentro de uma perspectiva favorável, os argumentos perpassam por questões sobre a existência de uma boa infraestrutura, principalmente insumos e recursos financeiros para a realização da pesquisa.

\section{Segundo o Entrevistado (E4):}

"Ah, o que não nos falta é insumo. O insumo físico mesmo, nunca faltou dinheiro na unidade pra realizar inovação, sinceramente, a gente capta bem e tudo. E o nosso tema, ele é incrivel pra inovação, porque nós somos transversais".

Quanto ao apoio para a realização da pesquisa e da inovação, o Entrevistado (E1) coloca:

mas como um avanço dessa mentalidade mais pesquisa básica em direção à uma pesquisa mais mercadológica, é a aproximação, também inevitável, entre as áreas de $P \& D$ e TT, em parte pelo processo de qualificação tecnológica. (...) "Então acho que essa aproximação tem acontecido". (...) "Então hoje essas coisas tão muito alinhadas em prol do desenvolvimento tecnológico, em prol de fazer esse macroprocesso da inovação acontecer, da gente começar com a pesquisa mais básica entre áreas menores e fazer isso avançar.

No entanto, de acordo com os trechos acima, quanto à Infraestrutura interna para abarcar as atividades de P\&D e de inovação, as queixas foram maiores, portanto este recurso foi definido como uma fraqueza pela grande maioria dos entrevistados. De maneira resumida, o fator Pesquisa e Desenvolvimento - P\&D, analisado por meio dos cinco atributos descritos, foi definido da seguinte forma: 
Quadro 7: Análise VRIO dos atributos de P\&D do CNPS

\begin{tabular}{|l|l|l|}
\hline \multicolumn{1}{|c|}{ Atributo } & \multicolumn{1}{|c|}{$\begin{array}{c}\text { Força/ } \\
\text { Fraqueza }\end{array}$} & \multicolumn{1}{|c|}{ Implicância Estratégica } \\
\hline Quantidade de Recursos Humanos envolvidos em P\&D & Força & Paridade Competitiva \\
\hline Qualidade Técnica de Recursos Humanos de P\&D & Força & Paridade Competitiva \\
\hline Qualidade Inovadora de Recursos Humanos de P\&D & Fraqueza & Desvantagem Competitiva \\
\hline Infraestrutura Física, de TI e insumos para P\&D & Fraqueza & Desvantagem Competitiva \\
\hline Suporte à Inovação (ADM, TT e Negócios) & Força & Paridade Competitiva \\
\hline
\end{tabular}

Pela análise do Quadro 7, percebe-se que de maneira geral e para a maioria dos participantes, o fator P\&D na Embrapa Solos possui mais atributos considerados forças do que fraquezas. Somente a capacidade inovativa dos Recursos Humanos e a Infraestrutura física, de TI e insumos, são vistos como desfavoráveis.

O segundo aspecto do construto analisado foi a "Cultura voltada para inovação aberta". De acordo com a análise VRIO, este fator é visto como uma fraqueza e uma desvantagem competitiva para a Embrapa Solos, segundo 81\% dos participantes da pesquisa, conforme Figura 18.

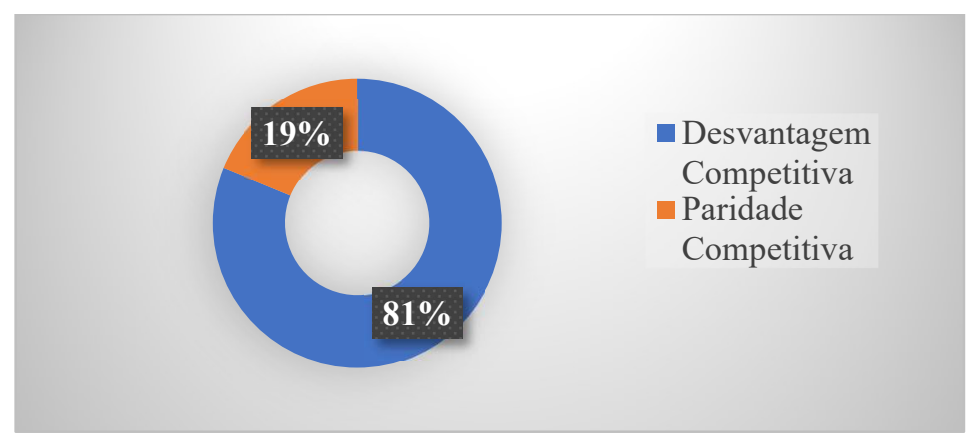

Figura 18: Cultura voltada para Inovação Aberta no CNPS

De fato, os argumentos colocados pelos entrevistados refletem a percepção quanto à falta de uma cultura voltada para a inovação. Segundo a grande maioria, a Unidade e a Embrapa como um todo, estão em um processo de implementação da cultura de inovação, que ainda requer um longo caminho.

Para ratificar a posição dos participantes sobre este fator, além da análise VRIO, alguns aspectos referentes à cultura organizacional, específicos em contextos de inovação, foram analisados, por meio de uma escala likert de cinco pontos, que apresenta um continuum variando de 1 (discordo totalmente) até 5 (concordo totalmente). Os resultados são sintetizados na Figura 19, cuja legenda representa DT (Discordo Totalmente); DP (Discordo Parcialmente); N (Neutralidade); CP (Concordo Parcialmente) e CT (Concordo Totalmente).

A Figura 19, portanto, mostra o nível de concordância e discordância dos respondentes quanto a cinco afirmações que apresentam aspectos cruciais referentes 
à cultura de inovação. Por meio da análise de concordância x discordância, é possível verificar o grau de familiaridade dos participantes com aspectos que fazem parte da cultura de inovação e o quanto desta cultura está internalizada na Unidade.

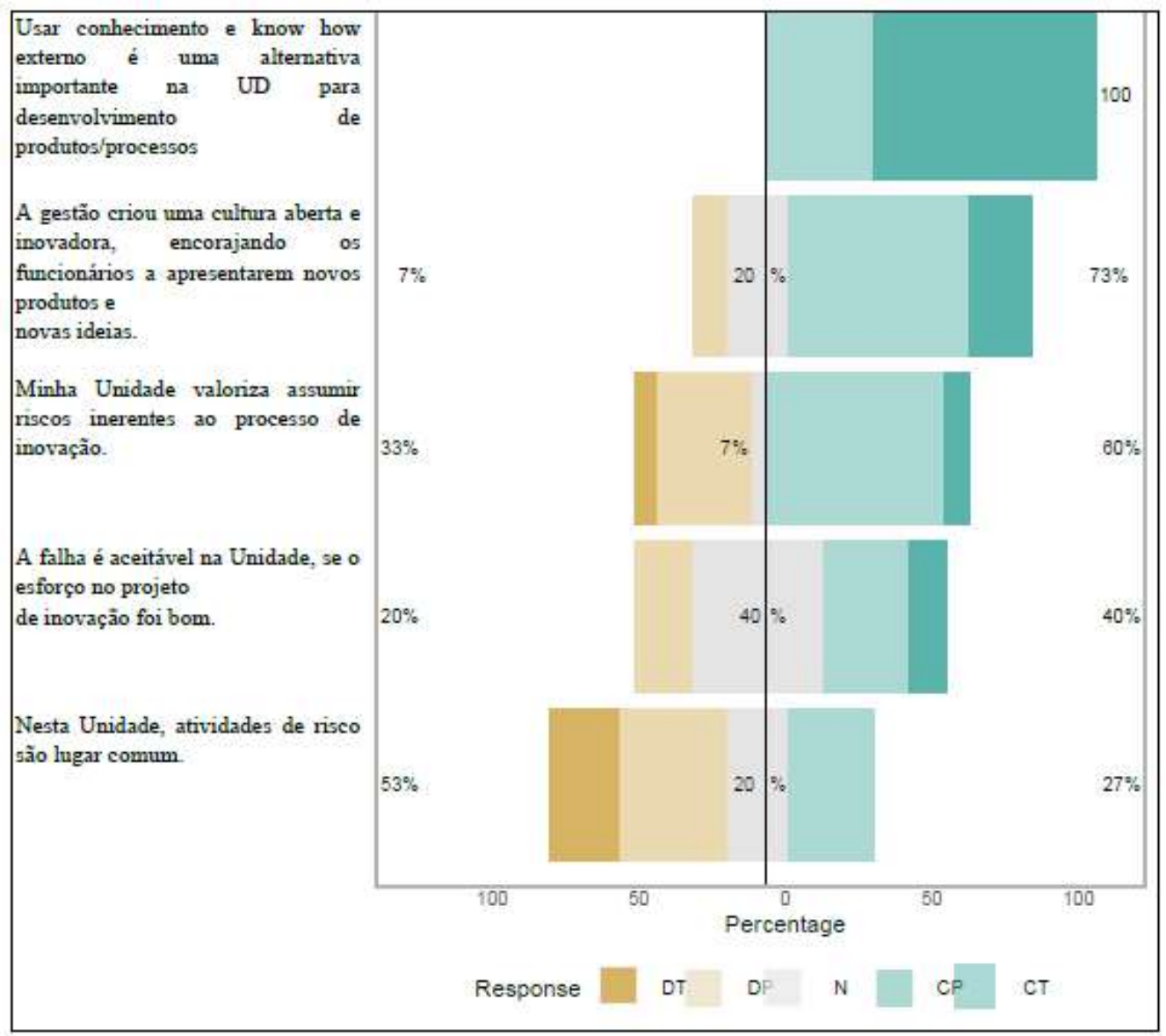

Figura 19: Gráfico de Concordância sobre aspectos culturais no CNPS

Pela análise da Figura 19, portanto, pode-se verificar que a última afirmativa descrita, representa a que os respondentes mais discordam, que corresponde à parcela de 53\%, divididos entre os que "Discordam Totalmente" e a maior parcela que "Discorda Parcialmente" com a seguinte afirmativa: "Nesta Unidade, atividades de risco são lugar comum".

Já a primeira afirmativa da Figura 19, corresponde àquela com maior concordância entre os participantes, variando as respostas entre "concordo parcialmente" e à grande parcela que "concorda totalmente" com o uso de conhecimento e know how externo, como alternativa importante para desenvolvimento de produtos/processos e serviços.

Em relação à quarta afirmativa, referente à aceitação de falhas quando há um esforço considerável durante a execução do projeto de inovação, grande parcela, 
correspondente à $40 \%$ da amostra, se mostrou neutra. Outra parcela concordou, ainda que parcialmente ou totalmente com essa afirmação.

De maneira geral, a maioria dos participantes mais concorda, seja de forma parcial ou total com as afirmativas da Figura 19, o que demonstra que para a maioria dos respondentes, a Unidade possui tais aspectos considerados importantes em contextos de inovação, mesmo que de forma parcial ou total.

No entanto, pelas entrevistas os participantes deixaram claro que a Embrapa como um todo e a Unidade, ainda estão em processo de adequação a esse novo paradigma e se adaptando aos conceitos e à cultura de inovação. No que tange a adequação em nível organizacional, o Entrevistado (E1) afirma:

Eu acho que a Embrapa, hoje, ela está numa espécie de encruzilhada, em que ela se pensa parte como universidade, ainda tem uma lógica assim meio autarquia, meio universidade, e parte como empresa, né, que são os negócios, ativos tecnológicos. Então acho que a Embrapa, hoje, vive esse dilema. E acho que na Embrapa Solos... isso acontece na Embrapa em geral, mas na Embrapa Solos, de maneira particular também.

\section{O Entrevistado (E6) complementa:}

Agora, o fato desse processo tá gerando resultado é um outro ponto. O formato pra centros de pesquisa como o nosso, que é um centro temático, em que a gente tem como principal ativo desse centro, a geração de conhecimento e banco de dados e o fato da empresa não saber lidar com esse tipo de resultado, não é um problema só do pesquisador, ainda é um problema da cultura organizacional, é um problema de você entender como você negocia esse ativo. Poucas unidades, eu posso te dizer praticamente nenhuma unidade ainda sabe fazer negócio com dados(...) a empresa como um todo ainda não tem um modelo de negócio pra dados. E isso gera uma grande insegurança porque antigamente dados $e$ informação era poder, hoje ele é negócio. Então... e a gente não mudou essa cultura ainda. Então, pra um centro como o nosso, é muito complexo a gente fazer isso, sendo que você não tem respaldo nenhum da alta gestão. (...) Então assim, a gente ainda passa por um momento de transição. E assim, não é só cultura de inovação da empresa, é a forma de fazer negócios com a inovação da empresa que ainda é imatura.

Já no nível individual, o Entrevistado (E5) coloca:

você tem um grupo olhando pra fora com uma visão mais aberta, mas você ainda tem muita gente num estado reativo, sabe? Com alguma aversão a essa introdução, e até acho que isso é normal, porque você tem um quadro de pessoas com, sei lá, 30 anos que estão al na Embrapa, estão acostumados a fazer do mesmo jeito e já tem gente nova que já começou outro processo de trabalho.

O terceiro fator do construto analisado se refere à "Tecnologia da Informação (TI) como suporte à inovação aberta". A Tabela 5 mostra o resultado deste aspecto com relação à análise VRIO. 
Tabela 5: Resultado da análise VRIO do recurso Tecnologia da Informação do CNPS

\begin{tabular}{l|l|l}
\multicolumn{3}{c}{ Tecnologia da Informação como suporte à inovação aberta } \\
\hline Porcentagem & Implicância Estratégica & Força/Fraqueza \\
\hline $19 \%$ & Paridade Competitiva & Força \\
\hline $0 \%$ & Vantagem Temporária & Força \\
\hline $6 \%$ & Vantagem Sustentável & Força \\
\hline $\mathbf{7 5 \%}$ & Desvantagem Competitiva & Fraqueza
\end{tabular}

Pelos resultados descritos na Tabela 5, a maioria dos participantes percebe o recurso como uma fraqueza para a Unidade, e portanto, uma desvantagem competitiva. Os participantes também foram questionados sobre a existência na Unidade de alguns aspectos específicos relativos à TI, cujas respostas obtidas, constam nos Figuras 20, 21 e 22:

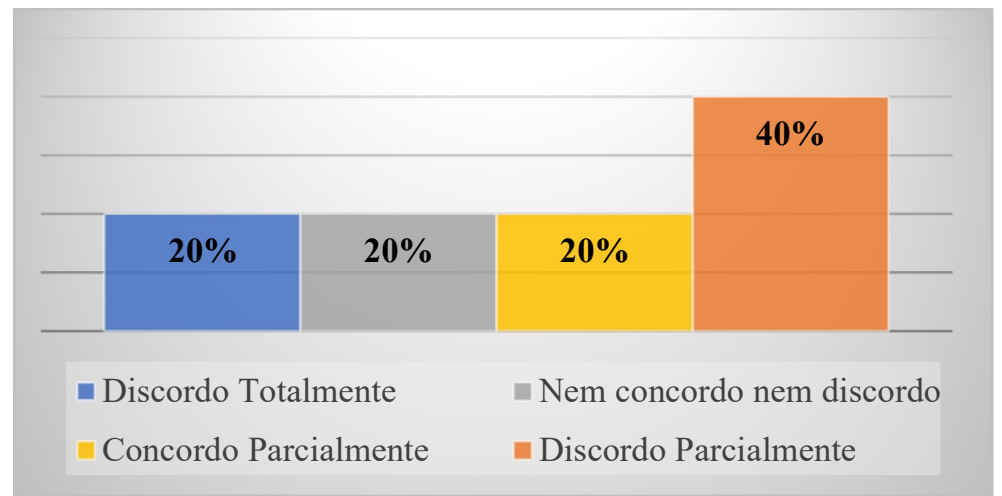

Figura 20: Sistemas de TI para inovação aberta no CNPS

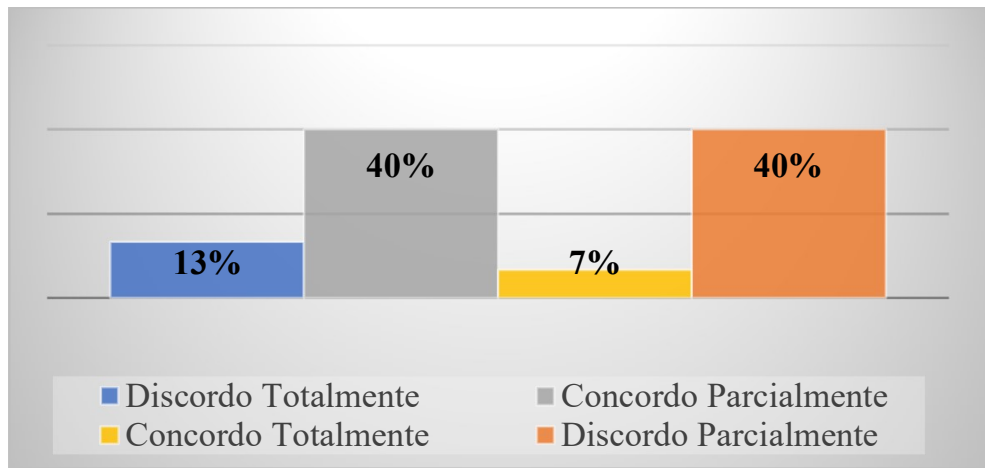

Figura 21: Sistemas de TI no CNPS: acesso a dados de colaboradores de inovação

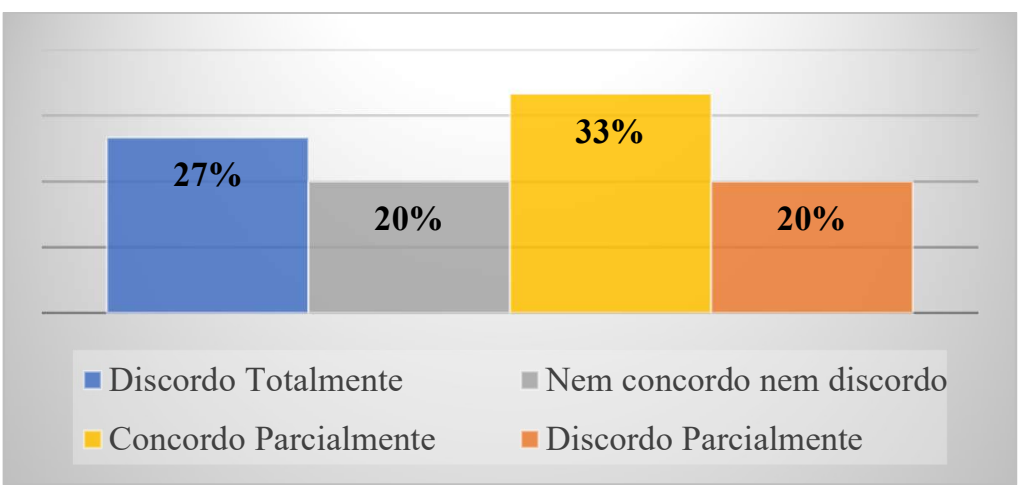

Figura 22: TI como repositório de memória organizacional no CNPS 
Com relação às Figuras 20 e 21, as respostas se mostraram bastante diversificadas entre os respondentes. Na Figura 20, 40\% dos respondentes, afirmam discordarem parcialmente da afirmação quanto à existência de sistemas de TI que dêem suporte às atividades de inovação aberta, tais como: Técnicas de varredura ambiental, plataformas de pesquisa e ferramentas de mineração de dados. Com relação à Figura 21, que corresponde ao aspecto específico "Sistemas de TI para acesso a dados e troca de informações com colaboradores da inovação", que se refere à existência de Plataformas de colaboração e comunicação, bem como ferramentas de conferência online, a amostra também se mostrou bastante heterogênea, $40 \%$ dos respondentes afirmam discordar parcialmente, enquanto outros $40 \%$ afirmam concordar parcialmente.

A Figura 22 também mostra posições bastante diversificadas com relação à existência ou não de sistemas de TI que funcionem como repositório de conhecimentos e memória organizacional, com o maior percentual, igual a 33\% que concorda parcialmente com a existência desses sistemas. No entanto, com exceção deste percentual, a maioria das respostas varia entre discordo parcialmente e discordo totalmente. Tais visões desfavoráveis vão ao encontro da análise VRIO realizada, cujo maior percentual avaliou a Tecnologia da Informação como uma fraqueza para a Unidade. Dessa forma, pode-se afirmar que a Unidade não possui um sistema de TI apropriado para abarcar de forma satisfatória as atividades de inovação aberta.

O quarto fator diz respeito à "Governança e Alinhamento Estratégico". Este fator foi analisado, por meio de quatro atributos, avaliados pela análise VRIO. O resultado mostra que dos quatro atributos, três são considerados pelos participantes da Embrapa Solos como Fraquezas, e apenas um é visto como uma Força para a Unidade, fonte de paridade competitiva.

Com relação aos atributos: "Tomada de decisão quanto ao uso de formas específicas de inovação aberta, de acordo com os problemas e desafios de inovação enfrentados" e "Definição clara de funções e responsabilidades da inovação aberta", ambos foram considerados fraquezas para a Unidade, cujos percentuais foram iguais para ambos os atributos, correspondentes a $56 \%$ da amostra.

Para o Entrevistado E(1) as estratégias de inovação aberta adotadas na Unidade, ainda não estão totalmente alinhadas à agenda da Unidade, formada pelos 
seus desafios de Inovação e suas contribuições ao VI Plano Diretor da empresa, embora tenha havido esforços nesse sentido.

A percepção do entrevistado está resumida na seguinte frase:

Mas assim, eu vejo que tem havido esforços ao longo dos anos pra aproximar a agenda institucional do novo macroprocesso de inovação. (...) a gente vem caminhando um pouco pra esse novo lugar do macroprocesso de inovação, enfim. Mas eu acho que tem sido feito sim, a agenda tem caminhado nesse sentido.

Com relação ao terceiro atributo que avalia a existência de um processo bem definido de seleção de parceiros, 69\% da amostra também considera o atributo como fraqueza. De acordo com o Entrevistado (E10) (...) "a seleção fica muito no nível individual'.O Entrevistado (E4) complementa essa visão:

Pois é, a prévia, é assim, é individuo. É individual. Eu consigo um contato, trago pra dentro da empresa, eu sou o radar, né? E isso não é muito produtivo, porque eu, primeiro, eu não sei se eu sou um radar bom. Entendeu? Se eu tô lá no meio, eu tô percebendo as oportunidades. Primeiro: eu posso querer só enxergar as oportunidades que me interessa e não interessa empresa, né? E, por último, eu não tenho uma visão sistêmica de que aquele ali, se eu tiver que fazer uma escolha, entendeu? Entre dois parceiros, eu não sei, eu não tenho ideia, eu não tenho o mapa, eu não tenho nada. Isso não... não tem futuro isso. Entendeu? A empresa que tem que ter um processo que as pessoas ali levam e ela, na verdade, assim, ela faça a digestão daquilo que aquelas antenas captaram, devolva pra aquele sujeito que trouxe, uma resposta objetiva. Porque às vezes, não tem resposta, o pesquisador chega todo empolgado: Nossa, fiz uma reunião lá com a cooperativa.... Fala pro chefe dele, fala pro parceiro dele, ai alguém fala assim: Ah é? Legal. Assim, morreu, né? Nunca mais eu vou trazer nada para empresa, eu vou tentar resolver sozinho. (...) Aí eu já começo a negociar sozinho. (...) Agora, se eu tivesse lá um sistema, assim, chegou de viagem: "Vamos bater um papo?. Na área de inovação. Porque hoje a gente faz um relatório malfeito, né? "Olha, quando você for por que que você não procura fazer um bate-papo com alguém e gravar, e fazer uma entrevista lá, capta isso ai melhor e sistematiza pra gente, que a gente vai te ajudar". Entendeu? Aí sim, o pesquisador, que é um sujeito dificil de mexer, ele vai se sentir muito bem. (...) Aqui tem uma oportunidade. E dá para ele um feedback. Olha, a próxima vez, se você quiser seguir com isso, o interesse da unidade e da empresa, e não do indivíduo, é esse(...).

O quarto e último atributo deste fator, avalia a percepção dos entrevistados, com relação ao "Gerenciamento da Propriedade Intelectual - PI".

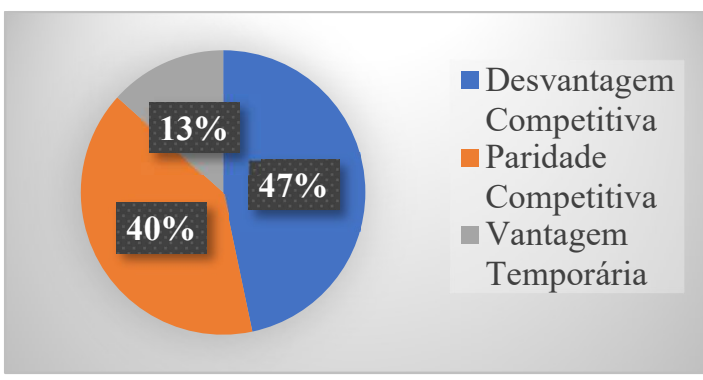

Figura 23: Gerenciamento da Propriedade Intelectual no CNPS 
A Figura 23 mostra que para uma maioria, igual a 53\%, a Propriedade Intelectual - PI é definida como uma força para a Unidade, no entanto, uma porcentagem alta, igual a $47 \%$ a considera uma fraqueza. Essa visão bem diversificada da PI também foi identificada nas entrevistas. Na fala dos entrevistados, foram percebidas ao mesmo tempo qualidades e pontos extremamente fortes da PI na Unidade e críticas em relação ao setor e a forma como a empresa lida com este atributo de uma forma geral.

Nosso comitê local de propriedade intelectual, eu acredito no trabalho que ele faz, acho que ele faz um trabalho muito bom, mas eu acho que falta equipe pra poder fazer mais, né? (...)é um comitê com poucas pessoas que trabalham realmente no assunto e tem uma demanda grande, e a gente não tem muitas expertises em propriedade intelectual. (...)É porque a sede, ela absorvia muito disso, de registrar as patentes, de fazer esse trabalho, e agora a sede tá colocando tudo pras unidades. (...)Tudo bem, vai botar pras unidade, ok, mas cadê a capacitação? Coloca a Entrevistada (E10).

O Entrevistado (E8) complementa: “A gente só tem uma pessoa que lida com isso". Na fala do entrevistado (E4), fica clara essa visão dicotômica com relação à $\mathrm{PI}$.

Ela não é satisfatória, mas ela está no caminho, ela é bem melhor do que em outras unidades(...) Agora, nós precisamos de aumentar a equipe... Porque nós temos um comitê local de propriedade intelectual, que ele precisa operar mais, ele não pode ser só deliberativo, entendeu?... Então, nós temos uma joia rara na empresa, mas a gente tem que fazer ela impactar mais.

No entanto, levando em consideração os depoimentos dos entrevistados, foi possível perceber que a Embrapa Solos possui um especialista na área de Propriedade Intelectual, e que segundo eles, é o grande diferencial da Unidade, principalmente quando comparada às demais Unidades da Embrapa. Dessa forma, foi possível concluir que este recurso pode ser considerado uma força para a Unidade e fonte de paridade competitiva, como definido por $40 \%$ da amostra.

O quinto fator analisado, diz respeito à "Capacidade de gerenciamento do conhecimento", que foi avaliado por meio de três atributos, também analisados pelo modelo VRIO.

A primeira afirmativa, constante no questionário, "Minha Unidade possui capacidade de explorar, criar, desenvolver, reter e transformar o conhecimento adquirido internamente ou externamente, de modo a gerar inovação", avalia as capacidades inventiva, absortiva, transformativa e inovativa da Unidade. De acordo 
com $73 \%$ dos respondentes, essas capacidades são consideradas uma fraqueza para a Embrapa Solos. O Entrevistado (E5), conforme mostra o extrato a seguir, deixa claro sua percepção quanto à dificuldade da Unidade em explorar, desenvolver, reter e disseminar os conhecimentos e informações adquiridas externamente.

\begin{abstract}
Por exemplo, a gente tem lá o nosso grupo de WhatsApp(...), onde a gente vê novas coisas, vê tendências, mas assim, acaba sendo algo que não fica muito fácil de ser visualizado, porque lá se você pegar tem 300 mil arquivos, todos eles... agora bem recente, por exemplo, um da ONU, (...) traz questão de solo, de ambiente, de não sei o quê, que tá relacionado com o nosso escopo de trabalho, por exemplo, mas assim, então, claro, a gente tá vendo isso, quem tá naquele grupo tá vendo isso, mas como que isso tá sendo transmitido pra quem tá na outra ponta, que é a pesquisa, entende? Eu acho que a gente ainda não conseguiu fazer esse link, assim, de forma muito efetiva e isso passa pela comunicação, eu não falo nem do NCO, mas de uma comunicação mais sistematizada, digamos assim. Acho que a gente precisa sistematizar um pouco melhor essas informações.
\end{abstract}

A segunda afirmativa do questionário: "Minha Unidade possui capacidade de transferir os conhecimentos internos que não são considerados centrais para o aproveitamento por outras organizações", visa captar a percepção dos participantes acerca da desorptive capacity da Unidade. Sobre essa capacidade, os dados estão apresentados na Tabela 6.

Tabela 6: Resultado da análise da capacidade desorptive capacity do CNPS.

\begin{tabular}{|l|l|l|}
\hline Porcentagem & Implicância Estratégica & Força/Fraqueza \\
\hline $\mathbf{5 3 \%}$ & Paridade Competitiva & Força \\
\hline $7 \%$ & Vantagem Temporária & Força \\
\hline $7 \%$ & Vantagem Sustentável & Força \\
\hline $33 \%$ & Desvantagem Competitiva & Fraqueza \\
\hline
\end{tabular}

Pela análise da Tabela 6, 67\% consideram este atributo uma força para a Unidade, sendo que a maioria destes, ou seja, 53\% consideram que tal atributo fornece uma paridade competitiva para a Unidade frente a seus pares.

O último atributo deste fator: "Minha Unidade possui capacidade de estabelecer links com parceiros, de modo que esses links facilitem o acesso a novos conhecimentos", visa analisar a capacidade conectiva dos atores da Unidade. Sobre este atributo, $64 \%$ o consideram dotado de valor e desenvolvido/aproveitado pela Unidade, o que lhe confere uma paridade competitiva.

O sexto e último recurso/capacidade analisada, referente ao primeiro construto, se refere à "Habilidades e Competências individuais", que foi avaliado 
por meio de três atributos distintos, cujos resultados das análises VRIO estão descritos nas Figuras 24, 25 e 26.

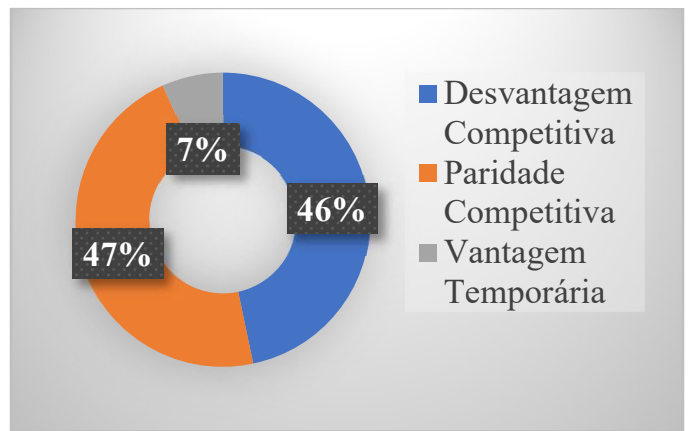

Figura 24: Liderança Pessoal por Pares e Corretagem Social no CNPS

\section{Mentalidade Tecnológica}

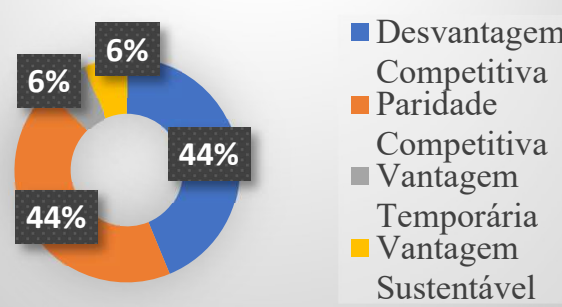

Figura 25: Mentalidade Tecnológica no CNPS

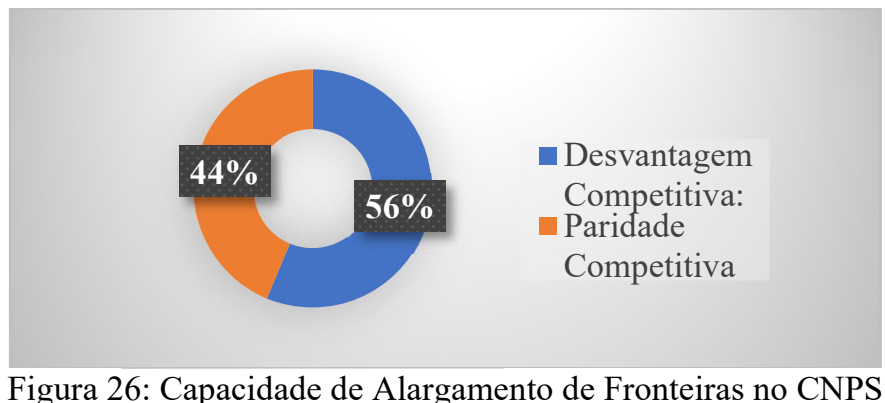

Com relação ao atributo, "Mentalidade Tecnológica", apresentado na Figura 25 , as respostas demonstram que a maioria, $56 \%$ dos respondentes, percebe o atributo como uma força para a Embrapa Solos, sendo que a grande maioria destes, uma parcela correspondente a $44 \%$ acredita que o atributo fornece à Unidade uma condição de paridade perante seus pares.

O outro atributo, "Liderança Pessoal por pares e corretagem social" conforme Figura 24, mostra que a maioria dos respondentes considera este atributo desenvolvido na Unidade, significando uma força e uma paridade competitiva. As respostas deste fator convergem com a resposta dada pelos respondentes no atributo: "Qualidade Técnica dos Recursos Humanos envolvidos em P\&D”, cuja 
grande maioria - 93\%, considera este atributo uma força na Unidade. De fato, a equipe e sua qualificação, foi uma qualidade recorrente na fala dos entrevistados.

O Entrevistado (E4) deixa claro a capacidade dos empregados de captar e trazer novos parceiros, por exemplo. "A chefia trabalha pra equipe, tem que ser. Então a pessoa traz o que ela quiser, ai você vai estudar o que que vai se fazer ou não”. O Entrevistado E(3) complementa:

(...). Eu acho que os pesquisadores, eles prospectam sim, principalmente quando eles precisam pra algum projeto, pra alguma ideia. E às vezes a gente consegue até avançar". (...)Claro que você vai encontrar uma série de dificuldades no meio do caminho, mas isso é muito válido, eu mesma aprendi muita coisa nesse processo. Então, isso mostra, assim, que quando você tem uma oportunidade, você entra nela, você tenta ao máximo acompanhar. Então eu acho que muita gente faz isso, e eu acho que tenta mesmo, muitas pessoas tentam fazer isso, mas é claro que nem sempre você consegue logo de cara solidificar uma parceria, de fato, porque isso é um trabalho bastante grande e demorado, e muitas vezes não dá certo, mas muitas vezes dá certo.

Já a "Capacidade de alargamento de fronteiras", avaliada por meio da afirmativa: "Os empregados da Unidade são atores flexíveis capazes de lidar com a heterogeneidade do conhecimento dos parceiros, com culturas organizacionais distintas, amenizando conflitos e facilitando diálogo entre múltiplos mundos”, é visto por $56 \%$ dos respondentes, como uma fraqueza, conforme Figura 26.

De forma a simplificar e facilitar a visualização dos recursos/fatores internos, quanto suas representações de forças e fraquezas para a Unidade, bem como suas implicações estratégicas, elaborou-se o Quadro 8.

Quadro 8: Relação das forças e fraquezas internas e implicações estratégicas no CNPS

$1^{\circ}$ Recurso: Pesquisa e Desenvolvimento

\begin{tabular}{|l|l|l|}
\hline \multicolumn{1}{|c|}{ Atributo } & \multicolumn{1}{|c|}{$\begin{array}{c}\text { Força/ } \\
\text { Fraqueza }\end{array}$} & Implicância Estratégica \\
\hline Quantidade de Recursos Humanos de P\&D & Força & Paridade Competitiva \\
\hline Qualidade Técnica dos Recursos Humanos de P\&D & Força & Paridade Competitiva \\
\hline Qualidade Inovadora dos Recursos Humanos & Fraqueza & Desvantagem Competitiva \\
\hline Infraestrutura Física, TI e insumos & Fraqueza & Desvantagem Competitiva \\
\hline Suporte à inovação & Força & Paridade Competitiva \\
\hline \multicolumn{3}{|c|}{$\mathbf{2}^{\mathbf{0}}$ Recurso: Cultura } \\
\hline Cultura voltada para inovação aberta & Fraqueza & Desvantagem Competitiva \\
\hline \multicolumn{3}{|c}{ Recurso: Tecnologia da Informação (TI) } \\
\hline Tecnologia como suporte à Inovação aberta & Fraqueza & Desvantagem Competitiva \\
\hline \\
$\mathbf{4}^{\mathbf{0}}$ Recurso: Governança e Alinhamento Estratégico
\end{tabular}




\begin{tabular}{|l|l|l|}
\hline $\begin{array}{l}\text { Tomada de decisões quanto ao uso de formas } \\
\text { específicas de inovação aberta de acordo com os } \\
\text { problemas e desafios de inovação enfrentados. }\end{array}$ & Fraqueza & Desvantagem Competitiva \\
\hline $\begin{array}{l}\text { Definição clara de funções e responsabilidades da } \\
\text { inovação aberta. }\end{array}$ & Fraqueza & Desvantagem Competitiva \\
\hline Processo de seleção de parceiros bem definido. & Fraqueza & Desvantagem Competitiva \\
\hline Propriedade Intelectual. & Força & Paridade Competitiva \\
\hline \multicolumn{2}{|c|}{$\mathbf{5}^{\mathbf{0}}$ Recurso: Capacidade de Gerenciamento do Conhecimento } \\
\hline $\begin{array}{l}\text { Capacidades Inventiva, Absortiva, Transformativa } \\
\text { e Inovativa }\end{array}$ & Fraqueza & Desvantagem Competitiva \\
\hline Desorptive Capacity & Força & Paridade Competitiva \\
\hline Capacidade Conectiva & Força & Paridade Competitiva \\
\hline \multicolumn{2}{|c}{ Recurso: Habilidades e Competências individuais } \\
\hline Mentalidade Tecnológica & Força & Paridade Competitiva \\
\hline Liderança Pessoal por Pares e Corretagem Social. & Força & Paridade Competitiva \\
\hline Alargamento de Fronteiras & Fraqueza & Desvantagem Competitiva \\
\hline
\end{tabular}

Pela análise do Quadro 8, conclui-se que dentre as 17 capacidades/atributos analisados, divididos entre os seis fatores, oito são consideradas como Forças internas para a Embrapa Solos e nove são consideradas fraquezas internas. Dentre os fatores, a "Governança e Alinhamento Estratégico" foi o que possui mais fraquezas de acordo com os participantes da pesquisa.

\subsubsection{2}

\section{Alianças e Portfólios de Alianças para impulsionar o desempenho de inovação.}

Nesta seção são apresentados os resultados quanto à identificação das alianças estabelecidas pela Unidade e seus parceiros de inovação, bem como as características dessas relações interorganizacionais consideradas cruciais para alavancar o desempenho de inovação na Embrapa Solos. Na Figura 27 são demonstrados os principais tipos de alianças estratégicas das quais a Unidade participa.

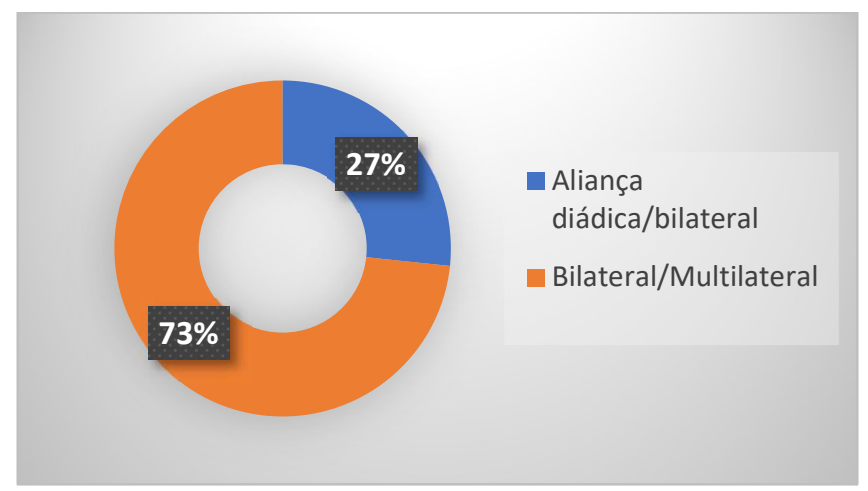

Figura 27: Alianças estabelecidas pelo CNPS 
Conforme a Figura 27, 73\% dos respondentes consideram que as alianças estabelecidas pela Unidade são tanto multilaterais quanto bilaterais. Alguns entrevistados também confirmaram essas percepções sobre a existência de ambos os tipos de alianças, e afirmam que esta definição depende dos tipos de projetos.

Então, a gente tem os dois tipos, vai depender do grupo. Por exemplo, o grupo que é mais voltado pra inovação aberta é um grupo que faz só parceria bilateral em função da especificidade da tecnologia, que é o fertilizante, o parceiro, ele quer exclusividade. Então, esse ai é parceria bilateral, não tem como ser multi. Num projeto como o grupo de zoneamento, por exemplo, você já começa a ter uma parceria que ela tem uma característica que pode ser público-privada. E ai eu vejo muito forte ali o grupo do Nordeste com essa visão. Já com o pessoal de serviços ambientais, esses grupos... esse grupo naturalmente faz parceria multiinstitucional. (Entrevistado E6).

Os participantes também foram questionados sobre a prática da inovação aberta na Unidade. A grande maioria, 67\% dos participantes, afirmaram que tal prática se dá por meio do estabelecimento de parcerias. Quanto à participação da Unidade em Alianças e Portfólios de alianças, os respondentes foram questionados acerca de quatro perspectivas sobre tal aspecto. As afirmações foram avaliadas por uma escala likert de 5 pontos, que apresenta um continuum variando de 1 (discordo totalmente) até 5 (concordo totalmente). Os resultados são apresentados Na Figura 28, cujas siglas da legenda representam: DT (Discordo Totalmente); DP (Discordo Parcialmente); N (Neutralidade); CP (Concordo Parcialmente) e CT (Concordo Totalmente). 


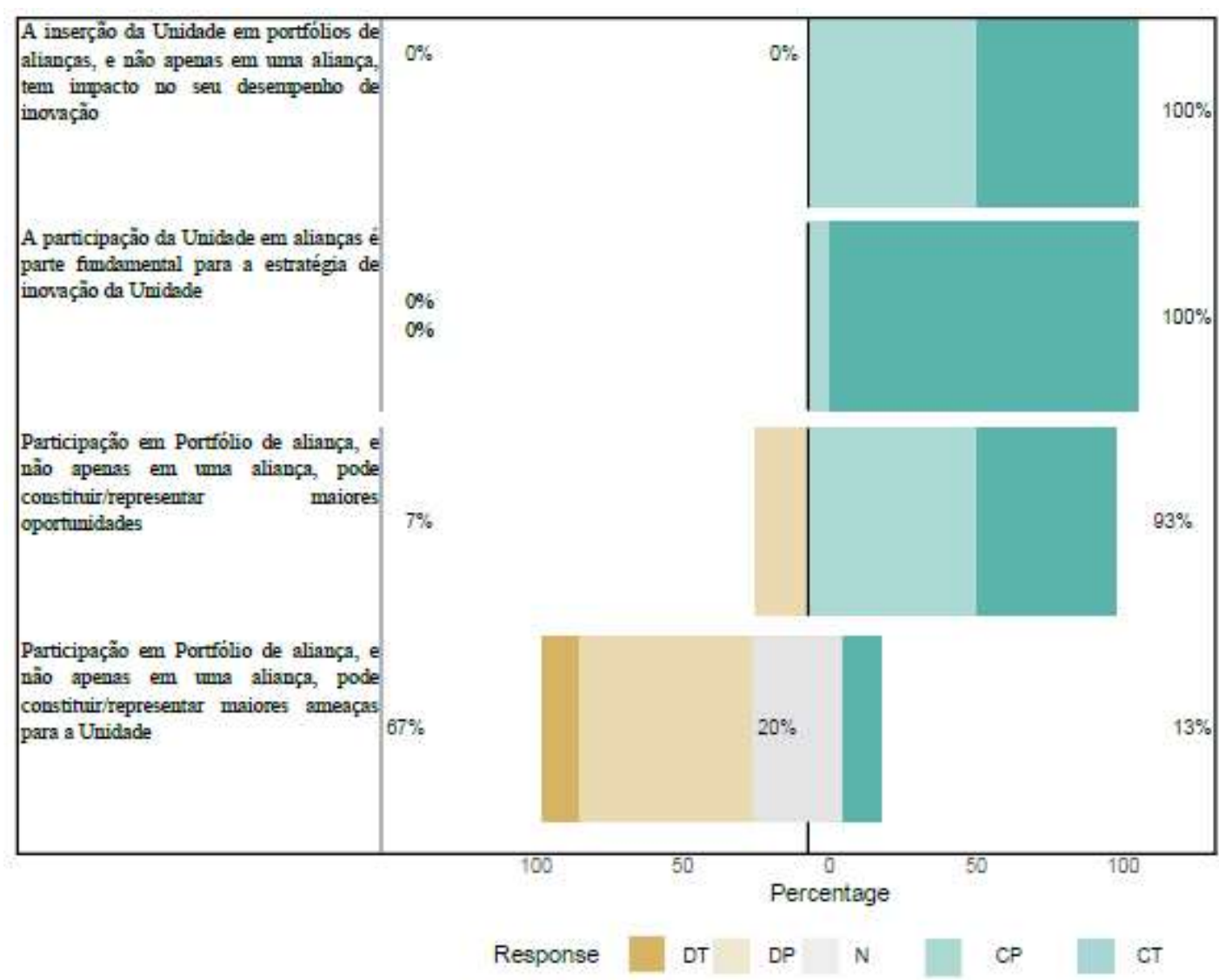

Figura 28: Gráfico de Concordância do CNPS sobre a participação em alianças

De acordo com a Figura 28, as duas primeiras afirmações apresentadas, não apresentaram nenhum nível de discordância entre os respondentes. As respostas variaram, em ambos casos, em "Concordo parcialmente" e "Concordo totalmente", o que demonstra que os respondentes acreditam que a participação da Unidade em alianças é parte fundamental para a sua estratégia de inovação, assim como concordam que a inserção em alianças tem impacto na estratégia no que concerne o desempenho de inovação. Veja alguns depoimentos acerca desta questão:

(...) Então, a gente tem que ter esse... eu acho que tem que ter essa equipe treinada pra isso, pra captar essas alianças, essas parcerias, e eu concordo com você que o futuro é esse, é compartilhamento de ações, porque ele vai ficar cada vez mais complexo, né? Mas a gente tem que tá inserido dentro desse processo e tem que ser valorizado dentro desse processo pra gerar beneficios pro país, né? Dentro de uma forma compartilhada. Entrevistado (E9).

No entanto, alguns respondentes ressaltaram algumas dificuldades que a Unidade enfrenta.

Eu tenho a sensação que as pessoas chegam muito de salto alto, como se nós fossemos, sabe, água no deserto, e sim, a gente é muito bom, a gente tem bastante expertise, mas o mundo é muito grande pra gente entender que nós temos, tipo, a vanguarda de tudo. Então acho que um pouco dessa... eu diria quase uma 
arrogância, que a gente tem impregnado na nossa cultura, que faz com que a gente tenha um pouco de dificuldade de olhar pra fora, pra fortalecer esse quesito de inovação aberta. (Entrevistado E5).

(...) E se relacionar com o parceiro que faz inovação aberta. O pesquisador não tem paciência, ele fala assim, "ah, esse cara fica me atropelando, esse cara fica me ligando toda hora", aí você não tem na retaguarda o pessoal de negociação, de articulação de parceria pra alentar esse cara, sabe? E ai você começa a gerar um desgaste desse cara com a equipe. E a chefia não tem tempo de fazer isso. Então, você precisa ter uma equipe ali estruturada, profissional, pra ajudar nesse processo, pra evitar esse desgaste com o teu PhD, com o cara que tem a possibilidade de acelerar esse processo de inovação (Entrevistado E6).

Quanto à participação da Unidade em Portfólios de Aliança, e não apenas em uma aliança, de acordo com a Figura 28, a maioria concorda que tal participação oferece maiores oportunidades para a Unidade, assim como, a maioria discorda que tal participação representa maiores ameaças à Embrapa Solos.

Quanto aos principais tipos de parceiros com os quais a Unidade estabelece parcerias para inovação, a Figura 29 apresenta os resultados encontrados.

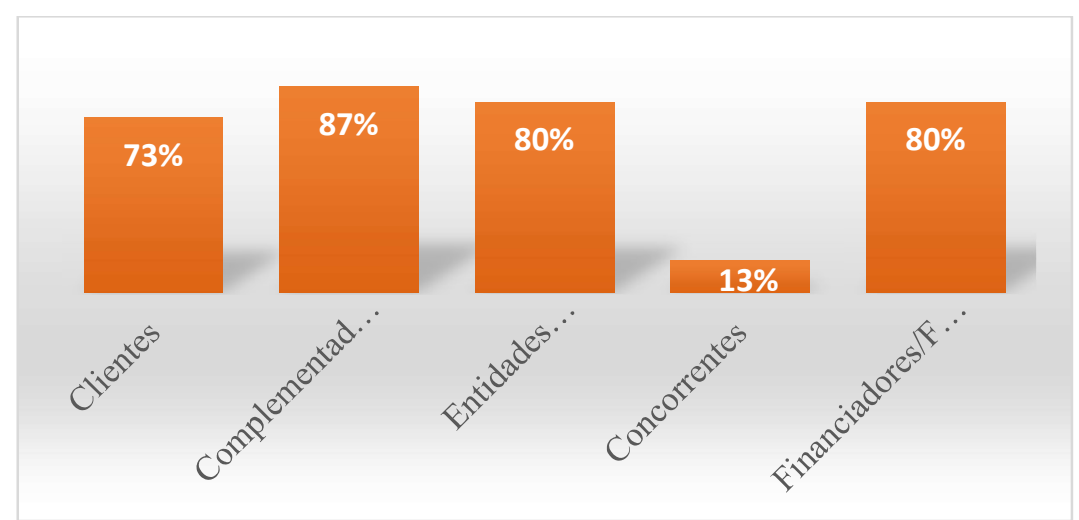

Figura 29: Tipos de Parceiros do CNPS

De acordo com a Figura 29, as principais alianças da Unidade, de acordo com $87 \%$ dos participantes, são estabelecidas com complementadores, seguidas pelas parcerias com Entidades Governamentais e Financiadores/Fomentadores, consideradas por igual parcela, de $80 \%$ dos respondentes, como as mais importantes.

Já a figura dos concorrentes, da pequena parcela dos respondentes que considera a existência deste tipo de parceria, estes, de forma majoritária, foram definidos como outras Unidades da Embrapa, demais Organizações Estaduais de Pesquisa Agropecuária - OEPAS, além de Universidades que concorrem em alguns 
editais para o mesmo tipo de propostas e realizam parcerias com empresas privadas, assim como a Embrapa Solos.

Para o Entrevistado (E6) a Embrapa Solos, por trabalhar com solo e água, temas transversais, possui concorrentes.

Dentro da Embrapa, por conta do nosso tema ser extremamente transversal, a gente tem vários concorrentes. E a Embrapa Solos, nós somos bons de liderar projetos, nós somos bons de liderar portfólios, mas nós somos ruins de fazer entregas de impacto pra sociedade, principalmente com parceiro privado. A gente publica livros lindos, papers lindos, mapas lindos, né? A gente é bom de entrevista, mas a gente... a gente tem dificuldade de concretizar isso numa estrutura, num projeto de inovação. E nisso a gente perde, porque a gente tem parceiros que fazem isso muito bem, a gente tem uns concorrentes internos na empresa que fazem isso muito bem". (...) a gente tem dificuldade nessa concorrência e no Rio de Janeiro isso vai aumentar, porque as universidades tão entrando no mesmo espaço que a gente. E ai a gente tá falando de uma PUC, a gente tá falando de uma UFRJ, a gente tá falando de uma UFF. (...)E a gente não tá se dando conta disso. E agora se a gente for ver, a gente tem metade do nosso quadro sendo professores lá dentro da UFF. Mas a gente não se junta com eles na hora de entrega de resultado.. Entrevistado (E6).

No entanto, como a parcela que considera os concorrentes como parceiros importantes para a inovação se mostrou inexpressiva, sendo correspondente a apenas 13\% dos respondentes, optou-se por não analisar os demais itens das alianças, levando em considerando este tipo de parceiro.

Com cada um desses atores estratégicos, a Embrapa Solos estabelece um tipo de aliança de inovação. Os respondentes identificaram os principais tipos para cada parceiro, conforme Tabela 7 .

Tabela 7: Tipos de Alianças por Tipos de Parceiros do CNPS

\begin{tabular}{l|l|l|l|l}
\multicolumn{1}{c|}{ Tipos de Alianças } & Clientes & Complementadores & $\begin{array}{c}\text { Entidades } \\
\text { Governamentais }\end{array}$ & $\begin{array}{c}\text { Fomentadores/ } \\
\text { Financiadores }\end{array}$ \\
\hline $\begin{array}{l}\text { P\&D em conjunto } \\
\text { (Acordo/Contrato) }\end{array}$ & $67 \%$ & $53 \%$ & $73 \%$ & $80 \%$ \\
\hline $\begin{array}{l}\text { Desenvolvimento/Co- } \\
\text { produção }\end{array}$ & $60 \%$ & $80 \%$ & $47 \%$ & $27 \%$ \\
\hline $\begin{array}{l}\text { Licenciamento de Patente } \\
\text { ou Know-How }\end{array}$ & $67 \%$ & $60 \%$ & $20 \%$ & $33 \%$ \\
\hline $\begin{array}{l}\text { Acordo/Contrato de de decimento de outros } \\
\text { fornecimos/materiais } \\
\text { insumos/Contrato de }\end{array}$ & $67 \%$ & $27 \%$ & $40 \%$ & $13 \%$ \\
\hline $\begin{array}{l}\text { Acordo/Ção de serviço } \\
\text { Prestaço }\end{array}$ & & $33 \%$ & $13 \%$
\end{tabular}

A partir da análise da Tabela 7, percebe-se que as alianças estabelecidas com os complementadores, consideradas pelos respondentes como as mais relevantes para inovação, são realizadas para: Desenvolvimento/Co-produção e 
Licenciamento de Patente ou Know-How. Já as alianças estabelecidas com as Entidades Governamentais e Financiadores/Fomentadores, são majoritariamente para realização de $\mathrm{P} \& \mathrm{D}$ em conjunto. Foram citados como exemplos de Financiadores/Fomentadores, várias agências de fomento à pesquisa, tais como Finep e Faperj e a própria Embrapa, através das chamadas para projetos do Sistema Embrapa de Gestão - SEG.

No entanto, é importante ressaltar a fala do Entrevistado (E1) sobre o papel da Embrapa como financiadora e a necessidade da participação crescente de parceiros externos no desenvolvimento dos projetos da Unidade:

“Mas esse fundo tende a decair um pouco, né, porque, enfim, a gente tá vivendo um cenário aí em que estão acontecendo cortes aí desse recurso. Então o nosso desafio hoje é procurar financiadores pros projetos".

De forma geral, pelos dados coletados nas entrevistas, as alianças estabelecidas com os complementadores, ocorrem com empresas privadas, que aportam conhecimentos, informações e know-how para complementar os conhecimentos da Unidade, e assim, possibilitar o fornecimento de serviços, produtos e/ou processos de melhor qualidade para o cliente final.

No entanto, de acordo com o Entrevistado (E4) as empresas privadas consideradas complementadoras, devem possuir também um setor de Pesquisa e Desenvolvimento, para serem capazes de aportar conhecimentos que contribuam no processo de inovação, caso contrário, a parceria se resume na busca da chancela da Embrapa, e nesse caso, não se configuraria como uma parceria de fato.

Pela análise de alguns trechos extraídos das entrevistas, percebeu-se, em alguns casos, que os tipos de parceiros se sobrepuseram, o que pode ter causado uma duplicidade de marcação de parceiros para determinados tipos de aliança. Um exemplo, são as parcerias para co-desenvolvimento, ou mesmo para P\&D em conjunto, com clientes e entidades governamentais, cujas entidades são também consideradas, muitas vezes, clientes para a Embrapa Solos. Assim como, em alguns casos, os complemetadores podem funcionar como fomentadores, à medida em que aportam, além de recursos complementares, recursos financeiros para o desenvolvimento conjunto dos projetos de inovação. Veja dois exemplos, nos trechos abaixo:

Os governos estaduais, quando contratam os zoneamentos que a Embrapa desenvolve, são clientes da Embrapa. Então a gente tem, atualmente, dois projetos em curso, que eu me recorde aqui, de zoneamento agroecológico, que é o 
Zoneamento Agroecológico do Mato Grosso do Sul, Zoneamento Agroecológico do Estado da Paraiba, que foram demandados pelos Governos Estaduais. Entrevistado (E1).

Então o nosso desafio hoje é procurar financiadores pros projetos. Então, em certa medida, boa parte dos complementadores vão atuar também como fomentadores, na medida em que eles também vão aportar recurso pra desenvolvimento dos projetos.

o cliente, então hoje, o nosso cliente muito ainda é o Governo, nosso cliente é o Governo, mas eu acho que a gente precisaria ter outros tipos de clientes, por que não outras empresas privadas?. Entrevistado (E3).

Com relação às Entidades Governamentais, de forma majoritária, foram citadas as Secretarias Estaduais de Agricultura de todo território nacional e o Ministério da Agricultura, Pecuária e Abastecimento - MAPA. Já como clientes também foram citadas várias empresas privadas e os Governos estaduais, que conforme mencionado, são também clientes da Unidade. A maioria das alianças estabelecidas com os clientes são para P\&D em conjunto, Licenciamento e/ou para Prestação de Serviços.

No que diz respeito à força das ligações das parcerias estabelecidas entre a Unidade e seus principais parceiros descritos na Figura 29, para a maioria dos participantes, essas ligações diferem de acordo com o tipo de parceiro. Dos 87\% que consideram a existência de parcerias da Embrapa Solos com complementadores, $47 \%$, ou seja, a maioria, considera tais ligações como fracas e amplas. Alguns entrevistados afirmam, que em geral, essas parcerias são pontuais e estabelecidas para o desenvolvimento de um projeto específico, e que assim que este projeto é finalizado, a parceria também se encerra. As ligações com clientes, foram caracterizadas também como fracas e amplas, de acordo com 67\% da amostra.

Já as ligações estabelecidas com os Formentadores/Financiadores e Entidades Governamentais, foram caracterizadas pelos respondentes, como ligações fortes e profundas, cujos percentuais foram de $60 \%$ e $67 \%$ respectivamente.

Com relação à natureza dessas ligações, para todos os tipos de parceiros, os respondentes concordam que existe um equilíbrio entre as alianças consideradas alianças de exploração (explorative) que visam a busca por novas informações e novos conhecimentos dos parceiros e alianças de aproveitamento (exploitative) cujo 
interesse recai sobre o aproveitamento e refinamento dos conhecimentos e recursos já existentes nos parceiros. Para os Fomentadores/Financiadores e Entidades Governamentais, o percentual referente aos que consideram a existência dos dois tipos de ligações é igual a $47 \%$ para ambos os casos. Para os Complementadores e Clientes, este percentual é igual a 40\% para os dois tipos de parceiros.

Com relação às distâncias geográficas dos parceiros e a Embrapa Solos, a Figura 30 mostra os principais resultados.

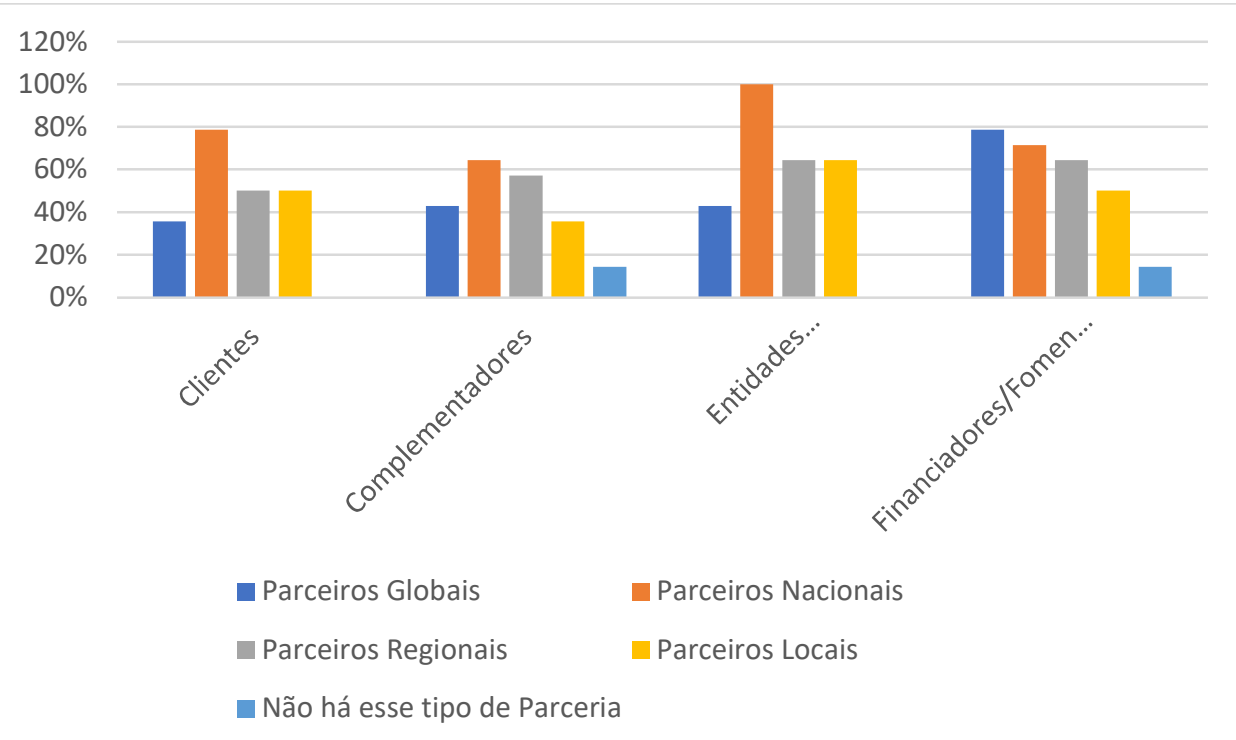

Figura 30: Distância Geográfica dos Parceiros do CNPS

Pela Figura 30, os clientes são considerados por $79 \%$ dos respondentes, como sendo, em sua maioria, parceiros nacionais, assim como os complementadores, cujo percentual é de 64\%. Já em relação aos Financiadores/Fomentadores, os mesmos são formados por parceiros globais, de acordo com $79 \%$ dos respondentes, seguidos pelos parceiros nacionais e regionais. Com relação às Entidades Governamentais, 100\% consideram que esses parceiros da Embrapa Solos são nacionais, seguidos por parceios também regionais e locais.

Ainda, de acordo com cada parceiro, existem principais tipos de recursos que a Unidade visa adquirir por meio da parceria estabelecida. Esses principais recursos, divididos por tipos de parceiros, estão descritos na Figura 31. 


\section{Recursos-Chave}

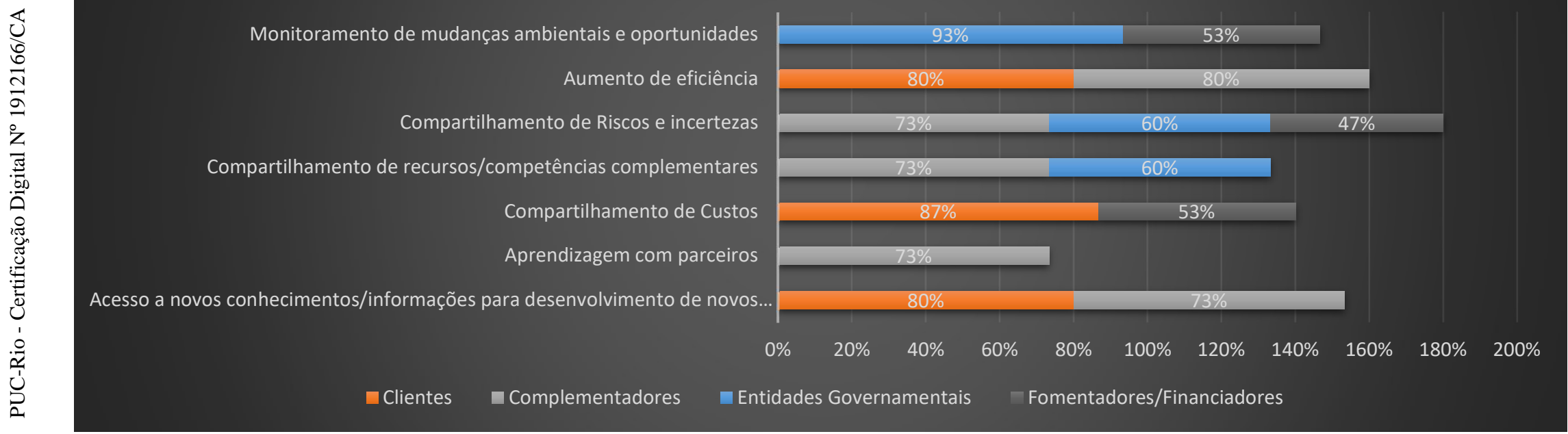

Figura 31: Principais Recursos-Chave dos parceiros do CNPS 
De acordo com a Figura 31, para 93\% dos respondentes, os principais recursos chaves adquiridos por meio das alianças estabelecidas com as Entidades Governamentais são para o Monitoramento de mudanças ambientais e oportunidades. Já as alianças realizadas com os clientes, visam majoritariamente, o compartilhamento de custos, conforme $87 \%$ dos respondentes, bem como o acesso a novos conhecimentos e informações e o aumento da eficiência, de acordo com igual parcela de $80 \%$. As alianças com os complementadores, em sua maioria, visam o aumento de eficiência, seguidas pelas parcerias que visam o acesso a novos conhecimentos e informações, o compartilhamento de recursos e competências complementares, a aprendizagem com parceiros e o compartilhamento de riscos e incertezas, de acordo com $73 \%$ da amostra. É importante ressaltar como tais parcerias são importantes para a Unidade, uma vez que representam uma força e fonte de vantagem competitiva temporária, traduzidas em benefícios diverisificados e complementares para a Unidade. As alianças com os Fomentadores, de acordo com igual parcela de $53 \%$, consideram que estas propiciam o compartilhamento de custos e o Monitoramento de mudanças ambientais e oportunidades.

Diante das características de cada relação interorganizacional, os participantes também foram questionados sobre a caracterização do Portfólio de Alianças como um recurso possível de gerar vantagem competitiva, caso as relações estabelecidas na média, com cada tipo de parceiro dentro do portfólio, fossem consideradas como valiosas, raras e inimitáveis.

Para apresentar os resultados dessa avaliação e finalizar a análise deste $2^{\circ}$ construto constante do modelo, o Quadro 9 descreve, de forma resumida, os diferentes aspectos das principais alianças da Unidade no que concerne à inovação, considerando os principais tipos de parceiros, tipos de alianças, suas características, bem como os recursos-chaves, e a implicação estratégica destas alianças para a Embrapa Solos. 
Quadro 9: Resumo das principais alianças do CNPS e suas características

\begin{tabular}{|c|c|c|c|c|c|c|c|}
\hline Tipo de Parceiro & Tipo de Aliança & $\begin{array}{l}\text { Distância } \\
\text { Geográfica }\end{array}$ & $\begin{array}{l}\text { Natureza das } \\
\text { Ligações }\end{array}$ & $\begin{array}{l}\text { Modalidade } \\
\text { das ligações }\end{array}$ & Recursos Chave & $\begin{array}{l}\text { Força/ } \\
\text { Fraqueza }\end{array}$ & $\begin{array}{l}\text { Implicância } \\
\text { Estratégica }\end{array}$ \\
\hline Clientes & $\begin{array}{l}\text { P\&D em conjunto/ } \\
\text { de Patente ou } \\
\text { Acordo/Contrato de } \\
\text { Arestaçãonento de } \\
\text { serviço }\end{array}$ & $\begin{array}{l}\text { Nacionais, } \\
\text { Regionais e Locais }\end{array}$ & $\begin{array}{ll}\text { Fraca } & \text { e } \\
\text { Ampla }\end{array}$ & $\begin{array}{l}\text { Explorative } \\
\text { Exploitative }\end{array}$ & $\begin{array}{l}\text { Compartilhamento de Custos/Acesso a novos } \\
\text { conhecimentos e informações/ } \\
\text { Aumento de eficiência }\end{array}$ & Força & $\begin{array}{l}\text { Paridade } \\
\text { Competitiva }\end{array}$ \\
\hline Complementador & $\begin{array}{l}\text { Desenvolvimento/Co-produção/ } \\
\text { Licenciamento de Patente ou } \\
\text { Know-How e P\&D em conjunto. }\end{array}$ & $\begin{array}{l}\text { Nacionais } \\
\text { Regionais }\end{array}$ & $\begin{array}{l}\text { Fraca e } \\
\text { Ampla }\end{array}$ & $\begin{array}{l}\text { Explorative } \\
\text { Exploitative }\end{array}$ & $\begin{array}{l}\text { Aumento de eficiência/ } \\
\text { Acesso a novos conhecimentos e informações/ } \\
\text { Aprendizagem com parceiros/ } \\
\text { Compartilhamento de recursos/competências } \\
\text { complementares, riscos e incertezas }\end{array}$ & Força & $\begin{array}{l}\text { Vantagem } \\
\text { Temporária }\end{array}$ \\
\hline $\begin{array}{l}\text { Entidades } \\
\text { Governamentais }\end{array}$ & $\begin{array}{l}\text { P\&D em conjunto/ } \\
\text { Desenvolvimento/Co-produção }\end{array}$ & $\begin{array}{l}\text { Nacionais, } \\
\text { Regionais e Locais }\end{array}$ & $\begin{array}{l}\text { Forte e } \\
\text { Profunda }\end{array}$ & $\begin{array}{l}\text { Explorative } \\
\text { Exploitative }\end{array}$ & 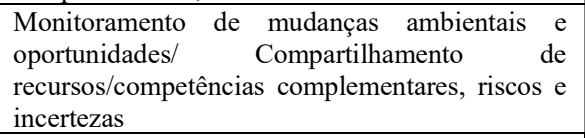 & Força & $\begin{array}{l}\text { Vantagem } \\
\text { Temporária }\end{array}$ \\
\hline $\begin{array}{l}\text { Fomentadores/ } \\
\text { Financiadores }\end{array}$ & $\begin{array}{l}\text { P\&D em conjunto/ Licenciamento } \\
\text { de Patente ou Know-How }\end{array}$ & $\begin{array}{l}\text { Globais, } \\
\text { Nacionais } \\
\text { Regionais }\end{array}$ & $\begin{array}{l}\text { Forte e } \\
\text { Profunda }\end{array}$ & $\begin{array}{l}\text { Explorative } \\
\text { Exploitative }\end{array}$ & $\begin{array}{l}\text { Monitoramento de mudanças ambientais e } \\
\text { oportunidades } \\
\text { e Compartilhamento de Custos }\end{array}$ & Força & $\begin{array}{l}\text { Paridade } \\
\text { Competitiva }\end{array}$ \\
\hline
\end{tabular}


Pela análise do Quadro 9, é possível observar que todas as relações foram definidas como forças para a Embrapa Solos, variando, no entanto, quanto às implicâncias estratégicas que cada tipo de parceria acarreta para a Unidade.

O percentual de $93 \%$ da amostra, considera as parcerias estabelecidas com clientes como forças para Unidade. Destes 93\%, a maioria, ou seja, 60\%, consideram essas relações fontes de paridade competitiva. Isso implica dizer que essas parcerias são valiosas, ou seja, permitem que a empresa melhore sua capacidade de inovação, e consequentemente, seu desempenho no que concerne à inovação. Assim como as parcerias estabelecidas com clientes, igual parcela de 93\% dos entrevistados considera as relações estabelecidas com os Fomentadores/Financiadores forças para a Unidade, cujo percentual de 63\% também as considera como fontes de paridade competitiva. Já as parcerias estabelecidas com complementadores e Entidades Governamentais, foram classificadas como forças e fontes de vantagem competitiva temporária para a Unidade, o que significa que, para os participantes da pesquisa, essas relações são aproveitadas pela Embrapa Solos, além de serem dotadas de valor e raridade.

No entanto, é importante observar também que nenhuma aliança foi classificada como inimitável, sendo assim, as forças que as parcerias trazem para a Embrapa Solos, de acordo com a percepção da maioria dos respondentes, não são forças que permitem o alcance de uma vantagem competitiva sustentável, ou seja, uma vantagem a longo prazo. Isso significa que ainda há margem para melhoria dessas relações. De forma geral, no entanto, as parcerias foram definidas como um recurso importante, independente do parceiro, uma vez que trazem benefícios e recursos-chave considerados cruciais para melhorar a capacidade de inovação da Embrapa Solos.

Após aplicação, na Embrapa Solos, do modelo teórico, elaborou-se o Quadro 10 que inter-relaciona as forças e fraquezas identificadas a partir da análise dos dois construtos: "Recursos, capacidades e características internas" e "Alianças e Portfólios de Alianças" para impulsionar o desempenho de inovação, com o intuito de identificar as complementariedades entre esses dois ambientes (interno e externo) que supram as lacunas existentes na Unidade e contribuam para a melhoria do desempenho de inovação da Embrapa Solos.

Além de melhoria das fraquezas internas por meio das alianças, as parcerias também contribuem para melhoria das forças internas existentes, de 
modo a tornar essas forças, fontes de vantagem competitiva sustentável para a Unidade. O Quadro 11 mostra como os benefícios advindos das alianças também potencializam as forças internas já existentes. 
Quadro 10: Relação entre Fraquezas Internas e Forças Externas do CNPS

\begin{tabular}{|c|c|c|c|c|c|c|}
\hline \multicolumn{2}{|c|}{ Construto } & \multirow{2}{*}{$\begin{array}{c}\text { Fatores Internos } \\
\text { Fraquezas internas }\end{array}$} & \multirow{2}{*}{\multicolumn{2}{|c|}{$\begin{array}{c}\text { Fatores Externos } \\
\begin{array}{c}\text { Superação/minimização das Fraquezas internas por meio das Forças advindas das } \\
\text { parcerias }\end{array} \\
\end{array}$}} & \multicolumn{2}{|c|}{ Construto } \\
\hline & & & & & & \multirow{13}{*}{ 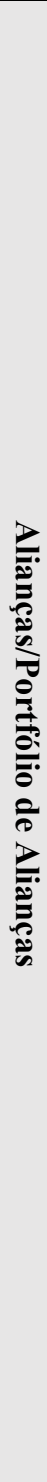 } \\
\hline \multirow{12}{*}{ 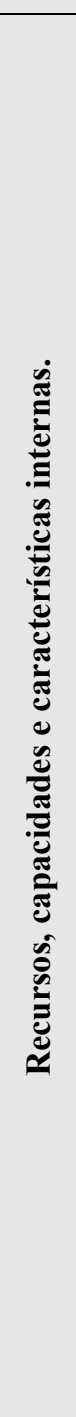 } & \multirow{12}{*}{$\begin{array}{c}\text { Fraquezas } \\
\text { internas }\end{array}$} & \multirow{2}{*}{$\begin{array}{l}\text { Qualidade Inovativa } \\
\text { dos Recursos Humanos de } \\
\text { P\&D }\end{array}$} & $\begin{array}{l}\text { Alianças para P\&D em parceria } \\
\text { com clientes e complementadores }\end{array}$ & $\begin{array}{l}\text { Acesso a novos conhecimentos e informações } \\
\text { e Aumento de Eficiência. }\end{array}$ & \multirow{12}{*}{$\begin{array}{l}\text { Forças } \\
\text { Externas }\end{array}$} & \\
\hline & & & $\begin{array}{l}\text { Alianças para P\&D em parceria } \\
\text { com Entidades Governamentais }\end{array}$ & $\begin{array}{l}\text { Compartilhamento de competências } \\
\text { complementares }\end{array}$ & & \\
\hline & & \multirow[t]{3}{*}{$\begin{array}{l}\text { Infraestrutura Física, de TI e } \\
\text { insumos para } \\
\text { realização especificamente } \\
\text { da P\&D }\end{array}$} & $\begin{array}{l}\text { Alianças para } \mathrm{P} \& \mathrm{D} \text { em conjunto } \\
\text { com clientes } \\
\text { fomentadores/financiadores }\end{array}$ & $\begin{array}{l}\text { Compartilhamento de Custos devido à falta de } \\
\text { insumos, como recursos financeiros. }\end{array}$ & & \\
\hline & & & $\begin{array}{l}\text { Alianças para } \\
\text { Desenvolvimento/Co-produção } \\
\text { com complementadores e entidades } \\
\text { governamentais }\end{array}$ & $\begin{array}{l}\text { Compartilhamento de recursos, riscos e } \\
\text { incertezas. }\end{array}$ & & \\
\hline & & & $\begin{array}{l}\text { Alianças para } \\
\text { Desenvolvimento/Co-produção } \\
\text { com complementadores }\end{array}$ & Aumento de eficiência & & \\
\hline & & \multirow[t]{2}{*}{$\begin{array}{l}\text { Cultura voltada } \\
\text { inovação aberta }\end{array}$} & $\begin{array}{l}\text { Alianças para } \mathrm{P} \& \mathrm{D} \text { em parceria } \\
\text { com clientes e complementadores }\end{array}$ & Acesso a novos conhecimentos e informações & & \\
\hline & & & $\begin{array}{l}\text { Alianças para } \\
\text { Desenvolvimento/Co-produção } \\
\text { com complementadores }\end{array}$ & Aprendizagem com parceiros & & \\
\hline & & \multirow[t]{3}{*}{$\begin{array}{l}\text { TI como suporte à } \\
\text { inovação aberta }\end{array}$} & $\begin{array}{l}\text { Alianças para } \\
\text { Desenvolvimento/Co-produção } \\
\text { com complementadores }\end{array}$ & $\begin{array}{l}\text { Aprendizagem com parceiros e acesso a } \\
\text { novos conhecimentos e informações }\end{array}$ & & \\
\hline & & & $\begin{array}{l}\text { Alianças } \\
\text { Desenvolvimento/Co-produção } \\
\text { com complementadores } \\
\text { Entidades Governamentais }\end{array}$ & $\begin{array}{l}\text { Compartilhamento de recursos/competências } \\
\text { complementares }\end{array}$ & & \\
\hline & & & $\begin{array}{l}\text { Alianças para P\&D em parceria } \\
\text { com clientes e complentadores }\end{array}$ & $\begin{array}{l}\text { Acesso a novos conhecimentos e informações } \\
\text { e Aumento de eficiência }\end{array}$ & & \\
\hline & & \multirow{2}{*}{$\begin{array}{l}\text { Tomada de decisão quanto } \\
\text { ao uso de formas específicas } \\
\text { de inovação aberta de }\end{array}$} & $\begin{array}{l}\text { Alianças para } \\
\text { Desenvolvimento/Co-produção } \\
\text { com complementadores }\end{array}$ & Aprendizagem com parceiros & & \\
\hline & & & $\begin{array}{l}\text { Alianças para P\&D em parceria } \\
\text { com clientes e complementadores }\end{array}$ & $\begin{array}{l}\text { Acesso a novos conhecimentos e informações } \\
\text { e aumento de eficiência. }\end{array}$ & & \\
\hline
\end{tabular}




\begin{tabular}{|c|c|c|c|c|}
\hline \multirow{9}{*}{$\begin{array}{c}\text { Fraquezas } \\
\text { internas }\end{array}$} & $\begin{array}{l}\text { acordo com os desafios de } \\
\text { inovação enfrentados. }\end{array}$ & $\begin{array}{l}\text { Alianças para } \mathrm{P} \& \mathrm{D} \text { em parceria } \\
\text { com Entidades Governamentais }\end{array}$ & $\begin{array}{l}\text { Monitoramento de mudanças ambientais e } \\
\text { oportunidades (Universidades, Secretarias } \\
\text { Estaduais de Ciência e Tecnologia). }\end{array}$ & \multirow{8}{*}{$\begin{array}{c}\text { Forças } \\
\text { Externas }\end{array}$} \\
\hline & \multirow[t]{2}{*}{$\begin{array}{l}\text { Definição clara de } \\
\text { funções e responsabilidades } \\
\text { da inovação aberta. }\end{array}$} & $\begin{array}{l}\text { Alianças para } \\
\text { Desenvolvimento/Co-produção } \\
\text { com complementadores }\end{array}$ & $\begin{array}{l}\text { Aprendizagem com parceiros, aumento de } \\
\text { eficiência }\end{array}$ & \\
\hline & & $\begin{array}{l}\text { Alianças para } \mathrm{P} \& \mathrm{D} \text { em parceria } \\
\text { com clientes e complementadores }\end{array}$ & $\begin{array}{l}\text { Acesso a novos conhecimentos e informações } \\
\text { e aumento de eficiência }\end{array}$ & \\
\hline & \multirow[t]{2}{*}{$\begin{array}{l}\text { Processo de seleção } \\
\text { de parceiros bem definido }\end{array}$} & $\begin{array}{l}\text { Alianças para } \\
\text { Desenvolvimento/Co-produção } \\
\text { com complementadores }\end{array}$ & $\begin{array}{l}\text { Aprendizagem com parceiros/ acesso a novos } \\
\text { conhecimentos e informações }\end{array}$ & \\
\hline & & $\begin{array}{l}\text { Alianças para P\&D em conjunto } \\
\text { com clientes e complementadores }\end{array}$ & $\begin{array}{l}\text { Acesso a novos conhecimentos e informações } \\
\text { e Aumento de eficiência }\end{array}$ & \\
\hline & \multirow[t]{2}{*}{$\begin{array}{l}\text { Capacidades Inventiva, } \\
\text { absortiva, transformativa } \\
\text { e inovativa }\end{array}$} & $\begin{array}{l}\text { Alianças para } \\
\text { Desenvolvimento/Co-produção } \\
\text { com complementadores }\end{array}$ & $\begin{array}{l}\text { Aprendizagem com parceiros/ acesso a novos } \\
\text { conhecimentos e; informações, } \\
\text { compartilhamento de recursos e competências } \\
\text { complementares e aumento de eficiência. }\end{array}$ & \\
\hline & & $\begin{array}{l}\text { Alianças para P\&D em conjunto } \\
\text { com clientes e complementadores }\end{array}$ & $\begin{array}{l}\text { Acesso a novos conhecimentos e informações } \\
\text { e Aumento de eficiência }\end{array}$ & \\
\hline & $\begin{array}{l}\text { Liderança Pessoal por Pares } \\
\text { e Corretagem Social. }\end{array}$ & $\begin{array}{l}\text { Alianças para } \\
\text { Desenvolvimento/Co-produção } \\
\text { com complementadores } \\
\text { Entidades Governamentais }\end{array}$ & $\begin{array}{l}\text { Aprendizagem com parceiros; Acesso a novos } \\
\text { conhecimentos e informações. }\end{array}$ & \\
\hline & \multirow{2}{*}{ Alargamento de Fronteiras } & $\begin{array}{l}\text { Alianças para P\&D em parceria } \\
\text { com clientes e complementadores. }\end{array}$ & $\begin{array}{l}\text { Aprendizagem com parceiros e Acesso a } \\
\text { novos conhecimentos e informações. }\end{array}$ & \\
\hline & & $\begin{array}{l}\text { Alianças para } \\
\text { Desenvolvimento/Co-produção } \\
\text { com complementadores }\end{array}$ & $\begin{array}{l}\text { Aprendizagem com parceiros e Acesso a } \\
\text { novos conhecimentos e informações. }\end{array}$ & \\
\hline
\end{tabular}


Quadro 11: Relação das Forças Internas e Externas do CNPS

\section{Fatores Externos}

Alianças para P\&D em parceria com $\quad$ Aprendizagem com parceiros

\begin{tabular}{l|l} 
Quantidade de Recursos & clientes e complementadores. \\
\cline { 2 - 3 } Humanos de P\&D & Alianças para P\&D em parceria com \\
& con C
\end{tabular}

Compartilhamento de competências

Forças

internas Governamentais

\begin{tabular}{l|l} 
& \\
Qualidade Técnica dos \\
Recursos Humanos de P\&D.
\end{tabular}

Alianças para P\&D em parceria com

Forças

Compartilhamento de competências

Externas

complementadores e Entidades

complementares.

Governamentais

Alianças para P\&D em parceria com $\quad$ Compartilhamento de competências

Suporte à inovação (ADM;

complementadores e Entidades

Governamentais

TT e negócios).

Alianças para P\&D em parceria com

clientes e complementadores.

Propriedade Intelectual.

Alianças para $\mathrm{P} \& \mathrm{D}$ em parceria com clientes e complementadores.

Aprendizagem com parceiros e Acesso a novos conhecimentos e informações.

Aprendizagem com parceiros e Acesso a novos conhecimentos e informações.

\begin{tabular}{l|l} 
Desorptive Capacity & $\begin{array}{l}\text { Alianças para licenciamento de } \\
\text { Patente e know-how com } \\
\text { complementadores }\end{array}$
\end{tabular}

Compartilhamento de Recursos complementadores

\begin{tabular}{l|l} 
Capacidade Conectiva & Alianças para P\&D em parceria com
\end{tabular}

clientes e complementadores.

Aprendizagem com parceiros; Acesso a novos conhecimentos e informações

e Aumento de eficiência.

\begin{tabular}{l|l} 
Mentalidade Tecnológica & Alianças para P\&D em parceria com
\end{tabular}

clientes e complementadores.

Aprendizagem com parceiros,

Acesso a novos conhecimentos e

informações e Aumento de eficiência. 


\subsubsection{3}

\section{Desempenho de Inovação}

Esta seção apresenta os resultados quanto à percepção dos participantes acerca do desempenho de inovação da Embrapa Solos, de 2019 a 2020, período que corresponde a implementação na Embrapa, do macroprocesso de inovação.

Com relação à quantidade de resultados gerados pela Unidade, os dados são apresentados nas Figuras 32, 33 e 34:

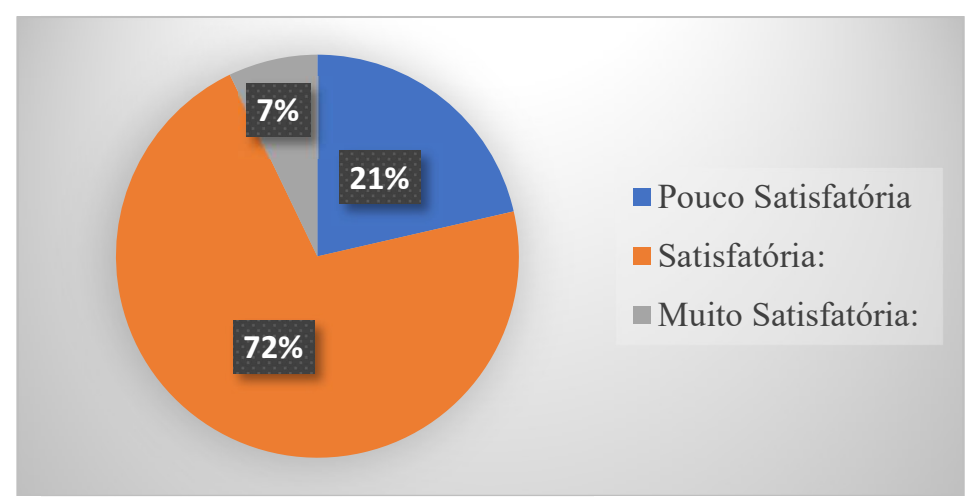

Figura 32: Quantidade de Ativos Pré-Tecnológicos produzidos pelo CNPS

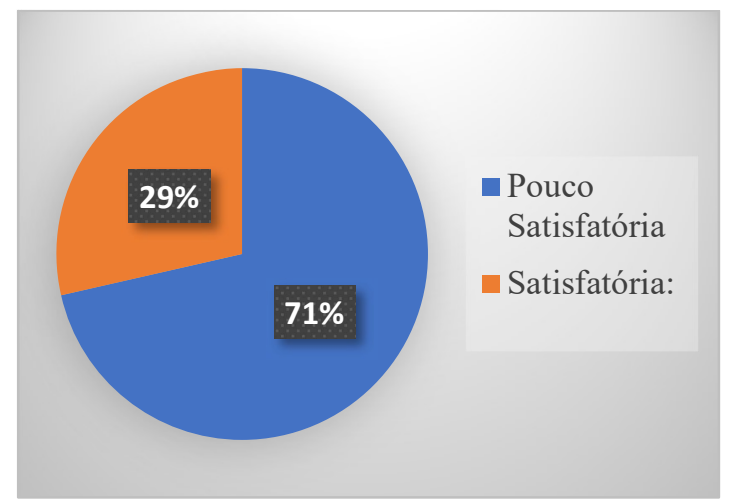

Figura 33: Quantidade de Ativos Tecnológicos produzidos pelo CNPS

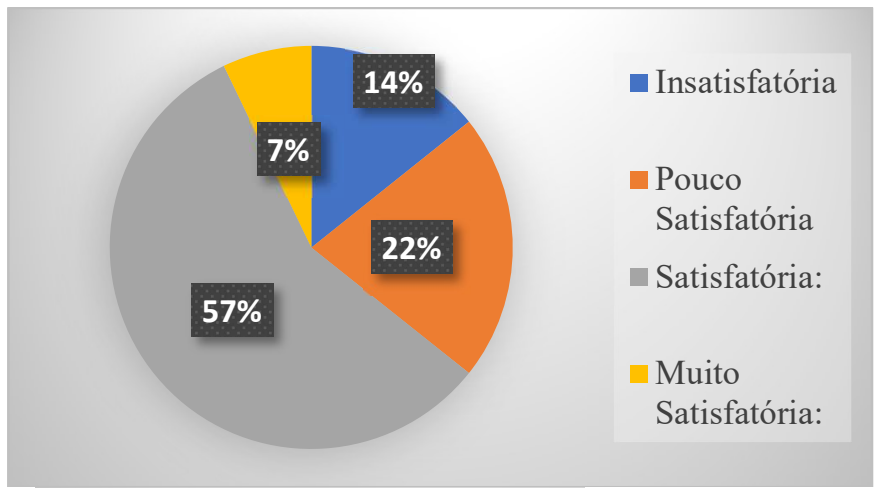

Figura 34: Quantidade de Apoio à Inovação produzidos pelo CNPS 
De acordo com as Figuras 32, 33 e 34, dentre os três tipos de resultados produzidos, os respondentes consideram a produção de Ativos Pré Tecnológicos como a mais satisfatória. A Figura 32 mostra que $72 \%$ dos participantes possuem essa visão. Com relação ao resultado “Apoio à inovação", Figura 34, 57\% dos participantes consideram a quantidade produzida satisfatória. Já em relação aos Ativos Tecnológicos, Figura 33, 71\% consideram a produção como pouco satisfatória. Alguns entrevistados exemplificam essa realidade:

Ah, eu acho que o que é mais relevante é o que era considerado no passado os ativos pré-tecnológicos, que são os bancos de dados, né? Que é a geração de novos dados de solo em escalas adequadas pra auxiliar a tomada de decisão e pra subsidiar a política pública, né? E ai o exemplo disso é o zoneamento de barragens subterrâneas, que ele culminou lá com uma política pública em Alagoas de implantação de barragens subterrâneas e o interessante é que o barragens subterrâneas, ele funciona a partir do zoneamento agroecológico de Alagoas, que tem a base de solos na escala 1 pra 100 mil. Então, a gente vem trazendo isso junto, que não fazer o levantamento de solos por fazer, é dá aplicação pra aquela informação de solo. Entrevistado (E9).

"Então eu acho que a nossa atuação tá muito mais em apoio à inovação, em ativos prétecnológicos do que TRLs mais avançadas" (Entrevistado E5).

Alguns entrevistados justificam a produção maior de Ativos Pré Tecnológicos e de Apoio à inovação, evidenciando que o papel da Unidade é, majoritariamente, produzir dados e conhecimentos nos temas solo e água, e não em produto em si, assim, pela própria missão e natureza da Unidade, seus resultados mais expressivos se concentram nesses dois tipos. Com relação a efetividade destes resultados, ou seja, com relação aos impactos que tais resultados geram, os dados são apresentados na Tabela 8 .

Tabela 8: Impactos dos resultados gerados pelo CNPS

Efetividade das inovações geradas em termos de seus impactos no desenvolvimento institucional?

\begin{tabular}{l|l}
\hline Impactos Pouco relevantes & $14 \%$ \\
\hline Relevantes & $\mathbf{7 1 \%}$ \\
\hline Muito relevantes & $14 \%$ \\
\hline Efetividade das inovações geradas em termos de seus impactos econômicos? \\
\hline Impactos Pouco relevantes & $\mathbf{5 7 \%}$ \\
\hline Relevantes & $43 \%$ \\
\hline Muito relevantes & $0 \%$ \\
\hline Efetividade das inovações geradas em termos de seus impactos socioambientais? \\
\hline Impactos Pouco relevantes & $14 \%$ \\
\hline Relevantes & $\mathbf{5 7 \%}$ \\
\hline Muito relevantes & $29 \%$ \\
\hline Efetividade das inovações geradas em termos de seus impactos na cadeia produtiva? \\
\hline Impactos Pouco relevantes & $\mathbf{5 0 \%}$ \\
\hline Relevantes & $29 \%$ \\
\hline Muito relevantes & $21 \%$
\end{tabular}


Pela análise da Tabela 8 , pode-se observar que em relação aos resultados gerados e seus impactos no que tange o desenvolvimento institucional e impactos socioambientais, a maioria dos respondentes consideram tais impactos como relevantes nesses dois aspectos. Em relação a efetividade dos impactos econômicos gerados, $57 \%$ dos participantes considera tal impacto como pouco relevante, assim como os impactos gerados na cadeia produtiva, cuja parcela de $50 \%$, também o consideram como pouco relevante. É importante observar também que para nenhum aspecto os resultados foram classificados como muito relevantes pela maioria dos participantes. Os impactos mais expressivos, são referentes ao desenvolvimento institucional. De forma geral, várias falas corroboram os achados quanto à quantidade de resultados gerados e seus impactos.

Eu acho que em número de produção, ele é satisfatório. O que acontece é que muitas vezes a gente não consegue emplacar. A gente não consegue, fica parado, engavetado. Entrevistado (E10).

Eu creio que sim, porque o resultado que nós temos gerado, eles estão causando muitas mudanças na sociedade. O programa nacional de solos, ele está mudando, completamente a lógica da ciência do solo, da gestão do solo e da água. Mudou completamente. Mudou, instaurou uma governança e a Embrapa Solos está à frente disso. (...) Tudo isso aí causa altíssimo impacto. Só que assim, ainda não anda da forma que a gente... que eu enxergo que deveria. (...) O macroprocesso de inovação ainda tá numa fase muito inicial de implantação da empresa, pra funcionar mesmo de fato, pra causar impacto. Entrevistado (E4).

Então, eu acho que a gente ficou muito tempo sofrendo com a definição de inovação. O que é inovação dentro daquilo que a gente faz? Só a partir do ano que vem que os produtos cartográficos ou um nome parecido com esse-que eu não lembro agora - vai ser inserido como inovação na Embrapa, que é o tipo de produto que a gente mais faz, que é super útil pra sociedade, pra várias instituições e a Embrapa não reconhecia, entende? Olha quanto tempo a gente passou, e ai o que acontece? Isso induz a um comportamento. As pessoas deixaram de produzir, de investir o seu tempo e tal, em produzir determinados produtos porque não era reconhecido pela Embrapa, então a gente fica - é isso que eu falo - a gente fica perdido, essa massa que fica perdida, então, assim, a gente perdeu muito tempo sem saber pra quê, o quê... afinal de contas, o que a gente faz é importante ou não? Né? (...) Então assim, mas eu acho que a gente, nesses 3 anos, a gente ficou muito sem definições, então eu acho que a partir de agora a gente tem que se estruturar realmente dentro dessa parte do que a gente produz realmente, o quê que é inovador e tentar dar uma melhorada pra que esses produtos que agregam muito conhecimento, eles sejam disponibilizados pra sociedade de uma forma mais facilmente utilizada (...) Entrevistada (E2).

Quanto ao grau de novidade das inovações produzidas pela Embrapa Solos, $71 \%$ consideram que a Unidade produz, majoritariamente, inovações incrementais. Para o Entrevistado (E9): 
E eu acho que a Embrapa Solos é geradora de base de conhecimento e de informação de qualidade. Então, eu acho que nossas inovações, elas chegam de uma forma incremental e eu colocaria elas assim numa escala regular, não diria assim, ah, a Embrapa Solos revolucionou(..) não, a gente tá olhando, tá olhando, tá colocando, tá incrementando, mas... tem espaço, tem espaço pra melhorar, mas vai precisar dessas parcerias.

Assim, ao observar as forças e fraquezas da Unidade e seu desempenho de inovação, percebe-se que as fraquezas internas detectadas podem estar impactando na capacidade da Unidade em atingir um desempenho de inovação muito satisfatório. Por outro lado, na percepção dos empregados, as alianças estabelecidas são consideradas como forças e suprem, em certa parte, as lacunas internas detectadas, ainda que tal complementação não seja suficiente para trazer uma vantagem competitiva sustentável para a Embrapa Solos. Dessa forma, pode-se concluir que sem a estratégia relacional, a Unidade poderia apresentar um desempenho de inovação ainda menos expressivo. Tal conclusão evidencia a importância da relação entre os dois mundos, interno e externo, e como tal ligação impacta positivamente no desempenho de inovação da Unidade.

Tais resultados lançam luz também para a necessidade de melhoria das relações com os potenciais parceiros de inovação, de modo que estas possam trazer, por meio de suas complementariedades, uma vantagem competitiva sustentável à Unidade, que se materialize na sua capacidade a longo prazo de produzir inovações de maiores impactos.

\section{3}

\section{Embrapa Agroindústria de Alimentos - CTAA}

O Centro Nacional de Pesquisa de Tecnologia Agroindustrial de Alimentos - CTAA é um centro temático da Embrapa que atua na pesquisa, desenvolvimento e inovação agroindustrial de alimentos. Busca diversificar o uso e melhorar o aproveitamento de matérias-primas agropecuárias, além de desenvolver técnicas de processamento que permitam a ampliação de seu período de consumo e/ou comercialização para a garantia da segurança e a qualidade dos produtos. Visa também o desenvolvimento de tecnologias e a sua transferência para agregar valor aos produtos, permitindo mais competitividade e sustentabilidade ao segmento agroindustrial, além do aumento da segurança alimentar e nutricional. Para tanto, a 
Unidade estabelece constantemente parcerias estratégicas para o desenvolvimento e a transferência de tecnologias, com foco no escalonamento e aplicação industrial dos processos e produtos gerados.

O Centro que possui atuação em âmbito nacional, fica localizado no bairro de Guaratiba, na cidade do Rio de Janeiro - RJ, em um terreno de aproximadamente 55 mil metros quadrados, sendo 15 mil de área construída. Para execução de seus projetos de pesquisa, a Unidade conta com um setor técnico dividido entre Laboratórios e Plantas Pilotos.

Após a implantação da Política de Comunicação da Embrapa, no final dos anos 90, o Centro passou a adotar o nome síntese de Embrapa Agroindústria de Alimentos.

A Unidade possui 143 empregados, dentre os quais 49 são pesquisadores, 47 são analistas, 39 Técnicos e 9 Assistentes.

A Unidade trabalha com as seguintes linhas temáticas: Segurança e Qualidade de Alimentos, Pós-Colheita e Processamento de Alimentos (incluindo Bioprocessos).

\subsection{1}

Descrição dos dados da Embrapa Agroindústria de Alimentos, de acordo com os construtos apresentados no modelo teórico.

\subsubsection{1}

\section{Recursos e capacidades internas.}

$1^{\mathrm{o}}$ aspecto analisado: Pesquisa e Desenvolvimento $-\mathrm{P} \& D$. Abaixo, são apresentados os resultados da análise dos cinco atributos relacionados à P\&D.

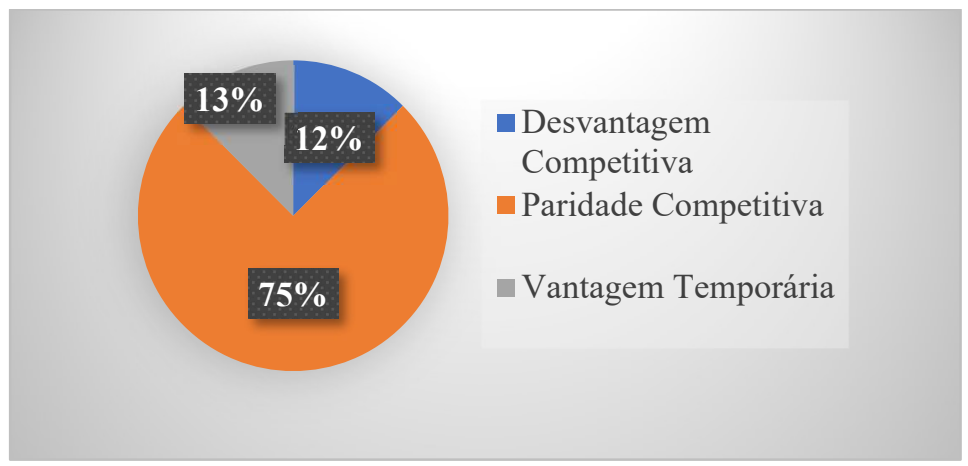

Figura 35: Quantidade de RH em P\&D no CTAA 


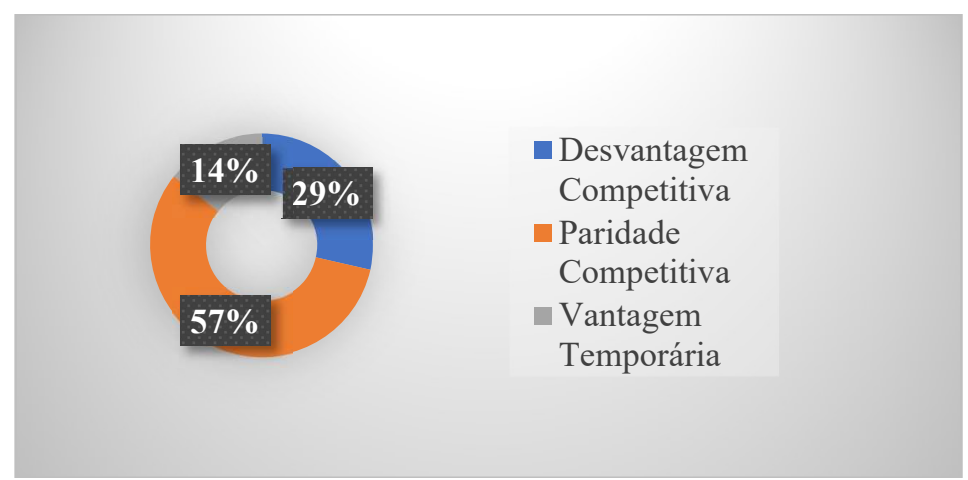

Figura 36: Qualidade Técnica de RH em P\&D no CTAA

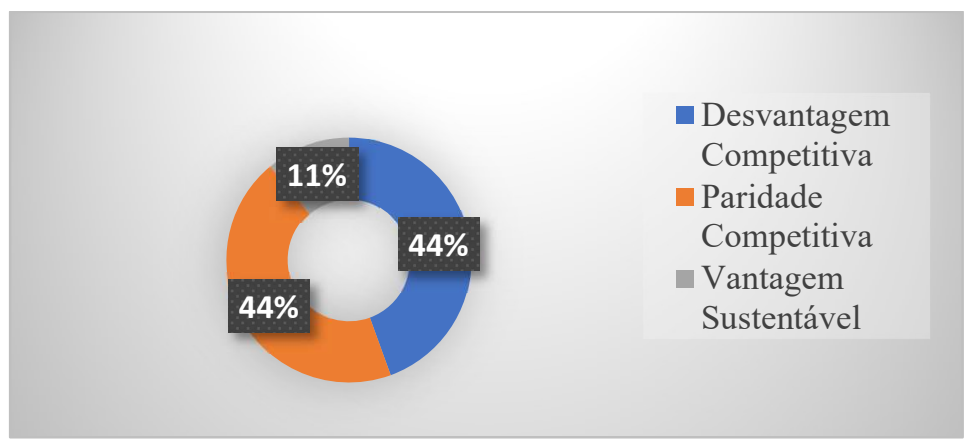

Figura 37: Qualidade Inovativa de RH no CTAA

Com relação aos Recursos Humanos envolvidos em Pesquisa e Desenvolvimento as Figuras 35, 36 e 37 mostram que, para os três atributos analisados, os respondentes consideram todos uma força, cuja implicação estratégica coloca a Unidade em uma condição de paridade competitiva frente a seus pares. Isto porque, embora os aspectos de qualidade e quantidade destes Recursos Humanos, sejam considerados como dotados de valor e aproveitados pela Unidade, não são raros e nem difíceis de imitar.

De acordo com a Figura 35, o percentual de respondentes que considera a quantidade deste recurso uma força, corresponde a $88 \%$, dentre os quais $71 \% \mathrm{o}$ avaliaram como fonte de paridade competitiva. Quanto à qualidade técnica destes Recursos Humanos, a força foi atribuída por $71 \%$ dos respondentes, cujo percentual de 57\% considera tal força fonte de paridade competitiva, conforme Figura 36. Já no aspecto da qualidade inovativa, os resultados da Figura 37, mostram que 55\% também avaliaram tal qualidade como força, embora nesse caso específico, a maioria tenha ficado pouco acima dos $50 \%$, sendo que $44 \%$ deste percentual classifica o recurso como fonte de paridade competitiva. Esse resultado demonstra que há uma divergência maior na visão dos respondentes quanto à capacidade inovativa dos Recursos Humanos envolvidos em P\&D na Unidade. Por meio das 
entrevistas, algumas falas em relação a este aspecto se sobressaíram e mostram os lados opostos de pensamento encontrados nos respondentes.

"Olha, eu acho que ponto forte, número 1, é a equipe. A gente tem uma equipe muito forte, muito bem formada" (Entrevistado E5).

O que a gente tem que melhorar: mudar aquela percepção que a gente tinha muito da Embrapa no passado, é que a gente tinha uma pegada muito mais acadêmica do que o de negócios. Talvez seja esse o nosso grande dilema a ser superado. (Entrevistado E1).

Com relação ao atributo: "Infraestrutura física, de TI e insumos para realização especificamente da P\&D”, a Figura 38 mostra que $63 \%$ dos participantes da pesquisa considera tal atributo uma força, sendo que destes, $38 \%$, o considera uma fonte de paridade competitiva e outros $25 \%$ o considera como fonte de vantagem temporária, ou seja, dotado de valor e raridade, sendo tal raridade sustentada apenas até que o recurso seja copiado, já que não é considerado como inimitável.

\begin{abstract}
Algumas falas corroboram a força atribuída a este atributo:
"Além disso, tem infraestrutura boa, né? Você vê, as unidades têm laboratórios, laboratórios onde você consegue achar equipamentos modernos, isso não tem nenhuma dúvida nisso" (Entrevistado E4).

(...)eu queria destacar dois aspectos aqui que tornam uma vantagem do CTAA quando a gente pensa nessa questão de inovação em termos de infraestrutura. Quando a gente pensa, por exemplo, na linha de tratamento térmico, que é uma coisa importante quando a gente pensa em novos produtos, quando a gente pensa em coordenação de alimentos, a gente (funciona) razoavelmente bem, razoavelmente bem. Nós temos equipamentos principais, a gente consegue fazer algumas simulações em pequenas escalas, e isso é uma vantagem muito grandes pras indústrias. E a gente tem um equipamento aqui de esterilização que, no Brasil, acho que só a Embrapa tem, talvez um ou outro instituto. Então, acaba que nós recebemos muitas empresas por causa desse equipamento. Então, a gente vê a importância do equipamento nessa questão da inovação (Entrevistado E1).
\end{abstract}

No entanto, foram identificadas algumas preocupações quanto à manutenção dessa infraestrutura que apoia as atividades de $\mathrm{P} \& \mathrm{D}$, o que representa e corrobora com a porcentagem de $38 \%$ daqueles que percebem o atributo como uma desvantagem competitiva. As falas a seguir, exemplificam tal visão:

O outro problema também que eu vejo, e ai é um problema agora, pontual, é a situação que a gente vem vivendo nos últimos anos, e dai não é tão pontual assim, que é a questão do sucateamento da infraestrutura. Então assim, a falta de recursos hoje pra pesquisa, impactando principalmente na manutenção e na renovação do nosso parque. (Entrevistado E5). 
a gente tem uma estrutura bacana, que é claro, precisa ser mantida, precisa de dinheiro para a manutenção, o que é um problema grave, dificil". (...) porque é uma estrutura muito cara de se manter mesmo, se desgasta, se deteriora com o tempo, né? (...) a gente tem muitos laboratórios, plantas pilotos, então a gente realmente precisaria ter um dinheiro para a manutenção preventiva e tudo mais, que não tem sobrado esse dinheiro nos últimos anos. (...) a gente tem uma garagem cheia de equipamentos obsoletos que não consegue fazer o leilão pra conseguir retirar aquilo de lá. (...) a gente tem um prédio inteiro que tá fechado há uns dois, três anos, que foi interditado (...) o terreno onde a gente... onde fica a Embrapa Agoindústria de alimentos, uma área de mangue, então a gente tem problemas de estrutura fisica dos prédios. Esse prédio, por exemplo, era um prédio onde tinha análise sensorial super bem equipada, super bem... funcionava super bem e tal, $e$ o prédio foi interditado pelo Ministério Público até, e aí a gente não tem verba, precisaria de muito dinheiro pra reformar esse laboratório. Então, a gente tá... a gente tem um outro laboratório sensorial, mas não em um local tão adequado quanto era antes, a gente improvisou e se adequou (Entrevistado E6).

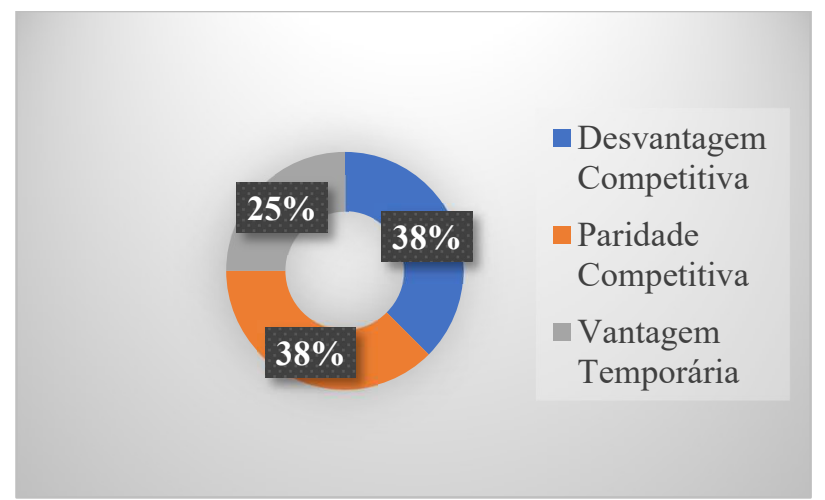

Figura 38: Infraestrutura Física, TI e insumos para P\&D no CTAA

Já com relação ao "Suporte à inovação", 73\% considera este atributo uma fraqueza para o CTAA, conforme Figura 39, ou seja, um atributo que não gera valor o valor adequado para a Unidade, sendo portanto, uma desvantagem competitiva.

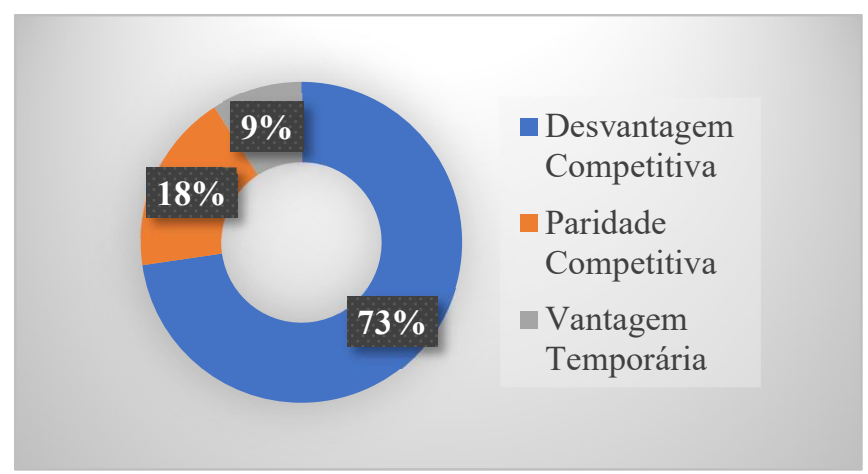

Figura 39: Suporte à inovação no CTAA

O Entrevistado E2, enfatiza a necessidade de treinamento e de um foco maior por parte da empresa, na área de Transferência de Tecnologia, uma das áreas de apoio à $\mathrm{P} \& \mathrm{D}$. 
a gente tem uma série de dificuldades, principalmente no que diz respeito até a própria natureza da área de Transferência de Tecnologia, que eu acho que essa área ainda não acordou que ela existe pra fazer transferência dos resultados gerados pela unidade. A área de Transferência de Tecnologia não é um saco aonde coloca tudo aquilo ali e diz, "vende", sabe? A área de transferência de tecnologia não tem treinamento. (...) "E diferente da pesquisa que tem uma área muito bem estruturada em termos de desenvolvimento, de competência, de atualização de pesquisadores, de... enfim, de treinamento formal e informal, a área de transferência de tecnologia, que deveria ser uma área que é... que é uma área que ocupa uma posição estratégica e deveria ter treinamento especifico pra isso, nunca teve, nunca teve, sabe? (Entrevistado E2).

De maneira resumida, o fator Pesquisa e Desenvolvimento - P\&D, analisado por meio dos cinco atributos descritos acima, foi definido da seguinte forma:

Quadro 12: Resultado da Análise VRIO dos atributos de P\&D do CTAA

\begin{tabular}{|l|l|l|}
\hline \multicolumn{1}{|c|}{ Atributo } & Força/Fraqueza & $\begin{array}{l}\text { Implicância } \\
\text { Estratégica }\end{array}$ \\
\hline Quantidade de Recursos Humanos envolvidos em P\&D & Força & $\begin{array}{l}\text { Paridade } \\
\text { Competitiva }\end{array}$ \\
\hline $\begin{array}{l}\text { Qualidade Técnica dos Recursos Humanos envolvidos em } \\
\text { P\&D }\end{array}$ & Força & $\begin{array}{l}\text { Paridade } \\
\text { Competitiva }\end{array}$ \\
\hline $\begin{array}{l}\text { Qualidade Inovativa dos Recursos Humanos envolvidos } \\
\text { em P\&D }\end{array}$ & Força & $\begin{array}{l}\text { Paridade } \\
\text { Competitiva }\end{array}$ \\
\hline $\begin{array}{l}\text { Infraestrutura Física, de TI e insumos para a realização da } \\
\text { P\&D }\end{array}$ & Força & $\begin{array}{l}\text { Paridade } \\
\text { Competitiva }\end{array}$ \\
\hline Suporte à Inovação (ADM, TT e Negócios) & Fraqueza & $\begin{array}{l}\text { Desvantagem } \\
\text { Competitiva }\end{array}$ \\
\hline
\end{tabular}

Pelo Quadro 12, percebe-se que somente um atributo "Suporte à inovação" é considerado uma fraqueza para a Unidade. Todos os demais atributos que compõem o fator P\&D são vistos como força e fontes de paridade competitiva.

O segundo aspecto analisado foi: "Cultura como suporte à inovação aberta". Para 64\%, a cultura em termos de inovação, é vista como uma fraqueza para o CTAA e fonte de desvantagem competitiva, conforme mostra a Figura 40.

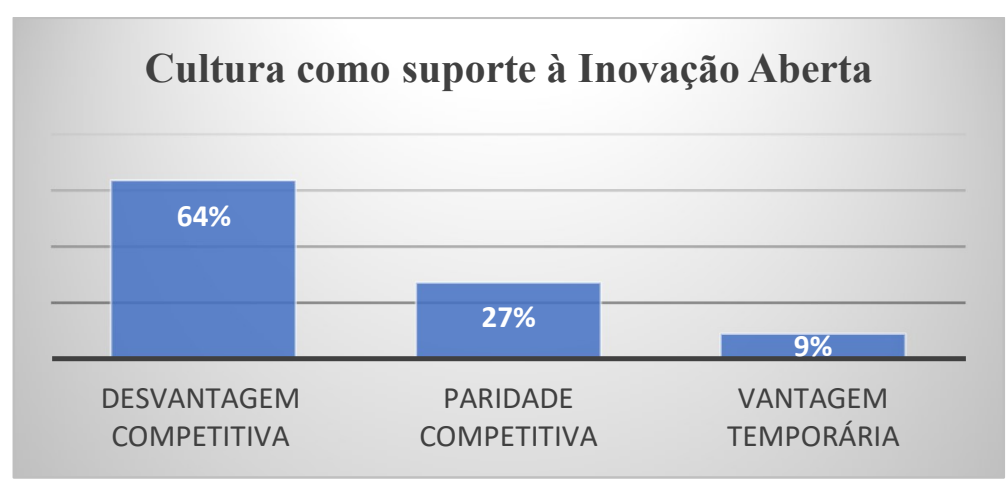

Figura 40: Cultura como suporte à inovação aberta no CTAA 
Os participantes foram questionados também sobre alguns outros aspectos relacionados à cultura organizacional, específicos e importantes em contextos de inovação. As afirmações foram analisadas por meio de uma escala likert de cinco pontos, que apresenta um continuum variando de 1 (discordo totalmente) até 5 (concordo totalmente). Os resultados são sintetizados na Figura 41, cuja legenda representa DT (Discordo Totalmente); DP (Discordo Parcialmente); N (Neutralidade); CP (Concordo Parcialmente) e CT (Concordo Totalmente).

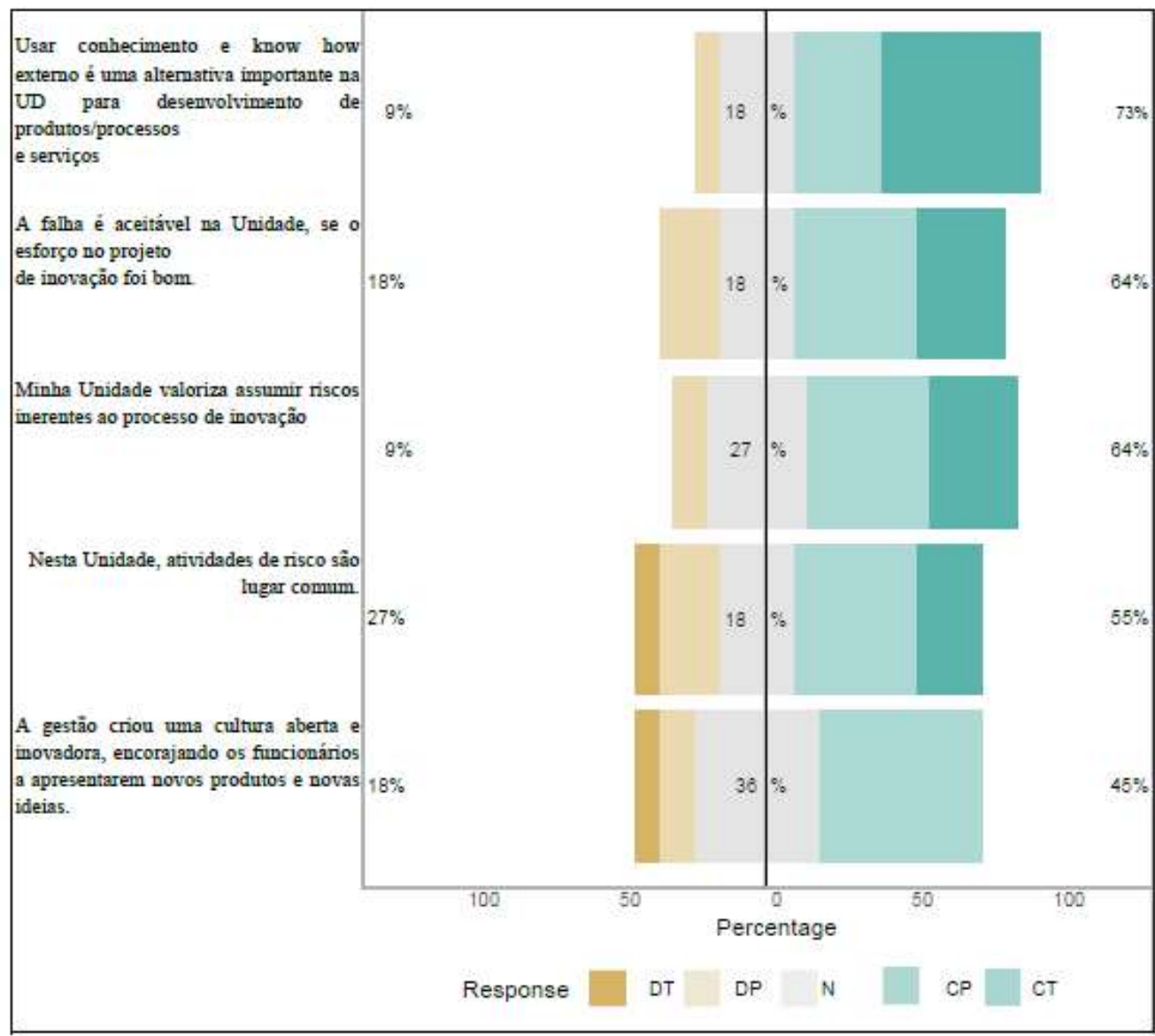

Figura 41: Gráfico de Concordância sobre aspectos culturais do CTAA

Pela análise da Figura 41, percebe-se que a afirmação que os respondentes mais concordam, se refere à primeira: "Usar conhecimento e know how externo é uma alternativa importante na UD para desenvolvimento de produtos/processos e serviços". Apenas 9\% discordam parcialmente deste aspecto. Por outro lado, a última alternativa da Figura, é a que os participantes mais discordam e diz respeito à “A gestão criou uma cultura aberta e inovadora, encorajando os funcionários a apresentarem novos produtos e novas ideias". 
Algumas falas exemplificam que de um modo geral, não há ainda uma cultura institucionalizada na Embrapa como um todo e na Unidade. Para o Entrevistado E2:

Eu acho que ela é até inexistente em termos de unidade, em termos de cultura mesmo, em termos daquilo que se persegue como inovação aberta principalmente.(...) Eu acho... até que o próprio pesquisador que faz inovação, ele não... ele não percebe a inovação que ele tá fazendo, ele não percebe o trabalho dele... ele não consegue entender que aquilo que ele tá fazendo é uma inovação, ele não situa isso, entendeu? Então, eu acho que muito se perde por isso, por essa falta de internalização da cultura e da pessoa entender, "não, eu vou fazer disso aqui, desse meu resultado, uma inovação aberta", ou vou buscar estender esse resultado de forma tal, que eu consiga fazer uma inovação aberta. Ele não tem isso dentro dele e quando tem, tem de uma forma que não percebe que é isso que ele tá fazendo, entendeu? Faz parcerias, sabe? Busca ali... busca uma complementação, mas uma complementação pra obtenção de um resultado de projeto, não de um resultado de inovação.

Para o Entrevistado E4, "a Embrapa funcionava, não só a Embrapa, muitas instituições funcionavam de maneira fechada, então têm alguns aspectos que não estão desenvolvidos".

O Entrevistado E1 corrobora com essa visão, mas complementa também a dificuldade de compreensão em nível individual, que muitas vezes ocorre pela vivência e experiência do empregado construída dentro da empresa.

macroprocesso de inovação, ele é uma transformação muito forte na empresa e muito boa, no meu modo de ver, mas a minha crítica em termos de organização é que a gente não solidificou ainda esse processo. Eu acho que ele pode ser melhor solidificado. (...) Se você pensar bem, Paula, a gente fala muito em escala de maturidade, em escala TRL, MRL, CTR, mas a gente pouco fala em stage-gate. Stage-gate é um negócio fundamental". (...)A nivel aqui individual, como eu falei, tem aquela turma, desde o cara que já absorveu isso aí, já tocou, e tem a turma que vai no vácuo, vai no grupo. (...) essa questão de entender o macroprocesso de inovação, é quando o pesquisador, ele tem, por prática, conversar muito com o setor produtivo, conversar muito com empresário. Quando você vê que a pessoa é muito acadêmica, muito presa ao seu mundo laboratório, ao seu mundo planta piloto, ela não consegue entender muito bem isso aí não.

Por fim, quanto à afirmação: "Minha Unidade valoriza assumir riscos inerentes ao processo de inovação", embora a grande maioria dos respondentes concorde com tal afirmação, na prática e no dia a dia, o receio e a dificuldade em assumir riscos, são atitudes que ainda existem. A fala do Entrevistado E5 exemplifica tal receio dos empregados com questões de risco:

Então assim, é um desafio, você não sabe se você... você promete que você vai fazer um queijo vegetal, né? Que vai ter uma boa aceitação, que vai derreter, que vai ser possivel de ralar, mas você não sabe como é que vai ficar, se as pessoas realmente vão gostar, porque elas sempre vão comparar com aquilo que elas já tão acostumadas, que é o queijo, então a empresa assume o risco, o parceiro 
assume um risco e isso é uma coisa ainda difícil, porque não tá na nossa cultura, né?

O terceiro aspecto analisado foi referente à Tecnologia da Informação - TI, como suporte à inovação aberta".

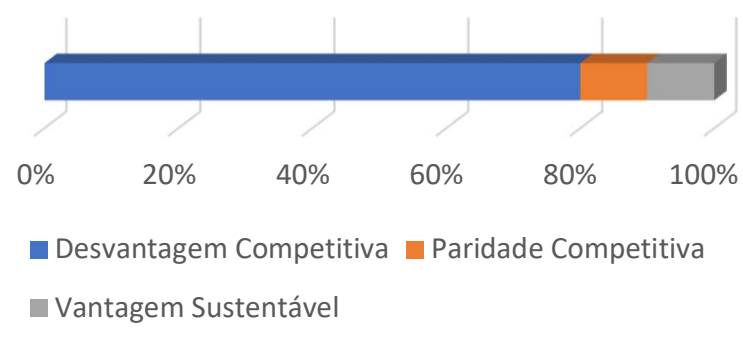

Figura 42: TI como suporte à inovação aberta no CTAA

A Figura 42 mostra que, de acordo com $80 \%$ da amostra, a TI é vista como uma fraqueza e uma desvantagem competitiva dentro da Unidade. Os participantes também foram questionados sobre a existência na Unidade de alguns aspectos específicos relativos à TI, cujas respostas obtidas, constam no Gráfico de concordância, Figura 43, cuja legenda representa DT (Discordo Totalmente); DP (Discordo Parcialmente); N (Neutralidade); CP (Concordo Parcialmente) e CT (Concordo Totalmente). 


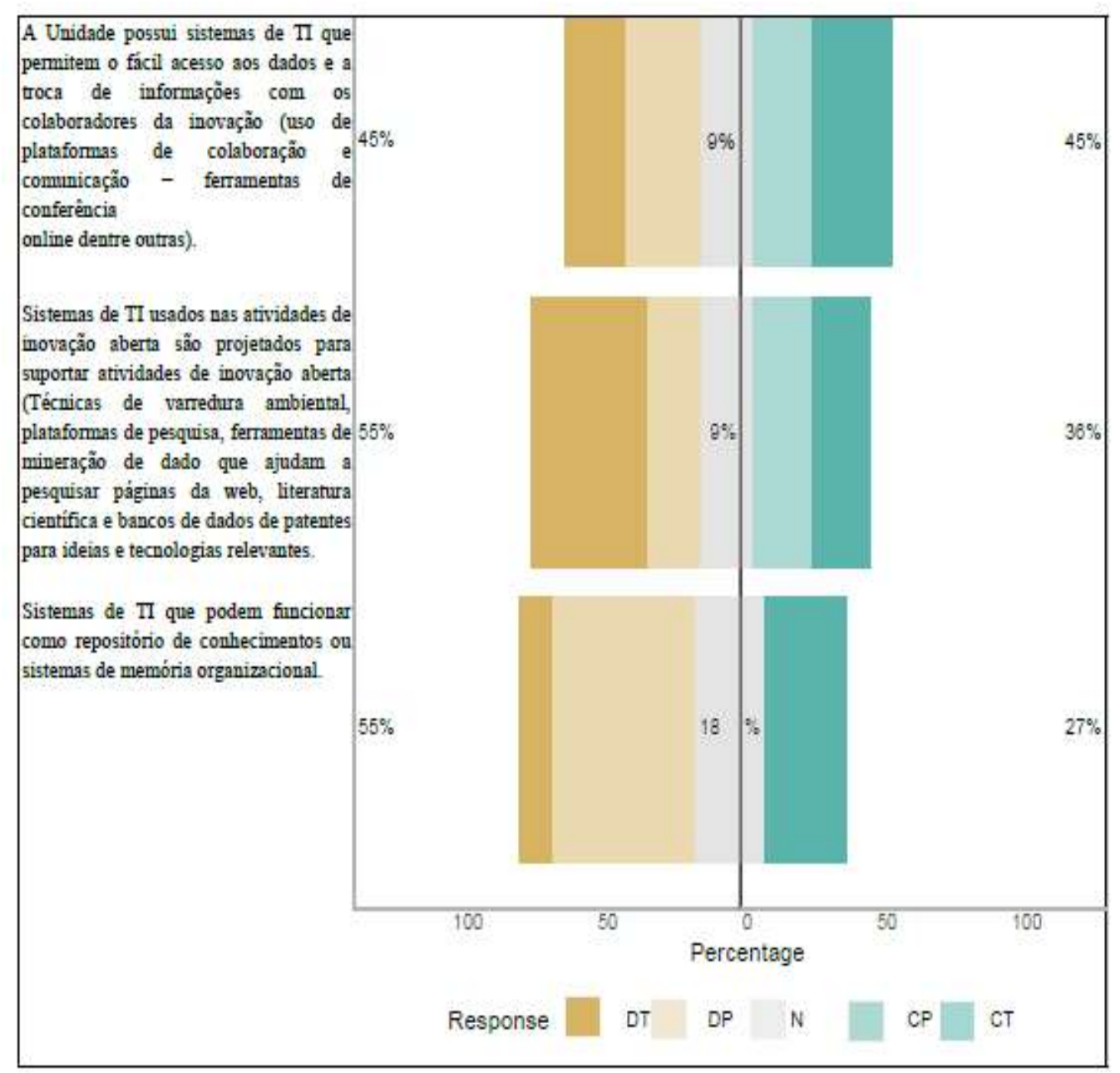

Figura 43: Gráfico de Concordância sobre aspectos de TI do CTAA

A primeira afirmativa, constante na Figura 43, mostra uma heterogeneidade em relação à visão dos participantes da pesquisa sobre a existência na Unidade, de sistemas de TI que permitam acesso a dados e a troca de informações de forma rápida com os colaboradores da inovação aberta. Dentre os participantes, $45 \%$ se dividem entre aqueles que concordam parcialmente ou concordam totalmente com a existência deste recurso na Unidade, enquanto outros $45 \%$ se dividem entre os que discordam parcialmente ou totalmente com esta afirmação. No entanto, quando comparamos com as demais afirmações da Figura 43, segunda e terceira afirmações, percebe-se que a maioria dos participantes discordam parcialmente ou totalmente das afirmações que visam analisar a existência na Unidade de Sistemas de TI que suportem e auxiliem as práticas de inovação aberta. Essa porcentagem corresponde à 55\% para ambas colocações.

Além disso, de acordo com a análise VRIO, cujo resultado consta na Figura 42, a grande maioria defende que este recurso, de forma geral, é visto como uma 
fraqueza. Assim, por meio desta triangulação, é possível afirmar que a TI é considerada uma fraqueza para a Embrapa Agroindústria de Alimentos.

$\mathrm{O}$ quarto fator do primeiro construto analisado, diz respeito à "Governança e Alinhamento Estratégico". Este fator foi analisado, por meio de quatro atributos, avaliados pela análise VRIO. O primeiro atributo analisado foi: "Tomada de decisões quanto ao uso de formas específicas de inovação aberta de acordo com os problemas e desafios de inovação enfrentados". De acordo com as respostas obtidas pelo questionário, $64 \%$ considera que tal atributo é uma fraqueza institucional. Quando comparamos este resultado com as entrevistas, percebemos que de fato, este atributo ainda é visto como uma fraqueza na Unidade, no entanto, é importante também evidenciar que na percepção dos entrevistados, a Unidade tem feito esforços interessantes no sentido de tomar decisões que alinhem melhor as estratégias de inovação aberta com os objetivos estratégicos. Algumas falas abaixo, corroboram e exemplificam esta visão.

Eu acho que a gente melhorou muito nesse ano, do ano passado pra cá melhor falando. Foi quando a gente realmente parou, enquanto chefia, junto com o CTI (do NAP), a gente parou pra poder pensar a unidade, então, a gente... nós identificamos ali oito linhas que poderiam... linhas que caracterizam bem a nossa unidade. Em cima dessa rede, a gente fez a discussão toda dentro do NAP, a gente fez todo um trabalho de conversar com parceiro externo, pra poder ouvi-los um pouco. Então, a gente levantou muita informação que foi fruto das nossas propostas do edital SEG agora que a gente fez. Não quer dizer que vamos ter sucesso, mas espero que isso ajude no sucesso e nos resultados (Entrevistado E1).

(...)as metas foram criadas em cima de demandas reais e que a gente pode... quer dizer, eu acho que a gente até foi ambicioso assim, mas dentro do que a gente tinha competência pra fazer. Então assim, as nossas metas agora são assim, colocar tantos produtos no mercado pra idosos, tantos produtos no mercado pra atender demandas, questões de saúde, pessoas com alergia, com intolerâncias, celíacos, intolerante à lactose, produtos especificos, estudos clínicos, então a gente fez... a gente mudou a nossa forma de fazer os projetos... (Entrevistado E6).

Então, eu acho que ela está começando a colaborar mais, entendeu? Ainda, ainda carece de mais direcionamento. Essa é a palavra que pra mim falta. Falta você direcionar, entendeu? Direcionar pra onde você quer ir... (...) pra onde você quer ir? Aonde você quer chegar? O que você pretende no futuro, entendeu? Essa é a questão. Então, você pode ter cinco, seis áreas de trabalho, mas você tem que concentrar, em no máximo, duas. Porque onde tudo é prioridade, nada se alcança. Então, assim, você tem que ter priorização de resultados ou de áreas de pesquisa, para que você possa almejar, alcançar determinadas metas. (Entrevistado E3)

Quanto ao segundo atributo deste aspecto: "Definição clara de funções e responsabilidades da inovação aberta", as respostas mostraram uma divisão entre as visões dos respondentes. A metade, ou seja 50\%, considera o atributo como 
fraqueza enquanto os outros $50 \%$ consideram o atributo como força e fonte de paridade competitiva. No entanto, confrontando as respostas com as entrevistas realizadas com alguns participantes, foi possível perceber que ainda não há na Unidade, funções definidas, com setores estruturados para abarcar a inovação aberta. A fala do respondente E2, mostra que, de forma geral, tudo ainda está em processo de construção e rearranjo na Embrapa e na Unidade também.

“(...) existe um macroprocesso de inovação, tudo bem, ótimo, que bom, e dai?? Como é que a gente se agregou a isso? Como a gente assimilou isso? Sabe? O que tem de assimilado desse macroprocesso de inovação? É só o papel que você olha e Muitas vezes só na teoria" (Entrevistado E2).

Quanto ao "Processo de Seleção de parceiros", para 64\% este é considerado uma fraqueza. Para o Entrevistado (E5):

Eu acho que, na nossa unidade, nós ainda precisamos evoluir. Eu vejo que tem unidades hoje que, inclusive, para esses projetos de inovação aberta, eles abrem editais pra convidar, e nós ainda não estamos exercendo isso, que eu acho que é um risco, inclusive, em termos de empresa pública. Mas a gente precisa evoluir muito ainda. A nossa unidade precisa evoluir.

Já para o Entrevistado E1, não há esse processo na Unidade, mas há uma explicação para isso.

Quando a gente fala "seleção de parceiro", isso é algo que eu, falando sinceramente com você, a gente não tem aqui dentro procedimento pra falar que eu vou selecionar A ou B. Mas isso tem uma explicação. A gente não tem muita... não é nossa prática aqui de fazer licenciamento, por exemplo, de tecnologia. Ai sim, eu teria que estar fazendo isso. Acaba que, como a nossa unidade, ela... vamos botar assim, nós temos 50 pesquisadores e cada pesquisador tem sua linha de trabalho. Então, acaba que essa entrada de parceiro aqui é muito pulverizada. Então, o que que eu quero dizer com isso? Às vezes no nosso próprio contato com o setor aí fora, em um trabalho nosso que acaba sendo específico, é um parceiro que nos procura, e não se aplica esse contexto de eu ter que fazer uma seleção de parceiros, eu não tenho uma disputa de três, quatro pessoas me procurando pra poder fazer alguma coisa, aí eu tenho que pensar. Não acontece. Normalmente, é... eu tenho um trabalho aqui que eu tenho um parceiro que me procura pra fazer aquele trabalho. Com exceção da própria questão de plant-based, que a gente tem contratos ligados a isso aí. O que a gente faz não é necessariamente uma seleção de parceiros, mesmo porque, o que a gente faz é tomar todo o cuidado de que o objeto que eu trate com o parceiro, não seja o mesmo objeto que eu trate com outro. Ou seja, se uma empresa A quer um produto comigo, e a empresa $B$ quer o mesmo produto, eu não fecho com a empresa $B$. (...) Isso é importante no nosso contexto de agroindústria, que como eu não trabalho com cultivar, não trabalho com semente, então, o meu tipo de trabalho que eu faço, envolve confidencialidade, envolve sigilo, envolve exclusividade, porque acaba que são projetos especificos que a empresa bota dinheiro aqui dentro.

O Entrevistado E6 corrobora com essa visão:

Eu acho que assim, pelo menos na nossa unidade, eu vejo mais são os parceiros procurando... nos procurando. (...)eu vejo mais as empresas buscando a Embrapa 
por alguma necessidade específica, do que a gente... a gente vai atrás numa necessidade, né? Numa questão especifica, né? tem algumas Embrapas que tem programas, tem vitrines, tem questões mais, digamos... acho que as Embrapas que trabalham diretamente com agronomia, elas têm mais essa interface, a gente é um pouco diferenciado de outras Embrapas assim, mas a gente tem bastante, a gente bastante coisa por demandas... demandas públicas mesmo.

Quanto ao último atributo "Propriedade Intelectual", para a grande maioria dos respondentes, parcela esta correspondente a $67 \%$, o atributo é visto como uma força, dentre os quais $44 \%$, considera como fonte de vantagem competitiva temporária para a Unidade. Isto porque o atributo é considerado desenvolvido e aproveitado, além de dotado de valor e raridade. No entanto, por não ser considerado inimitável, essa vantagem será temporária, condicionada à capacidade de outra empresa em copiá-la.

O Entrevistado E5 expressa de forma clara essa visão positiva a respeito da Propriedade Intelectual na Unidade, no entanto, ressalta preocupações quanto à questões de manutenção da qualidade da gestão da PI a longo prazo.

A gente tem um CLPI, vamos dizer assim, muito bem dirigido. a gente precisa ampliar a tomada de decisão dos outros membros do CLPI no CTAA. Ou seja, hoje, eu tenho um presidente do CLPI, que sabe muito, e que vem se capacitando há muitos e muitos anos, e na hora que ele se aposentar, eu vejo isso como uma grande ameaça pro Centro. Então, eu acabei de conversar com ele nesse sentido, entendeu? Como que a gente pode fazer pra que os outros membros do CLPI se envolvam da mesma maneira? Não tenham medo de tomar decisão, entendeu? Esse tipo de coisa. Também é um caminho, mas Paula, não é simples também não.

O quinto fator se refere à "Capacidade de Gerenciamento do conhecimento" que foi avaliado por meio de três atributos e pela análise VRIO.

A primeira afirmativa, constante no questionário, "Minha Unidade possui capacidade de explorar, criar, desenvolver, reter e transformar o conhecimento adquirido internamente ou externamente, de modo a gerar inovação", avalia as capacidades inventiva, absortiva, transformativa e inovativa da Unidade. As respostas mostraram uma divisão e uma falta de consenso entre os respondentes sobre a qualificação deste atributo. Metade dos respondentes considera o atributo como uma fraqueza, fonte de desvantagem competitiva, enquanto a outra metade $50 \%$, considera o atributo como uma força, fonte de paridade competitiva.

A fala do Entrevistado E1 mostra claramente essa divisão na Unidade, entre um público que já está mais envolvido nos processos de inovação enquanto outra parcela ainda tem dificuldades para abarcar esses novos processos. 
a gente é um processo, o macroprocesso de inovação, ele é uma transformação muito forte na empresa e muito boa, no meu modo de ver, mas a minha crítica em termos de organização é que a gente não solidificou ainda esse processo. Eu acho que ele pode ser melhor solidificado. A gente fez uma pesquisa ano passado, os resultados, sei lá, grosseiramente falando, 50, 60\% do grupo entendia muito bem o macroprocesso em inovação.

Assim, é possível afirmar que a Unidade ainda não possui uma maturidade interna, no sentido de internalização plena de conceitos e conhecimentos que propiciem um ambiente totalmente favorável à inovação.

$\mathrm{O}$ segundo atributo diz respeito à desorptive capacity, capacidade da Unidade em transferir seus conhecimentos internos, que não são considerados centrais, para que sejam utilizados externamente, por outras empresas. Para 55\%, essa capacidade é definida como fraqueza e fonte de desvantagem competitiva.

O terceiro atributo, diz respeito à análise da capacidade conectiva, avaliada por meio da seguinte afirmação: "Minha Unidade possui capacidade de estabelecer links com parceiros, de modo que esse link facilite o acesso a novos conhecimentos". Para $80 \%$ dos respondentes, tal atributo representa uma força e para $70 \%$ destes, é dotado de valor e aproveitado pela Unidade, logo é definido como uma força e fonte de paridade competitiva para o CTAA.

O sexto e último fator referente à: "Recursos e capacidades internas", corresponde à análise das Habilidades e Competências individuais". Este fator foi analisado por meio de três atributos, que avaliaram a mentalidade tecnológica, a capacidade de Liderança pessoal por pares e corretagem social, bem como a capacidade de alargamento de fronteiras. Tais capacidades foram avaliadas por meio de afirmativas, cuja avaliação se deu pela análise VRIO.

De acordo com os resultados, todos os três atributos foram considerados fraquezas, fontes, portanto, de uma desvantagem competitiva. Os resultados são representados nas Figuras 44, 45 e 46: 


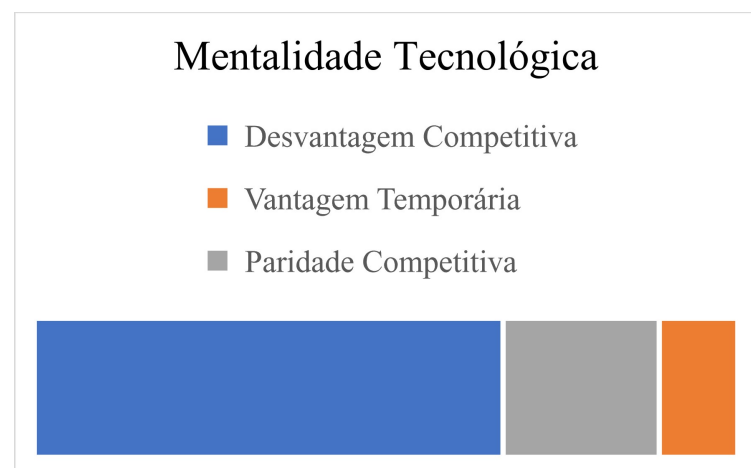

Figura 44: Mentalidade Tecnológica no CTAA

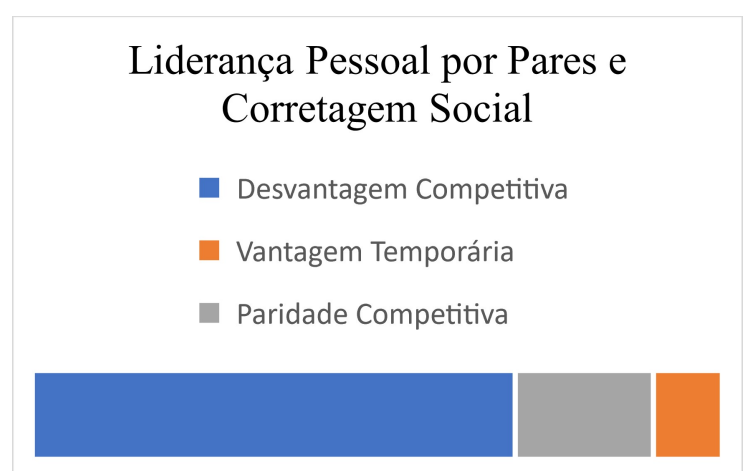

Figura 45: Liderança Pessoal por Pares e Corretagem Social- CTAA

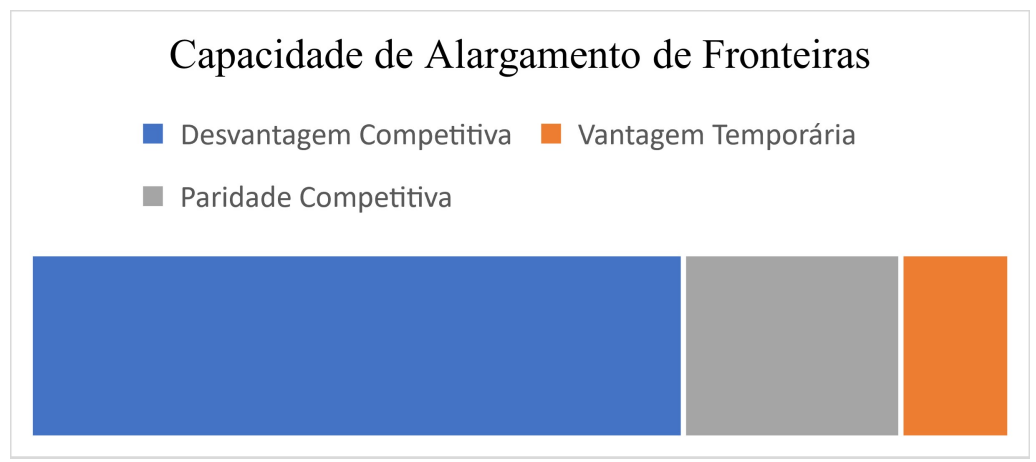

Figura 46: Capacidade de Alargamento de Fronteiras no CTAA

A mentalidade tecnológica foi avaliada por meio da afirmativa: "Os empregados da Unidade, envolvidos na Inovação aberta, possuem mentalidade tecnológica e lidam bem com novas tecnologias." Conforme Figura 44, para a maioria, correspondente a $67 \%$, o atributo foi considerado uma fraqueza na Unidade. Já a "Liderança pessoal por pares e corretagem social", foi avaliada por meio da afirmativa "Os empregados da Unidade, de forma individual e independente de estruturas e incentivos formais, são capazes de conectar novos parceiros que possam ajudar a atingir objetivos estabelecidos". De acordo com 70\% dos respondentes, Figura 45, é fraca a capacidade de conectar novos parceiros. De fato, a fala abaixo corrobora tal visão:

Mas vai muito mesmo dessa postura das pessoas de... sempre, de olhar, conversar com um cara externo e fazer uma ligação com aquilo que a gente tem aqui dentro. Quando a gente faz isso, funciona, dá certo. Mas um dia a gente chega num número maior de pessoas, tá difícil ainda (Entrevistado E1).

Quanto à capacidade de "Alargamento de Fronteiras", a Figura 46 mostra que a maioria, quantitativo igual a $67 \%$ também considera fraca essa capacidade na Unidade. A avaliação deste fator se deu pela seguinte afirmativa: "Os empregados da Unidade são atores flexíveis e capazes de lidar com a heterogeneidade do 
conhecimento dos parceiros, com culturas organizacionais distintas, amenizando conflitos e facilitando diálogo entre múltiplos mundos".

De forma a simplificar e facilitar a visualização dos recursos/fatores internos, quanto suas representações de forças e fraquezas para a Unidade, bem como suas implicações estratégicas, elaborou-se o Quadro 13.

Quadro 13: Relação das Forças e Fraquezas e implicações estratégicas no CTAA

\begin{tabular}{|c|c|c|}
\hline \multicolumn{3}{|c|}{$1^{\circ}$ Recurso: Pesquisa e Desenvolvimento } \\
\hline Atributo & Força/Fraqueza & Implicância Estratégica \\
\hline Quantidade de Recursos Humanos em P\&D & Força & Paridade Competitiva \\
\hline $\begin{array}{l}\text { Qualidade Técnica dos Recursos Humanos } \\
\text { em P\&D }\end{array}$ & Força & Paridade Competitiva \\
\hline Qualidade Inovadora dos Recursos Humanos & Força & Paridade Competitiva \\
\hline $\begin{array}{l}\text { Infraestrutura física, de TI e insumos } \\
\text { para realização da P\&D }\end{array}$ & Força & Paridade Competitiva \\
\hline Suporte à inovação (ADM; TT e negócios) & Fraqueza & Desvantagem Competitiva \\
\hline \multicolumn{3}{|c|}{$3^{\circ}$ Recurso: Cultura } \\
\hline Cultura voltada para inovação aberta & Fraqueza & Desvantagem Competitiva \\
\hline \multicolumn{3}{|c|}{$3^{\circ}$ Recurso: Tecnologia da Informação (TI) como suporte à Inovação Aberta } \\
\hline Tecnologia como suporte à Inovação aberta & Fraqueza & Desvantagem Competitiva \\
\hline \multicolumn{3}{|c|}{$4^{0}$ Recurso: Governança e Alinhamento Estratégico } \\
\hline $\begin{array}{l}\text { Tomada de decisões quanto ao uso de formas } \\
\text { específicas de inovação aberta de acordo com } \\
\text { os problemas e desafios de inovação } \\
\text { enfrentados. }\end{array}$ & Fraqueza & Desvantagem Competitiva \\
\hline $\begin{array}{l}\text { Definição clara de funções e responsabilidades } \\
\text { da inovação aberta. }\end{array}$ & Fraqueza & Desvantagem Competitiva \\
\hline Processo de seleção de parceiros bem definido. & Fraqueza & Desvantagem Competitiva \\
\hline Propriedade Intelectual. & Força & Vantagem Temporária \\
\hline \multicolumn{3}{|c|}{$5^{\circ}$ Recurso: Capacidade de Gerenciamento do Conhecimento } \\
\hline $\begin{array}{l}\text { Capacidades Inventiva, Absortiva, } \\
\text { Transformativa e Inovativa }\end{array}$ & Fraqueza & Desvantagem Competitiva \\
\hline Desorptive Capacity & Fraqueza & Desvantagem Competitiva \\
\hline Capacidade Conectiva & Força & Paridade Competitiva \\
\hline \multicolumn{3}{|c|}{$6^{\circ}$ Recurso: Habilidades e Competências individuais } \\
\hline Mentalidade Tecnológica & Fraqueza & Desvantagem Competitiva \\
\hline $\begin{array}{l}\text { Liderança Pessoal por Pares e Corretagem } \\
\text { Social. }\end{array}$ & Fraqueza & Desvantagem Competitiva \\
\hline Alargamento de Fronteiras & Fraqueza & Desvantagem Competitiva \\
\hline
\end{tabular}

Pela análise do Quadro 13, conclui-se que dentre as 17 capacidades/atributos analisados, divididos entre os seis fatores, seis são consideradas como Forças internas para a Embrapa Agroindústria de Alimentos e 11 consideradas fraquezas internas. Dentre os fatores, a "Governança e Alinhamento Estratégico"; "Habilidades e Competências Individuais" e "Capacidade de Gerenciamento do Conhecimento" foram os que possuem mais fraquezas de acordo com os participantes da pesquisa. 


\subsubsection{2}

\section{Alianças e Portfólios de Alianças para impulsionar o desempenho de inovação.}

Nesta seção são apresentados os resultados quanto à identificação das alianças estabelecidas pela Unidade e seus parceiros de inovação, bem como as características dessas relações interorganizacionais consideradas cruciais para alavancar o desempenho de inovação na Embrapa Agroindústria de Alimentos CTAA.

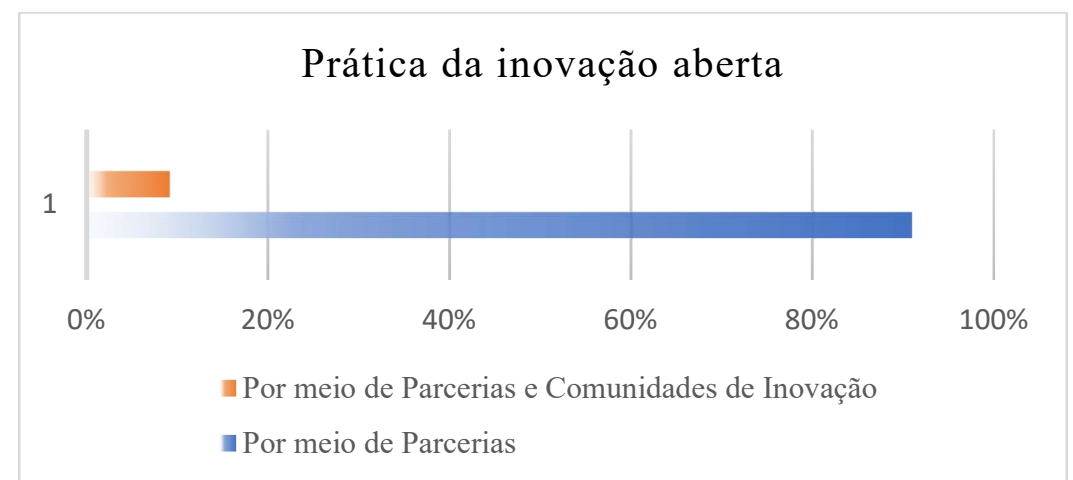

Figura 47: Prática da Inovação Aberta no CTAA

Conforme Figura 47, para 91\% dos respondentes, o CTAA, pratica a inovação aberta por meio de parcerias. Os participantes também foram indagados sobre a importância da participação da Unidade em alianças, se as mesmas são consideradas partes fundamentais para a estratégia de inovação da Unidade, e ainda, se geram impacto no seu desempenho de inovação, ou ainda, se representam maiores ameças ou oportunidades para o CTAA. A Figura 48 - Gráfico de concordância, mostra o grau de concordância dos participantes acerca de tais afirmativas. 


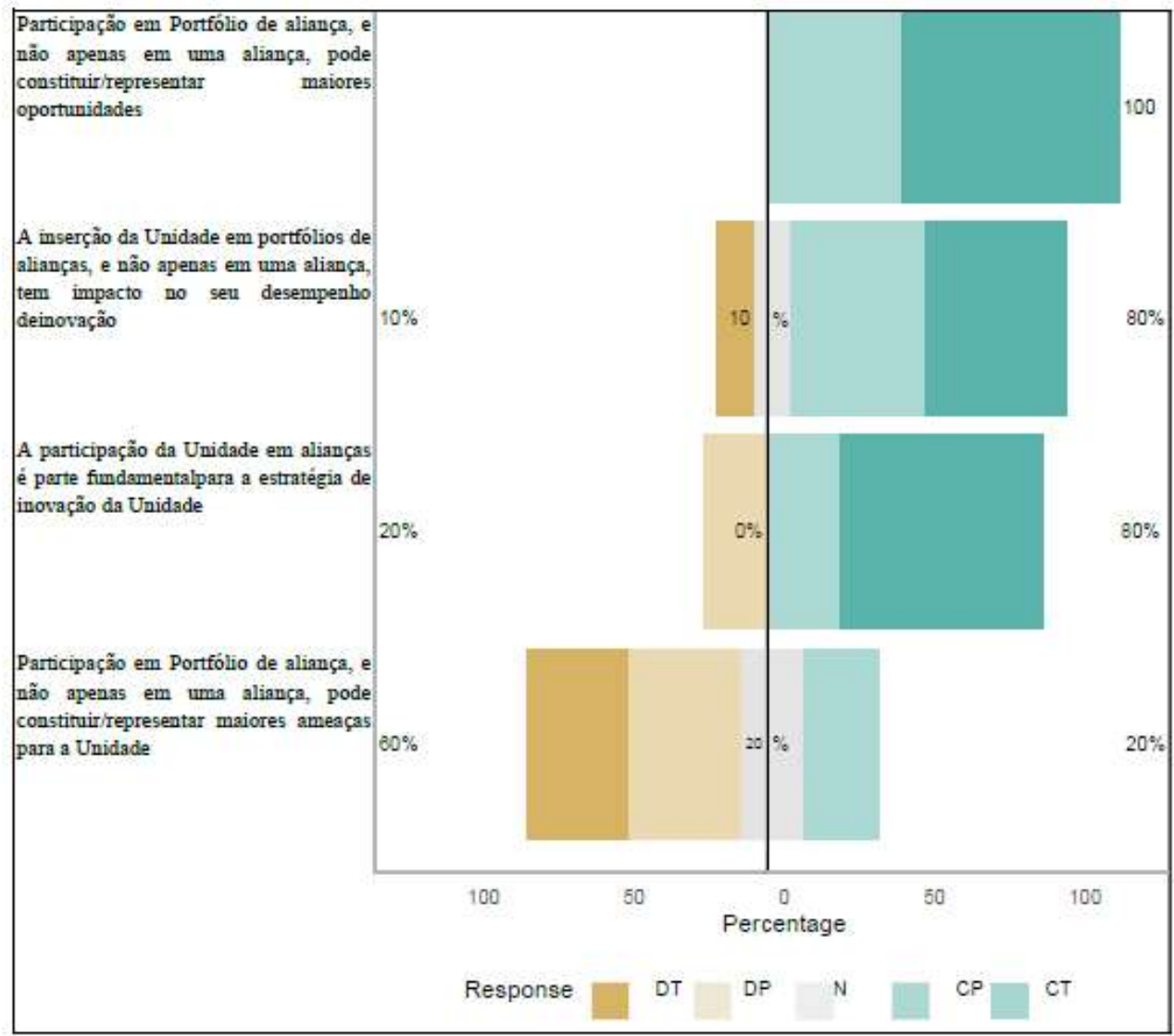

Figura 48: Gráfico de Concordância quanto à participação do CTAA em alianças

Pela análise da Figura 48, terceira afirmativa, é possível perceber que a grande maioria dos participantes considera a participação do CTAA em alianças, parte fundamental para sua estratégia de inovação. De forma coerente, a grande maioria discorda de forma parcial ou total com a representação de maiores ameças para o centro, no caso de envolvimento da Unidade em portfólios de alianças, conforme última afirmativa. Sendo assim, todos os participantes, conforme primeira afirmativa, percebem tal participação como representação de maiores oportunidades para a Unidade no que tange à inovação, variando entre uma concordância parcial e total com essa participação.

Com relação à participação da Unidade em relações interorganizacionais de forma bilateral ou multilateral, conforme Figura 49, os participantes se dividiram de forma igual, entre aqueles que consideram a participação da Unidade em alianças consideradas diádicas ou bilaterais, enquanto a outra metade considera que a Unidade participa de forma igual, em ambos tipos de parcerias, bilaterais e multilaterais. 


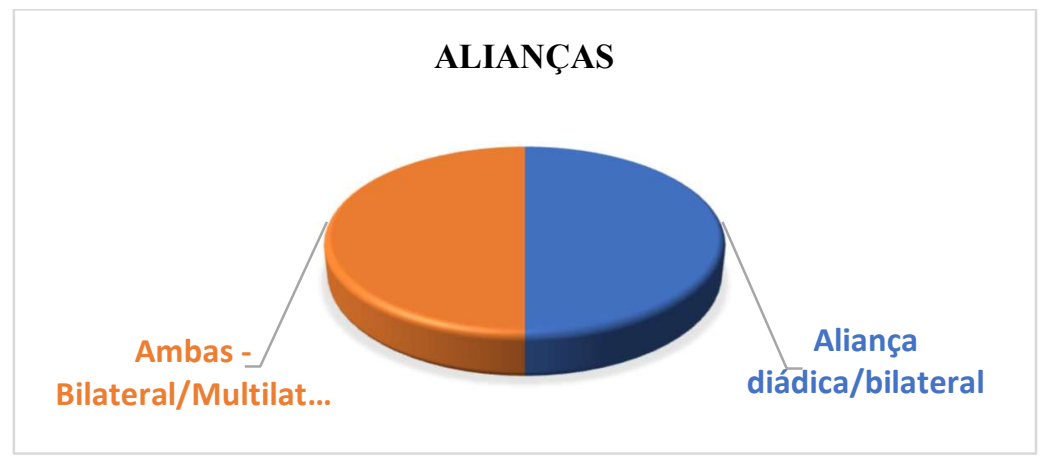

Figura 49: Alianças estabelecidas pelo CTAA

No entanto, com base nas respostas dos entrevistados, é possível perceber, que quando questionados sobre mais detalhes quanto a essa questão, a maioria afirma que a participação em alianças bilaterais é mais usual e recorrente na Unidade. Veja as falas que corroboram com essa conclusão:

O nosso contexto aqui é bilateral. (...) Até mesmo porque, são contatos muito específicos de empresa, e esse nosso contexto aqui é concorrência pura, concorrência pura. Às vezes eu percebo empresas querendo entrar aqui, mas acaba querendo se aproveitar de alguma coisa. Então, a gente já corta logo. Então, não dá. Então, de fato, é bilateral pela característica do nosso trabalho aqui e pela característica dos contratos que a gente faz (Entrevistado E1).

Acho que tem os dois, mas eu diria que assim, quanto mais parceiros você envolve, a nossa... pra você fazer um acordo de parceria é uma coisa bem complexa, assim, bem burocrática, e que vai e volta, vai e volta, vai e volta, o jurídico vai e volta. Então assim, não é uma coisa ágil. E quanto mais parceiros tão envolvidos, mais dificil fica a coisa. Por exemplo, agora mesmo, a gente acabou de apresentar um projeto pra uma empresa que nos procurou e eu chamei uma colega minha da universidade pra fazer parte desse grupo também. E ai a hora que eu enviei pro meu projeto... pro meu chefe, o projeto, pra ele avaliar, ele falou assim, "não, mas a gente não tem necessidade dessa universidade aqui, ela só vai atrapalhar a gente, porque vai ser mais um parceiro e mais um que vai ter que entrar na questão burocrática, na questão de assinar, de ver papelada, a gente não precisa deles, vamos tirar, vamos fazer a parceria só a gente com a indústria e depois se precisar da universidade, a gente vê mais pra frente e tal". Então assim, essas parcerias com vários órgãos, com várias entidades, elas são complexas. (Entrevistado E6).

\section{Para o Entrevistado E5:}

O CTAA é bilateral, o CTAA e um parceiro. (...) Eu acho que até o momento, quer dizer, foi uma questão de demanda mesmo, entendeu? Da gente... talvez projetos menos complexos, entendeu? Aonde foi possivel que a gente se organizasse sozinho. Mas eu concordo que a gente tem que aprender a contar, até pra gente poder ter projetos de maior risco, de maior, enfim. Projetos mais estimulantes, vamos chamar assim.

Na Figura 50, são tipificados os parceiros que a Unidade estabelece parcerias. 


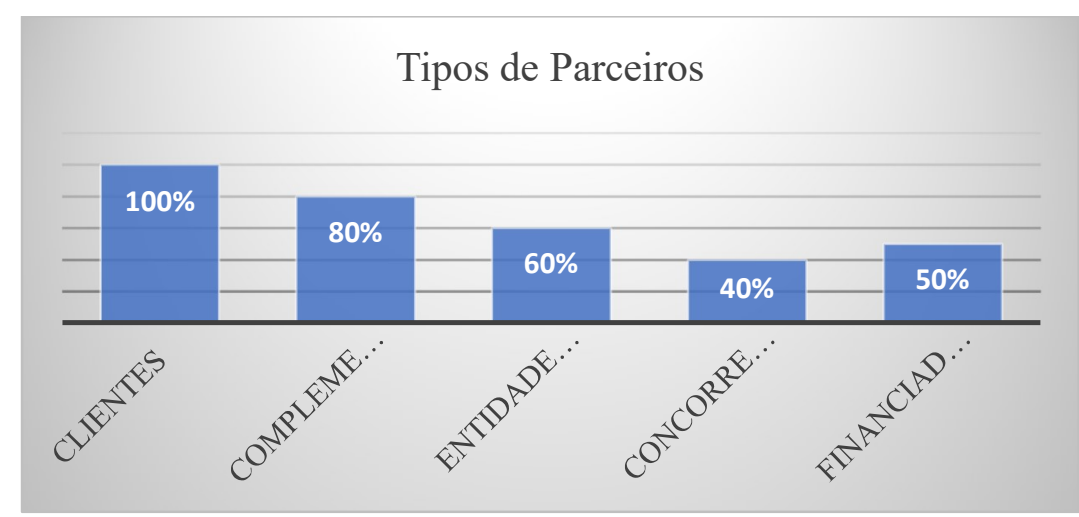

Figura 50: Tipos de Parceiros do CTAA

Para $100 \%$ dos respondentes, a Unidade realiza parcerias com clientes. De fato, os entrevistados citaram vários nomes definidos como clientes, com os quais a Unidade estabelece parcerias para realizar inovação. Alguns recorrentes foram: Coco Legal, Produtores Rurais, Empresas de processamento, de embalagem, pequenas e médias indústrias, dentre outros.

O segundo tipo de parceiro considerado mais relevante para a Unidade, foram os complementadores, segundo $80 \%$ dos respondentes, seguido pelas Entidades Governamentais. Pelas entrevistas, no entanto, percebe-se que em alguns casos, alguns tipos de parceiros se misturam, como é o exemplo das Entidades Governamentais e dos complementadores. A fala abaixo, do Entrevistado E2 mostra essa duplicidade:

$\dot{E}$, aí eu acho que... você falou isso, me veio a cabeça, os institutos e as universidades, aqueles que a gente sabe, institutos tecnológicos que desenvolvem conhecimento mesmo, que fazem pesquisa e que vão por outros caminhos. Por exemplo, hoje a gente tá... tem muito essa preocupação de desenvolver produtos saudáveis que fazem... que tem impacto na saúde humana, mas pra você fazer isso, às vezes você precisa fazer ensaios biológicos e isso a gente não tem. Então, a gente tem que buscar quem tenha. Universidades, institutos de pesquisa, sabe? Esses... esses, eu acho que ajudam muito a gente nessa complementação e de (arredondar) esse conhecimento nosso, sabe?

Em outros momentos, percebe-se também, a figura das entidades governamentais como clientes. Veja o depoimento do Entrevistado E6:

A gente tem muito, isso a gente tem bastante. Que é uma coisa que a Embrapa tem tradição de fazer, né? (...) Muitas demandas do próprio Mapa, da Anvisa também muitas vezes, porque a gente que trabalha com a área de alimentos, né? A gente, por exemplo, recentemente trabalhou com uma demanda de redução de sal e açúcar em produtos alimentícios, a gente participou dessa questão da rotulagem dos alimentos, dessa discussão de rotulagem dos alimentos, a gente participa de discussões de leis, por exemplo, eu participei agora da questão do queijo... do... da lei do queijo artesanal do estado do Rio de Janeiro. Então, a gente é chamado constantemente pra participar dessas questões... dessas discussões, então abre consulta pública do Mapa, da Anvisa, a gente é chamado pra dar opinião. Agora, 
por exemplo, a gente teve uma nota técnica com relação à essa questão de alimentos ultraprocessados. (...) o Inmetro também, tem vários colegas que apoiam o Inmetro, participam...

Quanto às Entidades Governamentais, foram recorrentes as falas que mostram a importância deste parceiro para a Unidade. Alguns nomes que foram mais citados, foram: o MAPA e a Anvisa.O Entrevistado E1 cita de forma clara a importância da parceria com este tipo de parceiro:

A gente atuou junto à Anvisa pra poder trabalhar questão de rotulagem. Então, um tema ai muito importante, sensivel pra indústria de alimentos. A gente tem parceria com o Mapa, pra trabalhar em cadeias produtivas, de azeite, que é algo importante, na própria plant-based, de ter uma cadeia importante também.

Já no caso dos concorrentes, estas foram as parcerias consideradas menos importantes quando comparadas à importância dos demais parceiros. Somente $40 \%$ considera essa parceria relevante para a Unidade. No entanto, para manter a coerência com os outros dois casos e considerando os depoimentos que mostraram uma dificuldade eventual na definição da existência da figura dos concorrentes para a Unidade, decidiu-se retirar a análise deste tipo de parceiro.

Com cada um desses atores estratégicos, a Embrapa Agroindústria de Alimentos estabelece um tipo de aliança de inovação. Os respondentes identificaram os principais tipos para cada parceiro, conforme Tabela 9.

Tabela 9: Tipos de Alianças de Inovação estabelecidas pelo CTAA

\begin{tabular}{l|l|l|l|l}
\multicolumn{1}{c|}{ Tipos de Alianças } & Clientes & Complementadores & $\begin{array}{c}\text { Entidades } \\
\text { Governa- } \\
\text { mentais }\end{array}$ & $\begin{array}{l}\text { Fomentadores/ } \\
\text { Financiadores }\end{array}$ \\
\hline $\begin{array}{l}\text { P\&D em conjunto } \\
\text { (Acordo/Contrato) }\end{array}$ & $80 \%$ & $60 \%$ & $60 \%$ & $50 \%$ \\
\hline $\begin{array}{l}\text { Desenvolvimento/Co- } \\
\text { produção }\end{array}$ & $80 \%$ & $50 \%$ & $20 \%$ & $20 \%$ \\
\hline $\begin{array}{l}\text { Licenciamento de Patente } \\
\text { ou Know-How }\end{array}$ & $80 \%$ & $40 \%$ & $20 \%$ & $20 \%$ \\
\hline $\begin{array}{l}\text { Acordo/Contrato de } \\
\text { fornecimento de outros } \\
\text { insumos/materiais }\end{array}$ & $60 \%$ & $30 \%$ & $10 \%$ & $20 \%$ \\
\hline $\begin{array}{l}\text { Acordo/Contrato de } \\
\text { Prestação de serviço }\end{array}$ & $100 \%$ & $10 \%$ & $30 \%$ & $10 \%$ \\
\hline
\end{tabular}

De acordo com a Tabela 9, no que se refere aos clientes, as parcerias são bastante heterogêneas, variando entre Acordos/contratos de Prestação de Serviços, P\&D em conjunto; Desenvolvimento/Co-produção e Licenciamento de Patente ou know-How. Já as parcerias estabelecidas com complementadores, para 60\%, essas são consideradas alianças para $\mathrm{P} \& \mathrm{D}$ em conjunto, seguidas pelas parcerias para 
Desenvolvimento/Co-produção. As parcerias com os Fomentadores/Financidadores, por sua vez, são estabelecidas, em sua maioria, para realização de $\mathrm{P} \& D$ em conjunto.

No que diz respeito à força das ligações das parcerias estabelecidas entre a Unidade e seus principais parceiros, essas estão descritos na Figura 51. Para a maioria dos participantes, essas ligações estabelecidas diferem de acordo com o tipo de parceiro. As parcerias estabelecidas com clientes, Entidades Governamentais e Financiadores/Fomentadores, são consideradas parcerias fortes e profundas, enquanto as parcerias estabelecidas com complementadores são vistas como fracas e amplas.

O Entrevistado E1 ratifica a existência de laços fortes com parceiros, o que favorece as parcerias de longa data e que geram sempre novos projetos em parceria.

Têm várias empresas, mesmo que sejam empresas que fazem análise com a gente, faz há anos já isso aí (...) nós estamos discutindo agora o tipo III com eles. Então, a gente sempre mantém, eu diria assim, com exceção de prestação de serviço que são mais rápidas, empresas de pesquisa, a gente mantém contato sempre, parceria que... a nossa ideia é que sejam parcerias longas mesmo.

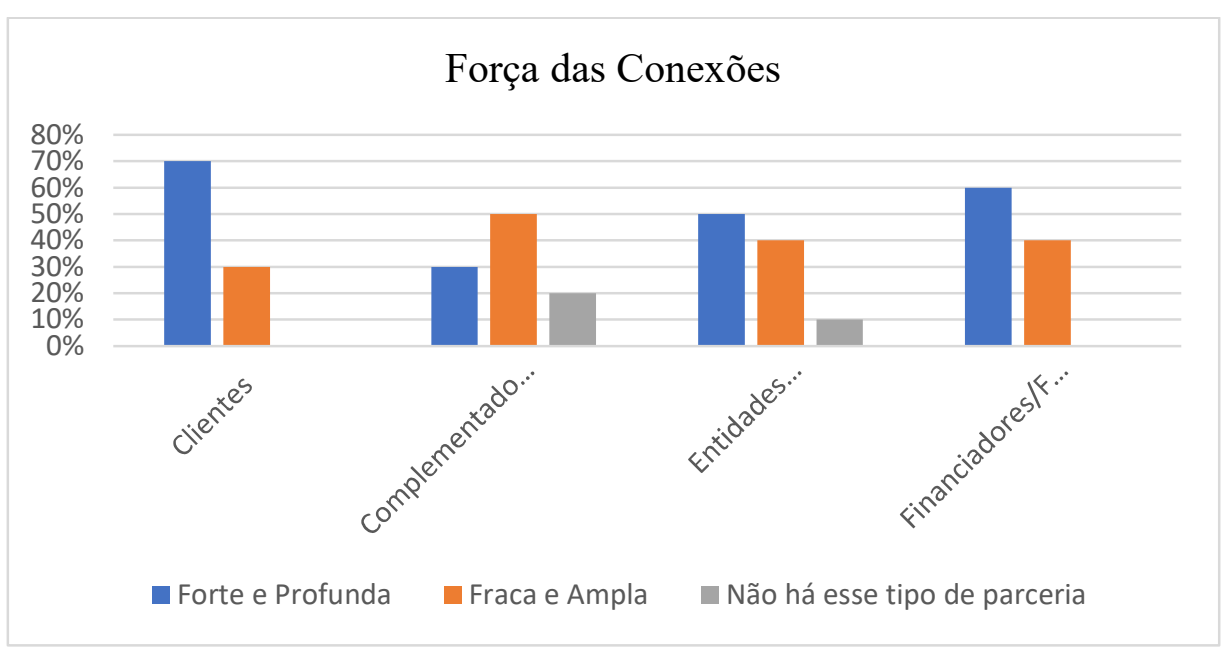

Figura 51: Força das Conexões das alianças estabelecidas pelo CTAA

Já para outros entrevistados, as parcerias, independente dos tipos de parceiros, são consideradas em geral, fracas. O Entrevistado E4 expressa sua visão quanto a fraqueza das ligações estabelecidas entre a Unidade e seus parceiros:

E eu venho criticando no sentido de... do mesmo jeito que a gente na vida normalmente a gente fala que você tem que saber cultivar amizade, é a mesma coisa que tem que saber cultivar parceria. Não é só quando você precisa da instituição ou você precisa da pessoa que você tem... você vai lá, você chama a pessoa, tem muita maneira de fazer isso, eu penso em coisas simples que a gente precisava fazer, por exemplo, precisava dar prêmio pra parceiros, você precisaria mandar uma carta no final do ano ou depois no final de um projeto, você não tem... 
não tem... eu sempre reclamei... reclamei dessas coisas. Isso eu acho que é um aspecto fundamental, que não existe ainda, não tô sentindo mesmo.

Os participantes também foram interrogados quanto à natureza das ligações das parcerias estabelecidas. Para a metade dos respondentes, as ligações estabelecidas com clientes e complementadores são divididas entre alianças consideradas de exploração (explorative) que visam a busca, tanto de novos parceiros quanto de novas informações e conhecimentos, bem como alianças de aproveitamento (exploitative), que visam o aproveitamento de informações e conhecimentos já existentes nesses tipos de parceiros. Já as ligações estabelecidas com as Entidades Governamentais e Fomentadores/Financiadores foram consideradas, pela metade dos respondentes, como alianças que visam a exploração (explorative). No entanto, como essas parcerias foram definidas pelos entrevistados como as mais tradicionais e duradouras na Unidade, foi possível defini-las como alianças de aproveitamento (exploitative).

No caso dos complementadores e clientes, pela análise das respostas, no entanto, foi possível verificar a predominância das ligações consideradas como explorativas (explorative). Veja a fala do Entrevistado E2 que corrobora com essa afirmação:

Eu acho que isso acontece dentro dos projetos de pesquisa, digamos assim, a medida que os portfólios vão mudando, vão se modernizando e vão demandando por novos conhecimentos, o pesquisador, ele também começa a fazer prospecção de parceiros que possam complementar aquela atividade dele pra atender aquele... aquela demanda, aquele portfólio. Então, eu acho que isso acontece sim, eu acho que isso acontece estimulado por esses projetos de pesquisa, né?

Quanto às suas distâncias geográficas, a Figura 52 traz o panorama destas parcerias estabelecidas com a Unidade.

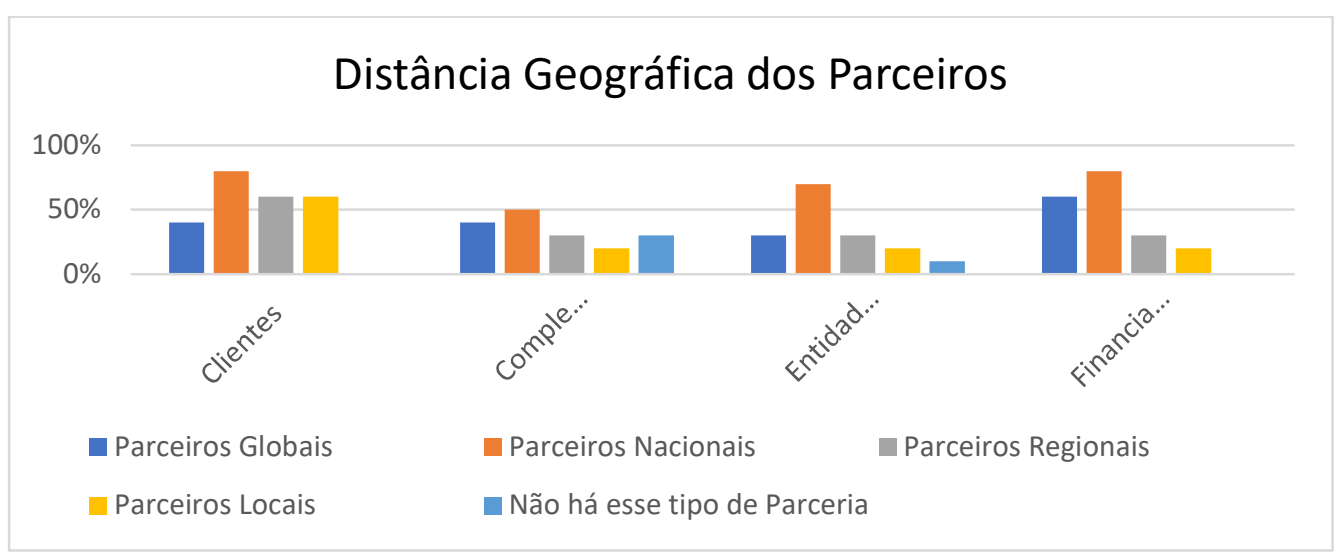

Figura 52: Distância Geográfica dos Parceiros do CTAA 
De acordo com a Figura 52, percebe-se a predominância de parcerias nacionais para a Unidade, independente do tipo de parceiro. Tal resultado vai ao encontro do papel da Unidade, cuja atuação é em nível nacional.

Ainda, de acordo com cada parceiro, existem principais tipos de recursos que a Unidade visa adquirir por meio da parceria estabelecida. Esses principais recursos, divididos por tipos de parceiros, estão descritos na Figura 53. 


\section{Recursos Chave}

Licenciamento de tecnologias e/ou know how Monitoramento de mudanças ambientais e oportunidades Redução do ciclo de vida do produto

Compartilhamento de Riscos e incertezas

Compartilhamento de recursos/competências complementares Compartilhamento de Custos

Aprendizagem com parceiros Acesso a novos conhecimentos/informações

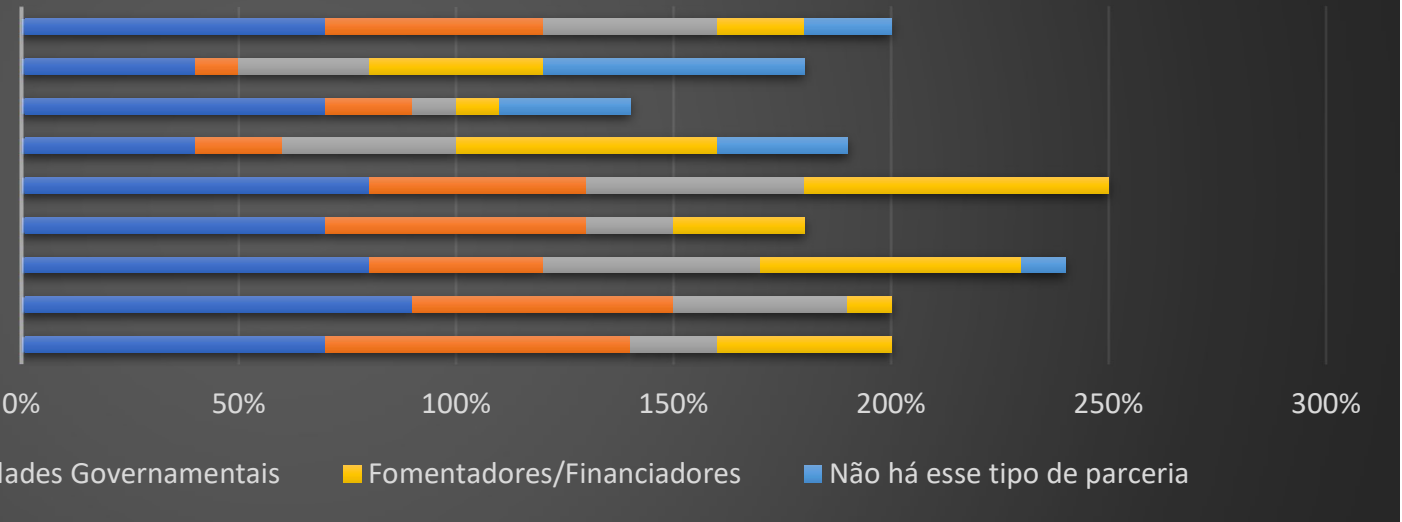

Figura 53: Recursos-Chave dos parceiros do CTAA 
Segundo os resultados descritos na Figura 53, as parcerias estabelecidas com clientes, visam, majoritariamente, aprendizagem, seguida, por alianças que visam o compartilhamento de custos, riscos e incertezas. Já as parcerias com complementadores, de acordo com $70 \%$ dos respondentes, visam o acesso a novos conhecimentos e informações, seguidos pelas parcerias para aprendizagem, bem como para compartilhamento de recursos e competências complementares. Para $60 \%$, as parcerias estabelecidas com as Entidades Governamentais visam, de forma majoritária, o compartilhamento de custos, riscos e incertezas, assim como as parcerias estabelecidas com Fomentadores/Financiadores, que também são realizadas, de forma majoritária, para compartilhamento de custos e de riscos e incertezas.

Para finalizar a análise deste $2^{\circ}$ construto constante do modelo, o Quadro 14 descreve, de forma resumida, os diferentes aspectos das principais alianças da Unidade no que concerne à inovação, considerando os principais tipos de parceiros, tipos de alianças, suas características, bem como os recursos-chaves e a implicação estratégica destas alianças para a Embrapa Agroindústria de Alimentos.

Pelo Quadro 14, percebe-se que todas as parcerias são vistas, pela grande maioria dos respondentes, como forças, fontes de paridade competitiva para a Unidade, o que significa dizer, que tais relações são dotadas de valor e desenvolvidas/aproveitadas pela Unidade, no entanto, estas não são consideradas nem raras e nem inimitáveis, não sendo, portanto, fontes de vantagens competitivas temporárias e nem tão pouco sustentáveis.

Cabe ressaltar, ainda, que cada parceria, por ser caracterizada como força, traz benefícios e recursos-chaves considerados importantes para melhorar a capacidade de inovação da Embrapa Agroindústria de Alimentos - CTAA. 


\begin{tabular}{|c|c|c|c|c|c|c|c|}
\hline Tipo de Parceiro & Tipo de Aliança & $\begin{array}{l}\text { Natureza das } \\
\text { Ligações }\end{array}$ & $\begin{array}{l}\text { Distância } \\
\text { Geográfica }\end{array}$ & $\begin{array}{l}\text { Modalidade } \\
\text { das ligaçôes }\end{array}$ & Recursos Chave & $\begin{array}{l}\text { Forçal } \\
\text { Fraqueza }\end{array}$ & $\begin{array}{l}\text { Implicância } \\
\text { Estratégica }\end{array}$ \\
\hline Clientes & $\begin{array}{l}\text { Acordo/Prestacãa de Serviços; P\&D } \\
\text { em conjunto:Desenvolvimento/CD- } \\
\text { producão; Licenciamento de Patente } \\
\text { ou Know-How }\end{array}$ & $\begin{array}{ll}\text { Forte } & \mathrm{e} \\
\text { Profunda } & \end{array}$ & Nacionais & Explorative & 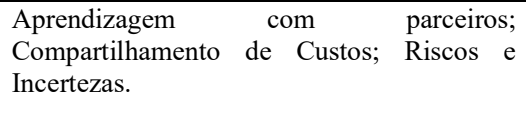 & Força & $\begin{array}{l}\text { Paridade } \\
\text { Competitiva }\end{array}$ \\
\hline Complementadores & $\begin{array}{l}\text { P\&D em conjunto; } \\
\text { Desenvolvimento/Co-produção. }\end{array}$ & $\begin{array}{l}\text { Fraca e } \\
\text { Ampla }\end{array}$ & Nacionais & Explorative & $\begin{array}{l}\text { Acesso a novos conhecimentos e } \\
\text { informaçoes; Aprendizagem com parceiros; } \\
\text { Compartilhamento de recursos/competências } \\
\text { complementares. }\end{array}$ & Força & $\begin{array}{l}\text { Paridade } \\
\text { Competitiva }\end{array}$ \\
\hline $\begin{array}{l}\text { Entidades } \\
\text { Governamentais }\end{array}$ & $\begin{array}{l}\text { P\&D em conjunto; Acordo/Prestação } \\
\text { de Serviços }\end{array}$ & $\begin{array}{l}\begin{array}{l}\text { Forte e } \\
\text { Profunda }\end{array} \\
\end{array}$ & Nacionais & Exploitative & $\begin{array}{llll}\begin{array}{l}\text { Compartilhamento } \\
\text { incertezas }\end{array} & \text { de custos; riscos e } & \text { e }\end{array}$ & Força & $\begin{array}{l}\text { Paridade } \\
\text { Competitiva }\end{array}$ \\
\hline $\begin{array}{l}\text { Fomentadores/ } \\
\text { Financiadores }\end{array}$ & $\begin{array}{l}\text { P\&D em conjunto; } \\
\text { Desenvolvimento/Co-Produção; } \\
\text { Licenciamento de Patente ou Know- } \\
\text { How }\end{array}$ & $\begin{array}{l}\text { Forte e } \\
\text { Profunda }\end{array}$ & Nacionais & Exploitative & $\begin{array}{l}\text { Compartilhamento de riscos e incertezas; } \\
\text { Aumento de eficiência e } \\
\text { Compartilhamento de Custos }\end{array}$ & Força & $\begin{array}{l}\text { Paridade } \\
\text { Competitiva }\end{array}$ \\
\hline
\end{tabular}


Após aplicação, na Embrapa Agroindústria de Alimentos, do modelo teórico, elaborou-se o Quadro 15 que inter-relaciona as forças e fraquezas identificadas a partir da análise dos dois construtos: "Recursos e capacidades internas" e "Alianças e Portfólios de Alianças para impulsionar o desempenho de inovação", com o intuito de identificar as complementariedades entre esses dois ambientes (interno e externo) que supram as lacunas existentes na Unidade e contribuam para a melhoria do desempenho de inovação da Embrapa Agroindústria de Alimentos.

Além da melhoria das fraquezas internas por meio das alianças, as parcerias também contribuem para melhoria das forças internas existentes, de modo a tornar essas forças fontes de vantagem competitiva sustentável para a Unidade. O Quadro 16 mostra como as parcerias potencializam, por meio de seus benefícios, as forças internas existentes. 
Quadro 15: Relação entre Fraquezas internas e Forças Externas do CTAA

\begin{tabular}{|c|c|c|c|c|c|c|}
\hline \multicolumn{2}{|c|}{ Construto } & \multirow{2}{*}{\begin{tabular}{|l|} 
Fatores Internos \\
raquezas internas
\end{tabular}} & \multirow{2}{*}{\multicolumn{2}{|c|}{$\begin{array}{c}\text { Fatores Externos } \\
\begin{array}{c}\text { Superação/minimização das Fraquezas internas por meio das Forças } \\
\text { advindas das parcerias }\end{array} \\
\end{array}$}} & \multicolumn{2}{|c|}{ Construto } \\
\hline & & & & & & \multirow{14}{*}{ 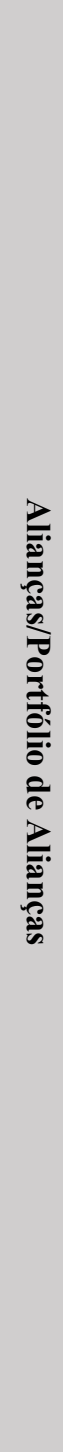 } \\
\hline \multirow{13}{*}{ 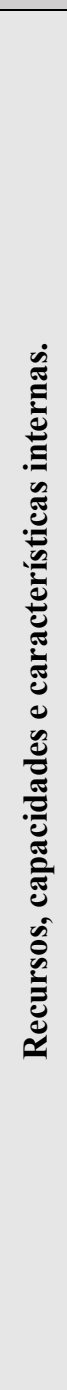 } & \multirow{13}{*}{$\begin{array}{c}\text { Fraquezas } \\
\text { internas }\end{array}$} & $\begin{array}{l}\text { Suporte à Inovação } \\
\text { (ADM, TT e Negócios) }\end{array}$ & $\begin{array}{l}\text { Alianças para P\&D em parceria com } \\
\text { clientes; complementadores }\end{array}$ & Aprendizagem com parceiros & \multirow{13}{*}{$\begin{array}{l}\text { Forças } \\
\text { Externas }\end{array}$} & \\
\hline & & \multirow{2}{*}{$\begin{array}{l}\text { Cultura voltada para } \\
\text { inovação aberta }\end{array}$} & $\begin{array}{l}\text { Alianças para P\&D em parceria com } \\
\text { clientes, complementadores }\end{array}$ & Aprendizagem com parceiros & & \\
\hline & & & $\begin{array}{l}\text { Alianças para Desenvolvimento/Co- } \\
\text { produção com complementadores }\end{array}$ & $\begin{array}{lr}\text { Acesso } \quad \text { a } & \text { novos } \\
\text { conhecimentos } & \text { e } \\
\text { informações. } & \end{array}$ & & \\
\hline & & \multirow{3}{*}{$\begin{array}{l}\text { TI como suporte à inovação } \\
\text { aberta }\end{array}$} & $\begin{array}{l}\text { Alianças para P\&D em parceria com } \\
\text { clientes, complementadores }\end{array}$ & $\begin{array}{l}\text { Aprendizagem } \\
\text { parceiros. }\end{array}$ & & \\
\hline & & & $\begin{array}{l}\text { Alianças para Desenvolvimento/Co- } \\
\text { produção com complementadores }\end{array}$ & $\begin{array}{lr}\text { Acesso a } & \text { novos } \\
\text { conhecimentos } & \text { e } \\
\text { informações. } & \end{array}$ & & \\
\hline & & & $\begin{array}{l}\text { Alianças para P\&D em parceria com } \\
\text { complentadores }\end{array}$ & $\begin{array}{l}\text { Compartilhamento de } \\
\text { recursos e competências } \\
\text { complementares }\end{array}$ & & \\
\hline & & \multirow{3}{*}{$\begin{array}{l}\text { Tomada de decisão quanto } \\
\text { ao uso de formas específicas } \\
\text { de inovação aberta de } \\
\text { acordo com os desafios de } \\
\text { inovação enfrentados. }\end{array}$} & $\begin{array}{l}\text { Alianças para P\&D em parceria com } \\
\text { clientes e complementadores }\end{array}$ & $\begin{array}{ll}\text { Aprendizagem } & \text { com } \\
\text { parceiros. } & \\
\end{array}$ & & \\
\hline & & & $\begin{array}{l}\text { Alianças para } \\
\text { produção com complementadores }\end{array}$ & $\begin{array}{l}\text { Acesso } \text { a } r \text { novos } \\
\text { conhecimentos e informações }\end{array}$ & & \\
\hline & & & $\begin{array}{l}\text { Alianças para P\&D em conjunto com } \\
\text { clientes, Entidades Governamentais }\end{array}$ & $\begin{array}{l}\text { Compartilhamento de riscos e } \\
\text { incertezas. }\end{array}$ & & \\
\hline & & \multirow{2}{*}{$\begin{array}{l}\text { Definição clara de funções } \\
\text { e responsabilidades da } \\
\text { inovação aberta. }\end{array}$} & $\begin{array}{l}\text { Alianças para P\&D em parceria com } \\
\text { clientes e complementadores }\end{array}$ & Aprendizagem com parceiros. & & \\
\hline & & & $\begin{array}{l}\text { Alianças para P\&D em parceria com } \\
\text { complementadores }\end{array}$ & $\begin{array}{lr}\text { Acesso }{ }^{2} & \text { novos } \\
\text { conhecimentos } & \text { e } \\
\text { informações. } & \end{array}$ & & \\
\hline & & \multirow[t]{2}{*}{$\begin{array}{l}\text { Processo de seleção de } \\
\text { parceiros bem definido }\end{array}$} & $\begin{array}{l}\text { Alianças para P\&D em parceria com } \\
\text { clientes e complementadores }\end{array}$ & Aprendizagem com parceiros. & & \\
\hline & & & $\begin{array}{l}\text { Alianças para P\&D em parceria com } \\
\text { complementadores }\end{array}$ & $\begin{array}{l}\text { Acesso a } \\
\text { conhecimentos } \\
\text { informações. }\end{array}$ & & \\
\hline
\end{tabular}




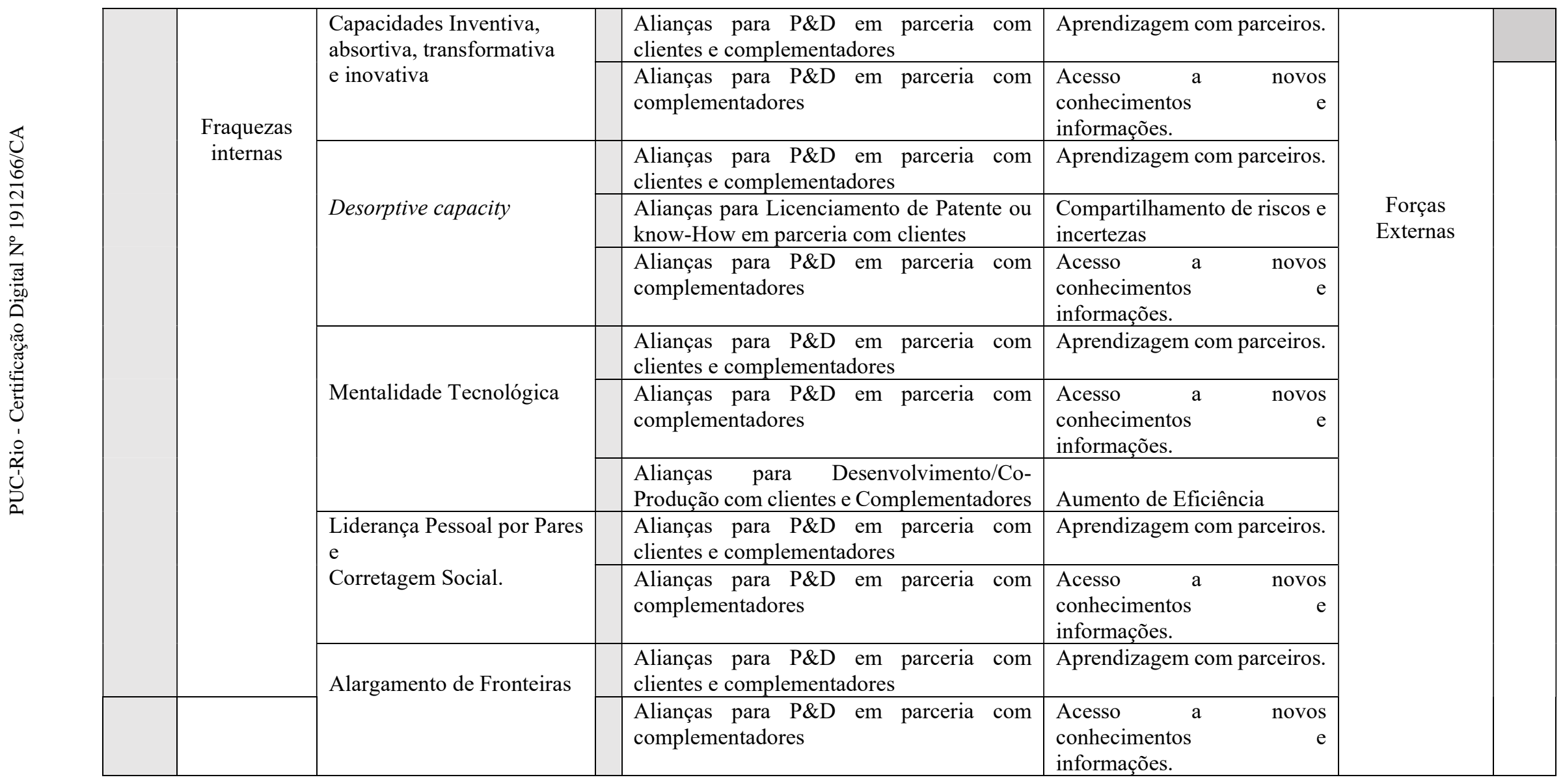


Quadro 16: Relação entre Forças internas e externas do CTAA

\begin{tabular}{|c|c|c|c|c|}
\hline \multirow{16}{*}{$\begin{array}{l}\text { Forças } \\
\text { internas }\end{array}$} & Fatores Internos & Fatores Externos & & \multirow{15}{*}{$\begin{array}{l}\text { Forças } \\
\text { Externas }\end{array}$} \\
\hline & $\begin{array}{l}\text { Quantidade Recursos } \\
\text { Humanos de P\&D }\end{array}$ & $\begin{array}{l}\text { Alianças para P\&D e Desenvolvimento/Co-Produção em } \\
\text { parceria com complementadores }\end{array}$ & $\begin{array}{l}\text { Acesso a novos conhecimentos } \\
\text { e informações }\end{array}$ & \\
\hline & \multirow{3}{*}{$\begin{array}{l}\text { Qualidade Técnica } \\
\text { dos Recursos } \\
\text { Humanos de P\&D. }\end{array}$} & 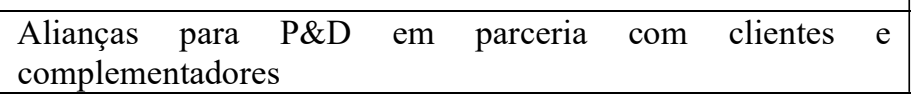 & Aprendizagem com parceiros & \\
\hline & & $\begin{array}{l}\text { Alianças para P\&D em conjunto e para Desenvolvimento/Co- } \\
\text { Produção com complementadores }\end{array}$ & $\begin{array}{l}\text { Acesso a novos conhecimentos } \\
\text { e informações. }\end{array}$ & \\
\hline & & Alianças para P\&D em parceria com complementadores & $\begin{array}{l}\text { Compartilhamento de } \\
\text { Recursos e competências } \\
\text { complementares. }\end{array}$ & \\
\hline & \multirow{3}{*}{$\begin{array}{ll}\text { Qualidade } & \text { Inovativa } \\
\text { dos } & \text { Recursos } \\
\text { Humanos } & \end{array}$} & Alianças para P\&D em parceria com complementadores & $\begin{array}{l}\text { Compartilhamento } \\
\text { competências } \\
\text { complementares. }\end{array}$ & \\
\hline & & $\begin{array}{l}\text { Alianças para P\&D e Desenvolvimento/Co-Produção em } \\
\text { parceria com complementadores }\end{array}$ & $\begin{array}{l}\text { Acesso a novos conhecimentos } \\
\text { e informações }\end{array}$ & \\
\hline & & $\begin{array}{l}\begin{array}{l}\text { Alianças para P\&D } \\
\text { complementadores }\end{array}\end{array}$ & Aprendizagem com parceiros & \\
\hline & \multirow{3}{*}{$\begin{array}{l}\text { Infraestrutura física, } \\
\text { de TI } \\
\text { e insumos para } \\
\text { realização da P\&D }\end{array}$} & $\begin{array}{l}\text { Alianças para P\&D e Desenvolvimento/Co-Produção em } \\
\text { parceria com complementadores }\end{array}$ & $\begin{array}{l}\text { Acesso a novos conhecimentos } \\
\text { e informações }\end{array}$ & \\
\hline & & $\begin{array}{l}\begin{array}{l}\text { Alianças para P\&D em parceria } \\
\text { complementadores }\end{array} \\
\text { com com }\end{array}$ & Aprendizagem com parceiros & \\
\hline & & $\begin{array}{l}\text { Alianças para P\&D com clientes; Entidades Governamentais e } \\
\text { Fomentadores/Financiadores }\end{array}$ & Compartilhamento de Custos & \\
\hline & \multirow{3}{*}{$\begin{array}{l}\text { Propriedade } \\
\text { Intelectual. }\end{array}$} & $\begin{array}{l}\text { Alianças para P\&D e Desenvolvimento/Co-Produção em } \\
\text { parceria com complementadores }\end{array}$ & $\begin{array}{l}\text { Acesso a novos conhecimentos } \\
\text { e informações }\end{array}$ & \\
\hline & & \begin{tabular}{lllllll|}
$\begin{array}{l}\text { Alianças para P\&D } \\
\text { complementadores }\end{array}$ & em & parceria & com & clientes & e \\
\end{tabular} & Aprendizagem com parceiros & \\
\hline & & Alianças para P\&D em parceria com complementadores & $\begin{array}{l}\text { Compartilhamento } \\
\text { recursos/competências } \\
\text { complementares. }\end{array}$ & \\
\hline & \multirow[t]{2}{*}{$\begin{array}{l}\text { Capacidade } \\
\text { Conectiva }\end{array}$} & $\begin{array}{l}\text { Alianças para P\&D e Desenvolvimento/Co-Produção em } \\
\text { parceria com complementadores }\end{array}$ & $\begin{array}{l}\text { Acesso a novos conhecimentos } \\
\text { e informações }\end{array}$ & \\
\hline & & $\begin{array}{lllllll}\begin{array}{l}\text { Alianças para P\&D } \\
\text { complementadores }\end{array} & \text { em } & \text { parceria } & \text { com } & \text { clientes } & \text { e } \\
\end{array}$ & Aprendizagem com parceiros & \\
\hline
\end{tabular}




\subsubsection{3}

\section{Desempenho de Inovação}

Esta seção apresenta os resultados quanto à percepção dos participantes acerca do desempenho de inovação da Embrapa Agroindústria de Alimentos, de 2019 a 2020, período que corresponde a implementação na Embrapa, do macroprocesso de inovação. Com relação à quantidade de resultados gerados pela Unidade, os dados são apresentados nas Figuras 54, 55 e 56:

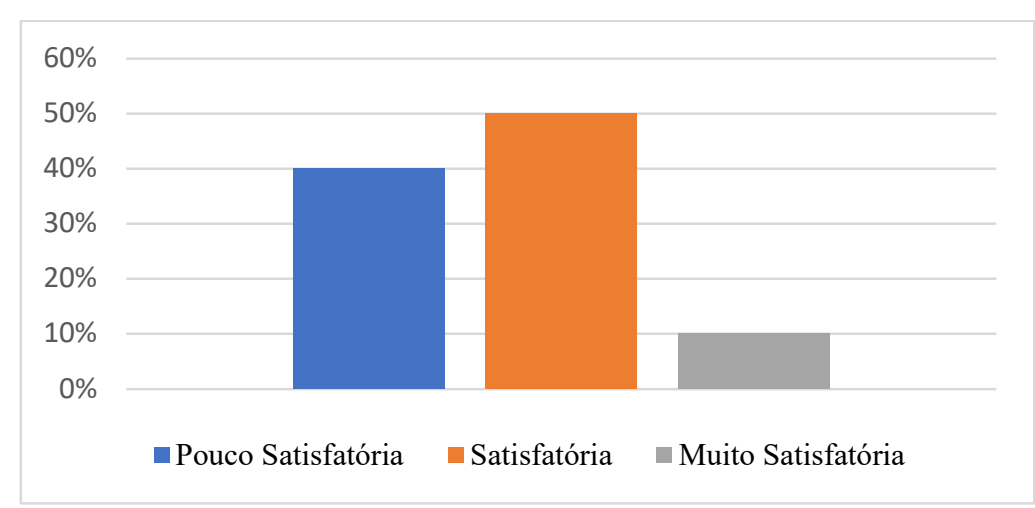

Figura 54: Ativos Pré-Tecnológicos produzidos pelo CTAA

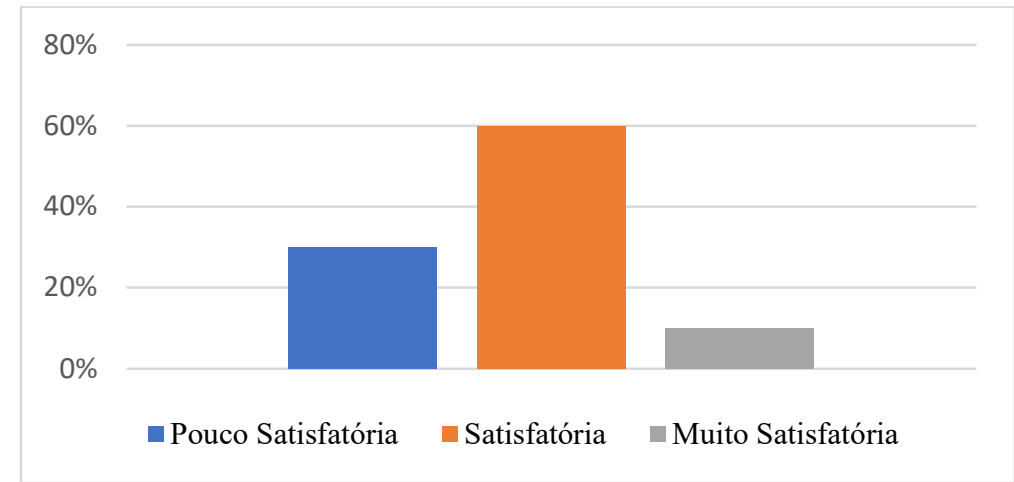

Figura 55: Ativos Tecnológicos produzidos pelo CTAA

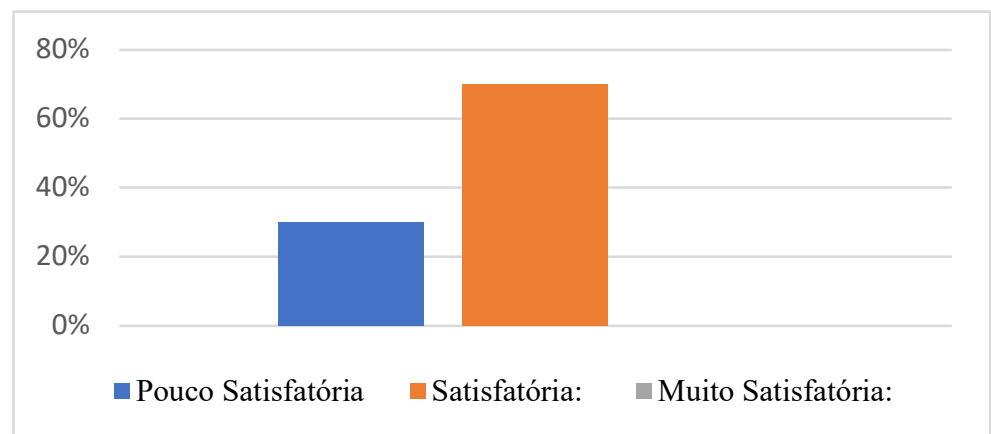

Figura 56: Apoio à Inovação produzidos pelo CTAA

De acordo com as Figuras 54, 55 e 56, para os três tipos de resultados produzidos, "Apoio à Inovação", “Ativos Pré-Tecnológicos" e "Ativos Tecnológicos", a maioria dos respondentes, considera tais produções satisfatórias. 
Por meio das entrevistas, buscou-se obter uma clareza maior quanto à percepção dos entrevistados acerca da quantidade dos resultados produzidos.

O Entrevistado E5 acredita que a produção de "Ativos Pré-Tecnológicos" e “Ativos-Tecnológicos", sejam as mais satisfatórias. O entrevistado ainda fornece um exemplo de um Ativo Tecnológico produzido, que acredita ter gerado impacto na sociedade. "Eu acho que o último agora, o hambúrguer vegetal com a Sottile, com essa empresa que a gente comentou”.

O Entrevistado E2, conforme passagem abaixo, corrobora com esta visão.

A gente tem gerado mais ativo tecnológico e ativo pré-tecnológico, a grande maioria dos nossos resultados, eles são processos, produtos e insumos. (...) Olha, um ativo tecnológico que a gente... e que inclusive, ele até, de uma certa forma, fez em parceria com a Embrapa Agroindústria Tropical, que são os produtos de fibra de caju, hambúrguer, coxinha. (...)Porque ele atende ao mercado, né? Tem feito muito sucesso e a gente tem sido muito procurado por causa disso, a gente tem contrato, não pode reproduzir esse ativo, sabe? Mas a competência a gente tem de fazer produtos similares a partir de outros produtos vegetais, sabe?

Eu acho que pré-tecnológicos também, porque como a gente trabalha muito com resíduo da indústria de alimentos, a gente trabalha muito com subproduto, extraindo compostos de interesses comerciais ou de interesses tecnológicos, e ai a gente tem muito esses insumos. Então, a gente trabalha muito com extratos ricos em pigmentos, extratos ricos em compostos bioativos, em compostos funcionais. Então, ai a gente chega nesse... nesse insumo pré-tecnológico, né? Que muitas vezes aí... mas assim, sempre visando a aplicação na indústria e sabendo que a indústria tá buscando isso também, né? (Entrevistado E6).

Por fim, o Entrevistado E1, também compartilha da mesma visão que os demais entrevistados. Veja o extrato abaixo:

"Ah, foram os tecnológicos, com certeza. (...) o próprio trabalho nosso com a empresa (Sotille), do (hambúrguer usando) fibra de caju. Isso fez um grande... foi um grande resultado".

Pelos extratos acima, pode-se verificar que de fato, para a grande maioria, os resultados mais satisfatórios, produzidos pela Unidade, foram os "Ativos Tecnológicos" e "Pré-Tecnológicos", com a apresentação de exemplos por parte dos entrevistados que mostram alguns desses tipos de ativos produzidos. $\mathrm{O}$ resultado "Apoio à Inovação", não foi mencionado pelos respondentes, embora, $70 \%$ tenha considerado a produção satisfatória, em termos de quantidade.

Outro ponto analisado foi com relação a efetividade destes resultados, no que diz respeito aos impactos gerados em diferentes contextos. Os resultados são apresentados na Tabela 10: 
Tabela 10: Impactos dos resultados produzidos pelo CTAA

Efetividade das inovações geradas em termos de seus impactos no desenvolvimento institucional?

\begin{tabular}{l|l}
\hline Impactos Pouco relevantes & $20 \%$ \\
\hline Relevantes & $\mathbf{8 0 \%}$ \\
\hline Muito relevantes & $0 \%$ \\
\hline Efetividade das inovações geradas em termos de seus impactos econômicos? \\
\hline Impactos Pouco relevantes & $40 \%$ \\
\hline Relevantes & $\mathbf{6 0 \%}$ \\
\hline Muito relevantes & $0 \%$
\end{tabular}

Efetividade das inovações geradas em termos de seus impactos socioambientais?

\begin{tabular}{l|l}
\hline Impactos Pouco relevantes & $\mathbf{4 0 \%}$ \\
\hline Relevantes & $\mathbf{4 0 \%}$ \\
\hline Muito relevantes & $20 \%$ \\
\hline
\end{tabular}

Efetividade das inovações geradas em termos de seus impactos na cadeia produtiva?

\begin{tabular}{l|l}
\hline Impactos Pouco relevantes & $20 \%$ \\
\hline Relevantes & $\mathbf{7 0 \%}$ \\
\hline Muito relevantes & $10 \%$
\end{tabular}

Pela análise da Tabela 10, pode-se observar que em relação aos resultados gerados e seus impactos, no que tange o desenvolvimento institucional, impactos econômicos e na cadeia produtiva, todos foram considerados, pela maioria, como impactos relevantes, com destaque para os impactos no desenvolvimento institucional, cujo percentual de $80 \%$ foi bastante expressivo. No que tange os impactos socioambientais, a amostra se mostrou bastante heterogênea, com uma parcela de $40 \%$ avaliando tais impactos como pouco relevantes, enquanto outros $40 \%$ consideraram os impactos socioambientais relevantes. Ainda uma pequena parcela avaliou o impacto como muito relevante.

No entanto, no que tange os impactos em nível socioambiental, o Entrevistado E2, conforme trecho abaixo, nos forneceu uma visão clara de como estes ainda podem se mostrar mais relevantes e mais expressivos.

Então, eu já fui, por exemplo, andando pra Friburgo, já fui, andei lá pra... nesses trabalhos que a gente faz de... enfim, de transferência de tecnologia, em que eu vi situações... Friburgo é um grande centro de produção de hortaliças, né? Frutas e hortaliças e eu fui, eu andando ali, eu via... eu via locais com infraestrutura e processos, sabe (...)eram coisas assim, tão rudimentares, tão... sabe? Tão ainda... que eu fiquei pensando, meu Deus do céu, com um centro da Embrapa dentro do Rio de Janeiro que atua nessa área, e esse pessoal trabalhando deste jeito, por quê? Como? Por que que não acontece? Cadê esses resultados que não chegam até aqui? Por que que não chegam? Se os resultados existem, as competências existem, a demanda existe, a necessidade existe, por que que a tecnologia que articula oferta e demanda numa cidade miserável, cada vez pior, que a referência 
é cada vez mais violência, safadeza, sacanagem, com essa quantidade toda, essa competência toda instalada no Rio de Janeiro, por quê? Não é um problema só da Embrapa, não, sabe?

Por meio do relato, pode-se concluir que a efetividade dos resultados gerados em termos de impactos socioambientais, ainda carece de melhorias, de modo que possa atender melhor às necessidades da sociedade. Dessa forma, embora as respostas tenham mostrado uma divergência de percepções entre os participantes, pode-se definir os impactos socioambientais apenas como satisfatórios, carecendo ainda de melhorias quanto sua efetividade.

Quanto ao grau de novidade das inovações produzidas pela Embrapa Agroindústria de Alimentos, 70\% consideram que a Unidade produz, majoritariamente, inovações incrementais. O Entrevistado E2 fornece uma explicação para a predominância deste tipo de inovação.

Na verdade, o nosso setor de alimentos, porque se você parar pra pensar, Paula, alimentos, cada vez mais, quanto mais próximo ao natural, né? Então, quer dizer, a gente em termos de inovação em alimentos, a gente não... sabe? Não tem... a gente tem que se utilizar de inovações de outras áreas pra tentar fazer o nosso alimento o mais próximo do natural possível. (...) Eu não preciso necessariamente fazer uma... uma inovação disruptiva pra que alguém se alimente. Eu tenho que entender que feijão com arroz é uma coisa muito gostosa e que a gente tem que fazer um meio disso chegar de uma forma mais barata pra todo mundo, sabe? Que seja preservada as suas características de nutrição, de frescor, tudo isso, a tecnologia de alimentos, ela entra pra isso.

Assim, ao observar as forças e fraquezas da Unidade e seu desempenho de inovação, percebe-se que as fraquezas internas superam as forças em termos de inovação e que tais fragilidades podem estar impactando na capacidade da Unidade em atingir um desempenho de inovação muito satisfatório. Por outro lado, as alianças estabelecidas são consideradas forças e suprem as lacunas internas detectadas, mesmo que de forma parcial, não sendo suficientes ainda para trazer uma vantagem competitiva à Embrapa Agroindústria de Alimentos. Dessa forma, pode-se concluir que sem a estratégia relacional, a Unidade poderia apresentar um desempenho de inovação menos expressivo, o que evidencia a importância da relação entre os dois ambientes interno e externo. O benefício advindo da ligação entre as alianças e os recursos internos, foi claramente citado pelos entrevistados, em trechos que mostram o impacto expressivo do produto: hamburguer vegetal, por exemplo. Produto produzido em parceria com a empresa Sotille e cujos resultados 
foram de extrema importância para a Unidade. Pelos relatos, fica evidente que sem essa parceria este resultado não teria sido atingido.

\section{4 \\ Embrapa Agrobiologia - CNPAB.}

O Centro Nacional de Pesquisa de Agrobiologia - CNPAB é uma Unidade da Embrapa, com atuação em todo território nacional. Possui pesquisas de temas básicos e é considerada referência em estudos voltados a avanços do conhecimento na área de Fixação Biológica de Nitrogênio (FBN). É também uma Unidade pioneira na Embrapa no desenvolvimento de pesquisas em agricultura orgânica e recuperação de áreas degradadas. A Unidade fica localizada no município de Seropédica, estado do Rio de Janeiro - RJ, com um quadro de aproximadamente 150 colaboradores, entre assistentes, técnicos, analistas e pesquisadores.

A história do Centro tem suas bases no trabalho desenvolvido pela pesquisadora Johanna Döbereiner, cujas principais linhas de pesquisa envolvem a técnica da fixação biológica de nitrogênio, além de agroecologia e produção orgânica, microbiologia e insumos biológicos, recuperação de áreas degradadas, genética molecular e bioquímica.

Atualmente, a Unidade desenvolve dezenas de projetos de pesquisa, dos quais, pelo menos a metade, está direta ou indiretamente associada com o uso de inoculantes e o processo da fixação biológica de nitrogênio - FBN.

Dentre as grandes contribuições da Unidade para a agricultura brasileira tem-se o estudo do uso de microrganismos para promover a FBN em substituição ao uso de fertilizantes nitrogenados na cultura da soja. $\mathrm{O}$ uso de inocultantes bacterianos garantiu a competitividade do grão brasileiro em relação a outros paises, o que refletiu diretamente na balança comercial do País, colocando o Brasil como segundo maior produtor mundial do grão, atrás apenas dos Estados Unidos e com uma economia anual de bilhões de dólares pela não utilização de fertilizantes nitrogenados. 


\subsection{1 \\ Descrição dos dados da Embrapa Agrobiologia, de acordo com os construtos apresentados no modelo teórico.}

\subsubsection{1}

Recursos, capacidades e características internas

$1^{\mathrm{o}}$ aspecto analisado: Pesquisa e Desenvolvimento - P\&D. Abaixo, são apresentados os resultados da análise dos cinco atributos relacionados à $\mathrm{P} \& \mathrm{D}$. De acordo com as Figuras 57 a 61, percebe-se que dos cinco atributos relacionados à P\&D, somente o "Suporte à Inovação (ADM, TT e Negócios)" Figura 61, foi considerado uma fraqueza para a Unidade e fonte de desvantagem competitiva. Os demais atributos foram considerados força e fontes de paridade competitiva, o que significa considerar tais aspectos como dotados de valor e aproveitados pela Unidade. Dos cinco aspectos, a "Qualidade Técnica dos Recursos Humanos envolvidos em P\&D” foi o que obteve uma melhor avaliação por parte dos respondentes. Todos os participantes, ou seja, $100 \%$ deles, classificaram o atributo como uma força para a Embrapa Agrobiologia, conforme Figura 58. Desse percentual, $60 \%$ considera o atributo desenvolvido/aproveitado pela Unidade, além de dotado de valor, e portanto, fonte de paridade competitiva. A "Quantidade de Recursos Humanos envolvidos em P\&D”, conforme Figura 57, também foi um atributo cujo grande percentual, igual a 92\%, o considera como força, sendo a grande maioria, $75 \%$ destes, o considera fonte de paridade competitiva.

Já a qualidade Inovativa, apesar de ter sido considerada pela maioria, como força, houve uma maior diversificação quanto à implicância estratégica de tal atributo, conforme Figura 59. No entanto, o percentual que se mostrou mais expressivo, foi a parcela de $33 \%$ que consideraram o atributo fonte de paridade competitiva para a Unidade. Por fim, conforme Figura 60, a Infraestrutura foi considerada como Força pela parcela de $83 \%$, dos quais $67 \%$ consideram como fonte de paridade competitiva.

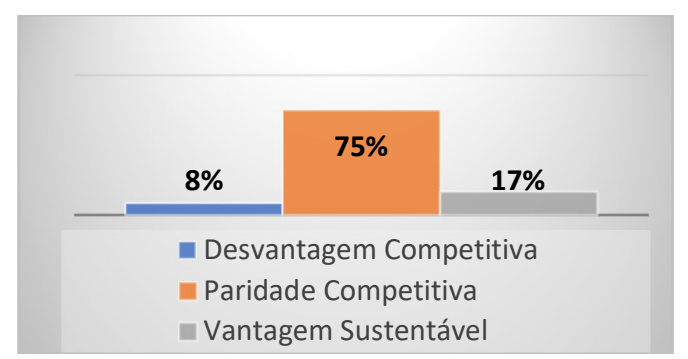

Figura 57: Quantidade de RH em P\&D no CNPAB 


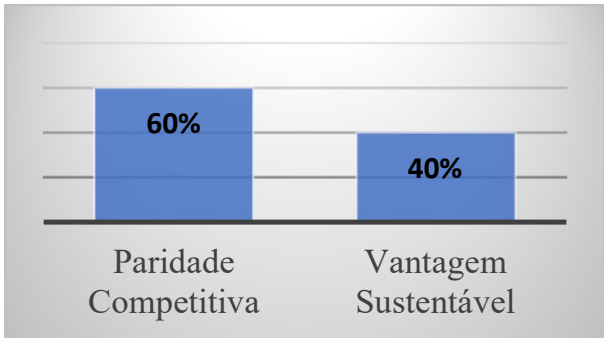

Figura 58: Qualidade Técnica de RH no CNPAB

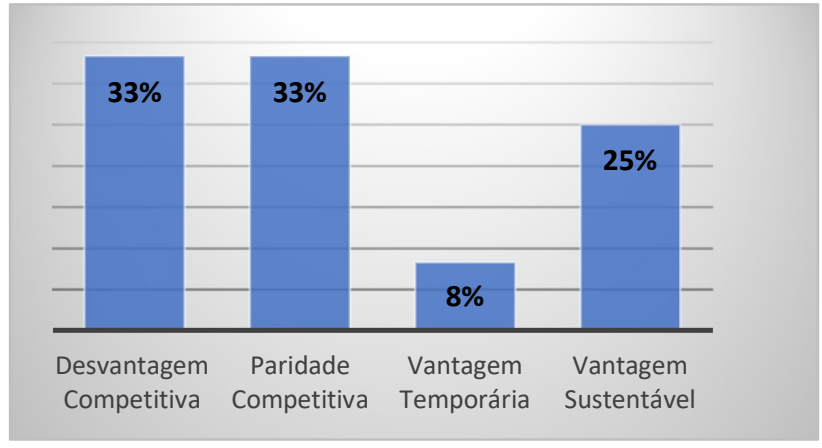

Figura 59: Qualidade inovativa de RH em P\&D do CNPAB

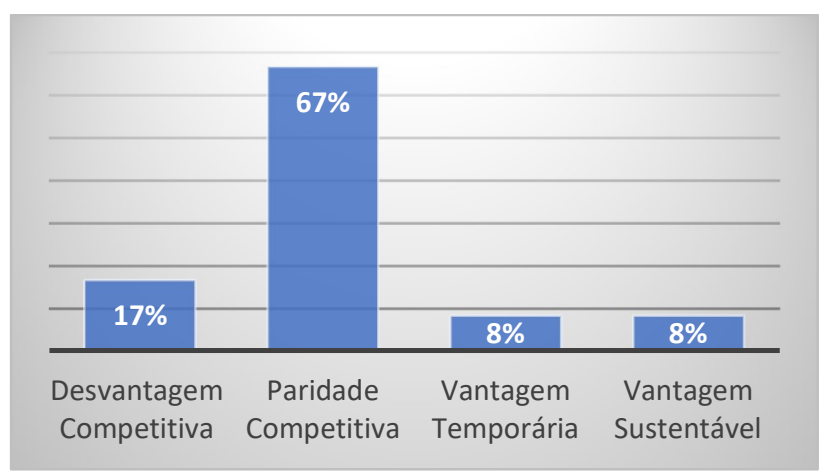

Figura 60: Infraestrutura Física, de TI e insumos da P\&D do CNPAB

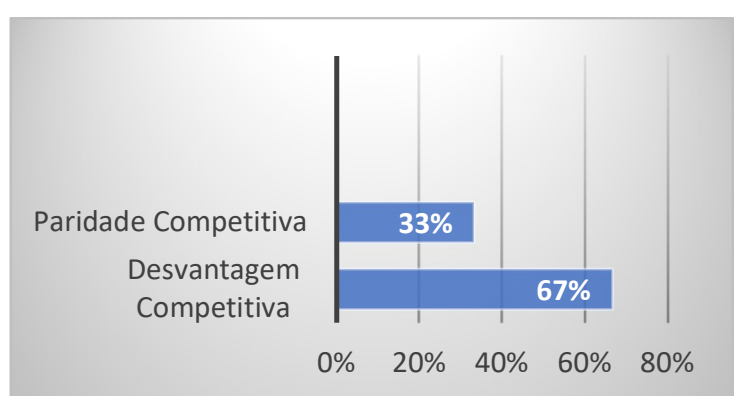

Figura 61: Suporte à inovação (ADM, TT e Negócios) no CNPAB

O Entrevistado E1 resume toda a visão dos aspectos fortes e fracos relacionados à Pesquisa e Desenvolvimento na Unidade.

Pontos fortes: material humano, a qualidade do recurso humano e a gestão de pesquisa. Bom, não só isso, né? A gestão de pesquisa é muito bem-feita. (...)Um outro ponto forte é a existência no campo experimental, a proximidade com a universidade rural, então isso dá uma capilaridade pra gente, que outras unidades podem não ter; a logística de uma forma geral, salas, laboratórios, viaturas, o pessoal de apoio. O pessoal de apoio, eu incluiria na qualidade do pessoal de uma 
forma geral. Os pontos fracos: a existência desse campo experimental, e ai já não é... na verdade, não é uma questão nossa, né? Mas com as modificações no perfil dos trabalhadores, empregados públicos, a partir dos anos 90, com a impossibilidade de contratar pessoal de campo e tal, não tem permitido uma reposição de pessoal, então a gente, ao mesmo tempo que tem uma área grande pra fazer pesquisa, nós temos pouca gente pra se comprometer com o trabalho de campo.

O Entrevistado E3 corrobora com a visão quanto a Unidade ainda carecer de um suporte maior para as atividades de $\mathrm{P} \& \mathrm{D}$ voltadas para inovação. Veja um extrato da fala deste Entrevistado abaixo:

Em geral, eu acho que... eu não sei se isso acontece em outras unidades, mas assim, ah, eu acho que uma divisão entre apoio e pesquisa (...) eu vejo as pessoas do apoio reclamando que, talvez, a gente não veja neles as dificuldades deles e talvez a gente, como pesquisador. E eu vejo o contrário, também, né?... a maior dificuldade é que a gente age no dia a dia, a gente é tão cobrado, cada um no seu campo de atuação, que a gente não vê que existe um objetivo comum, que é fazer aquela unidade e os compromissos da unidade. Eu acho que, talvez, isso devesse muito ser prioridade pros gestores, fazer todo mundo se sentir como numa unidade de verdade. Então, eu acho a maior dificuldade isso.

O segundo aspecto analisado foi: "Cultura como suporte à inovação aberta". Este aspecto foi, primeiramente avaliado por meio da análise VRIO, cujo resultado consta na Figura 62.

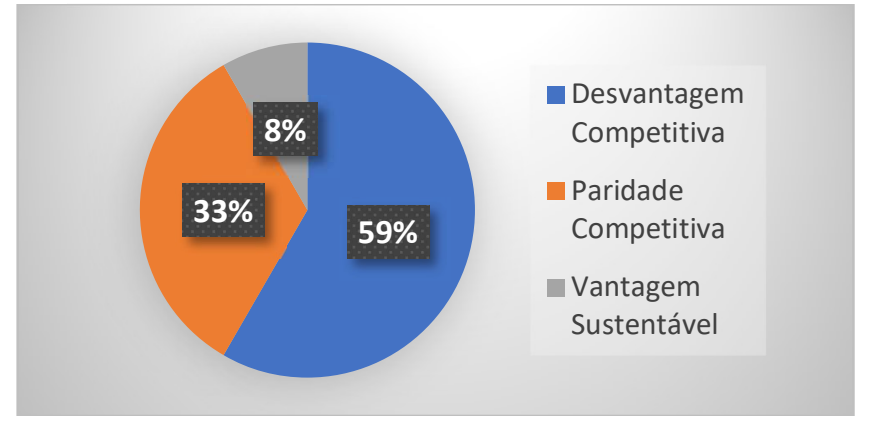

Figura 62: Cultura como suporte à inovação aberta no CNPAB

Pela Figura 62, percebe-se que mais de 50\% dos participantes consideram a Cultura de inovação um ponto fraco para a Unidade, e portanto, fonte de desvantagem competitiva.

Os participantes também foram questionados sobre alguns aspectos relacionados à cultura da inovação. Tal avaliação foi feita por meio de afirmativas, compostas por uma escala likert de cinco pontos, que apresenta um continuum variando de 1 (discordo totalmente) até 5 (concordo totalmente). Os resultados são sintetizados na Figura 63, cuja legenda representa DT (Discordo Totalmente); DP 
(Discordo Parcialmente); N (Neutralidade); CP (Concordo Parcialmente) e CT (Concordo Totalmente).

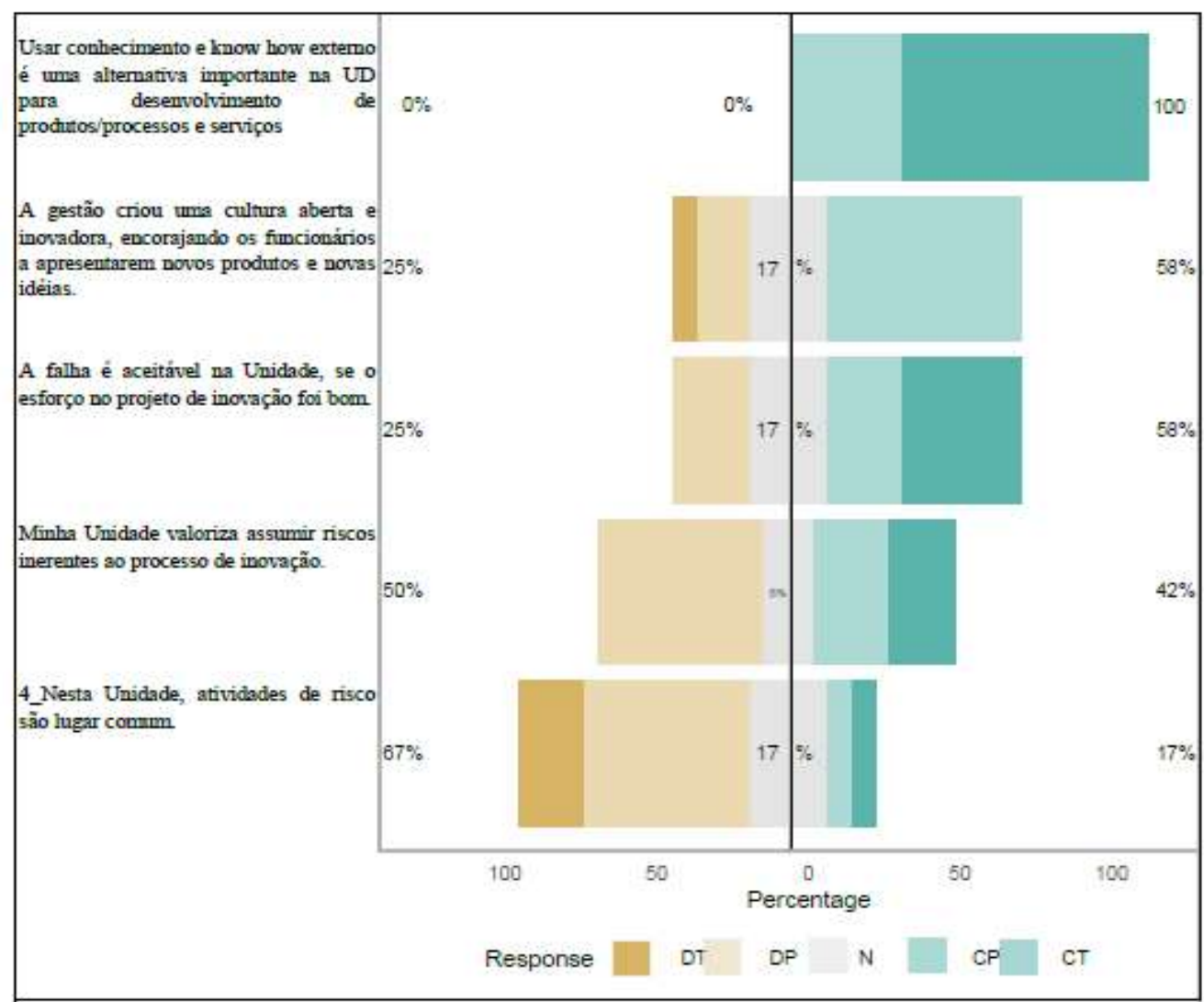

Figura 63: Gráfico de Concordância sobre aspectos culturais do CNPAB

Pela análise da Figura 63, percebe-se que a afirmativa com a qual os participantes mais concordam é a relacionada ao uso de conhecimento e know-how externo como uma alternativa importante para a Unidade, para desenvolvimento de novos produtos/processos e serviços. Os participantes se dividiram entre concordo parcialmente e concordo totalmente.

Por outro lado, a afirmativa que recebeu maior índice de discordância foi a útlima alternativa da Figura 63, relacionada à Unidade considerar as atividades de risco como lugar comum. Tal afirmativa obteve um elevado nível de discordância, equivalente à $67 \%$. De acordo com os entrevistados, a cultura de inovação ainda não foi totalmente internalizada na Unidade.

É. Ai você foi numa ferida grande, né? Que é justamente a questão de cultura. A gente trabalhou por muito tempo associado à universidade rural e dentro de uma perspectiva que a doutora Joana tinha em que a gente não... realmente a coisa que se valorizava muito era o avanço de conhecimento, né? Sem ter muito claro que a gente precisava de uma tecnologia no final. Lógico, a gente enxergava o potencial de transformação, mas não existia e hoje eu ainda acho um pouco fraco isso, tá mudando, tá melhorando, mas ainda é fraco, realmente esse direcionamento. Um pipeline, né? Tipo, olha, tudo bem, vamos trabalhar aqui, vamos trabalhar juntos 
e avançar pra chegar no final. Então eu, ao longo da minha carreira na Embrapa, eu comecei muita coisa e parei no meio, contribui com conhecimento e depois mudamos de direção: "Ah, vamos pesquisar isso agora", né? Você muda totalmente o caminho. Então eu acho que essa cultura tá sendo internalizada aos poucos, essa mudança de comportamento, devido ao sistema que a Embrapa implantou de projetos. A gente agora passou a ser cobrado, por exemplo, a gente tem as etapas do desenvolvimento da tecnologia, que é as TRLs, Technology Readiness Levels. (...) É. Pra conseguir uma TRL mais alta, né? Então eu falei: "Cara, nem pensei nisso, que tinha que fazer isso". Então, ou seja, nós vamos sentir ainda muito a falta justamente dessa cultura, que pra mim foi o grande gargalo, a gente não cresceu com uma cultura de empresa, a gente cresceu com uma cultura de universidade, então agora temos que mudar os hábitos. (Entrevistado E2).

No entanto, embora os entrevistados considerem fraca a cultura na Unidade no que concerne à inovação, também consideram que estão sendo feitos esforços no sentido de tornar tal cultura algo natural na Unidade, no entanto, este é um trabalho que demanda tempo e esforço.

O terceiro aspecto analisado foi referente à Tecnologia da Informação - TI, como suporte à inovação aberta".

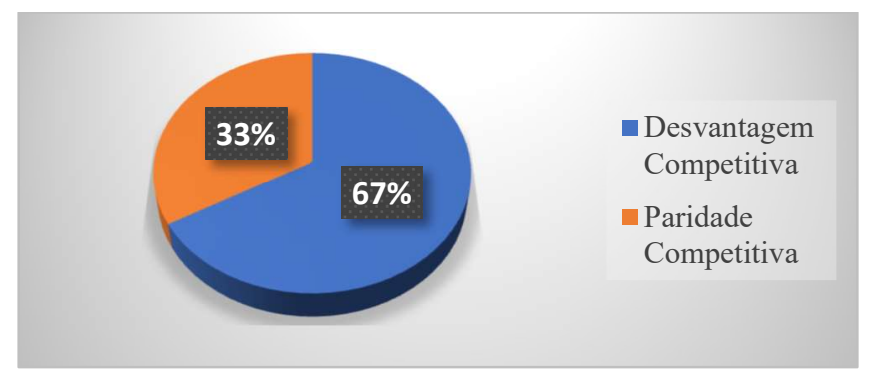

Figura 64: TI como suporte à inovação aberta no CNPAB

A Figura 64 mostra que para $67 \%$ da amostra, este recurso é visto como uma fraqueza para a Embrapa Agrobiologia e fruto de uma desvantagem competitiva quando comparada a seus pares. Sobre a TI, os participantes da pesquisa também foram indagados sobre alguns aspectos. Esses aspectos foram avaliados por meio de uma escala likert de 5 pontos, que apresenta um continuum variando de 1 (discordo totalmente) até 5 (concordo totalmente).

As respostas obtidas, constam na Figura 65 - Gráfico de concordância abaixo, cuja legenda representa DT (Discordo Totalmente); DP (Discordo Parcialmente); N (Neutralidade); CP (Concordo Parcialmente) e CT (Concordo Totalmente). 


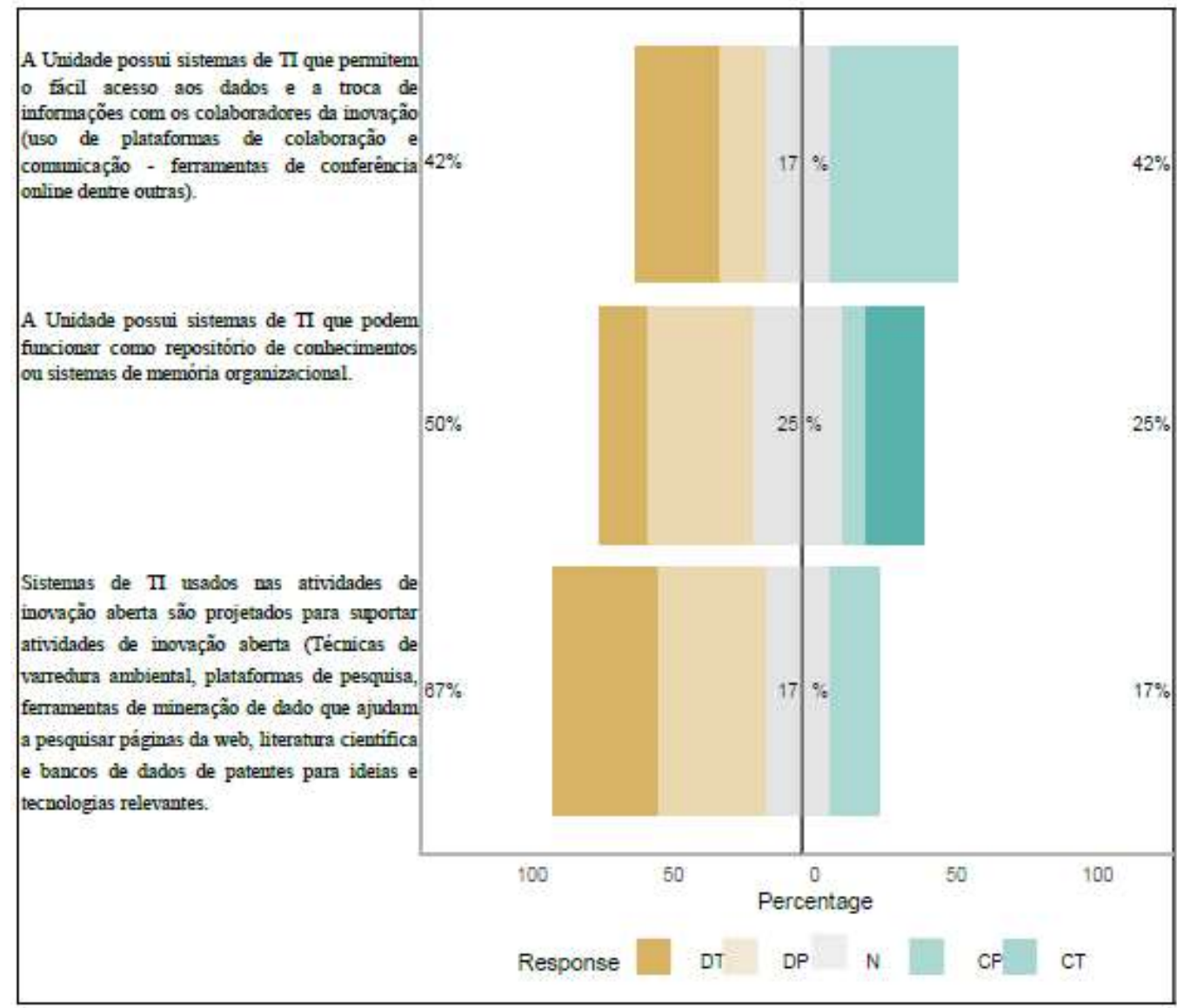

Figura 65: Gráfico de Concordância sobre aspectos de TI do CNPAB

Pela análise da Figura 65 , percebe-se uma discordância grande com relação a todas as três afirmações, sendo a última afirmativa do gráfico, a que representa maior discordância, percentual este igual a 67\%. A partir desses resultados, é possível afirmar que os participantes corroboram, em sua maioria, com a falta de sistemas de TI que abarquem as atividades de inovação e inovação aberta de forma efetiva na Unidade.

O quarto fator do primeiro construto analisado, diz respeito à "Governança e Alinhamento Estratégico". Este fator foi analisado, por meio de quatro atributos, que constam nas Figuras 66 a 69, que mostram os resultados da análise VRIO.

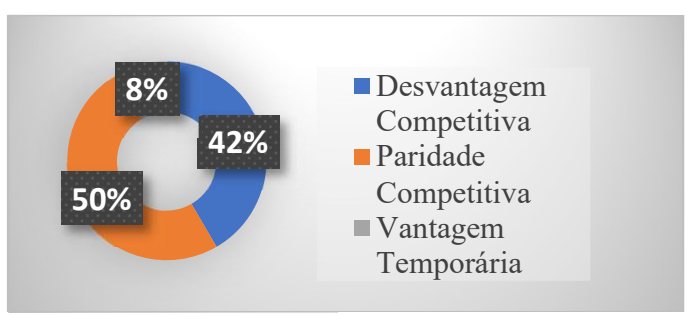

Figura 66: Tomada de decisões no CNPAB 


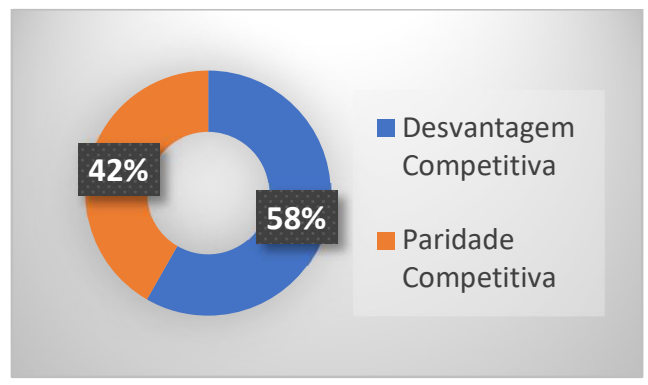

Figura 67: Definição de responsabilidades

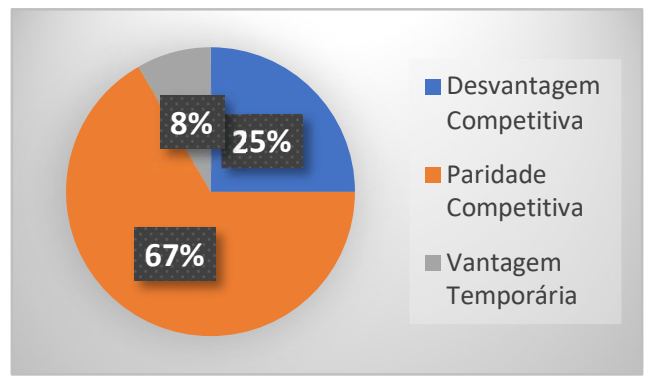

Figura 68: Gerenciamento de PI

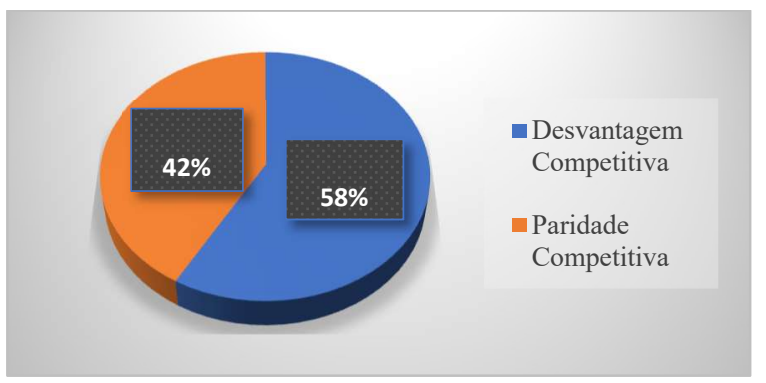

Figura 69: Processo de Seleção de Parceiros-CNPAB

O primeiro atributo analisado, conforme Figura 66, foi: "Tomada de decisões quanto ao uso de formas específicas de inovação aberta de acordo com os problemas e desafios de inovação enfrentados". Com relação a este atributo, as respostas mostraram que a maioria dos participantes, ou seja, 58\% destes, consideram o atributo uma força para a Agrobiologia, sendo que desta parcela, $50 \%$ consideram que o atributo confere à Unidade uma posição de paridade competitiva perante seus pares, já que este é definido como valioso e aproveitado pelo CNPAB. O Entrevistado E1 corrobora com este resultado:

Sim. Nós temos duas metas de inovação. Até hoje nós conseguimos estabelecer duas metas de inovação. E a gente tá conseguindo atender justamente por conta do processo de inovação aberta. Pelo menos em uma delas isso tá claro. (...) quando nós propusemos as metas, nós propusemos... não foi uma coisa, digamos, distante da realidade. (...) A gente propôs duas metas, porque eram duas linhas bem consolidadas e com uma demanda bem identificada pelos stakeholders. 
Outro aspecto analisado, conforme Figura 68 - "Gerenciamento da Propriedade Intelectual - PI", atributo considerado importante em contextos de inovação, também foi caracterizado, por $75 \%$ dos participantes, como uma força para a Unidade, cuja implicância estratégica, para $67 \%$ destes confere uma posição de paridade competitiva para a Unidade perante seus pares. O Entrevistado E1 mostra como este atributo é importante e desenvolvido na Unidade.

"A minha experiência com a Embrapa Agrobiologia de dez anos me possibilita dizer que a gente debate no sentido de estimular a distribuição dos beneficios da propriedade intelectual com os parceiros externos".

Já os outros dois atributos analisados: "Processo de seleção de parceiros", Figura 69, e "Definição clara de funções e responsabilidades da inovação aberta", Figura 67, foram considerados como fraquezas e fontes de desvantagem competitiva. Para ambos, a desvantagem foi caracterizada por igual parcela, correspondente a $58 \%$ dos participantes.

Com relação à seleção de parcerias, esses $58 \%$ consideram que não há um processo estruturado que gerencie essa seleção. Veja o relato do Entrevistado E1 sobre essa questão:

Não, eu não acho que haja um trabalho estruturado, um setor estruturado. Nós temos até um setor estruturado pra tratar da formalização das parcerias, mas no sentido de buscar parceiros, colocar parceiros no radar, fazer essa aproximação com potenciais parceiros, não, e tão pouco acho que haja isso na empresa. A empresa, acho que não tá preparada pra isso, né? Não se mobilizou pra isso ainda. Então, não há um processo de seleção. É eventual, é mais reativo... ou praticamente é reativo (Entrevistado $\mathrm{E} 1)$.

O quinto fator se refere à "Capacidade de Gerenciamento do conhecimento" que foi avaliado por meio de três atributos, também avaliados pela análise VRIO.

A primeira afirmativa, constante no questionário, "Minha Unidade possui capacidade de explorar, criar, desenvolver, reter e transformar o conhecimento adquirido internamente ou externamente, de modo a gerar inovação", avalia as capacidades inventiva, absortiva, transformativa e inovativa da Unidade. Para 73\% dos participantes, tais capacidades foram avaliadas como forças para a Unidade. Este percentual, no entanto, se dividiu quanto à implicância estratégia que tais capacidades trazem para a Unidade. No entanto, a maioria, ou seja, $45 \%$ desta parcela, considera que as capacidades são fontes de paridade competitiva, uma vez que são valiosas e desenvolvidas na Unidade. 
O Entrevistado E3 acredita que essas capacidades são desenvolvidas e fortes na Unidade, dentro de um contexto de inovação aberta que está ainda em processo de implementação, o que significa que, embora seja uma força, ainda precisa de melhorias.

Então, como eu disse antes, estamos aprendendo. Então, com certeza, e eu acho que a gente vai crescer e vamos fazer. Eu vejo os gestores e as pessoas envolvidas nisso muito voltados... por exemplo, a nossa chefe geral, que era chefe de pesquisa antes, ela se envolveu muito nisso, em trazer isso de uma forma pra isso se tornar uma coisa mais presente na nossa vida. Então, acho que, até o momento, fizemos o que foi possivel, o que conseguíamos fazer. Então, ainda é tímido, claro, há melhorias a serem feitas. Suficiente não é, acho que todo mundo tem consciência que não é.

A segunda afirmativa constante no questionário, diz respeito à desorptive capacity, capacidade da Unidade em transferir seus conhecimentos internos, que não são considerados centrais, para que os mesmos sejam utilizados por parceiros de inovação. Quanto à este atributo, 58\% consideram tam atributo fonte de paridade competitiva, o que significa dizer que o atributo é dotado de valor e aproveitado pela Unidade.

O terceiro atributo, diz respeito à análise da capacidade conectiva, avaliada por meio da seguinte afirmação: "Minha Unidade possui capacidade de estabelecer links com parceiros, de modo que esse link facilite o acesso a novos conhecimentos". De acordo com as respostas, 56\% consideram essa capacidade pouco desenvolvida na Unidade, o que se torna uma fraqueza, com implicância de desvantagem competitiva.

Eu imagino, assim, pelo que a gente vê, eu sou do CTI e tal, que essas parcerias, quem escolhe esses parceiros, são os próprios... é a própria equipe do projeto. $O$ líder do projeto... (...) Então, quando a gente expõe, deixa claro quais são as nossas linhas de pesquisa em alguma feira, em alguma... né? (...) Então... mas isso não é uma coisa muito comum, a gente não corre atrás desses parceiros pensando no que a gente quer, eu acho, na Agrobiologia. A gente faz pouco disso.

O sexto e último fator referente à: "Recursos, capacidades e características internas", corresponde à análise das Habilidades e Competências individuais". Este fator foi analisado por meio de três atributos, que avaliaram a mentalidade tecnológica, a capacidade de Liderança pessoal por pares e corretagem social, bem como a capacidade de alargamento de fronteiras. Tais capacidades foram avaliadas por meio de afirmativas, cuja avaliação se deu pela análise VRIO. 
De acordo com os resultados, apenas a "Mentalidade Tecnológica", conforme Figura 71, foi definida como uma fraqueza para a Unidade, de acordo com $64 \%$ da amostra. Já as habilidades de "Liderança pessoal por pares e corretagem social" e a "Capacidade de Alargamento de Fronteiras" foram definidas como forças e fontes de paridade competitiva, conforme mostram as Figuras 70 e 72 , respectivamente.

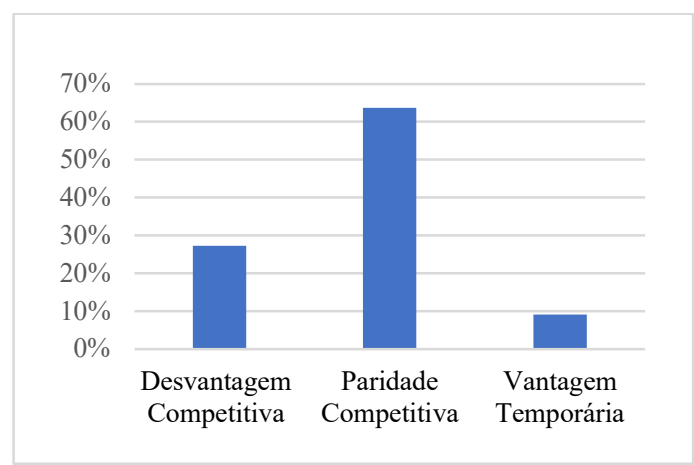

Figura 70: Liderança por Pares e Corretagem

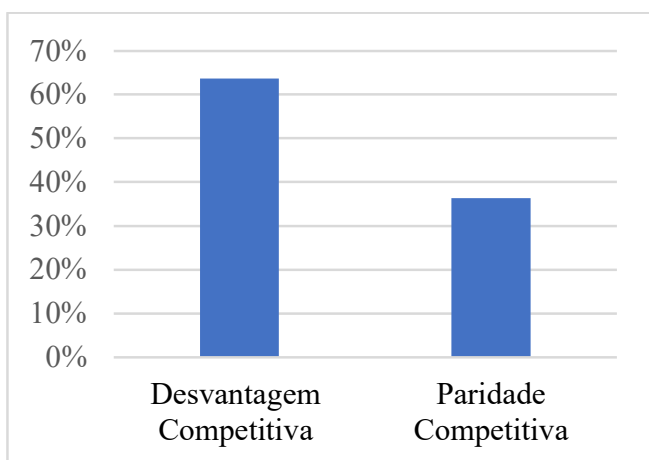

Figura 71: Mentalidade Tecnológica no CNPAB

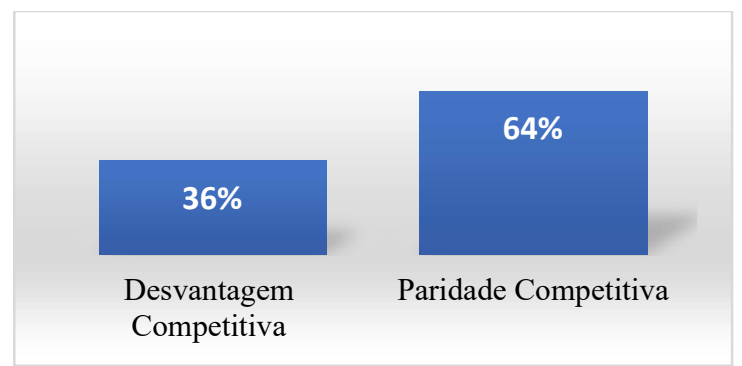

Figura 72: Capacidade de Alargamento de Fronteiras no CNPAB

Quanto a essas habilidades de nível individual, vários entrevistados ressaltaram a capacidade dos indivíduos, principalmente, pesquisadores da Unidade, em conectar parceiros para desenvolvimento de projetos de inovação, e ainda, afirmam que tais habilidades são importantes, já que a Unidade ainda não possui processo estruturado de seleção e conexão com parceiros.

Veja alguns relatos abaixo que corroboram com essa visão: 
A empresa, acho que não tá preparada pra isso, né? Não se mobilizou pra isso ainda. Então, não há um processo de seleção. Existem casos assim... coincidentemente, eu estive envolvido no... eu tenho mais esse perfil, mas é uma coisa muito individual também. (...)E nós estamos, hoje, conseguindo estabelecer uma parceria. Numa dessas minhas tentativas, uma delas virou (Entrevistado E1).

Quando você participa de congresso, participa de eventos científicos muitas vezes ai surgem as parcerias, é alguém que você apresenta um resultado seu de pesquisa e ali já tem, muitas vezes, pessoas de empresas que sabem da tua história, sabem que você vai lá falar e a pessoa fica esperando por um contato depois casual ali, pra ver se tem como interagir, e ai numa conversa surgem ideias e possibilidades. Não é talvez a maneira mais certa pra uma empresa trabalhar, a gente deveria ter uma coisa mais estruturada (Entrevistado E2).

De forma a simplificar e facilitar a visualização dos recursos/fatores internos, quanto suas representações de forças e fraquezas para a Unidade, bem como suas implicações estratégicas, elaborou-se o Quadro 17.

Quadro 17: Relação das Forças e Fraquezas Internas do CNPAB e suas implicações estratégicas

$1^{\circ}$ Recurso: Pesquisa e Desenvolvimento

\begin{tabular}{|l|c|c|}
\hline \multicolumn{1}{|c|}{ Atributo } & $\begin{array}{c}\text { Força/ } \\
\text { Fraqueza }\end{array}$ & Implicância Estratégica \\
\hline Quantidade de Recursos Humanos de P\&D & Força & Paridade Competitiva \\
\hline Qualidade Técnica dos Recursos Humanos de P\&D & Força & Paridade Competitiva \\
\hline Qualidade Inovativa dos Recursos Humanos & Força & Paridade Competitiva \\
\hline Infraestrutura física, de TI e insumos para P\&D & Força & Paridade Competitiva \\
\hline Suporte à inovação (ADM; TT e negócios) & Fraqueza & Desvantagem Competitiva \\
\hline
\end{tabular}

$3^{\circ}$ Recurso: Cultura

\begin{tabular}{|l|l|l|}
\hline Cultura voltada para inovação aberta & Fraqueza & Desvantagem Competitiva
\end{tabular} $3^{\circ}$ Recurso: Tecnologia da Informação (TI) como suporte à Inovação Aberta

\begin{tabular}{|l|l|l}
\hline Tecnologia como suporte à Inovação aberta & Fraqueza & Desvantagem Competitiva
\end{tabular}

$4^{\circ}$ Recurso: Governança e Alinhamento Estratégico

\begin{tabular}{|l|c|l|}
\hline $\begin{array}{l}\text { Tomada de decisões quanto ao uso de formas } \\
\text { específicas de inovação aberta de acordo com os } \\
\text { problemas e desafios de inovação enfrentados. }\end{array}$ & Força & Desvantagem Competitiva \\
\hline $\begin{array}{l}\text { Definição clara de funções e responsabilidades da } \\
\text { inovação aberta. }\end{array}$ & Fraqueza & Desvantagem Competitiva \\
\hline Processo de seleção de parceiros bem definido. & Fraqueza & Desvantagem Competitiva \\
\hline Propriedade Intelectual. & Força & Paridade Competitiva \\
\hline \multicolumn{3}{|c|}{$\mathbf{5}^{\mathbf{0}}$ Recurso: Capacidade de Gerenciamento do Conhecimento } \\
\hline $\begin{array}{l}\text { Capacidades Inventiva, Absortiva, Transformativa e } \\
\text { Inovativa }\end{array}$ & Força & Paridade Competitiva \\
\hline Desorptive Capacity & Força & Paridade Competitiva \\
\hline Capacidade Conectiva & Fraqueza & Desvantagem Competitiva \\
\hline \multicolumn{3}{|c}{ Recurso: Habilidades e Competências individuais } \\
\hline Mentalidade Tecnológica & Fraqueza & Desvantagem Competitiva \\
\hline Liderança Pessoal por Pares e Corretagem Social & Força & Paridade Competitiva \\
\hline Alargamento de Fronteiras & Força & Paridade Competitiva \\
\hline
\end{tabular}


Pela análise do Quadro 17, conclui-se que dentre as 17 capacidades/atributos analisados, divididos entre os seis fatores, 10 foram considerados forças e 7 foram considerados como fraquezas para a Embrapa Agrobiologia - CNPAB. Dentre os fatores, a "Governança e Alinhamento Estratégico" foi o recurso que possui mais fraquezas, de acordo com os participantes da pesquisa.

\subsubsection{2}

\section{Alianças e Portfólios de Alianças para impulsionar o desempenho de inovação.}

Nesta seção são apresentados os resultados quanto à identificação das alianças estabelecidas pela Unidade e seus parceiros de inovação, bem como as características dessas relações interorganizacionais consideradas cruciais para alavancar o desempenho de inovação na Embrapa Agrobiologia.

Para $100 \%$ dos participantes da pesquisa, a Unidade pratica a inovação aberta por meio de parcerias.

Dessas parcerias, de acordo com a Figura 73, 67\% consideram que as relações interorganizacionais realizadas pela Unidade são, majoritariamente, relações bilaterais, realizadas entre a Unidade e um parceiro.

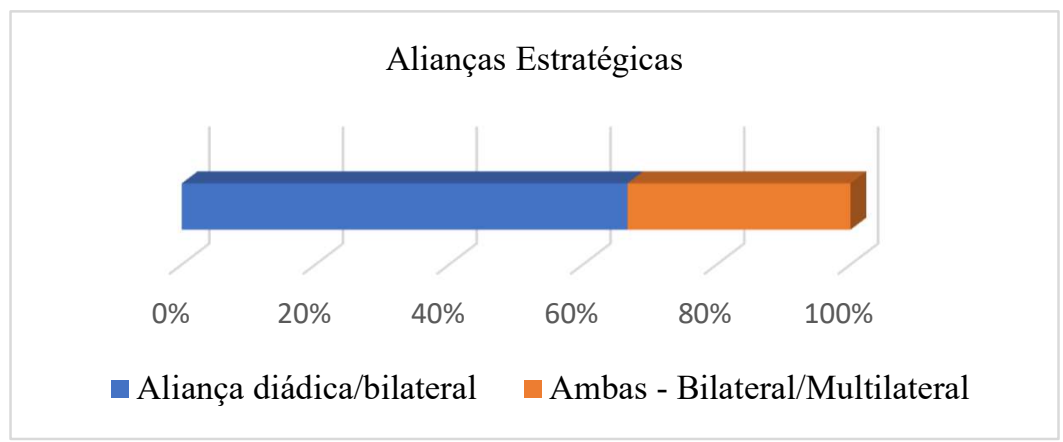

Figura 73: Alianças estabelecidas pelo CNPAB

Pelas entrevistas também foi possível notar a predominância das parcerias bilaterais. Veja alguns exemplos:

Ah, não tenho dúvida. Entre Embrapa e outro parceiro, certamente. Nunca multilaterais (...) "Não sei. Talvez, por exemplo, imagine que a gente tá fazendo uma coisa nova, estamos tateando ainda isso. É muito mais fácil você lidar com um, talvez a insegurança, o desconhecimento, traga isso. É mais seguro você lidar com um que você ainda nem sabe nem como lidar, do que lidar com vários parceiros (Entrevistado E3). 
"A maioria é bilateral. Nós recebemos um recurso do laboratório para desenvolver e testar alguns produtos. É assim, nesse sentido” (Entrevistado E4).

Os participantes da pesquisa também foram indagados sobre a visão deles com relação à participação da Embrapa Agrobiologia em alianças e portfólios de alianças, no sentido de tais envolvimentos representarem ou não maiores oportunidades para a Unidade, bem como se tais participações de fato causariam impacto no desempenho de inovação da Unidade. As avaliações destes aspectos foram feitas por meio de uma escala likert, que varia entre 1 discordo totalmente a 5 concordo totalmente.

A Figura 74 -Gráfico de concordância, mostra o grau de concordância dos participantes. A legenda apresentada no gráfico, representa DT (Discordo Totalmente); DP (Discordo Parcialmente); N (Neutralidade); CP (Concordo Parcialmente) e CT (Concordo Totalmente).

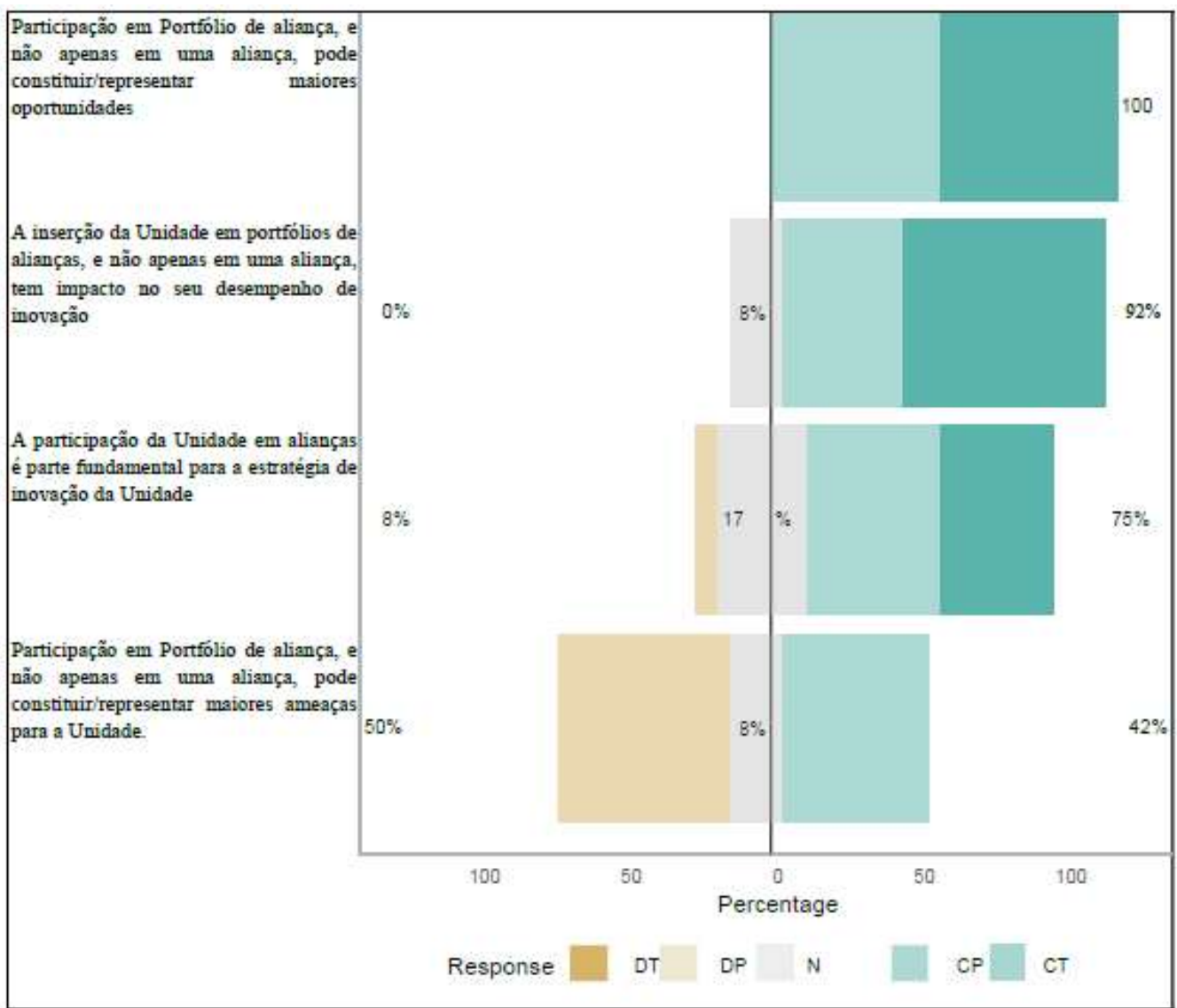

Figura 74: Gráfico de Concordância sobre as alianças estratégicas do CNPAB 
Pela análise da Figura 74, percebe-se que a grande maioria dos participantes considera a participação da Unidade, em relações interorganizacionais, importantes e que tais inserções têm impactos no desempenho de inovação da Unidade.

Com relação a primeira afirmativa constante na Figura 74, 100\% dos participantes concordam parcial ou totalmente que a participação nessas relações representa maiores oportunidades para a Embrapa Agrobiologia. Dessa forma, a última afirmativa, que representa o inverso, ou seja, que a participação em portfólios de aliança pode representar maiores ameaças à Unidade, foi a que apresentou maior grau de discordância por parte dos participantes, que se dividiram entre os que discordam parcialmente e totalmente com tal afirmação.

As parcerias são também estabelecidas com diferentes tipos de parceiros. Conforme mostra a Figura 75, para 100\% dos participantes, o CNPAB realiza alianças com Entidades Governamentais. Para 92\%, a Unidade realiza parcerias com Fomentadores/Financiadores, seguidos pelas alianças com clientes, cujo percentual foi igual a $75 \%$, e por fim, $67 \%$ acreditam que as alianças são feitas com complementadores. Os participantes também foram indagados quanto à existência de alianças com parceiros denominados como concorrentes, no entanto, não houve percentual com relação a este tipo de parceria.

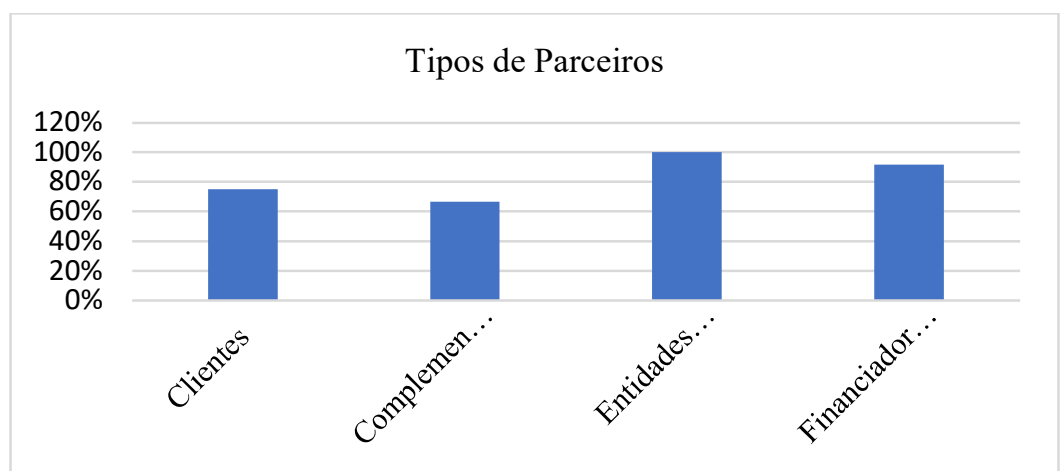

Figura 75: Tipos de Parceiros do CNPAB

Com cada um desses atores estratégicos definidos pelos participantes, a Embrapa Agrobiologia estabelece um tipo de aliança de inovação. Os respondentes identificaram os principais tipos para cada parceiro, conforme Tabela 11. 
Tabela 11: Tipos de Alianças estabelecidas pelo CNPAB

\begin{tabular}{l|l|l|l|l} 
Tipos de Alianças & Clientes & Complementadores & $\begin{array}{c}\text { Entidades } \\
\text { Governamentais }\end{array}$ & $\begin{array}{l}\text { Fomentadores/ } \\
\text { Financiadores }\end{array}$ \\
\hline $\begin{array}{l}\text { P\&D em conjunto } \\
\text { (Acordo/Contrato) }\end{array}$ & $75 \%$ & $67 \%$ & $75 \%$ & $75 \%$ \\
\hline $\begin{array}{l}\text { Desenvolvimento/Co- } \\
\text { produção }\end{array}$ & $67 \%$ & $50 \%$ & $25 \%$ & $33 \%$ \\
\hline $\begin{array}{l}\text { Licenciamento de } \\
\text { Patente ou Know- } \\
\text { How de }\end{array}$ & $33 \%$ & $33 \%$ & $0 \%$ & $33 \%$ \\
\hline $\begin{array}{l}\text { Acordo/Contrato de } \\
\text { fornecimento } \\
\text { outros } \\
\text { insumos/materiais }\end{array}$ & $50 \%$ & $17 \%$ & $42 \%$ \\
\hline $\begin{array}{l}\text { Acordo/Contrato de } \\
\text { Prestação de serviço }\end{array}$ & $83 \%$ & $25 \%$ & $42 \%$ & $17 \%$
\end{tabular}

De acordo com a Tabela 11, em relação aos clientes, as parcerias são bastante heterogêneas, variando, majoritariamente, entre Acordo/Contratos de Prestação de serviços, parcerias para P\&D em conjunto e para Desenvolvimento/Co-Produção. Já as parcerias estabelecidas com complementadores são para $\mathrm{P} \& \mathrm{D}$ em conjunto, seguidas pelas parcerias para Desenvolvimento/Co-Produção e para Licenciamento de Patente e Know-How.

As parcerias com as Entidades Governamentais e Fomentadores/Financiadores são realizadas, em sua maioria, para P\&D em conjunto, de acordo com igual parcela de 75\% para esses dois tipos de parceiros.

No que diz respeito à força das ligações das parcerias estabelecidas entre a Unidade e seus principais parceiros, de acordo com a Figura 76, para a maioria dos participantes, essas ligações estabelecidas diferem de acordo com o tipo de parceiro. As parcerias estabelecidas com clientes, para a grande maioria dos participantes, são consideradas como alianças fracas e amplas, já as parcerias estabelecidas com as Entidades Governamentais e Financiadores/Fomentadores foram caracterizadas como parcerias fortes e profundas. 


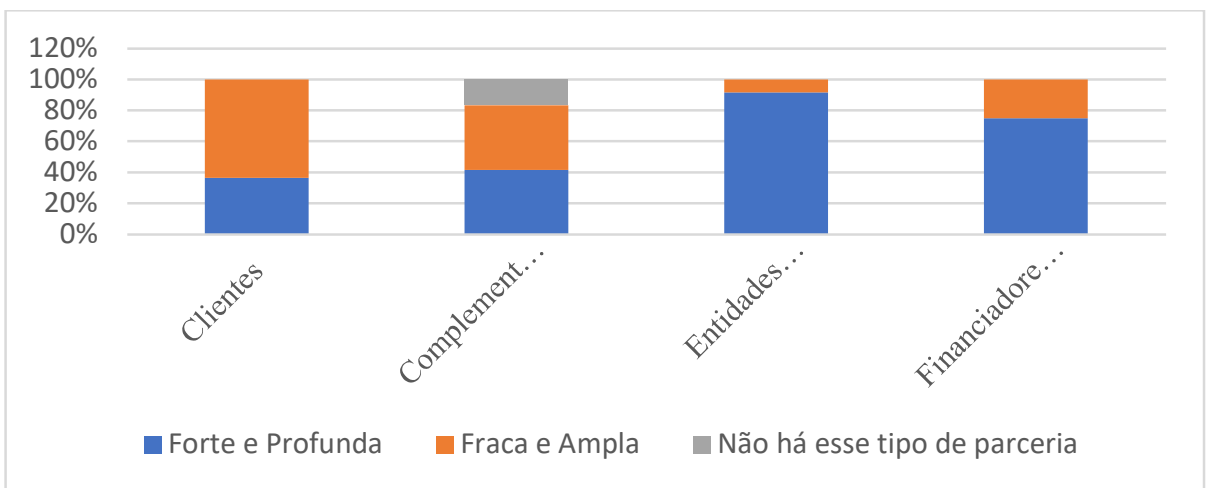

Figura 76: Força das Ligações estabelecidas pelo CNPAB

De fato, pelas entrevistas foi possível perceber que as parcerias estabelecidas, principalmente com as Entidades Governamentais são as consideradas duradouras e tradicionais. A parceria com a Universidade Federal Rural do Rio de Janeiro - UFRRJ, foi bastante citada como sendo uma parceria bastante forte e tradicional, impulsionada e beneficiada pela proximidade geográfica entre a Embrapa Agrobiologia e a Universidade, o que favoreceu a parceria de décadas.

O Entrevistado E2, explicita essa parceria de longa data, que favorece a confiança e a troca de informações. "A gente trabalhou e trabalha por muito tempo associado à universidade rural" (Entrevistado E2).

Além da Universidade, outras Entidades Governamentais foram citadas, tais como: Inea e Emater.

Alguns nomes de clientes citados pelos respondentes foram: Inea, a Agevap, o Comitê da Bacia do Guandu, a Abio e a Associação dos Produtores Orgânicos do Estado do Rio de Janeiro. Pelas respostas dos respondentes percebeu-se também que em alguns momentos esses tipos de parceiros se misturam, como o caso do INEA, uma Entidade Governamental, citada como um cliente.

Quanto aos Fomentadores/Financiadores, foram citados Faperj, a própria Agevap com os seus editais de pesquisa e o Fundo Newton.

Já em relação aos complementadores, as respostas se dividiram de forma igualitária, entre os que acreditam que essas relações são fracas e amplas e outra parcela que as considera como fortes e profundas. No entanto, pelas entrevistas foi possível confirmar que, de maneira geral, as parcerias tanto em relação aos clientes quanto complementadores, são vistas como fracas e amplas, isso porque ainda não há na Unidade, por exemplo, um setor estruturado que faça o acompanhamento 
destas parcerias, e que se preocupe em manter as relações mesmo quando não há projetos sendo desenvolvidos de forma conjunta.

Veja a fala abaixo que exemplifica essa conclusão:

(...)algumas empresas mantêm contato, de fato, com a gente por mais tempo, mas talvez ai tenha um outro problema que é entender qual seria a importância de manter esse bom relacionamento e se isso não deveria... ao invés de ficar muito a vontade pro pesquisador, que a gente acaba perdendo o contato, porque eu já desenvolvi o meu trabalho e já fui embora e esquece, né? E se não seria interessante pra unidade ter, de repente, dentro de algum núcleo, ai dentro de alguma gestão, uma estratégia de relacionamento com os seus parceiros, tanto com instituições que nos procuraram, mas que não se tornaram parceiros, quanto com aquelas que a gente mantém a parceria e com as que a gente já terminou a parceria, mas manter de algum jeito isso interligado. Isso acaba, minha visão é: acabou o serviço, acaba. A gente quase não vê mais, né? (Entrevistado E2).

Com relação à natureza das ligações, Figura 77, no que se refere aos clientes e complementadores, os respondentes acreditam que as parcerias estabelecidas são consideradas de exploração (explorative), ou seja, que visam explorar novas informações e novos conhecimentos dos parceiros, ou até mesmo de novos parceiros e alianças de aproveitamento (exploitative) cujo interesse recai sobre o aproveitamento dos conhecimentos e recursos já existentes nos parceiros.

Já com relação às Entidades Governamentais e Financiadores/Fomentadores, as ligações foram consideradas, pela maioria, como alianças de aproveitamento (exploitative) cujos interesses recaem sobre o aproveitamento dos recursos e informações já existentes nos parceiros.

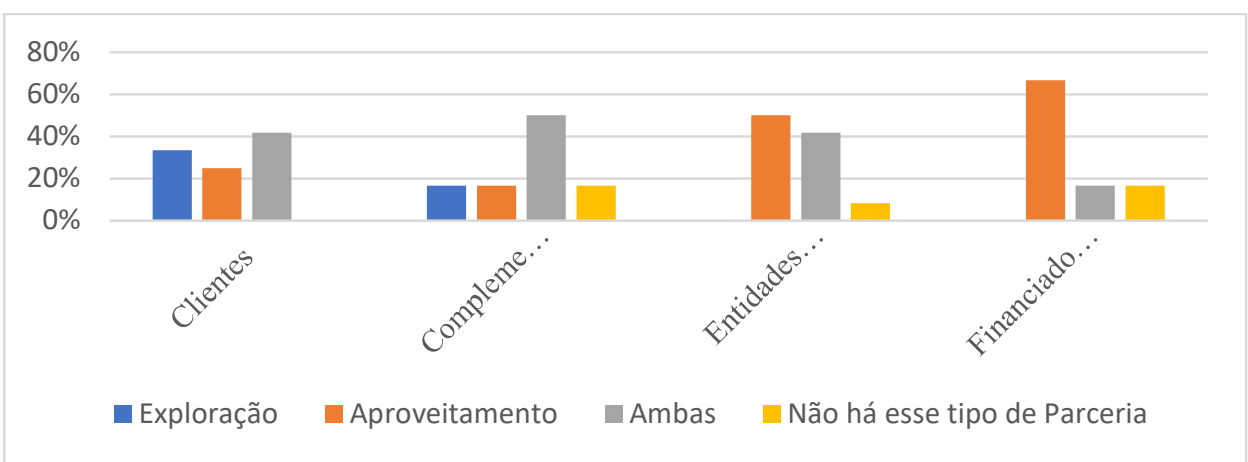

Figura 77: Natureza das Ligações das parcerias do CNPAB

Os parceiros também foram analisados quanto suas distâncias geográficas, tendo como base a Embrapa Agrobiologia. De acordo com a Figura 78, para a grande maioria dos participantes, todos os parceiros, independente do seu tipo, foram considerados, em sua maioria, como parceiros nacionais. Destaque para os clientes e Entidades Governamentais, cujos percentuais foram bastante elevados, $92 \%$ em relação aos clientes e $83 \%$ com relação às Entidades Governamentais. 
Já os Fomentadores/Financiadores foram considerados por $67 \%$ da amostra, como sendo predominantemente, parceiros globais.

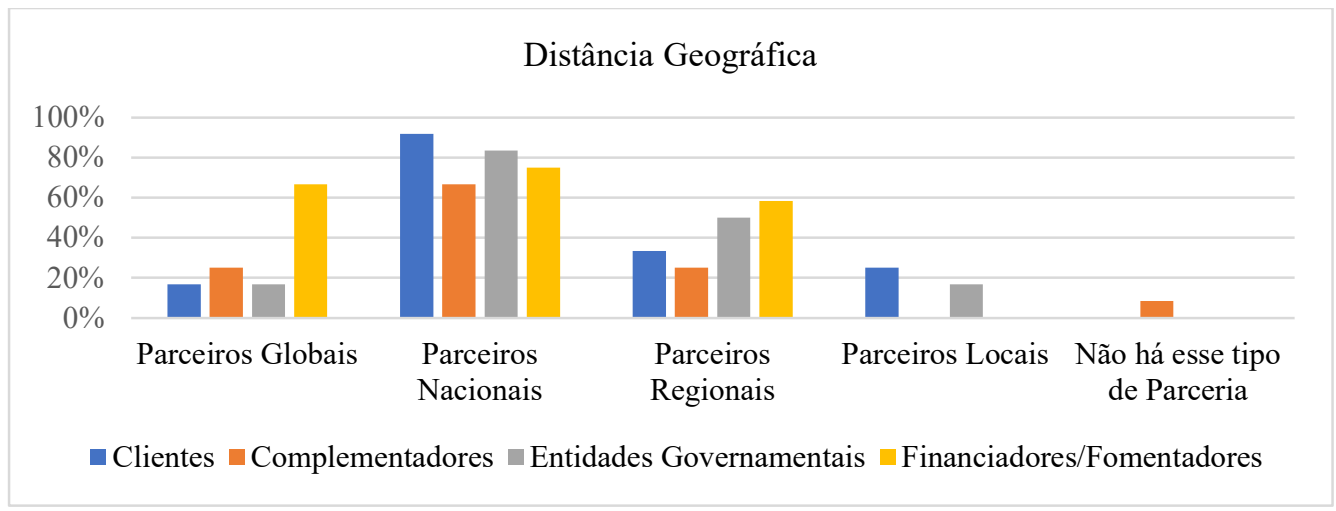

Figura 78: Distância Geográfica dos parceiros do CNPAB

Por fim, de acordo com cada parceiro, existem principais tipos de recursos que a Unidade visa adquirir por meio da parceria estabelecida. Esses principais recursos, divididos por tipos de parceiros, estão descritos na Figura 79.

Pela análise da Figura 79, percebe-se que para $83 \%$ dos respondentes, as alianças com clientes visam de forma majoritária, o acesso a novos conhecimentos/informações, seguido pelas parcerias para "Aprendizagem com parceiros" e "Aumento de eficiência”. Já com relação aos complemetadores, para a grande maioria, correspondente à $67 \%$, essas parcerias são estabelecidas visando o "Compartilhamento de custos" e de "Recursos/competências complementares".

As parcerias com as Entidades Governamentais, por sua vez, visam os principais recursos, de acordo com $75 \%$ dos participantes: "Compartilhamento de Custos" e "Compartilhamento de recursos/competências complementares". Por fim, as parcerias firmadas com Financiadores/Fomentadores, para 75\% dos respondentes, visam o "Compartilhamento de Custos" e "Riscos e Incertezas".

Para finalizar a análise deste $2^{\circ}$ construto constante do modelo, o Quadro 17 descreve, de forma resumida, os diferentes aspectos das principais alianças da Unidade no que concerne à inovação, considerando os principais tipos de parceiros, tipos de alianças, suas características, bem como os recursos-chaves, e a implicação estratégica destas alianças para a Embrapa Agrobiologia. 


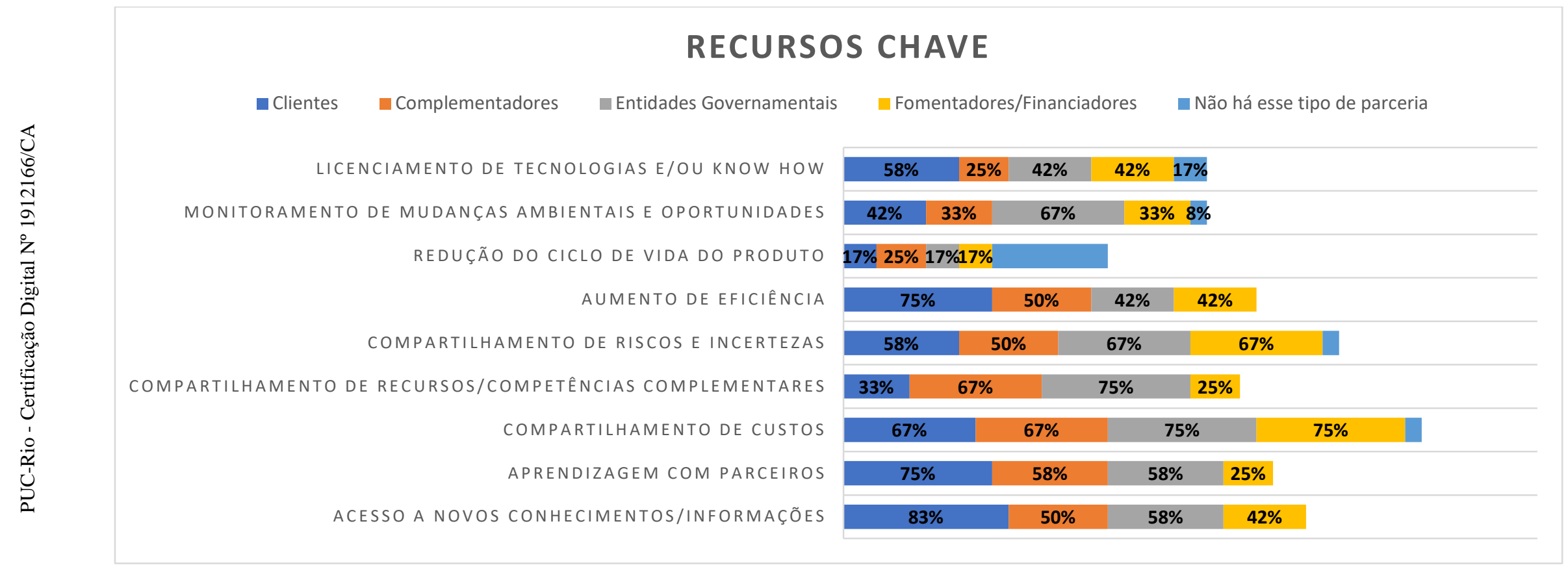

Figura 79: Principais Recursos-Chave dos parceiros do CNPAB 
Quadro 18: Resumo das principais alianças estratégicas do CNPAB e suas implicações estratégicas

\begin{tabular}{|c|c|c|c|c|c|c|}
\hline Tipo de Parceiro & Tipo de Aliança & $\begin{array}{c}\text { Natureza } \\
\text { das Ligações }\end{array}$ & $\begin{array}{l}\text { Modalidade } \\
\text { das ligações }\end{array}$ & Recursos Chave & $\begin{array}{c}\text { Força/ } \\
\text { Fraqueza }\end{array}$ & $\begin{array}{l}\text { Implicância } \\
\text { Estratégica }\end{array}$ \\
\hline Clientes & $\begin{array}{l}\text { Acordo/Contrato de Prestação de Serviço; } \\
\text { P\&D em conjunto (Acordo/Contrato); } \\
\text { Desenvolvimento/Co-Produção }\end{array}$ & Fraca e Ampla & $\begin{array}{l}\text { Exploitativel } \\
\text { Explorative }\end{array}$ & $\begin{array}{l}\text { Acesso a } \\
\text { conhecimentos/informações; } \\
\text { Aprendizagem com parceiros; } \\
\text { Aumento de eficiência }\end{array}$ & Força & $\begin{array}{l}\text { Paridade } \\
\text { Competitiva }\end{array}$ \\
\hline Complementador & $\begin{array}{l}\text { P\&D em conjunto (Acordo/Contrato); } \\
\text { Desenvolvimento/Co-Produção; } \\
\text { Licenciamento de Patente ou Know-How. }\end{array}$ & Fraca e Ampla & $\begin{array}{l}\text { Exploitative/ } \\
\text { Explorative }\end{array}$ & $\begin{array}{lr}\text { Compartilhamento de } & \text { Custos; } \\
\text { Compartilhamento } & \text { de } \\
\text { recursos/competências } & \\
\text { complementares; Aprendizagem com } \\
\text { parceiros. }\end{array}$ & Força & $\begin{array}{l}\text { Paridade } \\
\text { Competitiva }\end{array}$ \\
\hline $\begin{array}{l}\text { Entidades } \\
\text { Governamentais }\end{array}$ & $\begin{array}{l}\text { P\&D em conjunto (Acordo/Contrato); } \\
\text { Acordo/Contrato de Prestação de Serviço; } \\
\text { Desenvolvimento/Co-Produção }\end{array}$ & Forte e Profunda & Exploitative & 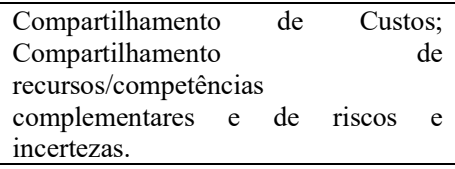 & Força & $\begin{array}{l}\text { Paridade } \\
\text { Competitiva }\end{array}$ \\
\hline $\begin{array}{l}\text { Fomentadores/ } \\
\text { Financiadores }\end{array}$ & $\begin{array}{l}\text { P\&D em conjunto (Acordo/Contrato); } \\
\text { Acordo/Contrato de fornecimento de outros } \\
\text { insumos/materiais; Desenvolvimento/Co- } \\
\text { Produção }\end{array}$ & Forte e Profunda & Exploitative & $\begin{array}{llr}\text { Compartilhamento } & \text { de } & \text { Custos; } \\
\text { Compartilhamento de } & \text { Riscos e } \\
\text { incertezas. } & & \end{array}$ & Força & $\begin{array}{l}\text { Paridade } \\
\text { Competitiva }\end{array}$ \\
\hline
\end{tabular}


Pela análise do Quadro 18 percebe-se que todas as parcerias são vistas como força e fontes de paridade competitiva o que significa dizer, que tais relações são dotadas de valor e desenvolvidas/aproveitadas pela Unidade, no entanto, estas não são consideradas nem raras e nem inimitáveis, não sendo, portanto, fontes de vantagens competitivas temporárias e nem tão pouco sustentáveis. Cabe ressaltar, ainda, que cada parceria, por ser caracterizada como força, traz benefícios e recursos-chaves considerados importantes para melhorar a capacidade de inovação da Embrapa Agrobiologia - CNPAB.

Após aplicação, na Embrapa Agrobiologia, do modelo teórico, elaborou-se o Quadro 19 que inter-relaciona as forças e fraquezas identificadas a partir da análise dos dois construtos: "Recursos, capacidades e características internas" e "Alianças e Portfólios de Alianças para impulsionar o desempenho de inovação", com o intuito de identificar complementariedades entre esses dois ambientes (interno e externo) que supram as lacunas existentes na Unidade e contribuam para a melhoria do desempenho de inovação da Embrapa Agrobiologia.

Além da melhoria das fraquezas internas por meio das alianças, as parcerias também contribuem para melhoria das forças internas existentes, de modo a tornar essas forças fontes de vantagem competitiva sustentável para a Unidade. O Quadro 20 mostra como os benefícios advindos das parcerias potencializam as forças internas. 


\begin{tabular}{|c|c|c|c|c|c|c|}
\hline \multirow{12}{*}{ 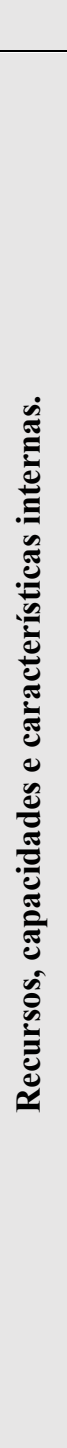 } & \multicolumn{2}{|c|}{ Fraquezas internas } & \multicolumn{2}{|c|}{$\begin{array}{c}\text { Superação/minimização das Fraquezas internas por meio das Forças advindas das } \\
\text { parcerias }\end{array}$} & & \multirow{12}{*}{ 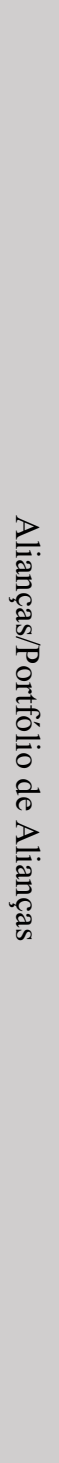 } \\
\hline & \multirow{11}{*}{$\begin{array}{l}\text { Fraquezas } \\
\text { internas }\end{array}$} & \multirow{4}{*}{$\begin{array}{l}\text { Suporte à } \\
\text { inovação }\end{array}$} & $\begin{array}{l}\text { Alianças para P\&D e/ou para Desenvolvimento/Co- } \\
\text { Produção em parceria com clientes }\end{array}$ & $\begin{array}{l}\text { Aumento de Eficiência e Acesso a } \\
\text { novos conhecimentos e }\end{array}$ & \multirow{11}{*}{$\begin{array}{l}\text { Forças } \\
\text { Externas }\end{array}$} & \\
\hline & & & $\begin{array}{l}\text { Alianças para P\&D e/ou para Desenvolvimento/Co- } \\
\text { Produção em parceria com Complementadores; } \\
\text { Entidades Governamentais; } \\
\text { Fomentadores/Financiadores }\end{array}$ & Compartilhamento de Custos e & & \\
\hline & & & $\begin{array}{l}\text { Alianças para P\&D e/ou para Desenvolvimento/Co- } \\
\text { Produção em parceria com complementadores e } \\
\text { Entidades Governamentais }\end{array}$ & $\begin{array}{l}\text { Compartilhamento de } \\
\text { recursos/Competências } \\
\text { complementares }\end{array}$ & & \\
\hline & & & $\begin{array}{l}\text { Alianças para P\&D e/ou para Desenvolvimento/Co- } \\
\text { Produção em parceria com } \\
\text { Fomentadores/Financiadores }\end{array}$ & $\begin{array}{l}\text { Compartilhamento de Riscos e } \\
\text { Incertezas }\end{array}$ & & \\
\hline & & $\begin{array}{l}\text { Cultura voltada } \\
\text { para inovação } \\
\text { aberta }\end{array}$ & $\begin{array}{l}\text { Alianças para P\&D e/ou para Desenvolvimento/Co- } \\
\text { Produção em parceria com Clientes e } \\
\text { complementadores }\end{array}$ & Aprendizagem com parceiros. & & \\
\hline & & \multirow{3}{*}{$\begin{array}{l}\text { Tecnologia } \\
\text { da Informação } \\
\text { como suporte à } \\
\text { inovação aberta }\end{array}$} & $\begin{array}{l}\text { Alianças para P\&D e/ou para Desenvolvimento/Co- } \\
\begin{array}{l}\text { Produça em parceria com Clientes e } \\
\text { complementadores }\end{array}\end{array}$ & Aprendizagem com parceiros. & & \\
\hline & & & $\begin{array}{l}\text { Alianças para } \mathrm{P} \& \mathrm{D} \text { e/ou para Desenvolvimento/Co- } \\
\text { Produção em parceria com complementadores e } \\
\text { Entidades Governamentais }\end{array}$ & $\begin{array}{l}\text { Compartilhamento } \\
\text { recursos/Competências } \\
\text { complementares }\end{array}$ & & \\
\hline & & & $\begin{array}{l}\text { Alianças para P\&D e/ou para Desenvolvimento/Co- } \\
\text { Produção em parceria com clientes }\end{array}$ & $\begin{array}{l}\text { Aumento de Eficiência e Acesso a } \\
\text { novos conhecimentos } \\
\text { informações. }\end{array}$ & & \\
\hline & & \multirow{2}{*}{$\begin{array}{l}\text { Definiçãa clara } \\
\text { de funções } \\
\text { e } \\
\text { responsabilidades } \\
\text { da inovação } \\
\text { aberta }\end{array}$} & $\begin{array}{l}\text { Alianças para P\&D e/ou para Desenvolvimento/Co- } \\
\begin{array}{l}\text { Produção em parceria com Clientes e } \\
\text { complementadores }\end{array}\end{array}$ & Aprendizagem com parceiros. & & \\
\hline & & & $\begin{array}{l}\text { Alianças para P\&D e/ou para Desenvolvimento/Co- } \\
\text { Produção em parceria com clientes }\end{array}$ & $\begin{array}{l}\text { Aumento de Eficiência e Acesso a } \\
\text { novos conhecimentos } \\
\text { informações. }\end{array}$ & & \\
\hline & & $\begin{array}{l}\text { Processo } \\
\text { de Seleção } \\
\text { de Parceiros }\end{array}$ & $\begin{array}{l}\text { Alianças para P\&D e/ou para Desenvolvimento/Co- } \\
\text { Produção em parceria com Clientes e } \\
\text { complementadores }\end{array}$ & Aprendizagem com parceiros. & & \\
\hline
\end{tabular}




\begin{tabular}{|c|c|c|c|c|}
\hline \multirow{6}{*}{$\begin{array}{l}\text { Fraquezas } \\
\text { internas }\end{array}$} & bem definido & $\begin{array}{l}\text { Alianças para P\&D e/ou para Desenvolvimento/Co- } \\
\text { Produção em parceria com clientes }\end{array}$ & $\begin{array}{l}\text { Aumento de Eficiência e Acesso a } \\
\text { novos conhecimentos } \\
\text { informações. }\end{array}$ & \multirow{6}{*}{$\begin{array}{c}\text { Forças } \\
\text { Externas }\end{array}$} \\
\hline & \multirow{2}{*}{$\begin{array}{l}\text { Capacidade } \\
\text { Conectiva }\end{array}$} & $\begin{array}{l}\text { Alianças para P\&D e/ou para Desenvolvimento/Co- } \\
\text { Produção em parceria com Clientes e } \\
\text { complementadores }\end{array}$ & Aprendizagem com parceiros. & \\
\hline & & $\begin{array}{l}\text { Alianças para P\&D e/ou para Desenvolvimento/Co- } \\
\text { Produção em parceria com clientes }\end{array}$ & $\begin{array}{l}\text { Aumento de Eficiência e Acesso a } \\
\text { novos conhecimentos } \\
\text { informações. }\end{array}$ & \\
\hline & \multirow{3}{*}{$\begin{array}{l}\text { Mentalidade } \\
\text { Tecnológica }\end{array}$} & $\begin{array}{l}\text { Alianças para P\&D e/ou para Desenvolvimento/Co- } \\
\text { Produção em parceria com Clientes e } \\
\text { complementadores }\end{array}$ & Aprendizagem com parceiros. & \\
\hline & & $\begin{array}{l}\text { Alianças para P\&D e/ou para Desenvolvimento/Co- } \\
\text { Produção em parceria com clientes }\end{array}$ & $\begin{array}{l}\text { Aumento de Eficiência e Acesso a } \\
\text { novos conhecimentos } \\
\text { informações. }\end{array}$ & \\
\hline & & $\begin{array}{l}\text { Alianças para P\&D e/ou para Desenvolvimento/Co- } \\
\text { Produção em parceria com complementadores e } \\
\text { Entidades Governamentais }\end{array}$ & $\begin{array}{l}\text { Compartilhamento } \\
\text { recursos/Competências } \\
\text { complementares }\end{array}$ & \\
\hline
\end{tabular}

Quadro 20: Relação das Forças internas e externas do CNPAB

\begin{tabular}{|c|c|c|c|c|}
\hline \multirow{6}{*}{$\begin{array}{l}\text { Forças } \\
\text { internas }\end{array}$} & \multirow{3}{*}{$\begin{array}{l}\quad \text { Fatores Internos } \\
\text { Quantidade de } \\
\text { Recursos } \\
\text { Humanos envolvidos } \\
\text { em P\&D }\end{array}$} & \multicolumn{2}{|c|}{ Fatores Externos } & \multirow{6}{*}{$\begin{array}{l}\text { Forças } \\
\text { Externas }\end{array}$} \\
\hline & & $\begin{array}{l}\text { Alianças para P\&D e/ou para } \\
\begin{array}{l}\text { Desenvolvimento/Co-Produção em parceria com } \\
\text { clientes }\end{array} \\
\end{array}$ & $\begin{array}{l}\text { Aumento de Eficiência e Acesso a } \\
\text { novos conhecimentos } \\
\text { informações. }\end{array}$ & \\
\hline & & $\begin{array}{l}\text { Alianças para P\&D e/ou para } \\
\text { Desenvolvimento/Co-Produção em parceria com } \\
\text { Clientes e complementadores }\end{array}$ & Aprendizagem com parceiros. & \\
\hline & \multirow{3}{*}{$\begin{array}{l}\text { Qualidade Técnica dos } \\
\text { Recursos } \\
\text { Humanos envolvidos } \\
\text { em P\&D. }\end{array}$} & $\begin{array}{l}\text { Alianças para P\&D e/ou para } \\
\begin{array}{l}\text { Desenvolvimento/Co-Produção em parceria com } \\
\text { clientes }\end{array} \\
\end{array}$ & $\begin{array}{l}\text { Aumento de Eficiência e Acesso a } \\
\text { novos conhecimentos } \\
\text { informações. }\end{array}$ & \\
\hline & & $\begin{array}{l}\text { Alianças para P\&D e/ou para } \\
\text { Desenvolvimento/Co-Produção em parceria com } \\
\text { complementadores e Entidades Governamentais }\end{array}$ & $\begin{array}{l}\text { Compartilhamento } \\
\text { recursos/Competências } \\
\text { complementares }\end{array}$ & \\
\hline & & $\begin{array}{l}\text { Alianças para P\&D e/ou para } \\
\text { Desenvolvimento/Co-Produção em parceria com } \\
\text { Clientes e complementadores }\end{array}$ & Aprendizagem com parceiros. & \\
\hline
\end{tabular}




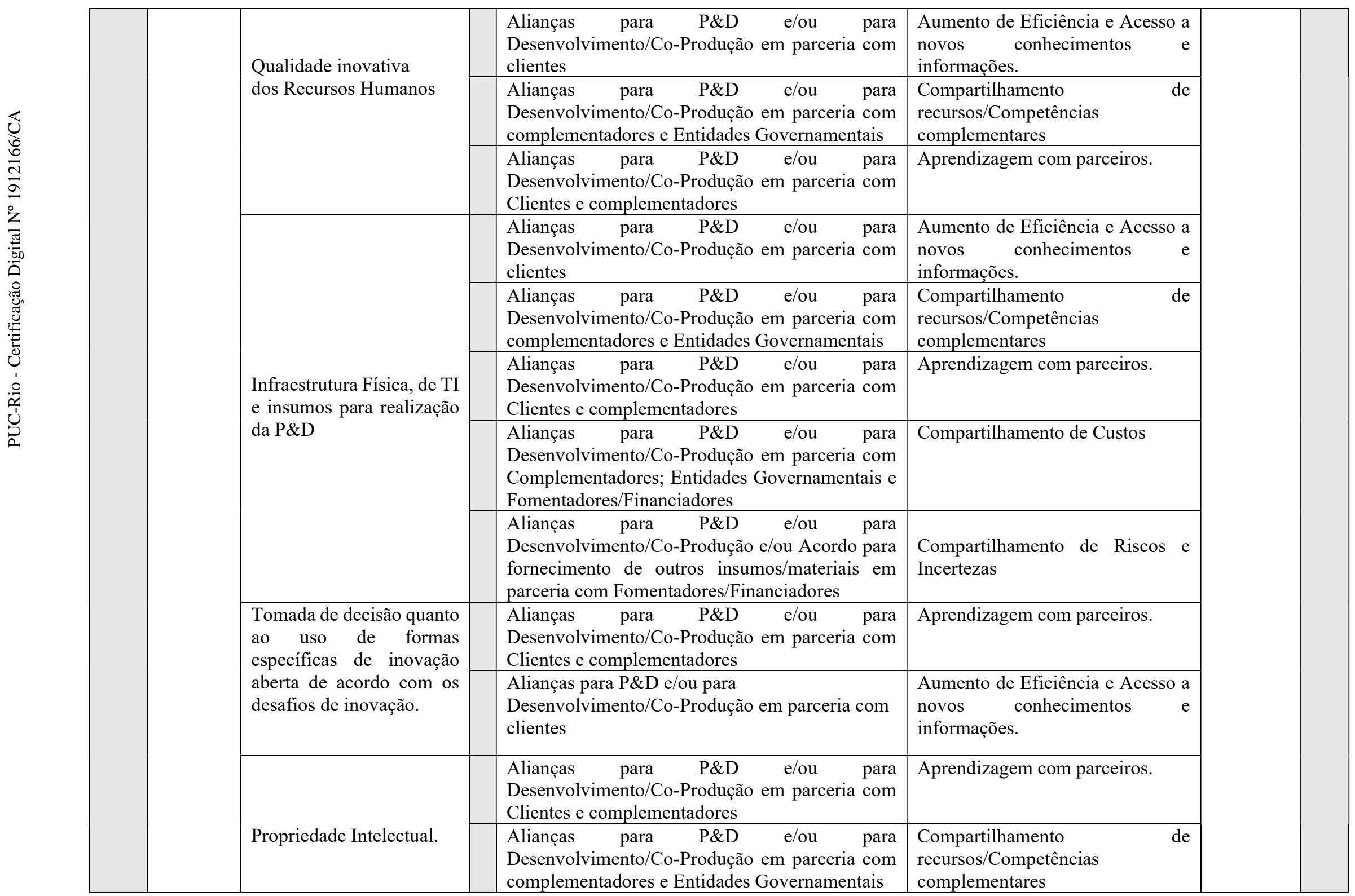




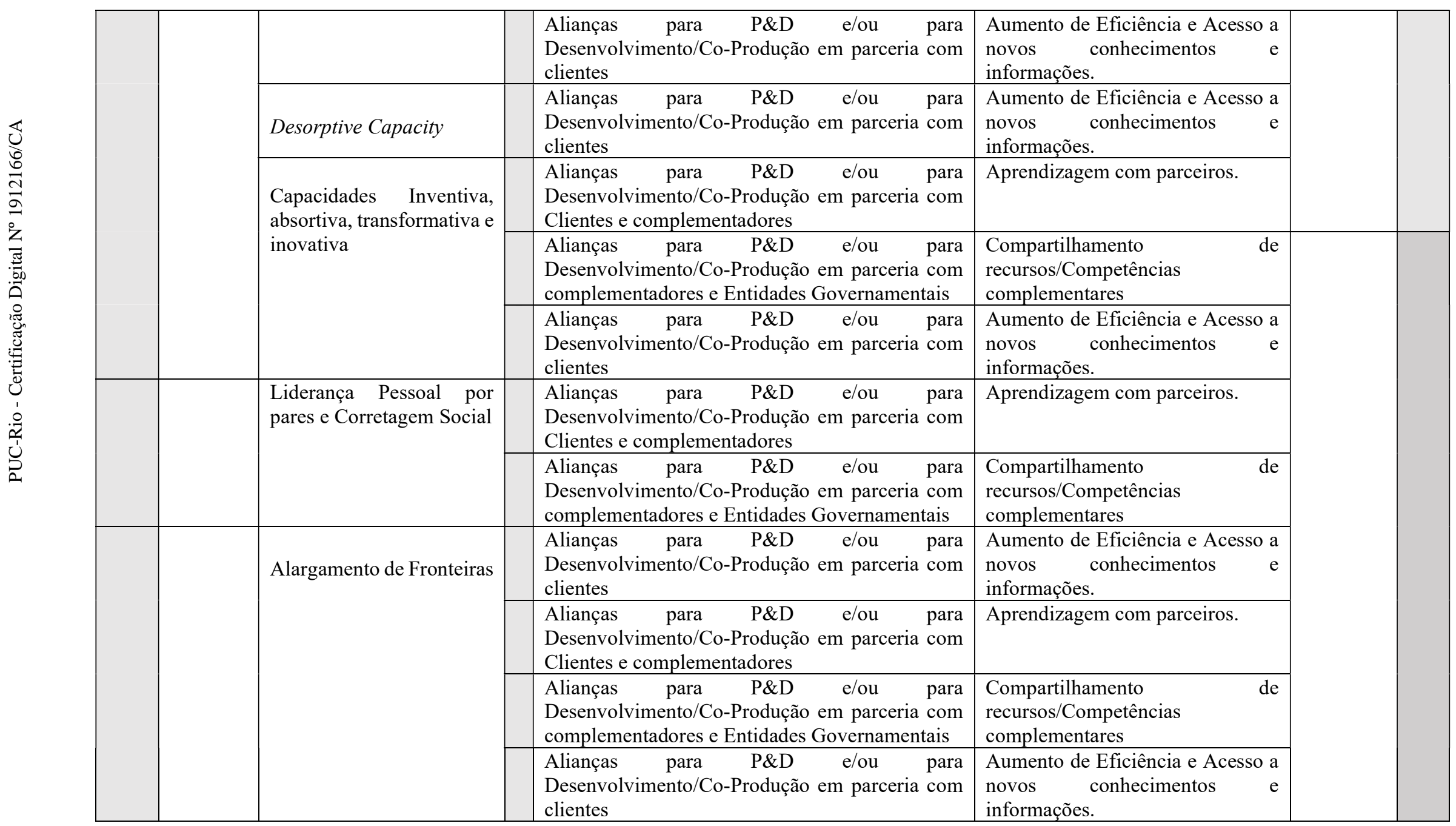




\subsubsection{3}

\section{Desempenho de Inovação}

Esta seção apresenta os resultados quanto à percepção dos participantes acerca do desempenho de inovação da Embrapa Agrobiologia, de 2019 a 2020, período que corresponde a implementação na Embrapa, do macroprocesso de inovação. Com relação à quantidade de resultados gerados pela Unidade, os dados são apresentados nas Figuras 80 a 82:

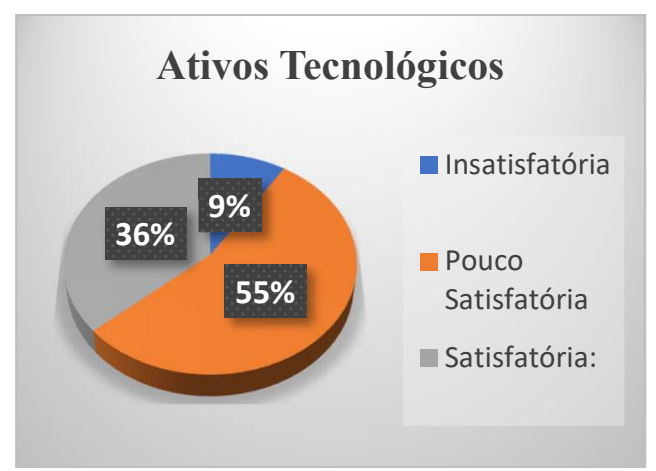

Figura 80: Ativos Tecnológicos do CNPAB

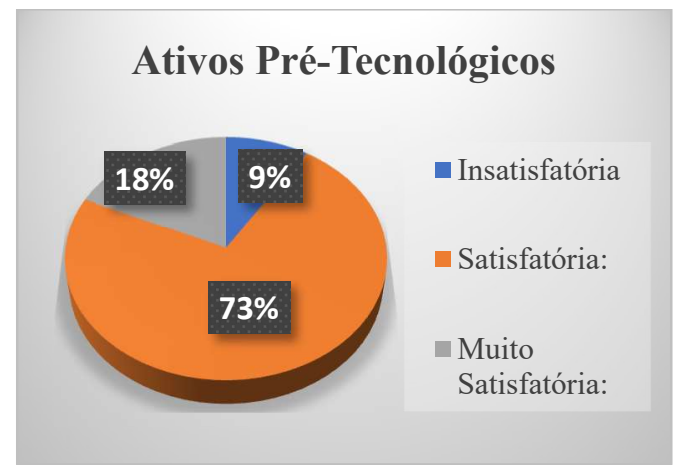

Figura 81: Ativos Pré-Tecnológicos do CNPAB

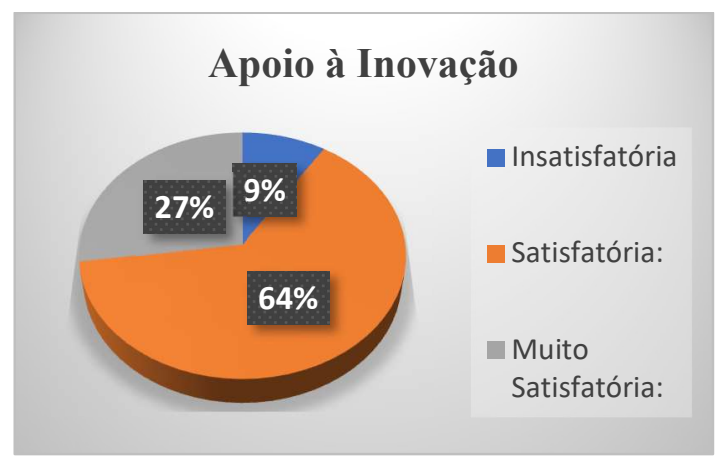

Figura 82: Apoio à Inovação do CNPAB

Pela análise das Figuras 81 e 82, os respondentes consideram a produção tanto de Ativos Pré-Tecnológicos e de Apoio à Inovação, como satisfatórios, sendo o percentual igual a $73 \%$ no caso dos Ativos Pré-Tecnológicos e 64\% com relação ao resultado - Apoio à Inovação. Já em relação aos Ativos Tecnológicos, Figura 
80, a maioria dos participantes, percentual correspondente a $55 \%$, acreditam que a produção é pouco satisfatória. O Entrevistado E1 afirma sobre a produção de resultados pela Unidade: "Eu acho que pode melhorar, principalmente em relação à maturidade dos ativos, né? Os pré-tecnológicos ainda predominam, né”?

O Entrevistado E3 corrobora com essa visão, sobre a produção de AtivosPré-tecnológicos.

Ah, sim. Eu acho que é a caracteristica da agrobiologia os pré-tecnológicos, né? $O$ (pouco) de apoio a inovação acho que é uma coisa forte também, por exemplo, transferência de tecnologia, né? Talvez porque tem a fazendinha também, tem capacitação, e isso é apoio à inovação, né? Então, acho que é forte também. Mas, é mais... muito mais do que tecnológico, com certeza essas duas são mais do que o tecnológico, pré-tecnológico que apoia inovação.

O Entrevistado E2 faz algumas considerações sobre a produção dos resultados pela Unidade:

Olha, ativos pré-tecnológicos e de apoio à inovação é uma coisa que a gente produzia muito na unidade, só que isso não tem um valor, eu percebo, que ele não tem um valor pra empresa, de dinheiro, ele não significa captação de recurso, é você simplesmente transformar um trabalho que foi feito em alguma coisa que vai ser utilizada, uma política pública e tal, ou você vai ter um estoque ali atrás que pode um dia, se tiver investimento, ser transformado em tecnologia.

Com relação a efetividade destes resultados produzidos, em termos de impactos, a Tabela 12 mostra os resultados encontrados:

Tabela 12: Impactos dos resultados produzidos pelo CNPAB

Efetividade das inovações geradas em termos de seus impactos no desenvolvimento institucional?

\begin{tabular}{l|l}
\hline Impactos Pouco relevantes & $18 \%$ \\
\hline Relevantes & $\mathbf{8 2 \%}$ \\
\hline Muito relevantes & $0 \%$
\end{tabular}

Efetividade das inovações geradas em termos de seus impactos econômicos?

\begin{tabular}{l|l}
\hline Impactos Pouco relevantes & $27 \%$ \\
\hline Relevantes & $\mathbf{6 4 \%}$ \\
\hline Muito relevantes & $9 \%$ \\
\hline
\end{tabular}

Efetividade das inovações geradas em termos de seus impactos socioambientais?

\begin{tabular}{l|l}
\hline Impactos Pouco relevantes & $9 \%$ \\
\hline Relevantes & $\mathbf{5 5 \%}$ \\
\hline Muito relevantes & $36 \%$ \\
\hline
\end{tabular}

Efetividade das inovações geradas em termos de seus impactos na cadeia produtiva?

\begin{tabular}{l|l}
\hline Impactos Pouco relevantes & $27 \%$ \\
Relevantes & $\mathbf{5 5 \%}$ \\
\hline Muito relevantes & $18 \%$
\end{tabular}


Pela análise da Tabela 12, pode-se observar que em relação aos resultados gerados e seus impactos, todos os resultados foram considerados como tendo impactos relevantes, seja no desenvolvimento institucional, impactos socioambientais, econômicos ou na cadeia produtiva.

De fato, pelas entrevistas, é possível observar que os participantes corroboram com essa visão e acreditam que a produção de resultados na Unidade, gera impactos. No entanto, alguns entrevistados afirmam que há margem para melhorias e avanços e que tais melhorias são importantes para que a Unidade aumente sua capacidade de produção e inovação.

Veja alguns relatos abaixo sobre essas possibilidades de melhoria:

Ai, não sei te dizer isso. Eu acho que ainda, pra mim, não é muito claro isso, porque, por exemplo, a gente discute muito... a gente vê na história da própria empresa, e pessoas dizendo: "Olha, a Embrapa fez lá atrás e não faz nada há muito tempo, não é?". Houve uma recente discussão sobre a Embrapa na sociedade, como se... né? "Ah, vamos já atirar pedra, porque não tá fazendo". Não acho. Acho que continua fazendo da mesma forma. É que coisas, assim, inovadoras, elas são mais raras do que as coisas mais comuns, que fazem incrementos, mais discretos, né? (Entrevistada E3).

\section{Para o Entrevistado E4:}

Eu acho que foi dificil colocar no conceito das pessoas, inovação. No começo era uma palavra: Inovação. Inovação para causar um impacto na agricultura. Então, muitas tecnologias que nós temos produzido no campo, para o campo, dizem muito serem invenções, que são pesquisas que foram testadas e testadas e testadas e foise avançando e chegando lá. Sempre buscando um impacto, buscando uma inovação. Estava implícito isso. (...) Esse conceito que estamos buscando desde o inicio dessa conversa, que é produzir uma tecnologia que cause um impacto. Têm muitas tecnologias desenvolvidas com custo e tudo que não chegaram ao campo. Não chegaram. Por vários, vários problemas. A pesquisa, o laboratório estão aqui, mas tem que levar ao campo e isso implica outras atribuições. (...) tem que fazer diferente no campo. Essa inovação termina no campo. Só que nos falta o espaço a percorrer, o laboratório ou Centro de Pesquisa e o campo.

Quanto ao grau de novidade das inovações produzidas pela Embrapa Agrobiologia, 91\% consideram que a Unidade produz, majoritariamente, inovações incrementais.

Assim, ao observar o desempenho de inovação da Embrapa Agrobiologia, bem como suas forças e fraquezas internas, percebe-se que as fraquezas detectadas, embora em quantidade inferiores às demais Unidades analisadas, também podem estar impactando na capacidade da Unidade em atingir um desempenho de inovação muito satisfatório. Por outro lado, na percepção dos empregados, as alianças estabelecidas são consideradas como forças e suprem, em certa parte, as lacunas 
internas detectadas, ainda que de forma parcial, uma vez que a força advinda das parcerias são suficientes para trazer apenas uma paridade competitiva para a Embrapa Agrobiologia. Dessa forma, pode-se concluir que, o desempenho de inovação embora não seja ideal, é impactado positivamente pela relação entre os dois ambientes, interno e externo e que a ausência dessa ligação poderia impactar em um desempenho de inovação inferior tanto na percepção de seus empregados quanto nos resultados efetivamente encontrados no Relatório de Avaliação da Unidade, que será apresentado no próximo capítulo. 


\section{5}

\section{Análise Cruzada dos Casos e Discussão dos Resultados}

\section{1 Identificação de Forças e Fraquezas internas semelhantes}

Para discutir os resultados por meio da análise cruzada dos casos, é importante relembrar a pergunta central deste estudo: Como as redes de alianças e os recursos e capacidades internas se combinam e interferem no desempenho de inovação de três Unidades descentralizadas da Embrapa? Para responder a essa pergunta, o estudo primeiramente identificou as forças e fraquezas advindas dos recursos e capacidades internas das Unidades, no que concerne à inovação.

Todos os recursos e capacidades definidos como forças pelas três Unidades, com exceção da Propriedade Intelectual, foram considerados como fontes de paridade competitiva. Tal constatação indica que, mesmo que tais recursos e capacidades internas, sejam valiosos e aproveitados, eles foram definidos como perfeitamente imitáveis e não raros, o que proporciona às Unidades, apenas uma posição de igualdade competitiva (Barney \& Hesterly, 2015) quando comparadas a seus pares. Não foram encontrados, portanto, recursos e capacidades que pudessem contribuir para a melhoria das posições competitivas das Unidades ao longo do tempo, ou seja, que fossem considerados como fontes de vantagem competitiva, a despeito da Propriedade Intelectual, definido como fonte de vantagem competitiva temporária pela Agroindústria de Alimentos - CTAA.

De fato, conforme preconizam Barney \& Hesterly (2015) nem todos os recursos da empresa precisam ser fontes de vantagem competitiva, mas a existência de recursos considerados apenas como fontes de paridade, contribuem somente para a sobrevivência das organizações.

Esses resultados demonstram que, embora as Unidades tenham alta representatividade nas áreas em que atuam, tais representatividades podem estar ameaçadas, principalmente sob uma perspectiva de longo prazo, o que vai ao 
encontro da preocupação da empresa de forma geral, de que os sucessos do passado não significam garantia de sucessos futuros, haja vista a necessidade de reorganização de seus recursos para novos desafios, e que em contextos inovativos, dotados de alta incerteza, as grandes inovadoras do passado não são necessariamente as inovadoras do futuro.

De forma geral, a análise interna das três Unidades mostrou as seguintes similaridades quanto às forças e fraquezas de seus recursos críticos em contextos de inovação:

Quadro 21: Forças e Fraquezas comuns às Unidades

\begin{tabular}{|l|}
\hline \multicolumn{1}{|c|}{ Forças em comum } \\
\hline Quantidade de RH envolvidos em P\&D \\
\hline Qualidade Técnica do RH envolvido em P\&D \\
\hline Gerenciamento de Propriedade Intelectual - PI \\
\hline Fraquezas em comum \\
\hline Cultura \\
\hline TI como suporte à inovação aberta \\
\hline Definição de funções e responsabilidades da inovação aberta \\
\hline Processo de seleção de parceiros \\
\hline
\end{tabular}

Quanto às forças e fraquezas em comum detectadas, conforme Quadro 21, percebe-se que, grande parte delas, são semelhantes em decorrência das normas e regras iguais a que essas Unidades estão submetidas, bem como são frutos das mesmas restrições, o que as leva a ter dificuldades e facilidades semelhantes.

Os Recursos Humanos ligados à $\mathrm{P} \& \mathrm{D}$, por exemplo, no que tange à sua quantidade e qualidade técnica, foi considerado como força e fonte de paridade competitiva para as três Unidades.

De fato, pelas Unidades pertencerem à Embrapa, cuja atividade fim é a pesquisa, desenvolvimento e inovação (P\&D\&I) nas diversas áreas da agricultura, as áreas de $\mathrm{P} \& \mathrm{D}$ são formadas por pesquisadores altamente qualificados, os quais possuem doutorado ou pós-doutorado em universidades do Brasil e do exterior (Embrapa, n.d.). Além disso, seus empregados são selecionados por meio de concursos públicos, o que, contribui para a manutenção da qualidade técnica de todo o corpo técnico que integra a empresa. No entanto, a quantidade desses Recursos Humanos e sua alta qualidade técnica, não são recursos únicos e exclusivos dessas Unidades, sendo observados em outras Unidades da Embrapa e em outras Instituições Públicas, sendo, portanto, suficientes apenas para a manutenção de igualdade em termos de competição. A qualificação da equipe de P\&D de uma empresa, no entanto, é um importante indicador e medida de inovação, 
que demonstra o quanto a empresa investe e se preocupa com a inovação (De Carvalho et al., 2017). Além disso, estes recursos estão diretamente relacionados à produtividade da empresa, que favorece a diminuição do tempo de colocação de novos produtos no mercado e a expansão do acesso a novos mercados (Lopes \& de Carvalho, 2018).

Quanto ao Gerenciamento da Propriedade Intelectual, todas as três Unidades possuem um Comitê Local de Propriedade Intelectual - CLPI. Além disso, todas as Unidades estão submetidas à mesma Norma interna de Propriedade Intelectual - PI.

Embora o recurso tenha sido considerado como uma força, não foi observado, em nenhuma das três Unidades, um setor de PI adequado e devidamente estruturado para atender aos novos desafios decorrentes da inovação aberta, que:

- Concilie a defesa e proteção dos ativos com às ações colaborativas das Unidades e o meio externo (Grimaldi et al., 2021; Zhao et al., 2016) principalmente com o setor privado;

- Que possua agilidade na proteção (Barchi \& Greco, 2018), haja vista que o tamanho do setor e a existência de pessoas qualificadas em quantidade suficiente para atender a essas novas demandas e desafios também foi uma preocupação em comum;

- A definição de estratégias de negociação para a transferência de todos os tipos de inovações geradas em parceria com diversos tipos de parceiros, visando maior benefício para a sociedade (Grimaldi et al., 2021);

- Que elabore instrumentos contratuais mais sofisticados, que se preocupem não só com o processo de criação de valor da empresa, mas com processos de apropriação correta dos valores provenientes das inovações desenvolvidas em conjunto (Barchi \& Greco, 2018);

- Necessidade de adequação da norma de PI à diversidade de inovações geradas na empresa, as quais, segundo os entrevistados, estão muito voltadas para a proteção de produtos em detrimento às demais produções (de Carvalho et al., 2006).

De forma semelhante, o estudo de caso realizado por Teixeira (2018) em Institutos de Pesquisa do Estado de São Paulo, também demonstrou preocupação com a necessidade de adequação das atividades de PI às demandas da inovação 
aberta, mas ressaltam que na história da inovação no Brasil, é recente a prática da inovação como estratégia governamental. A própria Lei da Inovação (Lei 10.973/04) foi promulgada apenas no ano de 2004. Somente a partir daí, várias ações de inovação passaram a ser incentivadas, como a interação das Instituições Públicas com as empresas, além da criação de programas de governo para incentivo à inovação. Dessa forma, as Instituições Públicas, ainda se encontram em um processo de reorganização e reestruturações internas.

$\mathrm{Na}$ Embrapa, a empresa tem mostrado esforço nesse processo de adequação. A própria norma de Propriedade Intelectual, está em processo de reformulação e atualização. A importância da PI para a inovação gerada por Instituições Públicas, como a Embrapa, que detêm conhecimentos relevantes nas áreas em que atuam, contribuem com a preservação da liderança dessas instituições na geração de conhecimentos de ponta e na detenção das competências tecnológicas, ativos passíveis de negociações entre parceiros, o que possibilita trocas com condições mínimas de equilíbrio entre os envolvidos (Carvalho et al., 2006).

Em termos das fraquezas internas em comum, a cultura da inovação foi o fator considerado de maior fragilidade por todos os participantes das três Unidades, e portanto, fonte de desvantagem competitiva. A fragilidade cultural foi mencionada em várias respostas, mesmo quando o questionamento não era em relação à cultura da inovação. A cultura é um fator de impacto transversal e é considerada como a principal barreira à implementação da inovação aberta e a principal facilitadora desse processo (Hosseini et al., 2017; Ades et al., 2013; Zhao et al., 2016).

De forma unânime, as justificativas para a fragilidade desta cultura recaíram sobre:

- Adoção recente do macroprocesso de inovação pela Embrapa, ocorrido em 2018, o que significa que a empresa ainda está em processo de adaptação à nova realidade e a nova forma de se pensar a pesquisa;

- No nível organizacional, a percepção geral, é a de que a empresa também está em fase de transição entre uma lógica mais acadêmica adotada até então, em que se privilegia mais as produções científicas, para uma lógica voltada para a produção de resultados inovativos que gerem cada vez mais resultados e impactos na sociedade; 
- Imaturidade da empresa na sua forma de fazer negócios com as diferentes inovações geradas pelas suas áreas distintas, nas quais as Unidades atuam. Imaturidade consubstanciada nas suas normas e diretrizes que ainda precisam ser adaptadas ou estão em processo de adaptação (Barchi \& Greco, 2018);

- No nível individual, as Unidades estão, no geral, divididas entre aqueles empregados que já entendem e percebem a nova realidade da inovação e aqueles que ainda apresentam dificuldades de entendimento e aceitação; o que evidencia a negação de conhecimentos externos - Crise do não inventado aqui - (Not inventend here - NIH) (Cui et al., 2015; Mortara \& Minshall, 2011; Lifshitz-Assaf, 2018; Nestle et al., 2019; Ades et al., 2013; Barchi \& Greco, 2018) e o medo de arriscar, devido ao maior grau de incerteza inerente ao processo de inovação (Wu et al., 2019).

No entanto, percebeu-se também, que há esforços nas Unidades no sentido de fomentar a cultura da inovação. De forma particular, foram citadas iniciativas nesse sentido na Embrapa Solos, que desde 2018, vem promovendo eventos denominados "Encontros de Inovação". Iniciativas semelhantes foram realizadas em empresas consideradas inovadoras, como a Natura que criou o Programa Natura Campus, com o objetivo de mudar sua cultura interna (Ades et al., 2013), a Empresa Google estabeleceu um moderno e inovador modelo de gestão organizacional altamente flexível, com espaços físicos projetados para facilitar a livre circulação de idéias (Feijó, 2015). Ambas empresas verificaram impactos positivos em suas capacidades de inovação, advindos de tais ações.

Além disso, há nas três Unidades, um projeto desenvolvido em parceria, para a construção de um Polo de Inovação Tecnológica para a criação e estruturação de uma rede de inovação para o agronegócio no Estado do Rio de Janeiro, que dentre outros objetivos, tem o intuito de facilitar as relações das Unidades com o meio externo, principalmente o setor privado, além de outras ações de inovação.

As Unidades Solos e Agroindústria de Alimentos também realizaram uma pesquisa com o intuito de ter um diagnóstico do cenário atual dessas Unidades em relação à internalização do macroprocesso de inovação, e a partir daí, propor soluções e ações para facilitar sua internalização. Tais iniciativas demonstram 
atenção das lideranças no sentido de criação de ambientes mais propícios à inovação aberta (Wu et al., 2019), foco na capacidade de aprendizagem organizacional, que favorece o acúmulo de conhecimento (Paula \& Silva, 2017) essenciais para a melhoria da capacidade absortiva das empresas (Cohen \& Levinthal, 1990; Lopes \& de Carvalho, 2018) e vital para o sucesso em contextos de inovação aberta (Macedo-Soares et al., 2017; Zhao et al., 2016; Petraite et al., 2020).

Embora haja iniciativas de caráter organizacional, de forma geral, a cultura individual ainda é uma forte barreira (Lifshitz-Assaf, 2018). Além de práticas organizacionais para melhoria da cultura da inovação, práticas de remuneração e premiação podem ser utilizadas como alternativas para fomentar e incentivar os profissionais, principalmente os profissionais de P\&D (Cui et al., 2019).

A TI como suporte às atividades de inovação aberta, também foi definida como fraqueza comum. Os resultados mostraram que as Unidades ainda carecem de sistemas de TI apropriados, que facilitem as trocas de informações em tempo real com os colaboradores da inovação (plataformas de comunicação) (Cui et al., 2015), ausência de sistemas e softwares robustos, tais como, softwares de mineração de dados que permitam análises de cenários, tendências, análise de banco de dados de patentes, dentre outros. Além de tecnologias como simulação, realidade virtual que permitam a exploração de novas idéias, de informações de mercado e a integração dessas informações às equipes internas de trabalho (Dodgson et al., 2006).

Percebeu-se de forma geral, que devido às restrições orçamentárias que a empresa vem passando, relacionadas às políticas governamentais, tem sido difícil para as Unidades manterem e atualizarem seus recursos de TI, de forma a atender todas essas novas necessidades advindas da prática da inovação aberta. A Procter \& Gamble, empresa considerada um caso exemplar de inovação aberta, baseou seus processos de inovação aberta às Tecnologias da Informação e Comunicação. A empresa é uma das maiores detentoras de patentes em nível global, com mais de 29.000 patentes com outras 5000 sendo adicionadas em média a cada ano (Dodgson et al., 2006).

O processo de seleção de parceiros também foi definido como fraqueza. As Unidades mostraram não possuir um setor específico para esse fim. Muitos entrevistados das três Unidades afirmaram que os contatos e a escolha de parceiros se dá muito no nível individual, de forma pulverizada pelos empregados, baseados 
em seus contatos pessoais e com o relacionamento informal que estabeleceram ao longo de suas jornadas de trabalho.

Não há, portanto, um setor que estruture esse processo, embora a seleção errada de parceiros esteja entre os principais motivos para o fracasso das atividades de inovação aberta (Barchi \& Greco, 2018). As incertezas de mercado (Liang \& Mei, 2019), as incertezas inerentes à inovação e o medo de arriscar (Wu et al., 2019), levam ao reforço de relacionamentos com parceiros existentes, o que gera problemas de inércia na seleção (Liang \& Mei, 2019) e a perpetuação passiva de relacionamentos, que por vezes, não estão mais ligados às estratégias organizacionais (Haider \& Mariotti, 2016) além de serem prejudiciais para o aumento das inovações advindas da diversidade de parcerias e de conhecimentos heterogêneos (Jiang et al., 2010).

Outro ponto detectado é que as Unidades, muitas vezes, adotam uma postura muito mais reativa e responsiva às demandas que aparecem, do que uma postura proativa, que estuda, analisa, prospecta e seleciona de forma madura os melhores parceiros para seus projetos de inovação (Zhao et al., 2016). Mais uma vez, um bom exemplo de empresa brasileira que implantou um setor específico para esse fim foi a Natura, que criou uma unidade de inovação, gestão da inovação e gestão de parcerias centralizada em sua vice-presidência e formada por diversos profissionais de áreas distintas. Além disso, a empresa criou um Comitê de Gerenciamento de Rede, cujas principais atividades são: análise dos riscos na realização de projetos em parceria, análise das fontes de financiamento adequadas, controle de prazos para assinatura de acordos/contratos e prospecção de novos parceiros (Ades et al., 2013). Outro exemplo são os Institutos de Pesquisa do Estado de São Paulo, que por meio da criação de Núcleos de Inovação Tecnológica - NIT, estabeleceram uma estrutura para coordenar e gerenciar as relações das Instituições Públicas do Estado e das Universidades com o setor privado (Teixeira, 2018).

\section{2 \\ Identificação de Forças e Fraquezas distintas}

De forma individual, as Unidades também mostraram distinções em relação a alguns recursos e capacidades considerados como forças e fraquezas. 
Em termos de forças únicas, a Embrapa Solos mostrou possuir duas forças individuais, enquanto a Embrapa Agrobiologia mostrou possir um total de três forças distintas. Já a Embrapa Agroindústria de Alimentos não apresentou nenhuma força específica, quando comparada às outras duas Unidades. Todas as forças observadas são também compartilhadas por uma ou pelas outras duas Unidades. Quanto às suas fraquezas individuais, o CTAA apresentou apenas uma: Liderança Pessoal por Pares e Corretagem Social, capacidade específica do fator: Habilidades e Competências Individuais (Hosseini et al., 2017).

Pelas entrevistas, pôde-se concluir que essa fraqueza está intimamente relacionada à baixa cultura da inovação na Unidade, fator também observado como fraqueza nas demais Unidades analisadas. Os entrevistados, de forma geral, afirmaram que os empregados, de forma individual, têm iniciativas de conectar parceiros para o desenvolvimento de seus projetos, no entanto, na prática, a grande maioria dos projetos em parceria são desenvolvidos a partir da procura dos parceiros à Unidade, o que demonstra uma posição mais passiva e reativa dos empregados, embora a literatura aponte para a importância do nível individual e das competências para a inovação aberta (Petraite et al., 2020; Podmetina et al., 2018)

Com relação à Embrapa Agrobiologia, as seguintes forças específicas foram encontradas: $1^{\text {a }}$ : Tomada de decisões quanto ao uso de formas específicas de inovação aberta de acordo com os problemas e desafios de inovação enfrentados, capacidade pertencente ao fator: Governança e Alinhamento Estratégico; 2a Capacidades Inventiva, Absortiva, Transformativa e Inovativa, capacidades pertencentes ao fator: Capacidade de Gerenciamento do Conhecimento; e $3^{\text {a }}$ : Capacidade de Alargamento de Fronteiras, capacidade dentro do fator: Habilidades e Competências Individuais.

Pelas análises das informações coletadas, percebeu-se que a grande força da Unidade está na sua capacidade de trabalho em equipe, na participação de todos os empregados na elaboração das estratégias da Unidade, na discussão dos objetivos a serem alcançados e das práticas de inovação aberta que deverão ser realizadas para que a Unidade consiga atingir seus objetivos. Estes resultados, condizem com os estudos anteriores que ressaltam a importância do alinhamento estratégico com os problemas de inovação detectados e a estratégia de inovação aberta adotada. Essa tomada de decisão é imprescindível para o sucesso da inovação (Hosseini et al., 2017). 
Nesse contexto, embora a P\&D da Embrapa Agrobiologia seja também dividida por meio de seus Núcleos Temáticos, há, segundo os entrevistados, uma interação muito grande entre as equipes e destas com o grupo que compõe o nível estratégico da Unidade, o que contribui para o alinhamento das decisões, tanto em termos de inovação quanto em outros aspectos. Essa maior coesão da Unidade, foi percebida também por meio do questionário, cujas respostas se mostraram menos heterogêneas quando comparadas às outras duas Unidades.

A Unidade também mostrou possuir capacidade inventiva, absortiva, transformativa e Inovativa, o que significa ser capaz de gerenciar com êxito sua base de conhecimento ao longo do tempo, de realinhar e reajustar seus conhecimentos internos e externos, de acordo com as demandas do ambiente (Lichtenthaler \& Lichtenthaler, 2009) assim como a capacidade de lidar com culturas distintas e com a heterogeneidade do conhecimento de seus parceiros, facilitando o diálogo entre os múltiplos mundos (Habicht et al., 2012). Empresas que não conseguiram desenvolver essas capacidades de gerenciamento do conhecimento ou que focaram em apenas uma delas, foram drasticamente abaladas, muitas inclusive foram fundidas e absorvidas pelos seus concorrentes (Puffal et al., 2019; Dodgson et al., 2006). As capacidades de gerenciamento do conhecimento estão diretamente relacionadas às capacidades de exploração (exploration) do conhecimento, de aproveitamento (exploitation) e de retenção de conhecimentos, cujo equilíbrio entre elas, mostram uma capacidade de ambidestria organizacional, considerada antecedente importante à inovação (March, 1991; Vogel \& Güttel, 2013; Lichtenthaler \& Lichtenthaler, 2009).

Por outro lado, sua capacidade conectiva é considerada fraca. As ações da Embrapa Agrobiologia com relação ao estabelecimento de links com parceiros, de modo a facilitar trocas de informação, ainda são feitas, na maioria das vezes, de forma informal e individual. A Unidade mostrou não possuir diretrizes e ações institucionalizadas para a manutenção dos relacionamentos com parceiros, mesmo quando não há desenvolvimento de projetos em parceria (Lichtenthaler \& Lichtenthaler, 2009).

Com relação à Embrapa Solos, as forças específicas observadas foram: o Suporte à inovação (ADM; TT e negócios) e a Mentalidade Tecnológica.

Um dos esforços mencionados por alguns entrevistados, que demonstram a força do suporte à Pesquisa e Desenvolvimento e às atividades de inovação na 
Embrapa Solos, dizem respeito à maior integração entre os setores de Transferência de Tecnologia - TT e os setores de P\&D, como o Comitê Técnico Interno - CTI, Comitê de Propriedade Intelectual - CLPI e as Chefias da Unidade, tanto Geral quanto Chefia de P\&D. Essa aproximação tem trazido resultados importantes, no sentido de fortalecimento da cultura da inovação. Além de aproximações realizadas por meio de sistemas de suporte à pesquisa, efetuados pela empresa de modo geral, esses setores na Embrapa Solos também têm se esforçado para trabalhar de forma conjunta e diretamente com os pesquisadores, fornecendo apoio no desenvolvimento dos projetos, fomentando a cultura da produção de resultados e na análise de viabilidade dos possíveis resultados gerados. Essas ações encontram respaldo na literatura, que mostra que o trabalho em equipe e o envolvimento de todos nos processos inovativos têm impactos positivos no desempenho inovativo (Feijó, 2015; Zhao et al., 2016).

Já com relação às fraquezas específicas, foram observadas: a qualidade inovativa dos Recursos Humanos envolvidos nas atividades fim dessa Unidade (P\&D\&I) e a Infraestrutura física, de TI e insumos para a realização da P\&D.

Com relação à capacidade inovativa, a Embrapa Solos, de forma mais intensa, mostrou fragilidades com relação aos seus profissionais de $\mathrm{P} \& \mathrm{D}$, os quais demonstraram maiores dificuldades para lidar com as atividades de inovação, segundo os participantes. Fato que não foi observado com tanta intensidade nas demais Unidades. Esses desafios também foram encontrados no trabalho realizado por Lifshitz-Assaf (2018) que realizaram um estudo longitudinal na Nasa. Os resultados mostraram que a abertura da empresa para as atividades de inovação aberta afetou a identidade dos profissionais de $\mathrm{P} \& \mathrm{D}$, que apresentaram dificuldades para abrir seus limites e fronteiras do conhecimento para os conhecimentos externos, com receio de perderem suas legitimidades e seus prestígios (LifshitzAssaf, 2018).

\section{3}

\section{Contexto das Alianças e Portfólio de Alianças}

Com relação às parcerias estabelecidas pelas três Unidades com seus parceiros de inovação, todas essas parcerias, independente do tipo de alianças, dos 
tipos de parceiros, da modalidade e natureza das ligações, e ainda, dos benefícios advindos, foram consideradas como forças para as Unidades.

As três Unidades praticam a inovação aberta por meio das parcerias e acreditam que tal prática gera impactos em seus desempenhos de inovação, assim como acreditam que a inserção em portfólios de alianças e não apenas em parcerias bilaterais, possibilita maiores oportunidades e são importantes a serem consideradas quando da elaboração de suas estratégias para inovação.

No entanto, embora as Unidades tenham tais percepções, para as Unidades CNPAB e CTAA, o envolvimento em parcerias se dá, de forma preponderante, por meio de relações bilaterais. Apenas a Embrapa Solos acredita que, de forma igual, a Unidade realiza parcerias tanto bilaterais quanto multilaterais. A explicação dada pelas Unidades para a realização de parcerias bilaterais é devido, em parte, pela característica do trabalho executado, que normalmente ocorre por demanda do parceiro, o qual exige exclusividade, enquanto a outra parte se explica pela insegurança no envolvimento de parcerias com múltiplos parceiros, cujos acordos se tornam mais complexos tanto em termos de negociações (Barchi \& Greco, 2018) quanto em termos de coordenação e governança das relações (Hoffmann, 2007).

Esses achados vão ao encontro das fragilidades internas em comum detectadas, no que diz respeito ao Gerenciamento da Propriedade Intelectual - PI, que embora tenha sido definido como força, em termos de adequação aos contextos de inovação aberta, percebeu-se a fraqueza deste recurso (Grimaldi et al., 2021). Além da PI, a falta de respaldo jurídico na elaboração de instrumentos para estabelecimento de parcerias com múltiplos parceiros (Barchi \& Greco, 2018) a ausência de setores estruturados que façam o gerenciamento, governança e acompanhamento das parcerias realizadas pelas Unidades (Hoffmann, 2007) e que realize, ainda, a prospecção e seleção dos melhores parceiros para inovação (Haider \& Mariotti, 2016), também podem ter contribuído para a baixa realização de parcerias multilaterais.

A baixa participação em parcerias com múltiplos atores e múltiplas oportunidades, pode também explicar os resultados medianos encontrados nos desempenhos de inovação, conforme detalhado nos resultados individuais das Unidades no capítulo anterior e cujas discussões serão apresentadas adiante, uma vez que trabalhos empíricos realizados encontraram uma relação positiva entre empresas que participam de portfólios de alianças e seus desempenhos de inovação, 
e que esses desempenhos, são em geral, maiores quando comparados aos desempenhos de empresas cujas parcerias se dão apenas por meio de relações bilaterais (Macedo-Soares et al., 2017).

De forma mais específica, as Unidades realizam alianças com vários tipos de parceiros (Contractor \& Lorange, 2002) no entanto, as parcerias estabelecidas com as Entidades Governamentais e com os Fomentadores/Financiadores foram consideradas, por todas as três Unidades, como relações fortes e profundas, que ensejam alianças sólidas, de alta confiança, com fluxo transparente e contínuo de informações (Zaheer et al., 2010). De fato, essas foram definidas pelos entrevistados como as parcerias mais tradicionais e duradouras das Unidades.

Em sua maioria, essas parcerias são formadas para realização de $\mathrm{P} \& \mathrm{D}$ em conjunto, cujos principais recursos proporcionados às Unidades CNPAB e CTAA, dizem respeito ao compartilhamento de riscos e incertezas e compartilhamento de custos.

De forma específica, para a Embrapa Solos, as parcerias com os Fomentadores/Financiadores também proporcionam o compartilhamento de custos, assim como as parcerias com as Entidades Governamentais proporcionam o compartilhamento de riscos e incertezas, mas acrescentam, em ambos tipos de parceiros, o Monitoramento de mudanças ambientais e oportunidades para a Unidade, que é considerado um importante mecanismo para que as empresas possam co-evoluir com o ambiente e serem capazes de manter suas competitividades (Wassmer, 2010).

O envolvimento em parcerias distintas, de forma simultânea, cujas finalidades sejam o compartilhamento de riscos e incertezas, também encontra respaldo na literatura, pois permitem que as empresas obtenham mais vantagens e benefícios de suas relações em geral, quando espalham seus riscos e superam de forma substancial as incertezas (Wassmer, 2010).

No entanto, retomando às discussões sobre o estabelecimento de relações fortes e profundas com esses tipos de parceiros, é crucial observar que, se por um lado esses laços são importantes por estabelecerem vínculos fortes, por outro, mostram que as Unidades, em geral, focam na realização de parcerias com as mesmas Entidades e Fomentadores, parceiros considerados de longa data. Tal rotina denota uma baixa capacidade na diversificação, na baixa procura por novos parceiros (novas Entidades Governamentais e novos Fomentadores/Financiadores) 
que tragam novas possibilidades e oportunidades essenciais em contextos inovativos. Essa baixa capacidade está intimamente relacionada a maior probabilidade de desenvolvimento de inovações incrementais, em detrimento às inovações radicais (Macedo-Soares et al., 2017).

Ainda, com relação à natureza das ligações estabelecidades com esses tipos de parceiros (Fomentadores/Financiadores e Entidades Governamentais), para o CTAA e CNPAB essas ligações são para aproveitamento, visam refinar e aproveitar os conhecimentos e informações de seus parceiros de longa data, para serem adaptados às suas necessidades. $\mathrm{O}$ foco não está, portanto, na procura por novas Entidades Governamentais nem por novos Fomentadores/Financiadores, o que é compatível com as parcerias fortes e profundas estabelecidas com tais parceiros.

Para o CNPS, as ligações visam tanto o aproveitamento dos recursos existentes quanto à exploração de novos recursos. No entanto, a Unidade considera tais ligações fortes e profundas, o que restringe a possibilidade de novas parcerias. Dessa forma, para essa Unidade é importante também privilegiar ligações menos intensas e menos duradouras, o que lhe fornecerá maior flexibilidade para novas explorações.

Com relação às parcerias estabelecidas com clientes, essas foram consideradas pelas três Unidades como alianças de Prestação de Serviços e P\&D em conjunto. Para a Embrapa Solos, no entanto, essas relações são também de Licenciamento de Patente ou Know-How. Já as parcerias com os complementadores, foram consideradas para as três Unidades, como para Desenvolvimento e Co-Produção e para Licenciamento de Patente ou know-How. De forma individual, a Embrapa Solos foi a Unidade que considerou possuir relações, fontes de vantagem competitiva temporária para a Unidade, como as relações estabelecidas com os complementadores, caracterizados como seus principais parceiros. Nesse caso, percebeu-se que muitos parceiros como clientes da Unidade, funcionam em determinados momentos, como complementadores, o que pode explicar a importância deste tipo de parceria e sua raridade, apontada pelos empregados. Da mesma forma, as parcerias com as Entidades Governamentais também foram definidas como vantagem competitiva temporária. De fato, as Entidades Governamentais, principalmente, as parcerias com as Secretarias Estaduais de Agricultura de vários estados, foram consideradas relações muito importantes para a Embrapa Solos. 
Embora os tipos de alianças sejam semelhantes em alguns benefícios que proporcionam, percebeu-se que o meio externo com os quais as Unidades se relacionam, são distintos, com parceiros diferentes para cada Unidade, provenientes de suas áreas de atuação distintas. O Quadro 22 mostra os principais tipos de parceiros, citados pelos entrevistados, de acordo com cada Unidade.

Quadro 22: Exemplo dos Principais Tipos de Parceiros por Unidade.

\begin{tabular}{|c|c|c|c|}
\hline $\begin{array}{l}\text { Tipos de } \\
\text { Parceiros }\end{array}$ & Embrapa Solos & $\begin{array}{l}\text { Embrapa Agroindústria de } \\
\text { Alimentos }\end{array}$ & $\begin{array}{l}\text { Embrapa } \\
\text { Agrobiologia }\end{array}$ \\
\hline Clientes & $\begin{array}{l}\text { Governos } \\
\text { Estaduais/ } \\
\text { Secretarias } \\
\text { Estaduais de } \\
\text { Agricultura }\end{array}$ & $\begin{array}{l}\text { Produtores Rurais, Empresas } \\
\text { de Processamento, de } \\
\text { embalagem, pequenas e } \\
\text { médias indústrias, Empresas } \\
\text { Privadas (Ex: Coco Legal); } \\
\text { Anvisa; MAPA. }\end{array}$ & MAPA; URRJ; INEA \\
\hline Complementadores & $\begin{array}{l}\text { Empresas } \\
\text { Privadas }\end{array}$ & $\begin{array}{l}\text { Empresas Privadas; } \\
\text { Institutos de Pesquisa } \\
\text { Ex: Realizam Ensaios } \\
\text { Biológicos; MAPA; Anvisa; } \\
\text { Inmetro }\end{array}$ & Empresas Privadas \\
\hline $\begin{array}{l}\text { Entidades } \\
\text { Governamentais }\end{array}$ & $\begin{array}{l}\text { MAPA e } \\
\text { Governos } \\
\text { Estaduais }\end{array}$ & $\begin{array}{l}\text { Institutos de Pesquisa; } \\
\text { MAPA, Anvisa, Inmetro } \\
\text { e Governos de } \\
\text { Estado, especialmente } \\
\text { Estado do Rio de Janeiro }\end{array}$ & 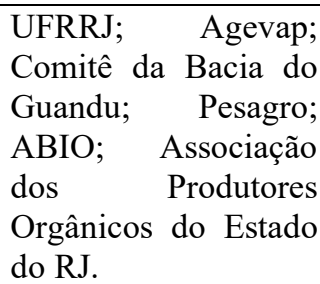 \\
\hline $\begin{array}{l}\text { Fomentadores/ } \\
\text { Financiadores }\end{array}$ & $\begin{array}{l}\text { Finep; Faperj; } \\
\text { Embrapa }\end{array}$ & $\begin{array}{l}\text { Embrapa; Faperj; Empresas } \\
\text { Privadas }\end{array}$ & $\begin{array}{l}\text { Faperj; Agevap; } \\
\text { Fundo Newton }\end{array}$ \\
\hline
\end{tabular}

Para as três Unidades, percebeu-se também, sobreposições em alguns tipos de parceiros. De acordo com o Quadro 22, percebe-se que as Entidades Governamentais, por exemplo, foram em alguns casos, consideradas também como clientes, como no caso dos Governos Estaduais para a Embrapa Solos e o Ministério da Agricultura, Pecuária e Abastecimento - MAPA, para a Embrapa Agroindústria de Alimentos. Os clientes e os complementadores, por sua vez, foram definidos em alguns casos também como Fomentadores/Financiadores, como também observado com as empresas privadas na Embrapa Agroindústria de Alimentos.

As Unidades Solos e Agrobiologia classificaram as relações com clientes e complementadores, como fracas e amplas, constituídas por fluxos menos intensos de informações e um menor nível de confiança. Tais relações foram consideradas pontuais e dinâmicas. No entanto, embora sejam relações menos intensas, proporcionam maior flexibilidade às Unidades para acesso a novos parceiros e novas possibilidades, o que está ligado a maior probabilidade de alcance e desenvolvimento de inovações radicais (Macedo-Soares et al., 2017). Para a 
Unidade Agroindústria de Alimentos, as relações com clientes foram definidas como forte e profundas, o que demonstra relações sólidas realizadas com estes tipos de parceiros. Com relação às parcerias com complementadores, estas foram consideradas como fracas e amplas por todas as três Unidades.

Dessa forma, verificou-se que as Unidades, em suas relações interorganizacionais conseguem equilibrar parcerias fracas e amplas com parcerias fortes e profundas. No entanto, não se verificou produções satisfatórias de inovações radicais pelas Unidades, o que nos leva a afirmar que as relações mais proveitosas são as estabelecidas com Entidades Governamentais e Fomentadores/Financiadores, que por serem fortes e profundas, ensejam inovações incrementais, consideradas as produções majoritárias das Unidades; ou ainda, que as relações estabelecidas com complementadores, não são consideradas tão heterogêneas assim, ao ponto de propiciarem as inovações radicais (Christensen, 1999).

$\mathrm{O}$ contexto analisado mostrou que as Unidades realizam parcerias com bastante frequência e há bastante tempo, antes mesmo da implementação do macroprocesso de inovação que passou a incentivar a realização dos projetos em parceria. No entanto, mesmo sendo algo realizado há bastante tempo, essas relações, principalmente aquelas estabelecidas com o meio privado, ainda carecem de governança, estrutura e de maior segurança.

De forma geral, no entanto, as alianças são importantes, pois trazem forças para as Unidades. No entanto, tais forças são fontes, em sua maioria, de paridade competitiva. Apenas as alianças com complementadores e Entidades Governamentais foram classificadas como fontes de vantagem competitiva temporária pela Embrapa Solos. Assim, de forma geral, as parcerias mitigam as fraquezas, mas não se traduzem em vantagens competitivas sustentáveis, o que pode explicar a ausência do desempenho superior a ser observado na próxima seção.

\section{4}

\section{Desempenho de inovação das Unidades}

Após a caracterização das forças e fraquezas detectadas na análise interna das Unidades, procedeu-se a comparação destas com os recursos trazidos pelas 
alianças na análise relacional, bem como a análise dos desempenhos de inovação das Unidades, de modo a responder a pergunta de pesquisa em sua totalidade.

De forma geral, conforme já mencionado, todas as parcerias das três Unidades, foram definidas como forças pelos participantes. Quanto aos recursos internos, a Unidade Agrobiologia foi a que apresentou menos fraquezas internas, seguida pela Embrapa Solos, e por último, a Unidade Agroindústria de Alimentos.

No entanto, de forma paradoxal, a Agroindústria de Alimentos foi a Unidade que apresentou o melhor desempenho de inovação na visão dos participantes. Todos os três tipos distintos de resultados produzidos (Ativos Tecnológicos, Ativos PréTecnológicos e de Apoio à Inovação) foram considerados satisfatórios, além de todos os impactos gerados (socioambientais, econômicos, na cadeia produtiva e impactos no desenvolvimento institucional) também foram considerados como relevantes. Dessa forma, percebe-se que as fraquezas não foram refletidas, na visão dos empregados, no desempenho de inovação desta Unidade.

$\mathrm{Na}$ Unidade Agrobiologia, embora esta tenha apresentado menos fraquezas, foi a que apresentou o desempenho de inovação mediano, quando comparada as demais Unidades analisadas, visto que para a Unidade, a quantidade de resultados gerados foi satisfatória, no que diz respeito aos Ativos Pré-Tecnológicos e de Apoio à Inovação. Já os impactos foram considerados relevantes para todos os quatro aspectos analisados.

Por fim, para a Embrapa Solos, a quantidade de resultados gerados foi considerada de forma semelhante a da Embrapa Agrobiologia, no entanto, no que se refere aos impactos, a Unidade só considerou relevante os impactos socioambientais e os impactos no desenvolvimento institucional.

De forma geral e comparável, os desempenhos de inovação encontrados, em termos de quantidade de resultados gerados, foram considerados como satisfatórios ou pouco satisfatórios. Para nenhuma categoria, dentre as três utilizadas pela empresa (Ativos Pré-Tecnológicos; Ativos Tecnológicos e de Apoio à Inovação) os resultados foram considerados como muito satisfatórios, o que permite concluir que há espaço para melhorias.

No entanto, embora as percepções dos participantes acerca dos desempenhos inovativos das Unidades tenham sido as apresentadas acima, a triangulação destes resultados com os que foram encontrados nos Relatórios de Avaliação de Desempenho das três Unidades, ano base 2019, revelaram 
discrepâncias relevantes. Por exemplo, de acordo com o Relatório da Agroindústria de Alimentos - CTAA (Embrapa, 2019d), dentre as três Unidades analisadas, foi a que apresentou o desempenho menos expressivo, no que tange à dimensão Efetividade, que trata diretamente da inovação, dos resultados e impactos gerados pela Unidade. Esta dimensão é composta por quatro diferentes critérios: Gestão da Inovação; Destaques de PD\&I; Qualidades das Avaliações de Impacto e Uso de conhecimento de Publicações.

Dessa forma, percebe-se uma distinção entre a percepção dos empregados desta Unidade, participantes da pesquisa, com os resultados por ela produzidos.

Tais distinções podem revelar aspectos intrínsecos importantes para a Gestão da Unidade. Por meio da triangulação, percebe-se que a Unidade tem uma visão correta de suas fragilidades internas uma vez que os resultados apresentados no Relatório, se mostraram menos satisfatórios em comparação às demais Unidades analisadas, o que demonstra que sua quantidade maior de gargalos internos pode estar impactando em resultados menos expressivos. Por outro lado, a percepção dos empregados de que a Unidade possui resultados inovativos satisfatórios e relevantes, demonstra uma Unidade menos madura em termos de inovação. Os empregados acreditam que os resultados produzidos são adequados, demonstrando uma visão mais tímida sobre as possibilidades de melhoria dos resultados gerados.

Dessa forma, é necessário que a Unidade promova ações mais efetivas com foco na produção de resultados e na disseminação de uma cultura interna de inovação, seja por meio de capacitações, treinamentos, na criação de ambientes e espaços que fomentem a criatividade, que estimulem o fornecimento de ideias e o trabalho em equipe, essenciais para a inovação (Feijó, 2015) haja vista que a cultura é considerada a principal facilitadora do processo de inovação (Hosseini et al., 2017; Zhao et al., 2016). Sugere-se também que a Unidade foque na sua capacidade de aprendizagem, considerada como antecedente crucial à inovação (Lopes \& de Carvalho, 2018).

Por outro lado, a Embrapa Solos foi a Unidade cujas percepções dos participantes da pesquisa se mostraram piores em relação ao seu desempenho de inovação. No entanto, pela triangulação dos dados com os resultados apresentados no Relatório de Avaliação de Desempenho da Unidade, ano base 2019 (Embrapa, 2019f), a Unidade obteve desempenho mais satisfatório no que se refere ao resultado da dimensão Efetividade quando comparada as duas outras Unidades. 
Dessa forma, percebe-se também uma discrepância entre as percepções dos empregados e os resultados de inovação efetivamente encontrados. Tais evidências refletem a existência de uma equipe mais exigente, que vislumbra resultados mais satisfatórios e relevantes, uma equipe mais madura em termos de inovação (Leon et al., 2020) que demonstra uma insatisfação com seu desempenho atual e que pretende alcançar patamares mais altos, na busca pelo aumento da produção de resultados mais inovativos e mais impactantes para a sociedade.

De fato, esta Unidade demostrou um grande esforço da equipe, em termos de ações que fomentam e melhoram a cultura da inovação. Algumas ações e projetos em andamento na Unidade foram citados pelos participantes, tais como: Encontros de Inovação, o Projeto Soils Play: o agro entrou no jogo (Embrapa, 2021) e a construção do Polo de Inovação Tecnológica do Agronegócio - PiTec Agro, projeto desenvolvido em parceria com as demais Unidades do Rio, que visam, dentre outras ações, disseminar a cultura da inovação de forma interna e aproximar a Unidade de potenciais parceiros, que a auxiliem na melhoria de seu desempenho de inovação.

Por fim, a Unidade Agrobiologia, na percepção dos participantes, foi a que apresentou a menor quantidade de fraquezas internas no que diz respeito à inovação e um desempenho de inovação mediano, na percepção de seus empregados, quando comparada à percepção dos empregados das outras duas Unidades.

Pela triangulação desses resultados com os apresentados na Avaliação de Desempenho Institucional, ano base 2019 (Embrapa, 2019e), a Unidade também mostrou um resultado mediano no que diz respeito à dimensão Efetividade, em relação às outras Unidades analisadas.

Tal confrontação mostra uma percepção mais real desta equipe em relação ao seu desempenho de inovação. De forma interna, como a Unidade foi a que apresentou a maior quantidade de forças, sendo essas fontes de paridade competitiva, esses achados são coerentes com a percepção dos participantes quanto ao desempenho mediano percebido e encontrado no Relatório, uma vez que forças definidas como fontes de paridade não trazem desempenhos superiores, mas sim, aqueles considerados na média.

Conforme já mencionado no início deste capítulo, esta Unidade também foi a que apresentou um grupo mais coeso e mais homogêneo, o que demonstra que, embora os resultados inovativos ainda não sejam ideais, internamente, a Unidade 
demonstra possuir características importantes para a inovação, que lhe dão oportunidades para alavancar seu desempenho, como a existência de um ambiente bastante flexível e com grande estabilidade (Leon et al., 2020) que valoriza a participação das equipes na construção de suas estratégias, alinhadas aos seus desafios de inovação, fatores considerados imprescindíveis em contextos inovativos (Hosseini et al., 2017).

\section{5}

\section{Conclusão}

Este estudo teve como principal objetivo analisar como as redes de alianças e os recursos e capacidades internas impactam no desempenho de inovação de três Unidades da Embrapa: Embrapa Solos, Embrapa Agroindústria de Alimentos e Embrapa Agrobiologia.

Considerando a percepção das equipes das três unidades e seus desempenhos de inovação em 2019, pode-se concluir que:

As Unidades não possuem recursos e capacidades críticas em contextos de inovação, que sejam fontes de vantagens competitivas nem temporárias, nem sustentáveis. Dessa forma, esses recursos e capacidades internas se mostram limitantes ao desempenho de inovação muito satisfatório e muito relevante nas três unidades da Embrapa.

Por outro lado, o desempenho de inovação parece não ser afetado negativamente pelos recursos humanos envolvidos em $P \& D$, nem pela sua quantidade nem tampouco pela sua qualidade técnica.

Já a rede de inovação das três unidades impacta positivamente seus desempenhos de inovação, por meio da mitigação de suas fraquezas internas e potencialização de suas forças, proporcionando um desempenho satisfatório na média. Pelos resultados, percebeu-se que sem as parcerias o desempenho das Unidades seria pior.

Embora os recursos analisados tenham sido considerados como fontes apenas de paridade competitiva, a partir da percepção dos entrevistados, foi possível observar que a grande força das Unidades, reside sob seus Recursos Humanos, dotados de alta capacidade e qualidade técnica, uma das forças em comum mais evidenciada pelos participantes das três Unidades, além da marca da Embrapa e sua 
credibilidade, ativos intangíveis conquistados ao longo dos 47 anos de história da empresa.

Além disso, percebeu-se que as Unidades, embora sejam pertencentes a mesma empresa e que por isso possuam fraquezas e forças em comum, elas também possuem particularidades e características distintas, que impactam de forma diferente em seus desempehos de inovação. Tais resultados evidenciam a importância e a influência do caminho, das escolhas estratégicas feitas pelas Unidades ao longo de suas histórias, o que lhes confere maturidades, forças, fraquezas e desempenhos distintos. Dessa forma, observa-se que por mais que a empresa tenha adotado um macroprocesso de inovação como norteador das suas atividades de inovação, parte do sucesso da sua implementação e da sua prática, dependem da autonomia que as Unidades possuem e da forma como decidem lidar com os processos de inovação internamente, sendo tais definições decisivas para suas capacidades de inovação.

Assim, diante de tais resultados e conclusões, confirmou-se que o arcabouço teórico utilizado e o modelo teórico proposto permitiram a identificação dos recursos e capacidades consideradas valiosas tanto internamente nas empresas como aqueles advindos das alianças e portfólios e como estes podem impactar na capacidade das empresas em alcançar desempenhos inovativos de sucesso.

Dessa forma, como contribuição prática, é imprescindível que os gestores foquem no treinamento e capacitação das equipes em práticas de inovação, principalmente, no contexto do Brasil, país considerado em desenvolvimento, no qual a capacidade absortiva das empresas é considerada menor. Nesses contextos, investir nessa capacidade absortiva de forma a melhorar a capacidade de aproveitamento dos recursos, conhecimentos e know-how advindos do ambiennte externo, principalmente das parcerias, é imprescindível para a melhoria da capacidade inovativa de forma geral. É importante também fomentar a prática de relações multilaterais e o envolvimento dessas Unidades da Embrapa em redes de alianças, uma vez que estudos mostram desempenhos inovativos mais satisfatórios nas empresas que se envolvem nesses tipos de relações. Além disso é importante investir na formalização de processos de inovação aberta, de forma a subsidiar a abertura dessas Unidades para a real e efetiva prática da inovação aberta.

No entanto, embora haja contribuições teóricas e práticas, limitações também foram identificadas. 


\section{6 \\ Limitações do estudo}

As limitações deste estudo referem-se a aplicação do modelo teórico em apenas três Unidades da Embrapa, dentro de um universo de 43 Unidades descentralizadas. Além disso, os casos selecionados, se referem a um único tipo de Unidade na empresa, definidas como temáticas. A empresa ainda é composta pelas Unidades de Produto e Regionais. Além disso, todas as Unidades analisadas embora se configurem em estudos de casos únicos, dadas suas áreas distintas de atuação, pertencem a uma mesma empresa, a Embrapa.

Ainda, apesar da boa vontade dos empregados em participar da pesquisa, observou-se que este número seria maior caso a empresa não estivesse em regime de teletrabalho, devido à pandemia da Covid 19. Tal fator, dificultou o acesso aos empregados, limitando o número de contribuições, além ainda da limitação de tempo para a realização desta pesquisa. No entanto, todas as limitações encontradas servem como base para futuras pesquisas.

\section{7 \\ Sugestões para futuras pesquisas}

Como desdobramentos, este estudo apresenta oportunidades para futuras pesquisas, por meio da aplicação do modelo teórico proposto nas demais Unidades descentralizadas da Embrapa, principalmente em Unidades de Produto ou Ecorregionais, Unidades de natureza distinta das escolhidas para este estudo de caso, definidas como Temáticas. Tal aplicação poderá contribuir ainda mais para o desenvolvimento da teoria, uma vez que será possível identificar as forças e fraquezas em contextos de natureza distintas, bem como as relações dessas Unidades com seu meio externo.

Além disso, sugere-se a aplicação do modelo em outras instituições públicas ou mesmo empresas do setor agropecuário ou de outros segmentos, que poderão trazer informações importantes e adicionais para o avanço do conhecimento. 


\section{6 \\ Referências Bibliográficas}

Abbade, E. B. (2010). Cooperação Interorganizacional : Fonte de Aprendizagem e Vantagem Competitiva ou Oportunismo ? Resumo Este ensaio teórico tem como proposta central efetuar uma discussão a respeito dos resultados possíveis advindos das estruturas de cooperação interorgani. Revista de Administração Da Unimep.

Abu Bakar, L. J., \& Ahmad, H. (2010). Assessing the relationship between firm resources and product innovation performance: A resource-based view. Business Process Management Journal, 16(3), 420-435. https://doi.org/10.1108/14637151011049430

Ades, C., Figlioli, A., Sbragia, R., Porto, G., Ary Plonski, G., \& Celadon, K. (2013). Implementing open innovation: The case of natura, IBM and Siemens. Journal of Technology Management and Innovation, 8(SPL.ISS.1), 12-25. https://doi.org/10.4067/s0718-27242013000300057

Ajuha, G. (2000). Collaboration networks: Structural holes and innovation: A longitudinal study. Administrative Science Quarterly, 3.

Alegre, J., Lapiedra, R., \& Chiva, R. (2006). A measurement scale for product innovation performance. European Journal of Innovation Management, 9(4), 333-346. https://doi.org/10.1108/14601060610707812

Allred, C. R., Fawcett, S. E., Wallin, C., \& Magnan, G. M. (2011). A Dynamic Collaboration Capability as a Source of Competitive Advantage. Decision Sciences, 42(1), 129-161. https://doi.org/10.1111/j.1540-5915.2010.00304.x

Altuzarra, A. (2017). Are there differences in persistence across different innovation measures? Innovation: Management, Policy and Practice, 19(3), 353-371. https://doi.org/10.1080/14479338.2017.1331911

Anandajayasekeram, P., \& Gebremedhin, B. (2009). Integrating Innovation Systems Perspective and Value Chain Analysis in Agricultural Research for development: Implications and challenges (I. L. R. I. (ILRI) (Ed.)). https://books.google.com.br/books?hl=pt-

$\mathrm{BR} \& 1 \mathrm{r}=\& \mathrm{id}=\mathrm{Jag} 3 \mathrm{nFkyyosC} \& \mathrm{oi}=\mathrm{fnd} \& \mathrm{pg}=\mathrm{PR} 4 \& \mathrm{dq}=\mathrm{ANANDAJAYASEKE}$ RAM,+P.\%3B+GEBREMEDHIN,+B.+Integrating+innovation+systems + per spective+and+value+chain+analysis + in + agricultural + research + for + develop ment:+Implications+and+challen

Araújo, M. J. (2007). Fundamentos de Agronegócios (E. A. S.A (Ed.)).

ASTI. (2013). Comparativo de mercado de países - América Latina e Caribe. https://www.asti.cgiar.org/benchmarking/lac

Barchi, M., \& Greco, M. (2018). Negotiation in Open Innovation_A Literature Review. Group Decis Negot, 343-374.

Barney, \& Hesterly. (2015). Strategic Management and Competitive Advantage (P. E. Limited (Ed.); $5^{\text {a }}$ Edição).

Barney, J. (1991). Firm Resources and Sustained Competitive Advantage. Journal 
of Management,

$17(1)$

99-120.

https://doi.org/10.1177/014920639101700108

Beaulieu, C. M. G. (2013). Dos Sistemas Nacionais de Pesquisa Agrícola aos Sistemas Nacionais de Inovação Agrícola_A inserção dos Institutos Nacionais de Pesquisa Agropecuária. In Unicamp (V̄ol. 53, Issue 9).

Bei, W., Chen, J., \& Wu, Z. Y. (2008). The analysis of relationship between $R \& D$ outsourcing and firm innovative performance from the perspective of open innovation.pdf.

Brasil. (2016). Novo marco legal da Ciência, Tecnologia e Inovação. https://www.mctic.gov.br/mctic/export/sites/institucional/arquivos/marco_le gal_de_cti.pdf

Brasil. (2020). Ata da $9^{a}$ Assembléia Geral Extraordinária - Altera o Estatuto da Empresa Brasileira de Pesquisa Agropecuária - Embrapa. https://www.embrapa.gov.br/documents/10180/36830205/Ata+da+9a+AGE+ 4dez2019/f2cdd976-3f2c-f44d-1502-bbc026a2169c

Brasil, B. (2020). O caminho do macroprocesso de inovação em 2020.

Brasil, B. dos S. A. F. (2019). Gerenciamento De Escopo Em Projetos Logísticos.

Camisón, C., \& Villar-López, A. (2014). Organizational innovation as an enabler of technological innovation capabilities and firm performance.pdf. Journal of Business Research.

Canciani, A., Cury, C., \& Carvalho, L. N. (2016). O Sistema Nacional de Pesquisa Agropecuária: Proposta de implementação para um novo modelo de gestão e governança.

Capdeville, G. de, Alves, A. A., \& Brasil, B. dos S. A. F. (2017). Modelo de Inovação e Negócios da Embrapa Agroenergia: Gestão Estratégica Integrada de P\&amp;D e TT (p. 48). http://www.embrapa.br/agroenergia/publicacoes

Carayannis, E. G., Sindakis, S., \& Walter, C. (2015). Business Model Innovation as Lever of Organizational Sustainability. Journal of Technology Transfer, 40(1), 85-104. https://doi.org/10.1007/s10961-013-9330-y

Carvalho, S. M. P. de, Filho, S. L. M. S., \& Paulino, S. R. (2006). Propriedade Intelectual e Dinâmica de Inovação na Agricultura. Revista Brasileira de Inovação, 5(2).

Castro, B. H. R. (2011). Influência da Estruturação de Departamentos de P\&D na Inovação: Um estudo na indústria de máquinas e implementos agrícolas no Brasil. Revista de Administração e Inovação, 8(1). https://doi.org/10.5773/rai.v8i1.742

Cgee. (2016). Arranjos para o futuro da inovação agropecuária no Brasil: Nova abordagem para o Sistema Nacional de Pesquisa Agropecuária - SNPA.

Chesbrough, H. W. (2003). Open Innovation - Open Innovation (Issue 1934). https://doi.org/10.1002/9781118786352.wbieg0528

Christensen, C. M. (1999). The innovator's dilemma: When new technologies cause great firms to fail by Clayton Christensen. In International Electronic Journal for Leadership in Learning (Vol. 3).

CNA. (2019). PIB do agronegócio. https://www.cnabrasil.org.br/noticias/pib-doagronegocio-cresce-3-81-em-2019

Cobeña, M., Gallego, Á., \& Casanueva, C. (2017). Heterogeneity, diversity and complementarity in alliance portfolios. European Management Journal, 5-6.

Cohen, W. M., \& Levinthal, D. A. (1990). Absorptive Capacity: A New Perspective on Learning and Innovation. Administrative Science Quarterly, 35(1), 128. https://doi.org/10.2307/2393553 
Consepa. (n.d.). Sistema Nacional de Pesquisa Agropecuária. Retrieved August 16, 2020, from https://consepa.org.br/snpa/

Contractor, F. J., \& Lorange, P. (2002). The growth of alliances in the knowledge based economy. International Business Review.

Cook, M., \& Mo, J. P. T. (2019). Architectural Modeling for Managing Risks in Forming an Alliance. Journal of Industrial Integration and Management, 04(03), 1950006. https://doi.org/10.1142/s2424862219500064

Cooper, R. G. (2008). Perspective: The Stage-Gate Idea-to-Launch Process Update, What's New and NexGen Systems Product Innovation Best Practices Series Perspective: The Stage-Gate Idea-to-Launch Process - Update, What's New and NexGen Systems. J. Product Innovation Management, 25(3), 213 232. https://doi.org/10.1111/j.1540-5885.2008.00296.x

Creswell, J. W. (2010). Projeto de pesquisa, Métodos qualitativo, quantitativo e misto.

Cui, T., Ye, H., Teo, H. H., \& Li, J. (2015). Information technology and open innovation: A strategic alignment perspective. Information and Management, 52(3), 348-358. https://doi.org/10.1016/j.im.2014.12.005

Cui, V., Ding, W. W., \& Yanadori, Y. (2019). Exploration versus exploitation in technology firms: The role of compensation structure for R\&D workforce. Research Policy, 48(6), 1534-1549. https://doi.org/10.1016/j.respol.2019.03.008

Cunha, K. D. A., Lucia, Y., Meza, F., \& Lucia, M. (2009). O sistema nacional de inovação e a ação empreendedora no Brasil. Revista de Administração e Contabilidade Da Unisinos. https://doi.org/10.4013/base.2009.62.03

Dahlander, L., \& Gann, D. M. (2010). How open is innovation? Research Policy, 39(6), 699-709. https://doi.org/10.1016/j.respol.2010.01.013

Davoudi, S. M. M., Fartash, K., Zakirova, V. G., Belyalova, A. M., Kurbanov, R. A., Boiarchuk, A. V., \& Sizova, Z. M. (2018). Testing the mediating role of open innovation on the relationship between intellectual property rights and organizational performance: A case of science and technology park. Eurasia Journal of Mathematics, Science and Technology Education, 14(4), 13591369. https://doi.org/10.29333/ejmste/83651

De Carvalho, G. D. G., Cruz, J. A. W., De Carvalho, H. G., Duclós, L. C., \& De Fátima Stankowitz, R. (2017). Innovativeness measures: A bibliometric review and a classification proposal. International Journal of Innovation Science, 9(1), 81-101. https://doi.org/10.1108/IJIS-10-2016-0038

Dewar, R. D., \& Dutton, J. E. (1986). The Adoption of Radical and Incremental Innovations: An Empirical Analysis. Management Science, 32(11), 14221433. https://doi.org/10.1287/mnsc.32.11.1422

Dodgson, M., Gann, D., \& Salter, A. (2006). The role of technology in the shift towards open innovation: The case of Procter \& Gamble. $R$ and $D$ Management, 36(3), 333-346. https://doi.org/10.1111/j.14679310.2006.00429.x

Eisenhardt, K. M. (1989). Building Theories from Case Study Research. 14(4), 532550.

Elo, S., \& Kyngäs, H. (2008). The qualitative content analysis process. Journal of Advanced Nursing, 62(1), 107-115. https://doi.org/10.1111/j.13652648.2007.04569.x

Embrapa. (n.d.a). Anos 70: $O$ conhecimento do solo. https://sistemas.sede.embrapa.br/40anos/index.php/linha_do_tempo/detalhes/ 
1970

Embrapa. (n.d.b). Embrapa - Quem somos. Retrieved June 14, 2020, from https://www.embrapa.br/quem-somos

Embrapa. (n.d.c). História da Embrapa. Retrieved August 14, 2020, from https://www.embrapa.br/memoria-embrapa/a-embrapa

Embrapa. (n.d.d). Pesquisa e Desenvolvimento. Embrapa. Retrieved February 22, 2021, from https://www.embrapa.br/pesquisa-e-desenvolvimento

Embrapa. (n.d.e). Programação de Pesquisa. Retrieved August 18, 2020, from https://www.embrapa.br/pesquisa-e-desenvolvimento/programacao-depesquisa

Embrapa. (n.d.f). Sistema Nacional de Pesquisa Agropecuária. Retrieved August 16, 2020, from https://www.embrapa.br/snpa

Embrapa. (2015). VI Plano Diretor da Embrapa: 2014-2034. In Embrapa (pp. 128). https://www.embrapa.br/busca-de-publicacoes/-/publicacao/1025506/viplano-diretor-da-embrapa-2014-2034

Embrapa. (2018). Pílulas do novo Sistema Embrapa de Gestão - SEG.

Embrapa. (2019a). Balanço Social da Embrapa 2019. https://www.embrapa.br/busca-de-publicacoes//publicacao/1121832/balanco-social-2019

Embrapa. (2019b). Embrapa em números. https://www.embrapa.br/documents/10180/1600893/Embrapa+em+Números/ 7624614b-ff8c-40c0-a87f-c9f00cd0a832

Embrapa. (2019c). Relatório de Gestão da Embrapa 2019.

Embrapa. (2019d). Resultado da Avaliação de Desempenho Institucional da Embrapa Agroindústria de Alimentos. In Embrapa (Vol. 11, Issue 1). http://scioteca.caf.com/bitstream/handle/123456789/1091/RED2017-Eng8ene.pdf? sequence $=12 \&$ isAllowed $=y \% 0$ Ahttp://dx.doi.org $/ 10.1016 /$ j.regsciu rbeco.2008.06.005\%0Ahttps://www.researchgate.net/publication/305320484 SISTEM_PEMBETUNGAN_TERPUSAT_STRATEGI_MELESTARI

Embrapa. (2019) $)$. Resultado final da Avaliação de Desempenho Institucional da Embrapa Agrobiologia.

Embrapa. (2019f). Resultado final da Avaliação de Desempenho Institucional da Embrapa Solos.

Embrapa. (2020). Relatório Anual da Embrapa Solos 2019.

Embrapa. (2021). SoilsPlay aproxima agronegócio da indústria dos jogos digitais. https://www.embrapa.br/busca-de-noticias/-/noticia/60171867/soilsplayaproxima-agronegocio-da-industria-dos-jogos-digitais

Época. (2018). Não é mais uma sandália, é uma ideia - eis o sucesso da Havaianas. Época https://epocanegocios.globo.com/Marketing/noticia/2018/04/nao-e-maisuma-sandalia-e-uma-ideia-eis-o-sucesso-da-havaianas.html

Estadão. (2016). Novas tecnologias e desafios para o agro. https://economia.estadao.com.br/noticias/geral,novas-tecnologias-e-desafiospara-o-agro, 10000060994

Feijó, B. V. (2015). O jeito google de ser. https://exame.com/pme/o-jeito-googlede-ser/

Feldmann, P. R. (2015). A busca de conhecimento externo à empresa como um meio para obtenção de vantagem competitiva: Estudos de casos de utilização de inovação aberta em empresas industriais brasileiras (Vol. 126, Issue 16). Universidade de São Paulo. 
Fritsch, M. (2017). The theory of economic development - An inquiry into profits, capital, credit, interest, and the business cycle. In Regional Studies (Vol. 51, Issue 4, pp. 654-655). https://doi.org/10.1080/00343404.2017.1278975

G1. (2019). Entenda como o agronegócio impulsiona a economia brasileira - G1. https://g1.globo.com/especial-publicitario/dia-doagricultor/brf/noticia/2019/08/05/entenda-como-o-agronegocio-impulsionaa-economia-brasileira.ghtml

Garcia, R., \& Calantone, R. (2002). A critical look at technological innovation typology and innovativeness terminology: A literature review. In Journal of Product Innovation Management (Vol. 19, Issue 2, pp. 110-132). https://doi.org/10.1016/S0737-6782(01)00132-1

Gerhardt, T. E., \& Silveira, D. T. (2009). Métodos de Pesquisa (UFGRS (Ed.)). https://books.google.com.br/books?hl=pt-

$\mathrm{BR} \& 1 \mathrm{r}=\& \mathrm{id}=\mathrm{dRuzRyEIzmkC \& oi}=$ fnd\&pg $=\mathrm{PA} 9 \& \mathrm{dq}=$ Gerhardt,$+\mathrm{T} .,+\% 26+\mathrm{S}$ ilveira, + D. + T. $+(2009) .+$ Métodos + de + Pesquisa $+\left(1^{\circ}\right) .+$ Porto + Alegre:+Editora $+\mathrm{da}+$ UFRGS.\&ots $=92 \mathrm{XaUYouOB \& sig}=8 \mathrm{~d} 0 \mathrm{MKFzKTX6jVVPBx} 9 \mathrm{e}-$ $\mathrm{d} 3 \mathrm{dPzFk} \mathrm{v}=$ onepage $\& \mathrm{q} \& \mathrm{f}=$ false

Gibbs, G. (2009). Análise de dados qualitativos. (Artmed (Ed.)).

Gil, A. C. (2008). Métodos e Técnicas de Pesquisa Social (6th ed.). Editora Atlas S.A.

Global Innovation Index. (2019). https://www.globalinnovationindex.org/gii-2019report

Gomes, R. M. (2014). Do Fonógrafo ao MP3 : Algumas Reflexões sobre Música e Tecnologia. Revista Brasileira de Estudos Da Canção, 5, 10.

Granovetter, M. S. (1973). The strength of weak ties. American Journal of Sociology, 78(6), 1360-1380.

Greco, M., Grimaldi, M., \& Cricelli, L. (2016). An analysis of the open innovation effect on firm performance. European Management Journal, 34(5), 501-516. https://doi.org/10.1016/j.emj.2016.02.008

Greco, M., Grimaldi, M., \& Cricelli, L. (2017). Hitting the nail on the head: Exploring the relationship between public subsidies and open innovation efficiency. Technological Forecasting and Social Change, 118, 213-225. https://doi.org/10.1016/j.techfore.2017.02.022

Grimaldi, M., Greco, M., \& Cricelli, L. (2021). A framework of intellectual property protection strategies and open innovation. Journal of Business Research, 123(September 2020), 156-164. https://doi.org/10.1016/j.jbusres.2020.09.043

Gulati, R. (1998). Alliances and networks. Strategic Management Journal, 19(4), 293-317. https://doi.org/10.1002/(SICI)1097-0266(199804)19:4<293::AIDSMJ982>3.0.CO;2-M

Gulati, R., Lawrence, P. R., \& Puranam, P. (2005). Adaptation in vertical relationships: Beyond incentive conflict. Strategic Management Journal, 26, 415-440.

Gulati, R., \& Singh, H. (1998). The Architecture of Cooperation: Managing Coordination Costs and Appropriation Concerns in Strategic Alliances Author ( $\mathrm{s}$ ): Ranjay Gulati and Harbir Singh Source: Administrative Science Quarterly, Vol. 43 , No. 4 ( Dec ., 1998 ), pp . 781-814 Publis. Administrative Science Quarterly, 43(4), 781-814.

Habicht, H., Möslein, K. M., \& Reichwald, R. (2012). Open Innovation Maturity. International Journal of Knowledge-Based Organizations, 2(1), 92-111. 
https://doi.org/10.4018/ijkbo.2012010106

Haider, S., \& Mariotti, F. (2016). The orchestration of alliance portfolios: The role of alliance portfolio capability. Scandinavian Journal of Management, 32(3), 127-141. https://doi.org/10.1016/j.scaman.2016.04.003

Hannachi, Y. (2015). Development and Validation of a Measure for Product Innovation Performance: The PIP Scale. Journal of Business Studies Quarterly, 6(3), 23-35.

Hoffmann, W. H. (2007). Strategies for managing a portfolio of alliances. Strategic Management Journal, 3(2), 54-67. http://repositorio.unan.edu.ni/2986/1/5624.pdf

Hosseini, S., Kees, A., Manderscheid, J., Röglinger, M., \& Rosemann, M. (2017). What does it take to implement open innovation? Towards an integrated capability framework. Business Process Management Journal, 23(1), 87-107. https://doi.org/10.1108/BPMJ-03-2016-0066

Huang, F., \& Rice, J. (2009). The role of absorptive capacity in facilitating "open innovation" outcomes: A study of australian SMEs in the manufacturing sector. International Journal of Innovation Management, 13(2), 201-220. https://doi.org/10.1142/S1363919609002261

Hubbard, C., Alvim, A. M., \& Garrod, G. (2017). Brazilian Agriculture as a Global Player. EuroChoices. https://onlinelibrary.wiley.com/doi/epdf/10.1111/1746692X.12142

Jiang, R. J., Tao, Q. T., \& Santoro, M. D. (2010). Alliance portfolio diversity and firm performance. In Strategic Management Journal (Vol. 31, Issue 10, pp. 1136-1144). https://doi.org/10.1002/smj.869

Juliao-Rossi, J., Forero-Pineda, C., Losada-Otalora, M., \& Peña-García, N. (2020). Trajectories of innovation: A new approach to studying innovation performance. Journal of Business Research, 115(June 2019), 322-333. https://doi.org/10.1016/j.jbusres.2019.11.026

Kale, P., \& Singh, H. (2009). Managing strategic alliances: What do we know now, and where do we go from here? Academy of Management, 26(2), 22. https://doi.org/10.1108/sd.2010.05626bad.004

Kale, P., Singh, H., \& Perlmutter, H. (2000). Learning and protection of proprietary assets in strategic alliances: Building relational capital. Strategic Management Journal, 21(3), 217-237. https://doi.org/10.1002/(SICI)10970266(200003)21:3<217::AID-SMJ95>3.0.CO;2-Y

Kattel, R., \& Mazzucato, M. (2018). Mission-oriented innovation policy and dynamic capabilities in the public sector. Industrial and Corporate Change, 27(5), 787-801. https://doi.org/10.1093/icc/dty032

Kim, L. (1997). Imitation to innovation_The dynamics of Korea's techonological learning (Harvard $\mathrm{Bu}$ ).

Laursen, K., \& Salter, A. (2006). Open for innovation: The role of openness in explaining innovation performance among U.K. manufacturing firms. Strategic Management Journal, 27(2), 131-150. https://doi.org/10.1002/smj.507

Leeuw, T. de, Lokshin, B., \& Duysters, G. (2014). - Returns to aliiance portfolio diversity_The relative effects of partner diversity on firms innovative performance and productivity. Journal of Business Research, 1839-1849.

Leon, G., Tejero, A., \& Franco-Riquelme, J. N. (2020). New methodology for profiling and comparison of open innovation models to conduct RD activities. IEEE Access, 
https://doi.org/10.1109/ACCESS.2020.2978933

Li, X., Du, J., \& Long, H. (2020). Understanding the green development behavior and performance of Industrial Enterprises (GDBP-IE): Scales Development and validation. Environmental Research and Public Health.

Liang, J., \& Mei, N. (2019). Inertia, uncertainty, and exploratory partner selection. Journal of Business and Industrial Marketing, 34(6), 1281-1296. https://doi.org/10.1108/JBIM-09-2017-0225

Lichtenthaler, U., \& Lichtenthaler, E. (2009). A Capability Based Framework for Open Innovation_Complementing Absorptive Capacity.pdf. Journal of Management Studies.

Lifshitz-Assaf, H. (2018). Dismantling Knowledge Boundaries at NASA: The Critical Role of Professional Identity in Open Innovation. In Administrative Science Quarterly (Vol. 63, Issue https://doi.org/10.1177/0001839217747876

Lopes, A. P. V. B. V., \& de Carvalho, M. M. (2018). Evolution of the open innovation paradigm: Towards a contingent conceptual model. Technological Forecasting and Social Change, 132(February), 284-298. https://doi.org/10.1016/j.techfore.2018.02.014

Lundvall, B.-A., Johnson, B., Andersen, E. S., \& Dalum, B. (2002). National systems of production, innovation and competence building. Research Policy.

Lundvall, B. A. (2016). The Learning Economy and the Economics of Hope (Anthem Pre).

Macedo-Soares, T. D. L. van A. de, Paula, F. D. O., \& Mendonça, H. L. (2017). Leveraging firm innovation performance through alliance portfolios in emerging economies : the role of absorptive capacity. Journal of Technology Management \& Innovation, 12(4), 10-21.

Macedo-Soares, T. D. van A. de. (2014). Assessing Strategies of Firms that Leverage Innovation through Alliance Portifolio or Networks: Proposing the Strategic Network Analysis Innovation Framework - SNA-IF. Business and Management Review, 4(1), 49-62.

Mankins, J. C. (1995). Technology readiness. Research Technology Management, 53(4), 52-59. https://doi.org/10.1080/08956308.2010.11657640

Manthey, N. B., Verdinelli, M. A., Rossetto, C. R., \& Carvalho, C. E. (2016). Desempenho da Inovação de Produto: Teste de uma Escala para Aplicação em PME's. Revista Ibero-Americana de Estratégia, 15(04), 43-62. https://doi.org/10.5585/riae.v15i4.2413

March, J. G. (1991). Exploration and Exploitation in Organizational Learning. Organization Science, 2(May 2014), 71-87.

Markides, C. (2006). Disruptive innovation: In need of better theory. Journal of Product Innovation Management, 23(1), 19-25. https://doi.org/10.1111/j.1540-5885.2005.00177.x

Martínez-noya, A., \& Narula, R. (2018). What more can we learn from R\&D alliances? A review and research agenda. Business Research Quartely, 21(3), 195-212. https://doi.org/10.1016/j.brq.2018.04.001

Mazzucato;, M., \& Penna, C. (2016). The Brazilian Innovation System_A MissionOriented Policy

Proposal.

https://www.cgee.org.br/busca?p_p_id $=101 \& p \_p \_l i f e c y c l e=0 \& p \_p \_s t a t e=m$ aximized\&_101_struts_action $=\% 2$ Fasset_publisher $\% 2$ Fview_content\&_101 redirect $=\overline{\%} 2 \mathrm{Fbusca} \% \overline{3} \mathrm{Fp} \_\mathrm{p} \_\mathrm{id} \% 3 \mathrm{D} 101 \% 26 \mathrm{p} \_\mathrm{p} \_$lifecycle $\% \overline{3} \mathrm{D} 0 \% 26 \mathrm{p} \_\mathrm{p} \_$st ate\%3Dmaximized\%26_101_struts_action\%3D\%252Fasset_publisher 
MCTIC. (2016). Estratégia Nacional de Ciência, Tecnologia e Inovação - 20162020.

MCTIC. (2019). Indicadores Nacionais de Ciência Tecnologia e Inovação. http://www.mctic.gov.br/mctic/export/sites/institucional/indicadores/arquivo s/Indicadores_CTI_2019.pdf

Mendonça, M. L. $\bar{R}$. F. de. (2013). Modo Capitalista de Produção e Agricultura : A construção do conceito de Agronegócio.

Mengel, A. A., \& Aquino, S. L. de. (2015). A modernização da Agricultura e a criação da Embrapa_Transformações na Pesquisa Agropecuária Brasileira. Campo-Território: Revista de Geografia Agrária, 4-27.

Mocker, M., \& Ross, J. W. (2017). The Problem with Product Proliferation. Harvard Business Review. https://hbr.org/2017/05/the-problem-with-productproliferation

Monteiro, F., Mol, M., \& Birkinshaw, J. (2017). Ready to be open? Explaining the firm level barriers to benefiting from openness to external knowledge. Long Range Planning.

Moreddu, C., Contini, E., \& Ávila, F. (2017). Challenges for the Brazilian Agricultural Innovation System. EuroChoices.

Moreira, F. G. P. (2016). A diversidade de portfólio de alianças e o desempenho das firmas industriais brasileiras em inovaçao de produto: o papel da capacidade de $P \& D$ e dos ativos complementares especializados.

Mortara, L., \& Minshall, T. (2011). How do large multinational companies implement open innovation? Technovation, 31(10-11), 586-597. https://doi.org/10.1016/j.technovation.2011.05.002

Mowery, D. C., Oxley, J. E., \& Silverman, B. S. (1996). Strategic alliances and interfirm knowledge transfer. Strategic Management Journal, 17(S2), 77-91. https://doi.org/10.1002/smj.4250171108

Muller, A., Välikangas, L., \& Merlyn, P. (2005). Metrics for innovation: Guidelines for developing a customized suite of innovation metrics. Strategy and Leadership, 33(1), 37-45. https://doi.org/10.1108/10878570510572590

Nalebuff, B., \& Brandenburger, A. (1997). Competitive and Cooperative Business Strategies for the Digital Economy. Strategy and Leadership, 25(6), 28-33.

Natalicchio, A., Ardito, L., Savino, T., \& Albino, V. (2017). Managing knowledge assets for open innovation: A systematic literature review. Journal of Knowledge Management, 21(6), 1362-1383. https://doi.org/10.1108/JKM-112016-0516

National Science Board - Science and Engineering Indicators. (2018). https://ncses.nsf.gov/pubs/nsb20203/cross-national-comparisons-of-r-dperformance\#figureCtr921

Nestle, V., Täube, F. A., Heidenreich, S., \& Bogers, M. (2019). Establishing open innovation culture in cluster initiatives: The role of trust and information asymmetry. Technological Forecasting and Social Change, 146(October 2016), 563-572. https://doi.org/10.1016/j.techfore.2018.06.022

OECD. (2002). Frascati Manual.

OECD. (2005). Manual de Oslo $3^{a}$ Edição.pdf(Vol. 1).

OECD, \& Eurostat. (2018). Oslo Manual 2018: Guidelines for Collecting, Reporting and Using Data on Innovation. In Journal of Chemical Information and Modeling. https://doi.org/10.1017/CBO9781107415324.004

Ozcan, P., \& Eisenhardt, K. (2009). Origin of alliance portfolios: Entrepreneurs, network strategies, and firm performance. Academy of Management Journal, 
52(2), 246-279. https://doi.org/10.5465/AMJ.2009.37308021

Patel, P., \& Pavitt, K. (1994). Economics of Innovation and New Technology National Innovation Systems: Why They Are Important, And How They Might Be Measured And Compared NATIONAL INNOVATION SYSTEMS : WHY THEY ARE IMPORTANT , AND HOW THEY MIGHT BE. Routledge, 77-95.

Paula, F. de O. (2017). The impact of strategic alliances and internal knowledge sources on the manufacturing firms'innovation and on their financial performance: A comparison between Brazil and Europe (Issue October).

Paula, F. de O., \& Silva, J. F. da. (2017). Innovation performance of Italian manufacturing firms: The effect of internal and external knowledge sources. European Journal of Innovation Management, 20(3), 428-445. https://doi.org/10.1108/EJIM-12-2016-0119

Paula, F. de O., \& Silva, J. F. da. (2018). Balancing internal and external R\&D strategies to improve innovation and financial performance. BAR - Brazilian Administration Review, 15(2). https://doi.org/10.1590/18077692 bar2018170129

Pellegrino, L. R. (2015). O efeito da diversidade da carteira de alianças na indústria farmacêutica brasileira.pdf.

Penteado, R., \& Fonseca, W. (2016). Brasil lidera investimentos em pesquisa agrícola na América Latina. Embrapa. https://www.embrapa.br/busca-denoticias/-/noticia/13128392/brasil-lidera-investimentos-em-pesquisaagricola-na-america-latina

Petraite, M., Pranciulyte, I., Maliatsina, I., \& Podmetina, D. (2020). Mediating role of open innovation capabilities in SMEs_unlocking competencies.pdf.

Podmetina, D., Soderquist, K. E., Petraite, M., \& Teplov, R. (2018). Developing a competency model for open innovation: From the individual to the organisational level. Management Decision. https://doi.org/10.1108/MD-042017-0445

Puffal, C. W., Puffal, D. P., \& Souza, Y. S. (2019). Absorptive Capacity of industrial companies in traditional sectors in the State of Rio Grande do Sul, Brazil. Revista de Administração Mackenzie.

Ramos, P. D. P. (2014). Conceitos de Agronegócio e Agricultura Familiar_Visões, importância e funcionamento.

Rea, L. M., \& Parker, R. A. (2000). Metodologia de pesquisa: do planejamento à execução (Pioneira (Ed.)).

Reichert, F. M., Camboim, G. F., \& Zawislak, P. A. (2015). Capacidades E Trajetórias De Inovação De Empresas Brasileiras. RAM. Revista de Administração Mackenzie, 16(5), 161-194. https://doi.org/10.1590/167869712015/administracao.v16n5p161-194

Remenyi, D., Williams, B., Money, A., \& Swartz, E. (2000). Doing Research in Business and Management.pdf. SAGE Publications.

Rothwell, R. (1994). Towards the Fifth-generation Innovation Process. In International Marketing Review (Vol. 11, Issue 1). https://doi.org/10.1108/02651339410057491

Schreiner, M., Kale, P., \& Cortsen, D. (2009). What really is Alliance management capability and how does it impact alliance outcomes and success? Strategic Management Journal, 1419(May 2007). https://doi.org/10.1002/smj

Schumpeter, J. A. (2003). Capitalism, Socialism \& Democracy (pp. 1-60). https://books.google.com.br/books?hl=pt- 
BR\&1r=\&id=MRg5crpAOBIC\&oi=fnd\&pg=PR2\&dq=schumpeter $+2013 \&$ ot $\mathrm{s}=\mathrm{oJ} 2 \mathrm{tWfbqw}-$

\&sig=8w6FjmRjF4u1ppBD6px5tUCil7o \#v=onepage\&q=schumpeter $2013 \& \mathrm{f}=$ false

Serra, F. A. R., Ferreira, M. P., Pereira, M. F., \& Lissoni, J. (2008). EVOLUÇÃO DA PESQUISA EM RBV : um estudo dos últimos EnANPAD' s. Revista Brasileira de Estratégia, 39-56.

Shipton, H., West, M. A., Dawson, J., Birdi, K., \& Patterson, M. (2006). HRM as a predictor of innovation. Human Resource Management Journal, 16(1), 3-27. https://doi.org/10.1111/j.1748-8583.2006.00002.x

Silveira, L. A. G., \& Cabral, A. S. (2007). Evolução dos modelos de inovação : o caso da Embraer.

Stutz, L. C., \& Pereira, M. F. (2019). Embrapa_Reestruturando-se para ampliar sua contribuição para a inovação no setor agropecuário brasileiro. Cadernos de Prospecção, 12(4), 767-782.

Taferner, B. (2017). a Next Generation of Innovation Models? an Integration of the Innovation Process Model Big Picture (C) Towards the Different Generations of Models. In Review of Innovation and Competitiveness (Vol. 3, Issue 3, pp. 47-60). https://doi.org/10.32728/ric.2017.33/4

Teece, D. J. (2007). Explicating dynamic capabilities: the nature and microfoundations of (sustainable) enterprise performance. Strategic Management Journal, 28, 1319-1350. https://doi.org/10.1002/smj

Teece, David J. (1998). Competition, cooperation, and innovation organizational arrangements for regimes of rapid technological progress. Journal of Economic Behavior and Organization, 1-25. https://doi.org/10.1142/9789812796929_0015

Teece, David J., Pisano, G., \& Shuen, A. (1997). Dynamic capabilities and strategic management. Strategic Management Journal, 509-533. https://doi.org/10.1142/9789812796929_0004

Teixeira, L. A. de C. (2018). Como os núcleos de inovação tecnológica dos institutos públicos de pesquisa podem contribuir para os resultados de inovação do Estado de São Paulo.

Tidd, J. (2001). Innovation management in context: Environment, organization and performance. In International Journal of Management Reviews (Vol. 3, Issue 3, pp. 169-183). https://doi.org/10.1111/1468-2370.00062

Tidd, J., Bessant, J., \& Pavitt, K. (2005). Managing Innovation_Integrating, Technological, market and organiational change (J. W. \& S. Ltd (Ed.)).

Vogel, R., \& Güttel, W. H. (2013). The dynamic capability view in strategic management: A bibliometric review. International Journal of Management Reviews, 15(4), 426-446. https://doi.org/10.1111/ijmr.12000

Wang, M. C., Chen, P. C., \& Fang, S. C. (2018). A critical view of knowledge networks and innovation performance: The mediation role of firms' knowledge integration capability. Journal of Business Research, 88(March), 222-233. https://doi.org/10.1016/j.jbusres.2018.03.034

Wassmer, U. (2010). Alliance portfolios: A review and research Agenda. Journal of Management, 36(1), 141-171. https://doi.org/10.1177/0149206308328484

West, J., \& Bogers, M. (2017). Open innovation: current status and research opportunities. Innovation: Management, Policy and Practice, 19(1), 43-50. https://doi.org/10.1080/14479338.2016.1258995

Wu, L. F., Huang, I. C., Huang, W. C., \& Du, P. L. (2019). Aligning organizational 
culture and operations strategy to improve innovation outcomes: An integrated perspective in organizational management. Journal of Organizational Change Management, 32(2), 224-250. https://doi.org/10.1108/JOCM-03-2018-0073

Xia, J., Wang, Y., Lin, Y., Yang, H., \& Li, S. (2018). Alliance Formation in the Midst of Market and Network: Insights From Resource Dependence and Network Perspectives. Journal of Management, 44(5), 1899-1925. https://doi.org/10.1177/0149206316630379

Yin, R. (1994). Discovering the future of the Case Study Method in Evaluation Research. Evaluation Practice, 15(3), 283-290.

Yin, R. K. (2013). Validity and generalization in future case study evaluations. Evaluation, 19(3), 321-332. https://doi.org/10.1177/1356389013497081

Yin, R. K. (2015). Estudo de Caso: Planejamento e Métodos (5 Edição). https://books.google.com.br/books?hl=pt-

BR\&lr=\&id=EtOyBQAAQBAJ\&oi=fnd\&pg=PR1\&dq=yin + design $+\mathrm{e}+$ méto dos\&ots $=$

kdhqoD1uD\&sig=aZhWz_MrVgjjq4LEvNijO0gIqqQ\&redir_esc $=y \# v=$ onep age \&q=yin design e métodos\& $\mathrm{f}=$ false

Ying, Q., Hassan, H., \& Ahmad, H. (2019). The Role of a Manager's Intangible Capabilities in a Resource Acquisition and Sustainable Competitive Performance. Sustainability.

Yu, B., Xu, H., \& Dong, F. (2019). Vertical vs. Horizontal: How strategic alliance type influence firm performance? In Sustainability (Switzerland) (Vol. 11, Issue 23). https://doi.org/10.3390/su11236594

Zaheer, A., Gözubuyuk, R., \& Milanov, H. (2010). It's the Connections: The Network Perspective in Interorganizational Research. Academy of Management Perspectives, $\quad$ Feb(1), 62-77. https://doi.org/10.5465/AMP.2010.50304417

Zhao, S., Sun, Y., \& Xu, X. (2016). Research on open innovation performance: a review. Information Technology and Management, 17(3), 279-287. https://doi.org/10.1007/s10799-015-0231-7 


\section{Anexos}

\section{Anexo 1 - QUESTIONÁRIO}

Análise dos Recursos,Capacidades Dinâmicas, Características Internas para prática da inovação

ㅁ. Questionàrio de pesquisa

$\not$

Confidencialidade

(i0) Essa pesquisa tem objetivos e interesses estritamente acadàmicos. Os dados e percepcöes levantados

* serão utlizados sornente para o deservotvimento desta pesquisa. Sob nenhuma hipotese seräo đuvigados ou repassados dados ou informaçóes fornecidas pelos entrevistados, nem serâo estes utilizados para outra finatidade senão a acadèmica aqui proposta. Garantimns que a identidade dos respondentes nāo serà revelada e nāo serão consideradas respostas corno posiçâo "oficial" da empresa. Muito chrigado por sua colaboraçẫo

\section{Participantes:}

Colaboradores da Empresa, de diversas àreas e riveis hierärquicos, que participen dos processos de tornada de decisāóo e de inovarâa nas Unidades.

Resultados esperados:

Respostas que retratem de maneira fiel as percepçōes dos colaboradores sobre os principais recursos e competéncias intemas, bem como das caracteristicas dos portfótios de alianças considerados criticos

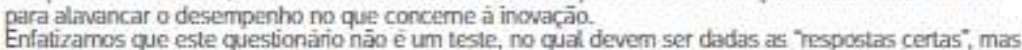
sim un instrumento de coleta de dedos que tende a retratar, de forma fiel, a percepchio dos participantes em relą̧äio aos tópicos esturłados.

Periodo de Anälise:

A pescuisa compreende anấlises referentes ao periodo de 2018 a 2020, periodo que compreende a adoçāo, pela Enbrapa, do macroprocesso de inovaçao como estratégia

Definiçāo central

Desempento de inovaçāo se refene à capacidade da empresa em lançar e introduvir nowos produtos, noras formas de produçāo, novars formas de organizaçāo, de desenvotver novas fontes de maténiasprimas, insurnos e novos mercados, que gerem impactos significativos para a própria empressa dou para o setor em que esta inserida, elou para o pass eicu para o mundo.

Instruçōes para preenchimento

1. Para responder às questōes, basta assinalar no espaço resenvado para as respostas.

2. Quando for o cass, e estiver indicado, múttiplas respostas poderäo ser assinaladas.

3. Atençấl Algurnas questōes contèm instrupōes especiais de proenchimento. Muitas pergurtas deste questionário săo do tipo "avalie a seguinte afimmasāo". As oppōes de resposta estaräo divididas em altemativas, em ordem crescente de concondância O pesquisadrya deve marcar uma única alternativa. sendo esta a que melhor reflete sua visáo sobre a pergunta feita.

Ue cancorda boen us temios acims

U Ue discordo dos termos acima 


\begin{tabular}{|c|c|}
\hline 回1 & 1 Qual o seu cargo? \\
\hline あ & $O$ Arailsta \\
\hline * & O Pesquisador \\
\hline 回 & Qual sua Unidade? \\
\hline \$ & O Embrapa Agrobiologin \\
\hline * & O Embrapa Agoindứstra do Aümertos \\
\hline & O Embrapa Solas \\
\hline 回2. & 2. Quanto tempo de Embrapa? \\
\hline \% & O Entre 6010 anos \\
\hline * & 0 Entre 11 e 20 anos \\
\hline & O Mats de 20 anos \\
\hline$\square^{3}$ & 3. Informe seu nxrne e setor de atuaça. Caso seja pesquisador, adicione sua tinha de pesquisa. \\
\hline \% & \\
\hline$*$ & \\
\hline
\end{tabular}

- RECURSOS CAPACIDADES DINÄMICAS E CARACTERISTICAS INTERNAS CRITICAS PARA ALAVANCAR b. O DESEMPEENHO NO QUE CONCERINE A INOVACAO

Instruçöes importantes:

As perguntas deste Bloco se referem aos recursos, capacidades e caracteristicas consideradas criticas no contexto de inovaçấa aberta.

Para resposta as perguntas de 1 a $\theta$ deste Bloco, o respondente deve seguir as duas seguintes orientaçoes:

$1^{\circ}$ - Para cada tipo de recurso, defina se a UD possui e o aproveita de forma efetiva, optando por uma das altemativas, conforme abaixo:

0 - Näo possui o recurso

1- Recurso pouco desenvolvido/Pouco aproveitado

2. Desenvolvido/Aproveitado

3- Muito desenvolvido/Muito aproveitado

$2^{\circ}$ - Caso a UD possua o recurso, deve responder, na mesma questão, se o recurso é considerado valioso; raro efou imitável. Nesse caso marque TODAS as aitemativas que juigar necessarias.

Definiçöes conceituais importantes para resposta ao questionário.

Recursos Valiosos

São aqueles que permitem que uma empresa melhore sua capacidade de inovação, $\epsilon$ consequentemente, seu desempenho no que concerne á inovaçäo.

Recursos Raros

São os recursos controlados por poucas empresas e que tendem a ser uma fonte de vantagem competitiva.

Recursos imitáveis

Refere-se à facilidade que outras empresas têm para imitaricopiar o recurso raro e valioso da organizaçäo. 


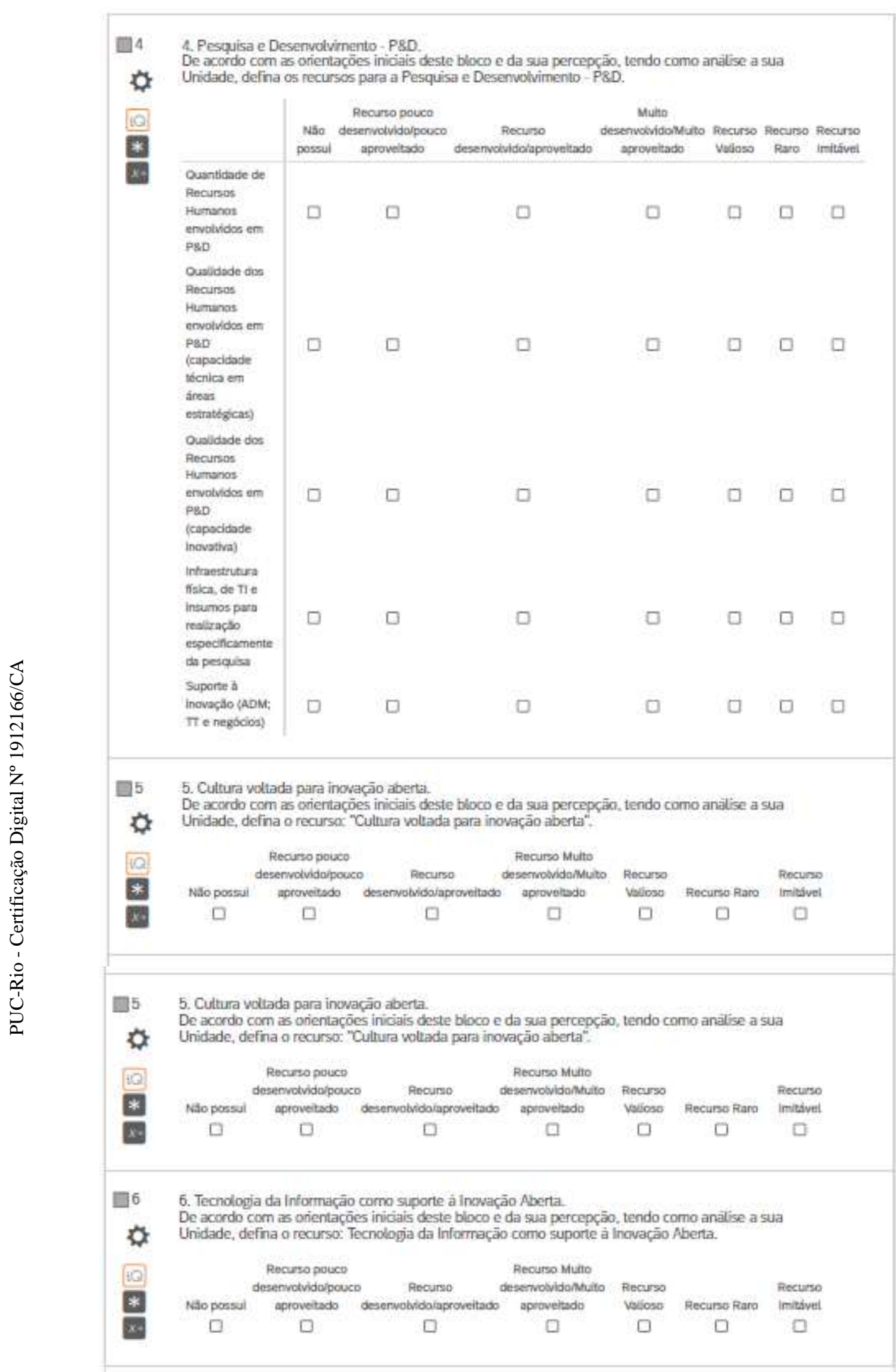




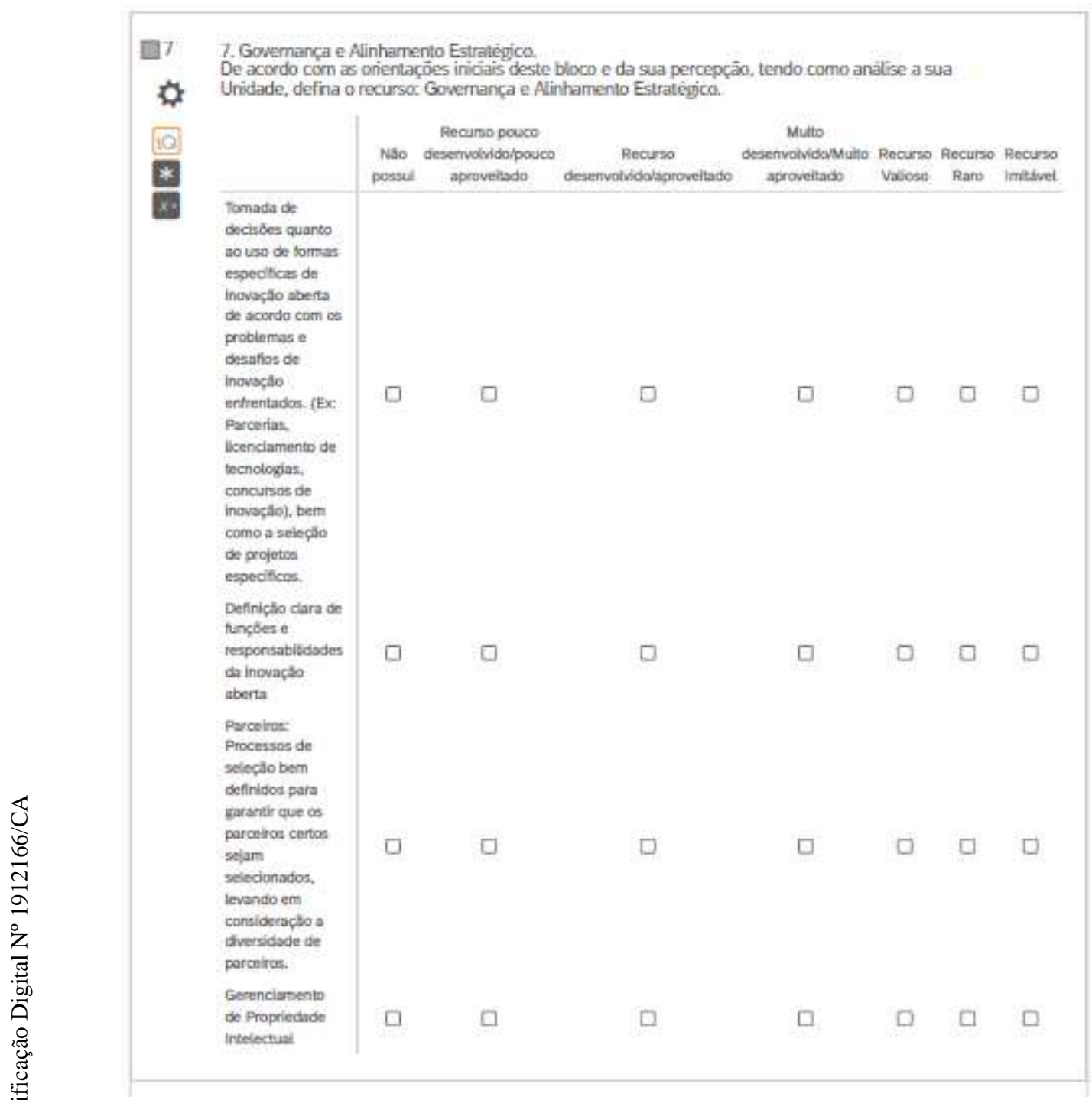




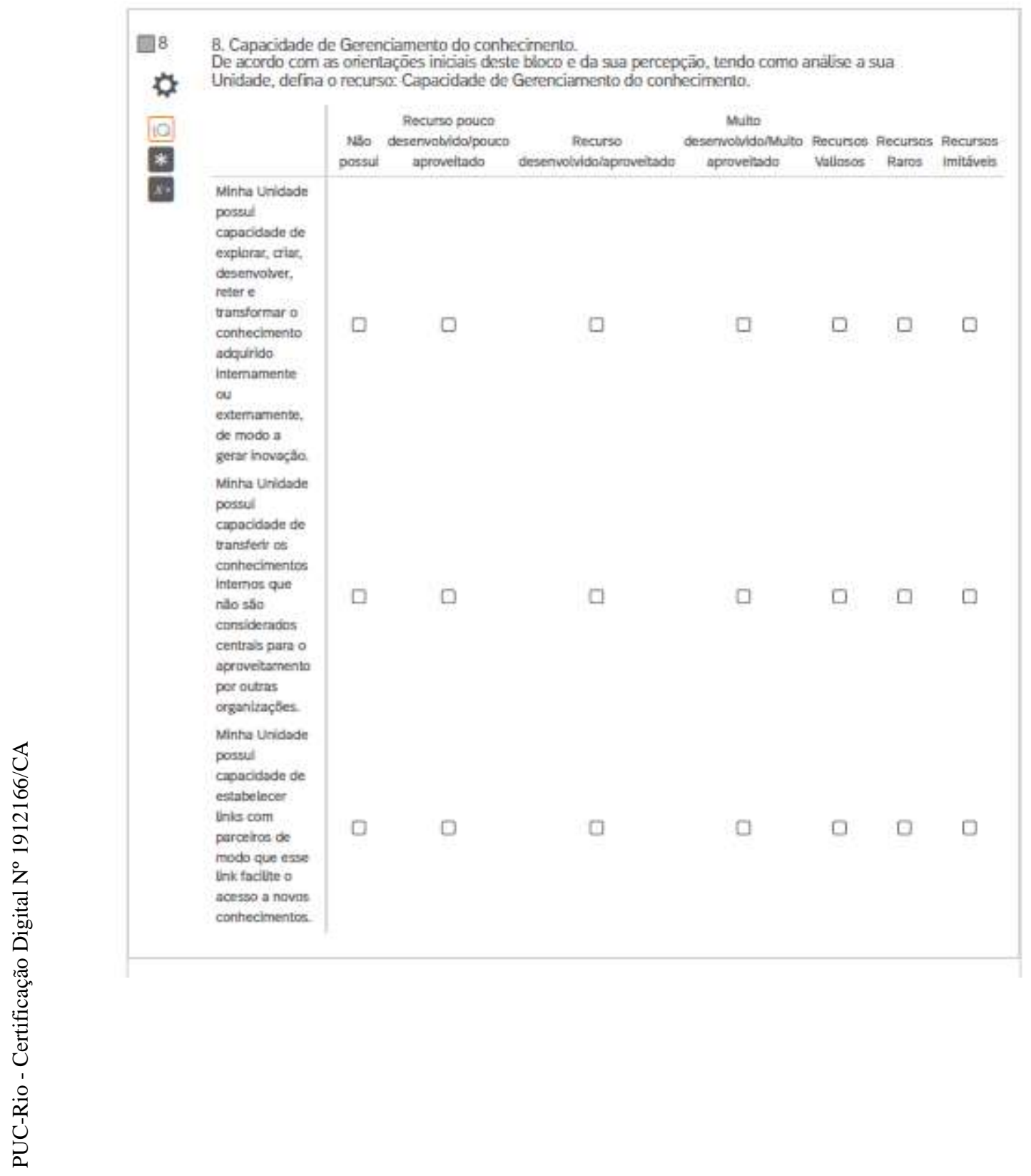




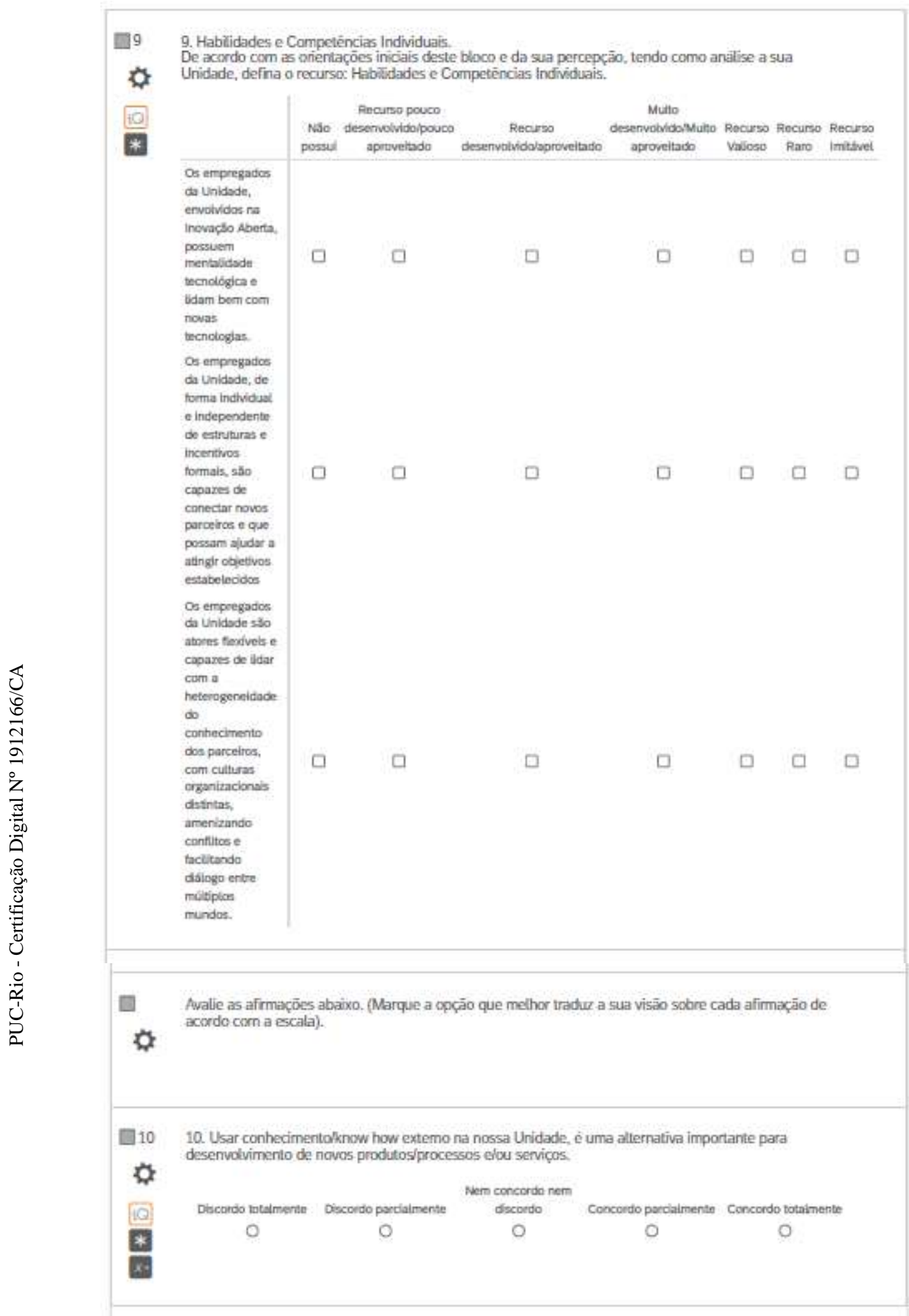


111 11 Minha Unidade valoriza assumir riscoss inerentes ao processo de inovacẫo

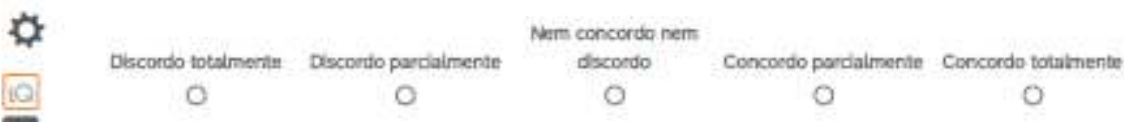

प12. 12 A falha é aceilàvel na Unidade, se a esforço no projeto de inovaçäo foi born.

\% Discondo tataiments Deconto parclaimente Nam concordo nem O

O Coocondo porciaimente concorda totaimente * O $\mathrm{O}$

13. Nesta Unidade, atividades de risco são lugpar comum.

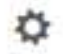
Dlecordo tataiments Descotio parciaimente Nem concordo nem discordo Concondo pordiaimente concordo totaimente O Q Q O 0

14 14. A gestäo criou uma cuttura aberta e inovadora para as atividades de desenvolvimento de novos produtos e processos, encorajando ativamente os funcionários a apresentarem nowos produtos en novas Q. ideias

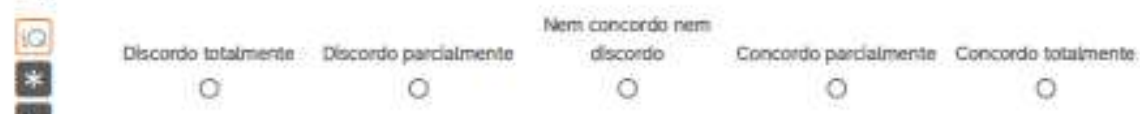

15. Os sistemas de TI usados em nossas atividades de inovaçâo aberta sāo projelados para suportar atividades de inovaçäo aberta (Técnicas de varredura ambiental; platalormas de pesquisac fertamentas de th mineracão de dados que ajudam a pesquisar päginas da web, literatura cientifica e bancos de dados de patentes para ideias e tecnologias relevantes.

* 10. Nem concordo nem

* Discordo totaimente Decondo pardaimente decondo Concoedo portiaimente Concordo totaimente *

O

$\mathrm{C}$

O

O

16. A Unidade possui sistemas de Tl que permitem o fácil acesso aos dados e a troca de informaçōes com os colaboradores da inovação (uso de plataformiss de colaboraçẫo e comunicaçāo - ferramentas da D. conferéncia online dentre outras)

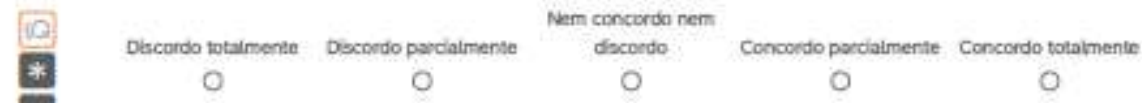

Q17 17. A Unidade possui sistemas de TI que podem funcionar como repositório de conhecimentos ou sistemas de memória organizacional.

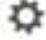

(iP) Discordo tutaimente Discordo parciaimente 0

$\mathrm{O}$ Nem concordo nem dscoedo concordo pordalmente concondo totaimentm 
D18 18. Como a Unidade pratica a inovaçāo aberta? (Marque quantas altemativas quiser).

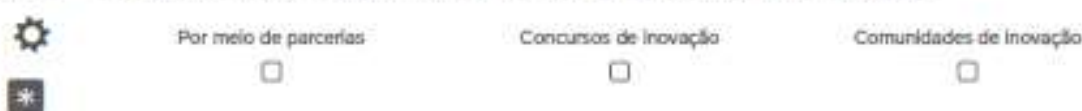

番

- aLanças e portFoluos de alianças para impulsionar o desempenho de inovaçá

\section{ALANCAS E PORTFÖLIOS DE ALIANCCAS PARA IMPULSIONAR O DESEMPENHO DE INONACÄO.}

1. As pergantas deste Bloco se referem à participaçāo das Unidades em Alancas/Portiolios de AVianças e as caracteristicas dessas relaçōes interorgarizacionais consideradas cruciais para alavancar o desempenho de inovaçāo.

19 19. As alianças estratègicas que a Unidade participa sầ tipicamente:

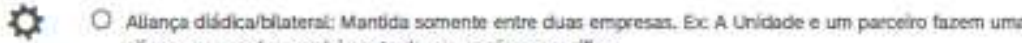
diança pars o deserwoblimento de um senvico especilico;

* O Aliança Muttibaterat: Montida com mals do duas empresan. (Ex: A Unidade passul allanças com diversos fnanciadores para o desenvatiminenta de um anvo produto ou serviç.)

O Ambos

O Năo paricipa de slanças

O Nธॅ。 sei

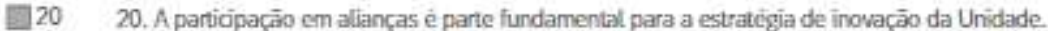

to Discordo totamerte Décoedo pordaimente Nem concordo nem disconto Coccoedo perdaimerten Concordo totaimentes $\mathrm{O}$ $\mathrm{O}$ O O

\section{Definiçấo conceitual (Questāo 21)}

\$

Complementadores: Atores que fornecem um produto ou servico que constitui um complemento tal que. quando associado a seu produto, o torna mais valioso a seus clientes (por exemplo: institutos de pesquisa e fou universidades).

21 21. Como parte da estratéga para inovar com deservokivimento e comercializaçäo de novos/melhores produtos eserviços, a Unidade estabelece alianças estratégjas corn. (Preencha todas as oppöes t. necessárias para a sua resposta)

* $\square$ cliente

X. $\square$ complementadore

O Entidades Govemamentals

C Concomentes

D. Frandadoresiformentadores 


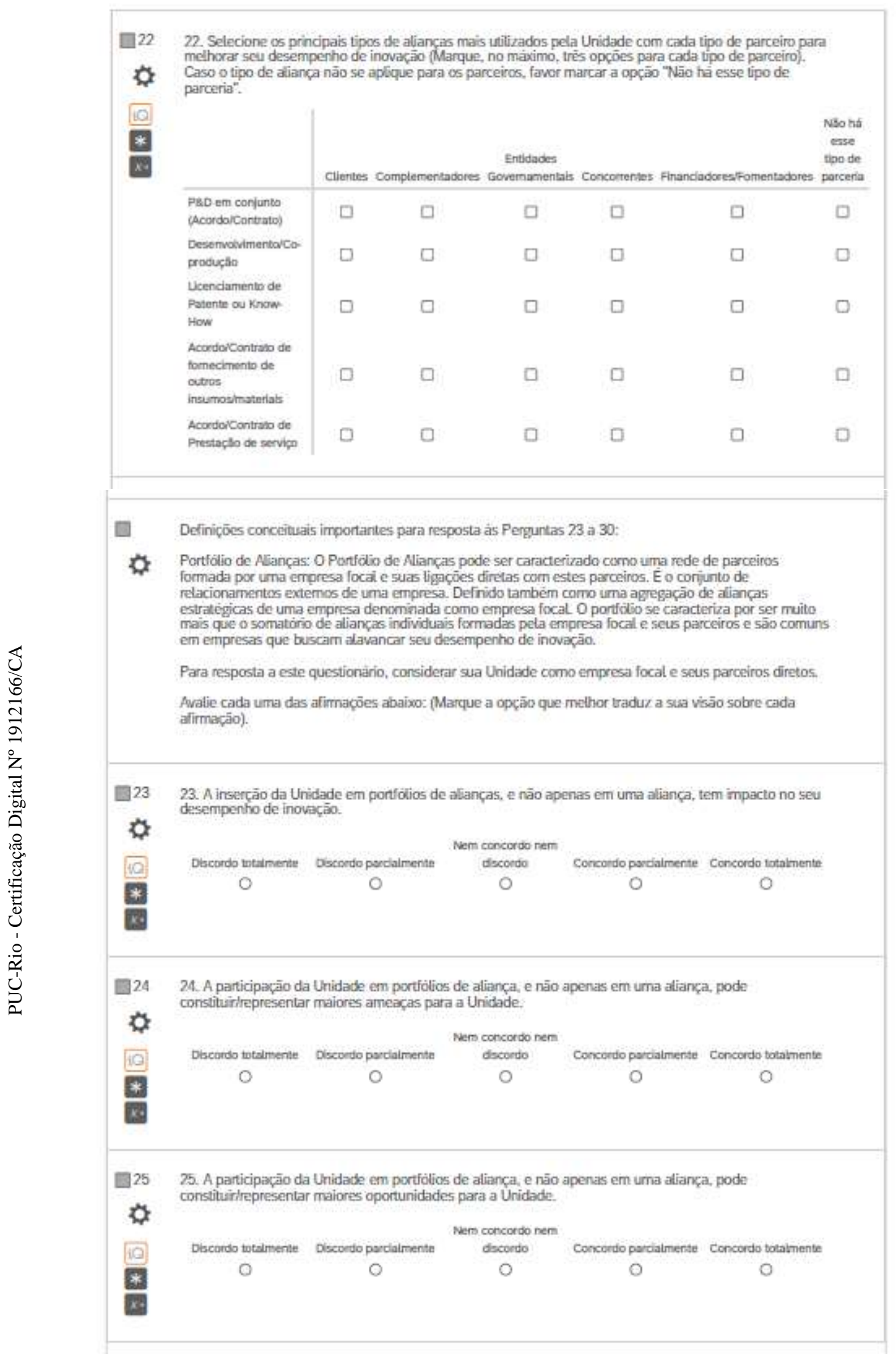




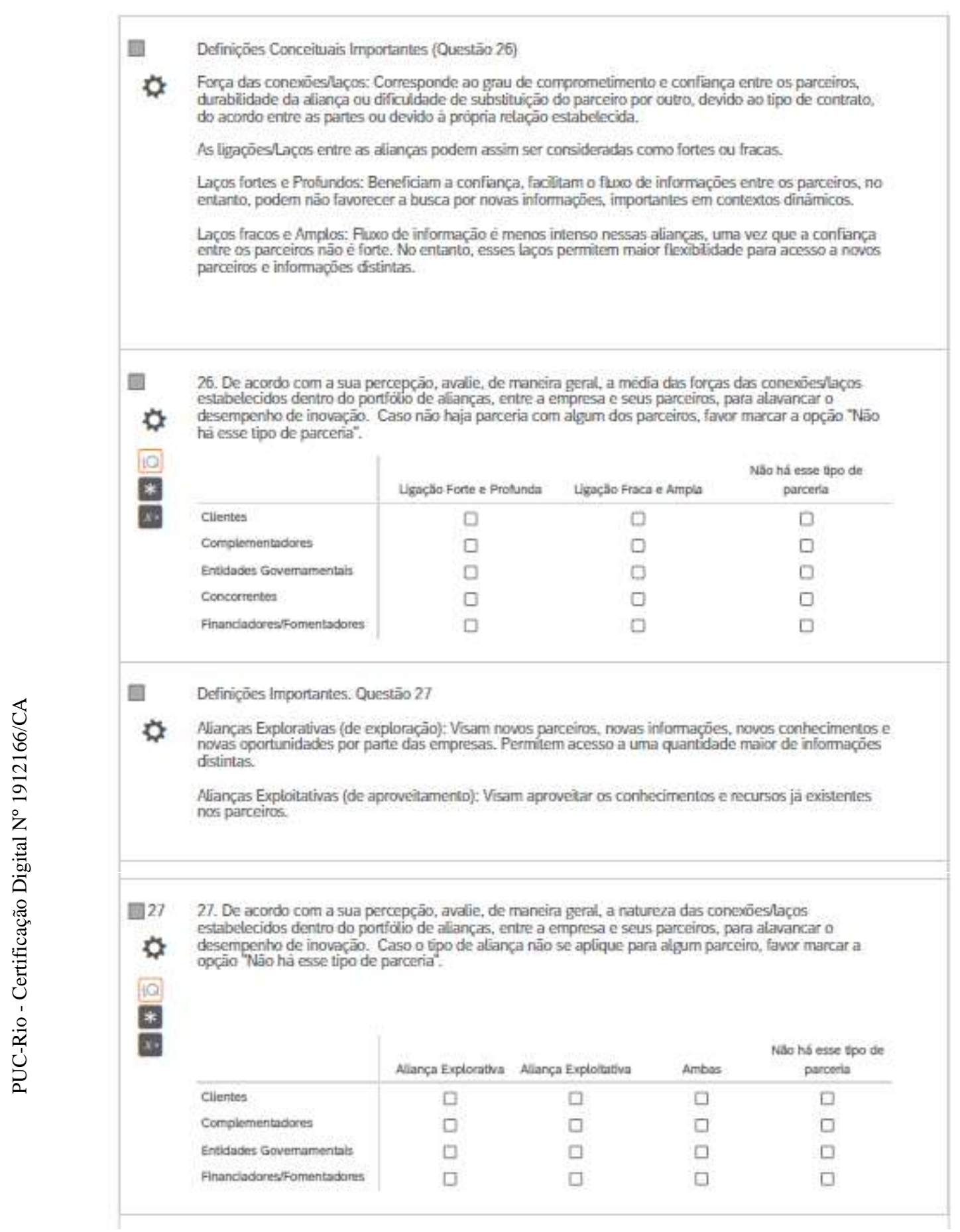




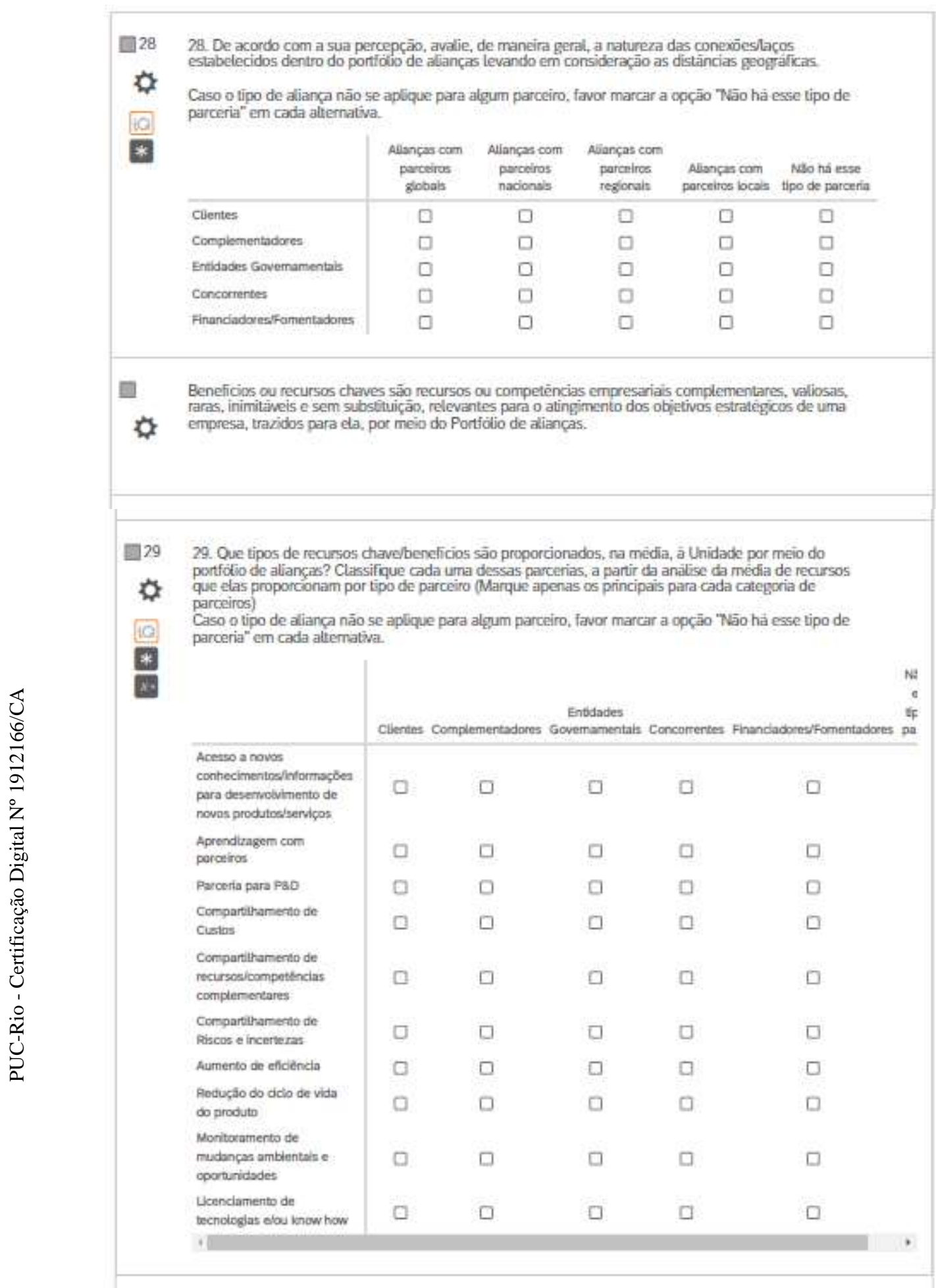




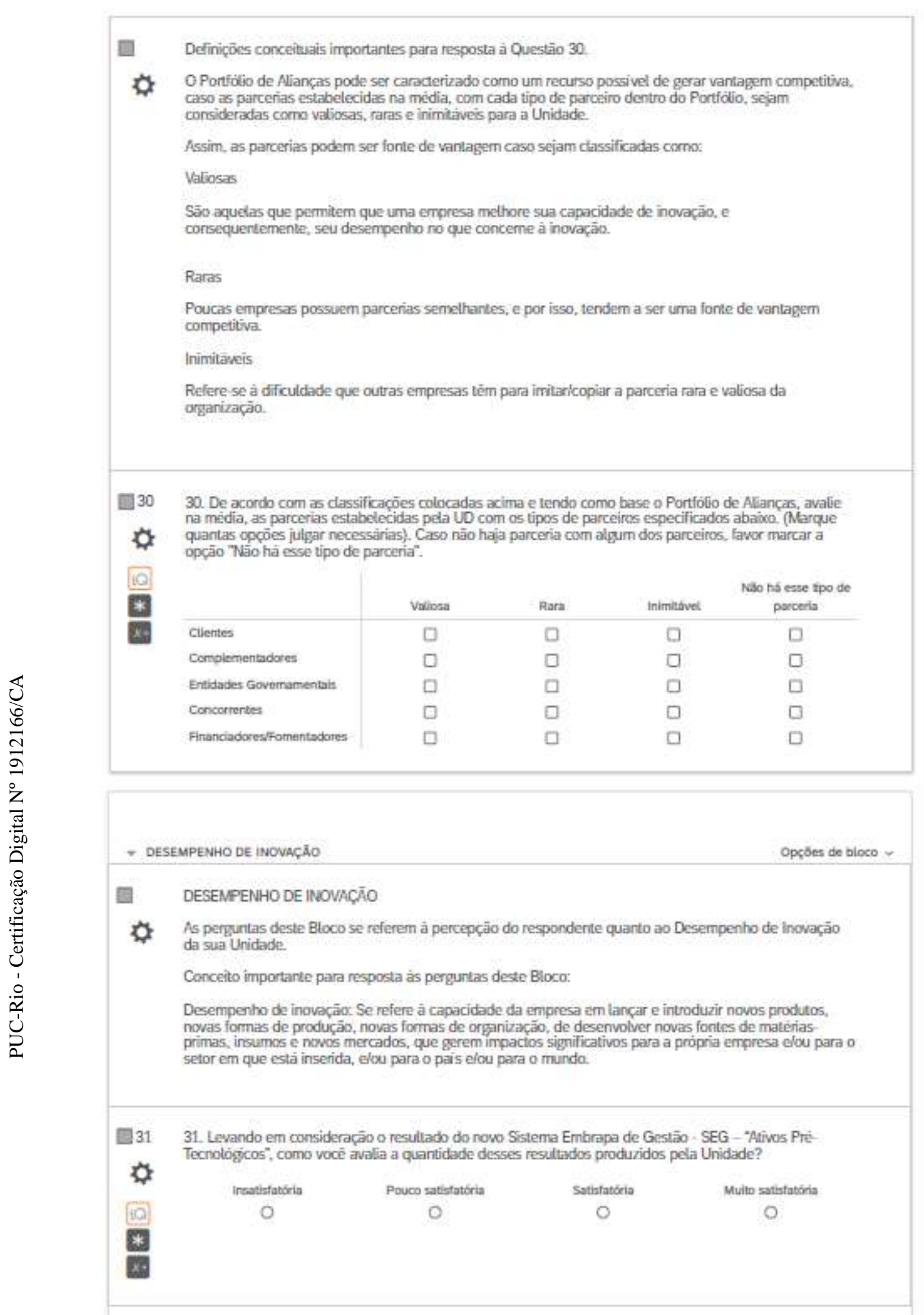




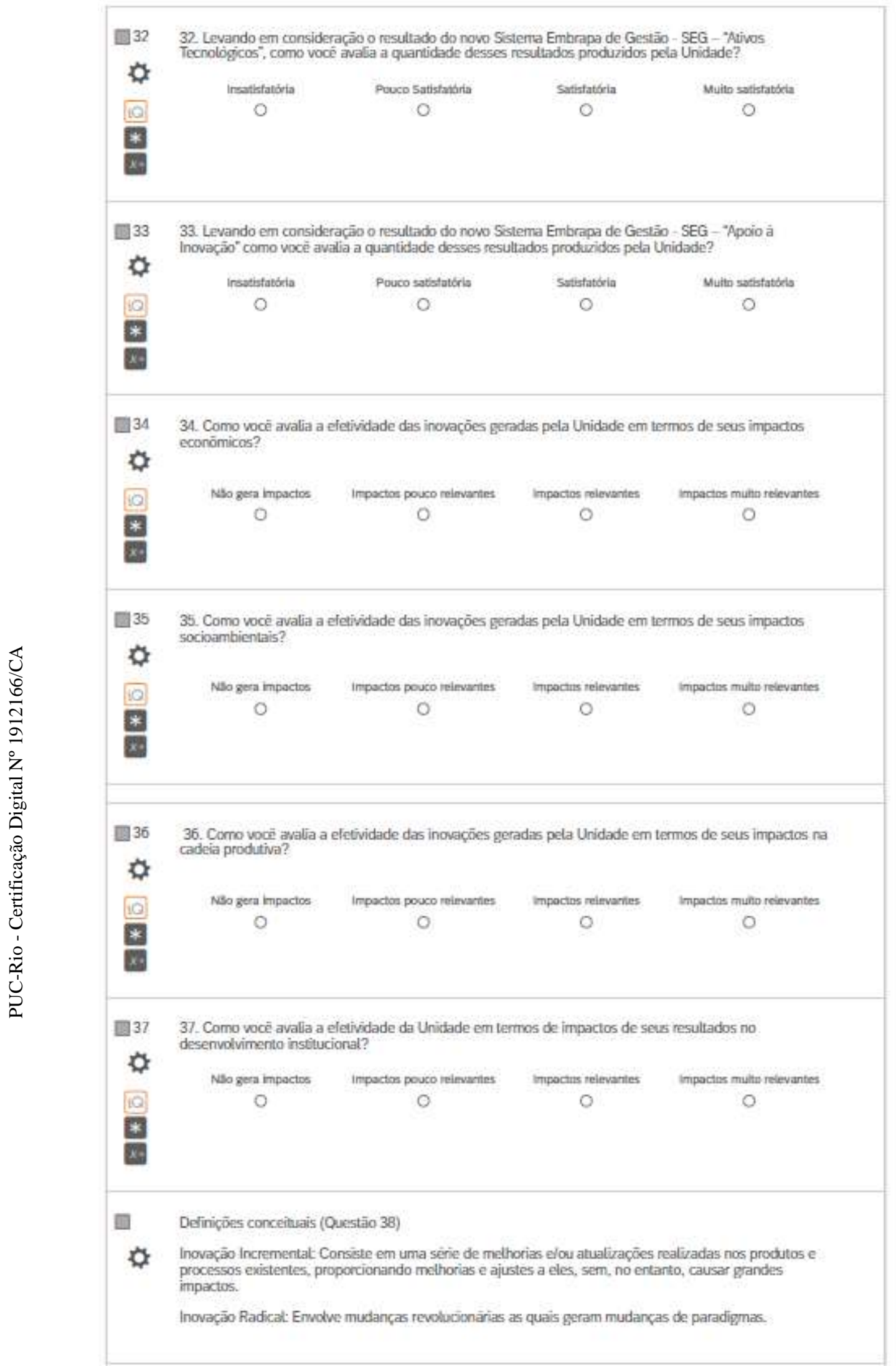




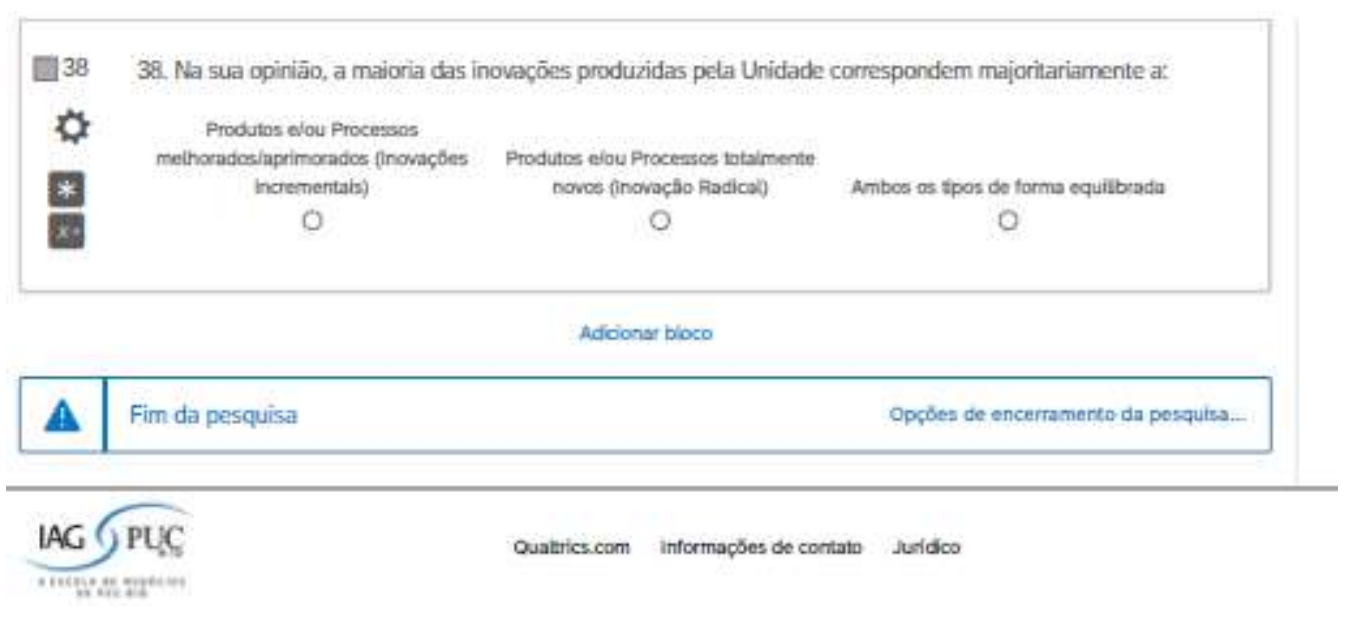

\section{Anexo 2 - ROTEIRO DE ENTREVISTA}

Identificação dos respondentes: Os respondentes não foram identificados por nomes, a fim de manter o sigilo. A identificação foi feita apenas por cargo, limitando-se a definição de Analista ou Pesquisador.

Objetivos e Resultados Esperados: A entrevista visa aprofundar e levantar percepções complementares apuradas nos questionários, bem como detectar outros fatores que podem interferir na formação dos resultados.

Declaração e Confidencialidade: Esta é uma pesquisa estritamente acadêmica, realizada pela aluna e seu orientador, Professor Fábio de Oliveira Paula. Assim, as respostas serão utilizadas apenas no escopo do estudo e não serão definidas como posição oficial da empresa.

PARTE 1: Análise dos recursos, competências e características internas críticas para a prática da inovação aberta.

\section{P\&D}

$1^{\text {a }}$ Pergunta - Com relação à Pesquisa e Desenvolvimento - P\&D, o que você considera serem os pontos fortes e fracos da Unidade, no que diz respeito aos Recursos Humanos, infraestrutura, insumos e outros?

\section{Cultura}

$2^{\text {a }}$ Pergunta - Quando falamos de inovação aberta, um importante fator diz respeito à cultura. Essa cultura, de maneira geral, se relaciona não só ao incentivo da alta gestão para que os empregados dêem sugestões para o desenvolvimento de novos produtos, novas ideias, que assumam riscos, dentre outros, mas está ligado também à capacidade da empresa em entender que grande parte do conhecimento que ela precisa para inovar, está fora dos "muros da sua empresa", que ela não detém todo 
o conhecimento, know how e nem todas as respostas para todos os problemas, e isso, inclui aceitar os conhecimentos externos e a busca por estes conhecimentos.

Em 2018, com o objetivo de aprimorar a gestão de projetos de pesquisa, desenvolvimento e inovação, a Embrapa adotou o macroprocesso de inovação, com foco em inovação aberta. Nesse contexto e dada a importância da cultura para a adoção efetiva da inovação aberta, como você vê a adoção desse modelo pelos empregados da sua Unidade? Você acredita que a cultura da inovação aberta foi efetivamente adotada por todos? Houve, ou ainda há alguma resistência à adoção desse novo modelo/paradigma?

\section{Governança}

No contexto da inovação aberta, é muito importante a existência de funções e responsabilidades bem definidas, como, por exemplo, especialistas em PI para defesa e ao mesmo tempo promoção da inovação.

$3^{\text {a }}$ Pergunta:-Especificamente sobre Propriedade Intelectual, você considera que a gestão de PI da Unidade é satisfatória em termos de proteção dos ativos de modo que estimula a inovação aberta? O que você considera que poderia melhorar em relação à essa gestão?

\section{Gestão de relacionamento com o parceiro}

4a Pergunta: Quanto ao processo de seleção de parceiros. Há um processo estruturado de seleção? Ou como é feita a seleção/escolha dos parceiros externos?

PARTE 2: Participação da empresa em alianças e Portfólio de Alianças para impulsionar seu desempenho em termos de inovação.

\section{Definições Conceituais:}

Portfólio de Alianças: Definido como uma rede formada por uma empresa focal e suas ligações diretas, sendo o portfólio de alianças o conjunto de alianças estratégicas possuídas por uma empresa denominada como empresa focal.

5 a Pergunta: Considerando a sua Unidade como empresa focal, quais são na sua visão, os principais atores envolvidos nas alianças que a UD estabelece? Cite alguns exemplos que lhe vêm à cabeça, levando em consideração os tipos de parceiros. (Pode levar em consideração os principais parceiros de acordo com sua área de atuação ou a Unidade de modo geral):

Clientes; Complementadores; Entidades Governamentais; Concorrentes; Fomentadores/Financiadores. 
6 Pergunta: Muitas empresas que praticam a inovação aberta por meio de parcerias, criam um setor específico para supervisionar seus relacionamentos interorganizacionais dada a complexidade. A Natura é um exemplo de empresa que criou esse setor.

Dentro desse contexto, uma vez formadas as parcerias (diádicas ou multilaterais) na sua Unidade, há um setor específico que gerencie essas parcerias? Há um acompanhamento para saber se elas estão cumprindo os objetivos para os quais foram criadas?

$7^{a}$ Pergunta: Levando em consideração os projetos em execução na sua Unidade, como estes são realizados de maneira geral: Envolvendo parcerias Bilaterais/diádicas? Ex: A UD executa um projeto em parceria com apenas um cliente para desenvolvimento de uma tecnologia/produto e/ou /serviço; ou com apenas um complementador; A UD e uma instituição de fomento para realização de outro projeto ou os projetos em sua maioria, envolvem mais de 1 parceiro (parcerias multilaterais/projetos em rede)?

$8^{\text {a }}$ Pergunta: Considerando o Portfólio de Alianças da Unidade, quais são as alianças que você considera como sendo as mais proveitosas, em termos de tipos de parceiros? Com clientes? Complementadores? Entidades Governamentais? Concorrentes? Fomentadores/Financiadores? Você acredita que há uma explicação para isso?

9 Pergunta: Como você caracteriza a capacidade da Unidade em manter as parcerias de longa data?

10 ${ }^{\text {a }}$ Pergunta: Você acredita que a sua Unidade procura constantemente, novos parceiros para realização de projetos de inovação em conjunto ou normalmente os projetos são desenvolvidos em parceria com os mesmos parceiros?

\section{PARTE 3 - DESEMPENHO DE INOVAÇÃO}

\section{Definições conceituais}

Desempenho de inovação se refere à capacidade da empresa em lançar e introduzir novos produtos, novas formas de produção, novas formas de organização, de desenvolver novas fontes de matérias-primas, insumos e novos mercados, que gerem impactos significativos para a própria empresa e/ou para o setor em que está inserida, e/ou para o país e/ou para o mundo. 
$11^{a}$ Pergunta: Levando em consideração a quantidade de inovações produzidas, o grau de impacto dessas inovações e o seu grau de inovação tecnológica, como você avalia o desempenho de inovação da sua Unidade nos últimos 2 anos (2019-2020)? 12 ${ }^{\text {a }}$ Pergunta: Quais categorias de resultados você considera que geraram mais impactos? Dê exemplos

\section{ALINHAMENTO ESTRATÉGICO}

$13{ }^{\text {a }}$ Pergunta: Levando em consideração as contribuições e metas da Unidade e da agenda da Unidade, você acredita que a estratégia de inovação aberta adotada é suficiente e colabora para atingir os objetivos estratégicos? Se sim, justifique sua resposta. 